


\section{URBAN MODERNITY IN \\ THE CONTEMPORARY GULF}

Urban Modernity in the Contemporary Gulf offers a timely and engaging discussion on architectural production in the modernization era in the Arabian Peninsula. Focusing on the 20th century as a starting point, the book explores the display of transnational architectural practices resulting in different notions of locality, cosmopolitanism, and modernity. Contextually, with an eye on the present, the book reflects on the initiatives that recently re-engaged with the once ville moderne which, meanwhile, lost its pivotal function and meaning.

A city within a bigger city, the urban fabric produced during the modernization era has the potential to narrate the social growth, East-West dynamics, and citizens' memories of the recent past. Reading obsolescence as an opportunity, the book looks into this topic from a cross-country perspective. It maps, reads and analyses the notion of modern heritage in relation to the contemporary city and looks beyond physical transformations to embrace cultural practices and strategies of urban re-appropriation. It interrogates the value of modern architecture in the non-West, examining how academic research is expanding the debate on Gulf urbanism, and describes how practices of reuse could foster rethinking neglected areas, also addressing land consumption in the GCC.

Presenting a diverse and geographically inclusive authorship, which combines established and up-and-coming researchers in the field, this is an important reference for academics and upper-level students interested in heritage studies, post-colonial urbanism, and architecture in the non-West. 
First published 2022

by Routledge

2 Park Square, Milton Park, Abingdon, Oxon OX14 4RN

and by Routledge

605 Third Avenue, New York, NY 10158

Routledge is an imprint of the Taylor \& Francis Group, an informa business

(C) 2022 selection and editorial matter, Sultan Sooud Al-Qassemi and Roberto Fabbri; individual chapters, the contributors

The right of Sultan Sooud Al-Qassemi and Roberto Fabbri to be identified as the authors of the editorial material, and of the authors for their individual chapters, has been asserted in accordance with sections 77 and 78 of the Copyright, Designs and Patents Act 1988.

The Open Access version of this book, available at www.taylorfrancis.com, has been made available under a Creative Commons Attribution-Non CommercialNo Derivatives 4.0 license.

\section{Trademark notice}

Product or corporate names may be trademarks or registered trademarks, and are used only for identification and explanation without intent to infringe.

\section{Publisher's Note}

This book has been prepared from camera-ready copy provided by the editors.
Library of Congress Cataloging-in-

Publication Data

Names: Fabbri, Roberto, editor. |

Al-Qassemi, Sultan Sooud, editor.

Title: Urban modernity in the contemporary

Gulf: obsolescence and opportunities /

edited by Roberto Fabbri, Sultan Sooud

Al-Qassemi.

Description: Abingdon, Oxon; New York:

Routledge, 2022. | Includes

bibliographical references and index.

Identifiers: LCCN 2021016546 (print) |

LCCN 2021016547 (ebook)

ISBN 9780367741921 (hardback) |

ISBN 9780367741969 (paperback) |

ISBN 9781003156529 (ebook)

Subjects: LCSH: Architecture and s ociety--Arabian Peninsula--History--

20th century. | Architecture and society--

Arabian Peninsula--History--21st century. |

Architecture, Modern--Conservation and restoration--Arabian Peninsula. | Cultural property--Protection--Arabian Peninsula. | East and West.

Classification: LCC NA2543.S6 U74 2022

(print) | LCC NA2543.S6 (ebook) |

DDC 720.1/03--dc23

LC record available at

https://lccn.loc.gov/2021016546

LC ebook record available at

https://lccn.loc.gov/2021016547

ISBN: 978-0-367-74192-1 (hbk)

ISBN: 978-0-367-74196-9 (pbk)

ISBN: 978-1-003-15652-9 (ebk)

DOI: $10.4324 / 9781003156529$

Typeset in Helvetica Neue

Design by Haller Brun, Amsterdam

Cover Image

Design Construction Group, Gulf

Bank,1961-63, detail of the North-East elevation, Kuwait City (Photo: Roberto Fabbri, 2015) 


\section{URBAN MODERNITY IN THE \\ CONTEMPORARY GULF Obsolescence and Opportunities}

Edited by

Roberto Fabbri

Sultan Sooud Al-Qassemi 


\section{TABLE OF CONTENTS}

vi

1

6

18

40

56

78

$$
\text { Jason Carlow }
$$

INDUSTRIAL PROMISES

Speculative thinking for Sharjah's industrial districts

\section{PART II}

\section{TRAJECTORIES OF GLOBAL PRACTICES}

\section{Michael Kubo}

100 BUILDING IDENTITIES

Transnational exchange and the authorship

of modern Gulf heritage

Kevin Mitchell

120 CHANGING FAÇADES IN GULF CITIES Identity, icons, and lamentations of loss 
Jumanah Abbas

138 THE CORNICHE

The representation of Doha's waterfront

and its institutional buildings

Faisal bin Ayyaf Al-Mogren

156 OPERATIONAL PLANNING

An alternative view of Doxiadis' project in Riyadh

Edward Nilsson

172 HISTORY, MEMORY, AND NARRATIVES

OF THE PAST AND FUTURE

The new souks in Kuwait

\section{PART III}

\section{HERITAGE AND THE MODERN}

Asseel Al-Ragam

192 INTERSECTIONS BETWEEN THE PUBLIC

AND PRIVATE SPHERES OF CULTURE

Modern heritage practices in Kuwait

Suha Hasan

206 A[N] ABSENT SPACE: 1355

Trinidad Rico

226 MODERNISM IN QATAR

Survival through reuse

Marco Sosa, Lina Ahmad

246 URBAN PORTRAITS

Preserving the memory of modern architectural heritage in the United Arab Emirates

264 CONCLUSIONS

Modernism's back and forth

272 AUTHORS' BIOGRAPHIES

$276 \quad$ INDEX 
ACKNOWLEDGEMENTS 
All chapters, with the exception of the Preface, Introduction, the chapter titled "Fragmentarium", and Conclusions, have been adapted from papers (original works) presented at the tenth Gulf Research Meeting (GRM), organized by the Gulf Research Centre Cambridge at the University of Cambridge on 15-18 July 2019. Within the framework of the tenth GRM, the editors of this book curated and directed the Workshop X, titled "Re-Engaging with the Gulf Modernist City: Heritage and Repurposing Practices". The 'original works' are (c) Gulf Research Centre Cambridge.

As the book's editors, Sultan and Roberto want to express their gratitude to all the participants of GRM 2019 Workshop $X$ for their contributions to the debate and for the collaborative spirit that ultimately generated the motivation to complete this publication: Jumanah Abbas, Lina Ahmad, Eithar Al-Hasni, Lulu Almana, Faisal bin Ayyaf Al-Mogren, Rana Al-Mutawa, Asseel Al-Ragam, Atef Alshehri, Jawaher Al-Sudairy, Rend Beiruti, Jason Carlow, Mohamed Elshahed, Suha Hasan, Michael Kubo, Ula Merie, Kevin Mitchell, Edward Nilsson, Todd Reisz, Trinidad Rico, Ahmed Shubbar, and Marco Sosa. The gratitude is extended to everyone at the GRM in Cambridge, UK, for their support and assistance in the workshop's preparation and following phases. In particular to: Dr. Christian Koch, Dr. Abdulaziz Sager, Dr. Oskar Ziemelis, Aileen Byrne, and Sanya Kapasi.

The editors' appreciation also goes to the team that collaborated on the book development and production. In particular: Eyad Houssami (copy-editing), Reem Khorshid (research), Sonja Haller, and Pascal Brun (graphic design). A great help for locating and reproducing some of the images contained in this publication came from Fatma Al-Sahlawi (Atlas Bookstore, Qatar), Roberta L. Dougherty (Yale University Library), Giota Pavlidou (Constantinos A. Doxiadis Archives, Athens), Aruna Sultan (Kuwait), Dar Al-Athar AlIslamiyyah (Kuwait), PACE (Kuwait) and William Pereira Jr and Scott Johnson (Johnson Fain, Los Angeles). Finally, the editorial team at Routledge: Grace Harrison, Francesca Ford, Rosie Anderson, Trudy Varcianna and Gabrielè Gaižutytè.

The book received a publication grant for open access license from the Barjeel Art Foundation, Sharjah (UAE). 


\section{PREFACE \\ Forms of engagement: Architectural modernism and heritage in the Arab Gulf states}

\section{Kishwar Rizvi}

Professor in the History of Art, Islamic Art and Architecture Yale University 
Modernity has a long past, and yet it continues to inspire the future. It is at once a marker of change and an aspiration, shared by communities across the globe. Disseminated through the implementation of new technologies, mobilization of resources, and mobility of ideas and people, modernity may be conceptualized as a transformational process, one that changed, and continues to change, the world. This collection of essays makes visible the complex global interactions that took place between individuals and institutions, between architects and their governmental sponsors, and the resultant architecture and urbanism of modern Arab Gulf states from the second half of the twentieth century to the present. Bringing together the work of practitioners and scholars, the volume considers issues of heritage and planning from a dynamic perspective, one that interrogates historical precedent to consider the futurity undergirding current trends. The aim of this preface is to present a broader context for these studies and to point to complementary issues that may open up avenues for further exploration.

In the nineteenth century, modernity was made manifest in urban contexts, for example, in the manner in which Cairo was reimagined as a cosmopolitan world city, with a new opera house celebrating the opening of the Suez Canal in 1869, and through the global trade of Egyptian cotton and Singer sewing machines, highlights of the world's fairs. Modernization was implemented by colonial mandate or through imperial command. For example, telegraph lines and other communication networks linked the cities of Turkey and Iran; and in Baghdad and Cairo, railways transported goods and people into towns undergoing rapid urbanization. Social change was actualized through the construction and establishment of new institutions, such as museums and universities. Architecture was called upon to monumentalize these transformations, acting as both an agent and mediator between often conflicting political and ideological beliefs. ${ }^{1}$ The Persian Gulf, in particular, was a conduit for people and commodities circulating between terrestrial and maritime routes connecting Asia to Europe, for example, linking Karachi to Bahrain, and further onward to London.

At the turn of the twentieth century, newly formed republics in the Middle East turned to their far distant antiquity as a source for constructing their national identities. The aim was to simultaneously erase the recent colonial or imperial past and narrate a new history based on indigenous forms and ideals. Such an 'invention' was crucial to forging the commonalities that would define the modern nation, such as language, tradition, and architecture, all of which would serve as symbols of an apparently unproblematic, and seamless, past. ${ }^{2}$ Public buildings were among the most obvious choices for the physical manifestation of a nationalist architectural style, one that would at once be modern and yet imbued with historical references. Banks and post offices 
would represent the civic contract written into the constitutions of newly emerging post-colonial nations.

The period following the Second World War witnessed a move towards international and development projects that aimed to connect with broader trends in architecture and urbanism. The discovery of oil in Iran and Saudi Arabia in the mid-twentieth century and the establishment of the Organization of the Petroleum Exporting Countries (OPEC) in Baghdad in 1960 shifted the focus of urban and architectural development towards the Persian Gulf, as explored in the essays in this volume. Countries which had once been protectorates of Britain subsequently gained their independence, forming autonomous kingdoms, such as Kuwait (1961), or federations, such as the United Arab Emirates (1971). Their capital cities were drastically expanded, with attention given to urban infrastructure and the development of new service institutions, such as hotels and airports. An iconic project of this type is the Hajj Terminal in Jeddah, Saudi Arabia, designed by the Bangladeshi engineer Fazlur Rehman of Skidmore, Owings \& Merrill (SOM) in 1982. The terminal, meant to hold the millions of Muslim pilgrims that arrive in Jeddah once a year to make the annual pilgrimage to the holy cities of Mecca and Medina, is a vast structure that gives the impression of a desert encampment. Although Jeddah is one of the most cosmopolitan, historical port cities in the world, the choice to evoke a primitive structure such as a tent for its airport terminal points to the manners in which nationalist ambitions coincide with the desire to reimagine a past and a heritage that is sometimes too reductive, obscuring heterodox realities. ${ }^{3}$

The past 40 years have also witnessed important ideological shifts, whereby religion has become an increasing presence in public and political lives and is visible in the types of patronage undertaken in the Arab Gulf states. Thus, state mosques are built within national boundaries but also on foreign soil, for ally countries, as ambassadorial gifts marking ethnic, religious, and political allegiances. ${ }^{4}$ An example is the Sheikh Zayed Mosque in Abu Dhabi, which is named after the founding emir of the United Arab Emirates (UAE). Making liberal use of architectural motifs taken from Mughal India to Umayyad Spain, the construction was supervised by the London-based multinational company, Halcrow Corporation, and completed in 2007 . The building is open to tourists and worshippers alike and is meant to convey a message of tolerance and multiculturalism in the UAE. Although built through material and expertise sourced from across the globe, more than anything else, the mosque serves as a collage of Islamic architectural history that represents the federation as an amalgam of different geographies and historical periods.

An important counterpoint to religion is a fascination with technology, which in the UAE has been realized in the construction of the tallest skyscraper in the world, the Burj Khalifa in Dubai, 
also designed by SOM (with Adrian Smith) and completed in 2010. Although the UAE - and Dubai in particular - is often studied in the context of exuberance and superlative architecture, it would be incorrect to view such projects simply through the lens of corporate modernity. Attention has also been given to cultural institutions in order to create a national identity and a tourist industry. For example, as the capital of the UAE, Abu Dhabi has built universities and museums, sometimes in collaboration with well-established partners from Europe and the United States, as exemplified by the presence of New York University and the Louvre Abu Dhabi. A similar stance is taken by the government of Qatar, which hosts a selection of universities from Europe and the United States represented in its Education City campus in Doha - and has invested heavily in museum building. If museums and universities were the building blocks of early twentieth-century statecraft, they return in the Gulf at the start of the twenty-first century as markers of transnational exchange, marking also shifts in capital and influence.

In the Middle East, broadly, four primary forms of engagement with architectural modernism may be identified in the period from the late nineteenth century to the present: modernization through infrastructure; nation-building; development and internationalism; and economic exuberance and Islamism. They can also be presented in a roughly chronological order: from the waning of the Ottoman Empire and the rise of European colonial interest in the Middle East; to the advent of independent nationstates; and to the present era of transnational connections. In the case of the Arab Gulf states represented in this volume, the chronologies may not line up in the same way; rather, they are contingent on the particularities of each country's historical context. Nonetheless, a discussion on heritage and modernity undergirds all these experiences, giving rise to new forms of civic and cultural preservation. These interactions will, in reality, have a tangible impact on the built environment and the lives of those who inhabit it.

What the essays in this volume make clear is that modernity may be enacted in different ways, yet the stage is a shared one. Whether considering the response to colonialism or nationbuilding, adopting corporate capitalism or a rhetoric of Third World development, or participating in the discourse on religious revivalism, architecture in the Gulf has never been created in isolation. As the examples presented in this volume make evident, architects and architectural concepts transcended geographical space and, in so doing, have transformed the urban and social contexts within which they were conceived. Indeed, it may be misleading to think of architecture in the region as a separate entity at all; rather, it may be folded into a broader representation of the modern world - one that is not simply divided by national identities or hemispherical boundaries but united through transnational connections 
and professional mobility. In such an ideation, we may rethink how we have conceptualized modernism itself, both as a disciplinary category and as an intellectual possibility. Looking forward, modernism's potential lies in its ability to transform, in this case, issues of inhabitation - that go beyond the individual biographies of elite architects and branded institutions - to pay greater attention to different scales of participation and impact. It may provide answers to reimagining a future that is inclusive and ethical and that takes seriously issues of sustainability and environmental change. In such a manner, architecture may be reinstituted at the forefront of contemporary culture, with its modernity not an artefact of the past but a function of contemporary design that serves as an inspiration for the future, in the Middle East and beyond. 


\section{Notes}

1 A now classic discussion on architecture and urbanism in colonial contexts is Nezar AlSayyad, ed., Forms of Dominance: On the Architecture and Urbanism of the Colonial Enterprise (Aldershot: Avebury, 1992).

2 See Eric Hobsbawm and Terence Ranger, eds., The Invention of Tradition (1983; repr. Cambridge: Cambridge University Press, 1992).

3 The terminal was preceded by another highly technical design, that of the InterContinental Dar Al-Hijra Madinah (1974), by Rolf Gutbrod and Frei Otto.

4 These trends are discussed in my book, Kishwar Rizvi, The Transnational Mosque: Architecture and Historical Memory in the Contemporary Middle East (Chapel Hill: University of North Carolina Press, 2015). 


\section{INTRODUCTION Re-Engaging the modern}

Roberto Fabbri and Sultan Sooud Al-Qassemi 
In the summer of 2018, the Municipality of Dubai launched the Modern Heritage Initiative with the intent to preserve a series of buildings from the 1970s, including John Harris' World Trade Centre and George Rais and Jafar Tukan's Al-Khuloud Nursery School among others. ${ }^{1}$ This was one of the rare occasions in which a Gulf Cooperation Council (GCC) government agenda placed the word 'heritage' in direct association with the architectural production of the modernization era. The Gulf has always maintained a complicated relationship with the notion of heritage, a concept often veiled by thirsty aspirations for newness and the expectation of perpetual modernization. However, the trend has been inverted in the past two decades when state-led interests for cultural legacies began to grow exponentially. At a different pace and with varying mechanisms, all the GCC governments 'rediscovered' and invested in their own cultural heritage, aiming at three main goals: to establish the tourism industry as an alternative to their oil-driven economy and real-estate speculation; to increase soft-power and prestige on the global stage; and to reinforce a nation-building narrative that could foster a stronger sense of belonging as partial compensation to citizens in anticipation of the foreseeable decline of welfare-state policies. ${ }^{2}$

Within this specific agenda, the regional definition of heritage tends to embrace what could be showcased as more authentic or, in other words, perceived as local, traditional, khaleeji, Islamic, and - most commonly - non-Western derivative. As discussed throughout this publication, 'authenticity' in the Gulf is often a boundless concept arching out to envelop elements perceived as autochthonous, even when they represent a (re)invented tradition, a mimic of the past or the result of a hybridization process. ${ }^{3}$ With all these governments' narratives insisting on the 'Arabness' of their local cultural roots, international agencies align to corroborate the vision: for instance, in 2011 UNESCO dedicated a special issue of its magazine World Heritage entirely to the Gulf countries. The journal is a catalogue of archaeological sites that depicts through ochre tones idyllic oasis landscapes and desert forts. ${ }^{4}$ The unprecedented transformation of the twentieth century that occurred in Gulf cities, which radically transformed both societies and the built environment with greyish, concrete tones, was not considered as strategically representative.

Like many aspects of the recent past, modern architecture struggled to compete with the 'golden age' represented by the pre-oil days. For decades, modernist buildings have been associated with the demolition of the traditional medina, with top-down plans and the gradual 'Westernization' of the region. In the second half of the twentieth century, rapid urban and social transformation was blamed for superimposing foreign narratives onto local customs, blurring the contours of native culture. As a consequence, people and institutions demonstrated disaffection and a low sense of belonging to the 1960s-1970s city. Today, these parts of the city 
are not the most appealing residential or commercial locations, and demolition is normally accepted as a common practice to liberate strategic central plots that can attract investors and real estate speculators. Moreover, since the local population has progressively snubbed the once ville moderne, it has become a vital and informal gathering point for 'other citizenships'. ${ }^{5}$

However, and despite its having often resulted in an incomplete vision, modernist architecture was the language - for better or worse - of Gulf cities' global aspirations in the twentieth century. Modernism, again, both in the arts and in architecture, has been instrumental in reconsidering and negotiating fluid concepts like tradition, contemporaneity, and identity in relation to social changes and transformations of the built environment. A city within a bigger city, the urban fabric produced in the Gulf during the modernization era lost its original meaning but acquired today the potential to narrate the social changes, economic growth, East-West dynamics typical of the region, and citizens' memories of a recent past.

In the last decade, new tangible interest for these artefacts has grown stronger, as demonstrated by a variety of new studies and initiatives: scholarly research and publications in addition to student theses as well as exhibitions, public debates, and a few place-making campaigns demonstrate a rising and compelling need to re-engage with the concrete city of the 1960s and 1970s. In this sense, it is indicative that the new Qatar National Museum was inaugurated in March 2018 showcasing a temporary exhibit, titled Making Doha, 1950-2030, that put in perspective the recent architectural successes of the country, such as the museum itself along with the early modern structures of the post-oil discovery era: in the exhibit presentation, co-curator Samir Bantal defined Doha as "a test ground for modern architecture and planning". 6 Earlier and similar examples of displays of modernism would be the Bahraini pavilion at the 14th Venice Architecture Biennale in 2014, which broadened the horizon towards all Arab lands, as well as the participation of Kuwait and the United Arab Emirates (UAE) in the 2012, 2014, and 2016 editions of the Biennale. ${ }^{7}$ Remarkably, Kuwait has also campaigned to introduce a national symbol, the notorious Kuwait Towers (Abraj Al-Kuwait by VBB and Marlene Bjørn, 1965-1977) into the UNESCO World Heritage tentative list. ${ }^{8}$ Also in Kuwait, two exhibitions have focused on the construction of the modern city on an architectural scale: one promoted by the museum Dar Al-Athar Al-Islamiyyah (DAI) in 2016 and one by the architectural firm Pan-Arab Consulting Engineers (PACE) for its 50th anniversary in $2018 .{ }^{9}$ The fervent climate present in the region is also reflected in a number of publications, which will be discussed in this introductory text and which have contributed to holding modern architectural production at the centre of the debate.

Now, if, as it seems, the Gulf will move towards the preservation of its recent 'physical past', what conservancy can be expected 
or envisioned? Architecture is meant to perform as a living organism in synergy with the urban environment. Given some Gulf cities' tendencies to 'spectacularize' or 'museumify' the built environment (e.g. heritage villages or history-themed malls) and given the wave of nostalgia perceivable especially on social media, what could be a projected trajectory for these specific artefacts in the near future?

\section{Obsolescence as opportunity}

The State of Arab Cities (SAC), redacted in 2020 by United Nations agencies UNDP and UN-Habitat as well as the Bahrain Center for Strategic, International, and Energy Studies, is considered one of the most comprehensive snapshots that cyclically assesses the status of urbanization in the Arab region; the analysis is conducted in alignment with the UN Sustainable Development Goals (SDGs), in particular with SDG 11: Sustainable Cities and Communities, which globally addresses the impact of overpopulation in urban centres. ${ }^{10}$ In this sense, the SAC 2020 is driven by an explicit sense of urgency for the continuous expansion of the Arab city's footprint due to urban drift and migration dynamics. These two factors are predicted to bring two-thirds of the population living in cities by the middle of this century. ${ }^{11}$ The Gulf is already leading the regional ranking with $80 \%$ of the population in Bahrain, Saudi Arabia, and the UAE living in urban areas - and figures rising up to $98 \%$ in Kuwait and $99 \%$ in Qatar. ${ }^{12}$

Although the Arab region is far from uniform, by analyzing a series of different indicators such as socio-economic context, financing capacities, and infrastructure stocks, the 2020 report portrays a bird's-eye view of the most common and acute challenges of the region, demonstrating how the current model of growth has generated an unsustainable built environment "exacerbating low-density urban sprawl, the cost of urbanisation and the dominance of individual transportation". ${ }^{13}$ At the same time, it fails to meet SDG 11 in terms of equality, participation, and inclusivity of the population: "the proliferation of the high-rise building and skyscraper model, and new development trends such as new cities, megaprojects and gated communities risk exacerbating existing spatial disparities and leaving a growing number of residents disadvantaged". ${ }^{14}$ The document concludes by proposing various remedies to invert the current trend. The recommendations range from economic diversification to more integrated planning strategies, sustainability, and measures to combat governance flaws, inefficiencies, and the monetization of urban space. ${ }^{15}$

By focusing on macroeconomic indicators and different models of governance, the document pays no heed to reflect on a crucial aspect that could potentially aid in containing urban sprawl as well as endemic land consumption: Gulf cities should reconsider already existing building stock, which in many occasions is either obsolete, underused, or abandoned, as an opportunity for localized 
interventions and participative efforts to bridge urban divides and stitch a discontinuous urban fabric. The act of preserving and reimagining a new life for an old, but not ancient, part of the city is not only a more efficient and ecological practice but also, as Marcus Berger, Heinrich Hermann, and Liliane Wong state, represents "the continuation of cultural phenomena through built infrastructure, connections across the fabric of time and space and preservation of memory". ${ }^{16}$

A culture of reuse, especially in highly consumeristic sites much like the Gulf, cannot be achieved overnight. It can only be built by an accumulative process made of studies, debates and conferences, public awareness campaigns, training of young professionals, state-led plans, and bottom-up initiatives. As previously mentioned, over the past ten years, efforts have multiplied in this direction although the number of buildings which have escaped the bulldozer by being repurposed has, regrettably, been very few. For instance, in 2016, the Bahrain Authority for Culture and Antiquities charged Studio Holtrop with the rehabilitation of the former Customs House/Post Office and the Qatar Museums recently reconverted the old Fire Station $\boldsymbol{\Delta}$ (built in 1982) into a residence for artists, maintaining the main defining aspects of the original building while adapting interiors to new functional needs. ${ }^{17}$ Similarly, Sharjah's 'Flying Saucer', originally a French restaurant built in 1978, was acquired in 2012 by Sharjah Art Foundation and converted into a cultural space for contemporary art. ${ }^{18}$ Finally, in 2011, DAl and the National Council for Culture, Arts and Letters of Kuwait repurposed the old American Missionary Hospital into an vital cultural hub for lectures, workshops, and exhibitions. $\Delta$ Conversely, a few examples of successful stories cannot compensate for the many more where demolition became the predictable solution due to the lack of appreciations, legal frames, economic incentives, and preservation plans necessary to do otherwise. Also, a new cultural centre cannot be the solution for repurposing all buildings in danger of demolition. In this framework, one of the main purposes of the book is to document and analyze samples of obsolete structures from the modernization era and to read, interpret, and examine their present condition and, when possible, envision an opportunity.

\section{The context}

The book builds on the past few decades of growing interest in Gulf modern architecture, which generated conspicuous traction in the field of regional urban studies. The concise review of literature on the matter included here below does not claim to be exhaustive but rather may portray a map of sources that helped to inform and shape the present study. Many of these titles showcased similarity or complementary aspects to the content offered in this publication. Similarly, several are a joint effort of many scholars and share common production dynamics, sourcing content from academic debate during workshops, conferences, and seminars. 


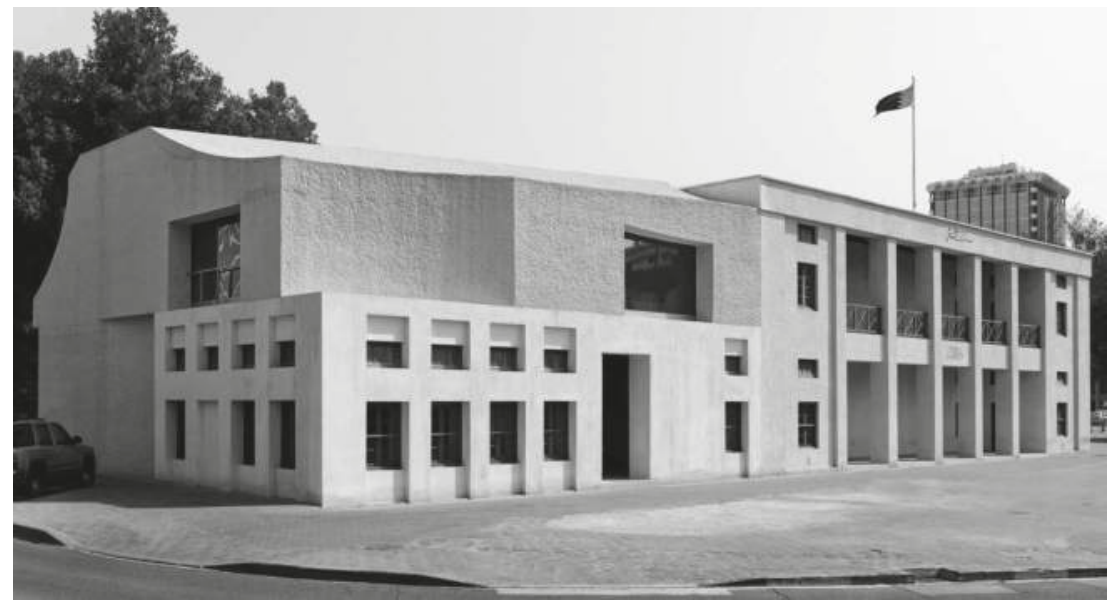

fig.1 Studio Holtrop, Customs House Extension, Manama, Bahrain, 2016-19 (Photo: Anne Holtrop, 2019. Reuse not permitted).

One major challenge for those interested in investigating the trajectories of Gulf modern architecture was the sparse literature on the subject, not to mention the lack of archival documentation, only partially compensated by some very active blogs and social media accounts dedicated to the topic. ${ }^{19}$ Before even attempting to historicize urban development in the region and to develop a possible notion of local modern heritage, the initial urge has been to map the survival of modern building stocks, retrace their history and information, and determine their current state. The manuscripts emerging from this initial phase each focus on a distinct GCC country. Among many, it is worth mentioning Fuccaro's Histories of City and State in the Persian Gulf. Manama since 1800 (2009); Salama and Wiedmann's Demystifying Doha (2013); Menoret's Abu Dhabi Guide: Modern Architecture 1950-1990 (2014); Bambling's Lest We Forget: Structure of Memory (2014); Fabbri, Saragoça, and Camacho's double volume Modern Architecture Kuwait 1949-89 (2016 and 2017); Bani Hashim's Planning Abu Dhabi (2019); Reisz's Showpiece City: The Architecture That Built Dubai (2020), and Al-Qassemi and Reisz's Building Sharjah (2021). ${ }^{20}$ In the same category, although with a broader geographical horizon, sits Arbid's Fundamentalists and Other Arab Modernisms (2014), a catalogue of the Bahraini pavilion at the 2014 Venice Biennale and the result of the foundation of the Arab Center for Architecture in Beirut, one of the first attempts to establish an institutional archive for twentieth-century architecture in the region. ${ }^{21}$

In parallel, and on broader disciplinary terms, several studies have focused on unsettled East-West dynamics. It is the case of Nasr and Volait's Urbanism Imported or Exported? Native 
Aspirations and Foreign Plans (2003): although not specifically on the Gulf, it opens up the discussion on decolonial studies and urban practices. ${ }^{22}$ Similarly, Isenstadt and Rizvi's Modernism in the Middle East (2008), Elsheshtawy's Planning Middle Eastern Cities (2004), followed by The Evolving Arab Cities (2011), and Golzari and Fraiser's Architecture and Globalization in the Persian Gulf Region (2015) define global patterns of practice in less explored territories and in alignment with the growing notion of 'other modernities'. ${ }^{23}$ More recently, Stanek's Architecture in Global Socialism (2019) expanded this argument by introducing the architects from the Soviet bloc among the usual geographies of knowledge exchange. ${ }^{24}$ Finally, the challenging task of defining the multifaceted reality of urban conditions in the region, representing the city as a rich site of investigation, from the modernization era to present times, is the core of Andraos and Akawi's The Arab City (2016) and Molotch and Pazzini's New Arab Urban (2019), as well as the two seminal volumes of Al-Manakh (2007 and 2010). ${ }^{25}$

With this theoretical framework in mind, and focusing on twentieth-century architecture in today's urbanity, the present study problematizes the tendency that shows modernization of the built environment as a one-directional phenomenon, a Westto-East technical knowledge export and not a layered relationship. Since all Gulf cities have had a very similar growth, a critical and cross-country examination of the architecture of the second half of the 1900s allows us to identify a salient possible trait of common khaleeji urban identity. An equally significant contribution is represented by the recognition of Gulf modernist architecture as a paradigm of the relationship between East and West, between historical patterns, indigenous narratives, and cosmopolitan aspirations. Since in most cases the parts of the city where these architectures sit have become areas for informal dwelling or gathering for foreigners, the book also investigates policies of exclusion in relation to the urban environment and how different interventions could rebalance the right to the city.

This volume analyzes and showcases the modern architectural project as an aspect of the contemporary instead of reading city transformation from a historical angle or considering only a present-day perspective as in much of the scholarship. Prior to this study, very little effort has been made to envision future scenarios for modern heritage in the region. With the intention to bridge this scholarly gap and by embracing contributions from authors of different backgrounds, the present research reflects on the legacy of modernism as an original contribution to transdisciplinary literature on the Gulf.

\section{Structure of the book}

The book opens with a consideration on modernity in the Arabian Peninsula in broad terms. Part I provides an insight into 
how the idea of modernism permeated architecture discourse in the Arab world and also how it has been adopted as the chosen language to showcase the state's progress in the second half of the twentieth century. The essays in this part reflect on the agents of change, from the literature coevally produced to governance practices and to the physical transformations of old traditional spaces. Adopting a cross-country perspective, the chapters read the present situation aiming to retrace the ville moderne once envisioned by rulers, architects, and authorities within the current urban fabric as an attempt to assess the legacy of the modernization project and its current potential. The chapters also explore the idea and significance of memory, obsolescence, and liminality as a consequence of the modernization process. As the Gulf city is in constant transformation, twentieth-century structures rapidly became outmoded, and that has led to a marginalization of these areas. Reflecting on abandoned or underused parts of the city, as well as industrial zones and outdated commercial areas, the chapters investigate liminal spaces as a product of modernization and as possible arenas of opportunity for the contemporary city. $\boldsymbol{\Delta}$

Part II delves into more specific reflections on the EastWest relationship in the modernization process. It reflects on patterns of cultural and technical exchange and the significant design opportunities that emerged in various cities of the Arabian Peninsula. Working at different scales, the chapters problematize notions such as locality, tradition, and authenticity by capturing how these plans were initially conceived to mediate global practice and local context and how they are now commonly perceived as alien to local culture, and therefore ignored, misinterpreted, or altered. These texts eventually suggest how authorship inevitably leads to different levels of acceptance in relation to the current, perfectible definitions of locality and authenticity. A much-needed, deeper understanding of the architectural 'primary sources' of Gulf urban history can lead to new purposing practices, instead of marginalization or demolition.

The last part of the book reflects on the concepts of heritage and culture assets and their physical embodiment in the Gulf. It considers governmental agendas and bottom-up initiatives to define, engage, and reclaim spaces of historic value, problematizing the notions of reuse versus 'museumification', and how they apply to the urban fabric of Gulf cities. The chapters showcase how modern heritage and its reuse have recently become part, however marginal, of the overall discourse of the heritage industry. Nonetheless, 'heritage-ization' could be a first important step towards preservation. To conclude, the section offers a perspective on how educational institutions, such as universities and, in particular, schools of architecture, could advocate for preservation practices and raise awareness among the future generation of p.198 professionals who will soon engage with the built environment. 


\section{Notes}

1 Caline Malek, "Rising Gulf Cities Look to Protect Landmarks", Arab News, September 3, 2018, accessed September 20, 2020, https://www.arabnews.com/ node/1366346/middle-east.

2 Many authors have voiced critical arguments on the construction of heritage in terms of identity-making and national(ist) narratives in the region. Among them: Karen Exell and Trinidad Rico, Cultural Heritage in the Arabian Peninsula: Debates, Discourse and Practices (Farnham:

Ashgate, 2014); Sultan Al-Qassemi, "The Gulf States' National Museums: Iconic Buildings and Collections Battleground for Future Identity", Gulf Affairs (Autumn 2016): 30-31; Kristin Smith Diwan, Gulf Societies in Transition: National Identity and National Projects in the Arabian Gulf States, workshop report (Washington, DC: Arab Gulf States Institute, 2016), accessed September 20, 2020, https://agsiw.org/ wp-content/uploads/2016/06/NationalIdentity_Web-1.pdf; Susi Mirgani, "Introduction: Art and Cultural Production in the GCC", Journal of Arabian Studies 7, no. 1 (August 2017): 1-11; Courtney Freer and Yasmine Kherfi, "Whose Story? Narrative of Nationalism in the Heritage Production of the Arabian Peninsula", LSE Middle East Centre Paper Series 39 (August 2020); Serena Wakefield, Cultural Heritage, Transnational Narratives and Museum Franchising in Abu Dhabi (Abingdon: Routledge, 2020).

3 On the relation between tradition and modernity in the built environment, see Miriam Cooke, Tribal Modern: Branding New Nations in the Arab Gulf (Berkeley: University of California Press, 2014); and also Roberto Fabbri, "Allegoric Envelopes: Metaphors, Analogies and Contextual Linkages in Recent Museums of the Arabian Peninsula" (forthcoming).

4 UNESCO, World Heritage. Special Issue: World Heritage in the Gulf Countries 60 (June 2011), accessed September 1 , 2020, https://es.calameo.com/read/ 00332997228 ca0bd1a46e.

5 With regard to migrant workers and 'other citizenships' in the region, see Neha Vora, Impossible Citizens: Dubai's Indian Diaspora (Durham: Duke University Press, 2013); Yasser Elsheshtawy, Dubai: Behind an Urban Spectacle (London: Routledge, 2010); Andrew M. Gardner, City of Strangers: Gulf Migration and the Indian Community in Bahrain (Ithaca: Cornell University Press, 2010). Also, in this book, see chapters 'Fragmentarium. Episodes of modernity in contemporary Kuwait City' and 'Industrial promises. Speculative thinking for Sharjah's industrial districts.
6 Making Doha, 1950-2030 was curated by Rem Koolhaas, Samir Bantal (OMA/AMO), and Fatma Al-Sehlawi (Atlas Bookstore). See OMA, "AMO-Designed and Curated Exhibition 'Making Doha, 1950-2030' Opens at the National Museum of Qatar", March 31, 2019, accessed September 25, 2020, https://oma.eu/news/ amo-designed-and-curated-exhibitionmaking-doha-1950-2030-opens-at-thenational-museum-of-qatar.

7 Regarding the participation of GCC countries in the Venice Biennale, see Bahrain Authority for Culture and Antiquities, "Bahrain at the 2014 Architecture Venice Biennale", accessed November 6, 2020, http://bahrainpavilion. bh/exhibition/fundamentalists-and-otherarab-modernisms; UAE Ministry of Culture and Youth, "National Pavilion United Arab Emirates", accessed November 6, 2020, https://nationalpavilionuae.org/ architecture/2020-2; and Noura Alsager, ed., Acquiring Modernity (Kuwait: National Council for Culture, Arts and Letters, 2014). 8 UNESCO World Heritage Center, "Abraj Al-Kuwait", accessed September 10, 2020, https://whc.unesco.org/en/ tentativelists/5933.

9 The exhibition Modern Architecture in Kuwait, 1949-89 was inaugurated in March 2016 at the Yarmouk Cultural Centre in Kuwait, and the PACE retrospective 50 Years of Architecture in Kuwait was inaugurated at Shaheed Park in 2018. 10 United Nations Development Programme (UNDP), "Goal 11: Sustainable Cities and Communities", accessed November 6, 2020, https://www.undp.org/ content/undp/en/home/sustainabledevelopment-goals/goal-11-sustainablecities-and-communities.html.

11 UNDP, UN-Habitat, and Bahrain Center for Strategic and Energy Studies, The State of Arab Cities 2020. Executive Summary (United Nations Publications, 2020), 5, accessed November 6, 2020, https://www.arabstates.undp.org/content/ dam/rbas/doc/capacity\%20building/ SACR\%202020\%20Executive\%20 Summary_En.pdf. 12 Brigitte Dumortier, "The Gulf Cities: A Composite and Evolving Urban Model", in IEMed. Mediterranean Yearbook 2016

(Barcelona: European Institute of the Mediterranean, 2016), 289.

13 UNDP, The State of Arab Cities 2020, 17.

14 Ibid., 15.

15 Ibid., 19-23.

16 Marcus Berger, Heinrich Hermann, and Liliane Wong, "Editorial", The Int/AR Journal 01 (2009), cited in Liliane Wong, Adaptive Reuse: Extending Lives of Buildings (Basel: Birkhäuser, 2017), 30-31. 
17 The adaptive-reuse project was conducted by Qatari architect Ibrahim Al-Jaida. See "Fire Station: Artist in Residence", accessed September 25, 2020, http://firestation.org.qa/en/about. 18 The rehabilitation was conducted by SpaceContinuum Design Studio. See Osman Can Yerebakan, "SpaceContinuum Design Studio Transforms Sharjah's The Flying Saucer into a Cultural Space", Interior Design (November 2, 2020), accessed November 6, 2020, https:// www.interiordesign.net/articles/18561spacecontinuum-design-studiotransforms-sharjah-s-the-flying-saucerinto-a-cultural-space.

19 Two relevant examples of online resources that collected and shared key information on the subject of modern architecture in the region in the Gulf are Yasser Elsheshtawy's Dubaization, https://dubaization.com, and Mohammed Elshahed's Cairo Observer, https:// cairobserver.com.

20 Nelida Fuccaro, Histories of City and State in the Persian Gulf. Manama since 1800 (Cambridge: Cambridge University Press, 2009); Ashraf Salama and Florian Wiedmann, Demystifying Doha: On Architecture and Urbanism in an Emerging City (Farnham: Ashgate, 2013); Pascal Menoret, ed., The Abu Dhabi Guide: Modern Architecture 1968-1992 (Abu

Dhabi: FIND, 2014); Michele Bambling, ed., Lest We Forget: Machines of Memories, catalogue of UAE pavilion exhibition at the 14th Venice Biennale (2014); Roberto Fabbri, Sara Saragoça, and Ricardo Camacho, Modern Architecture Kuwait 1949-89 (Zurich: Niggli Verlag, 2016); Ricardo Camacho, Sara Saragoça, and Roberto Fabbri, eds., Essays, Arguments and Interviews on Modern Architecture Kuwait (Zurich: Niggli Verlag, 2017); Alamira Reem Bani Hashim, Planning Abu Dhabi: An Urban History (Abingdon: Routledge, 2019); Todd Reisz, Showpiece City: How Architecture Made Dubai (Palo Alto: Stanford University Press, 2019); Sultan Al-Qassemi and Todd Reisz, Building Sharjah (Basel: Birkhäuser, 2021). 21 George Arbid, ed., Fundamentalists and Other Arabs Modernisms (Bahrain Ministry of Culture and Arab Center for Architecture, 2014).

22 Joe Nasr and Mercedes Volait, eds., Urbanism Imported or Exported? Native Aspirations and Foreign Plans (Chichester: Wiley, 2003); Sandy Isenstadt and Kishwar Rizvi, eds., Modernism in the Middle East: Architecture and Politics in the Twentieth Century (Seattle: University of Washington, 2008); Yasser Elsheshtawy, ed., Planning Middle Eastern Cities: An Urban Kaleidoscope in a Globalizing
World (London: Routledge, 2004); Yasser Elsheshtawy, ed., The Evolving Arab City: Tradition, Modernity and Urban Development (London: Routledge, 2011); Nasser Golzari and Murray Fraiser, Architecture and Globalization in the Persian Gulf Region (Abingdon: Routledge, 2015). 23 "Other Modernisms" is the title of 9th Do.co.mo.mo International Conference held in Istanbul, Turkey, in September 2006. The conference was one of the first occasions in which the international academic community shifted focus from the usual geography of modernist architecture (Western Europe, USA, and Latin America) to other and less known territories.

24 Łukasz Stanek, Architecture in Global Socialism: Eastern Europe, West Africa, and the Middle East in the Cold War (Princeton: Princeton University Press, 2019).

25 Amale Andraos and Nora Akawi, eds., The Arab City: Architecture and Representation (New York: Columbia Books on Architecture and the City, 2016); Harvey Molotch and Davide Ponzini, eds., The New Arab Urban: Gulf Cities of Wealth, Ambition, and Distress (New York: New York University Press, 2019); Ole Bouman, Mitra Khoubrou, Rem Koolhaas et al., eds. Archis: Al Manakh 12 (2006); Todd Reisz and Rem Koolhaas, eds., Archis: Al Manakh 2: Gulf cont'd 23 (2010). 
PART I 


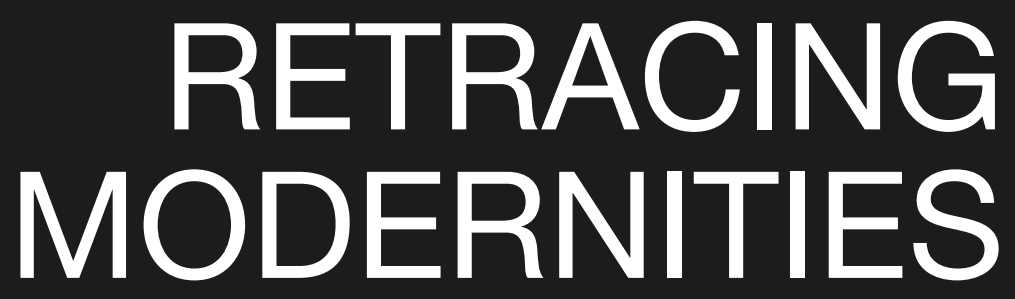




\title{
UDO KULTERMANN'S HISTORY OF ARAB CONTEMPORARY ARCHITECTURE
}

\author{
Mohamed Elshahed
}


If architectural style is simply reduced to arches, domes and proportions we must be reminded that construction technologies determined these elements. The shapes of arches, the dimensions of columns and thickness of walls are determined by the physics of materiality and the methods of construction. ${ }^{1}$

Sayed Karim, Al-Emara (Architecture) magazine, 1940

It was not until the 1940s and 1950s that modern forms had any appreciable impact on the 'less developed' countries, and these forms were usually lacking in the poetry and depth of meaning of the masterworks of the modern movement ... through the brainwashing of post-colonial elites (native born but foreign educated) with Western images and ideas that were upheld as 'progressive' counter-agents to an earlier era of 'backwardness and stagnation'. ' William Curtis, Architecture Since 1900, 1982

What is more important in the Arab states right now is not technology or the transfer of technology which has been developed in other countries but the revitalization of the Arab past, along with an appropriate amount of technology which is needed for specific tasks. ${ }^{3}$

Udo Kultermann, Contemporary Architecture in the Arab States, 1999

The heritage status of twentieth-century constructions is deeply contested across the 22 Arab states. ${ }^{4}$ In large part, this is due to the absence of locally produced histories of modern and contemporary architecture, of narratives that can abet thinking about recent constructions historically. ${ }^{5}$ There are acute crises regarding the study, documentation, and preservation of modern architecture in Egypt, Palestine, Iraq, Syria, and Lebanon - where the region's first generations of home-grown architects built; but the histories of their practices are largely unwritten, making the identification and potential preservation of their buildings a difficult task. In these locations, the rise of local expertise, delayed by the presence of colonial experts, came into being alongside nationalist and independence-oriented politics and revolutions after the First World War. Much of this architectural production has gone undocumented; its creators and authors have become anonymous; many buildings are undated; and much of this production no longer exists due to wars, speculative development, and a slew of other factors. In the aftermath of the oil embargo of 1973, American-oriented autocratic regimes across the Arab states favoured the foreign expert, giving new life to a colonial tradition that was only briefly challenged by Arab architects after the Second World War. ${ }^{6}$ In Gulf states, where urban landscapes have rapidly changed several times within a generation, development has come to supersede memory. ${ }^{7}$ 


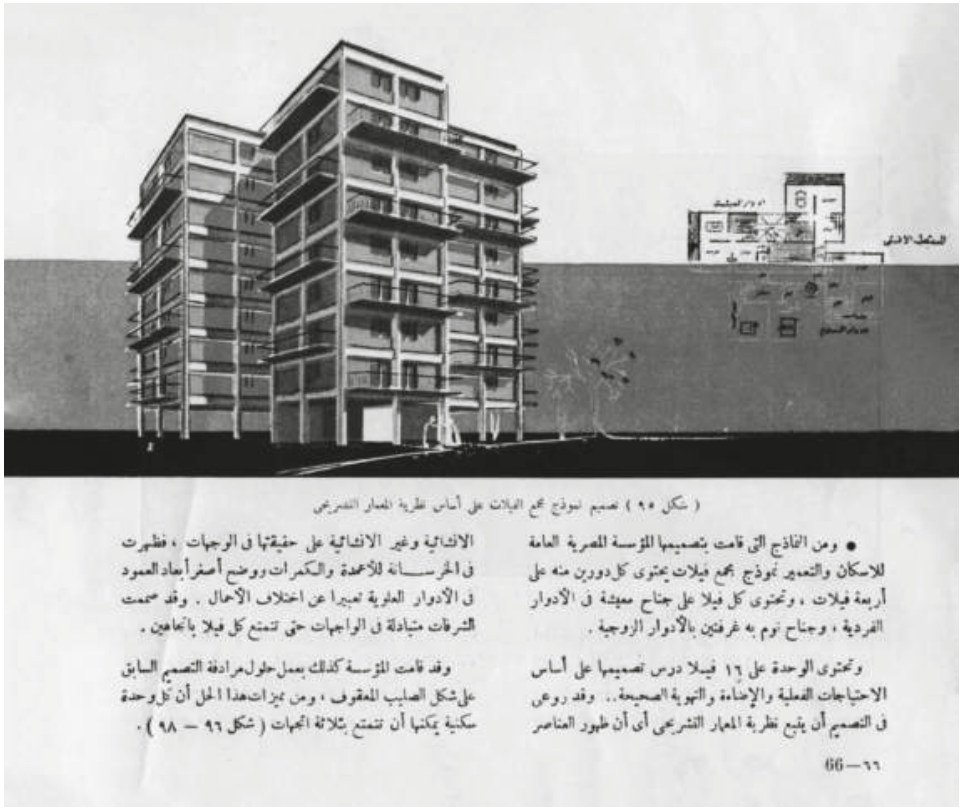

A page from Mohamed Hammad's 1963 book Egypt Builds, a survey of contemporary Egyptian architecture (Source: Mohamed Elshahed's personal collection. Reuse not permitted).

Taqiyy Al-Din Ahmad bin Ali Al-Maqrizi (1364-1442) chronicled the urban and rural landscapes of Egypt in the fifteenth century, and his project was revived in the nineteenth century by Ali Pasha Mubarak (1823-1893) with his monumental, 20-volume Al-Khitat Al-Tawfiqiyya Al-Jadida, providing a detailed street-bystreet description of Egyptian cities and towns. ${ }^{8}$ Despite these important precedents in historically recording the built environment, architectural history has not been institutionalized in much of the Arab world. A persistently absent aspect of architectural training and education in Arab states is the regional history of modern and contemporary practices. The history of these practices remains a frontier in research and writing, mostly done in English and rarely published in the region. As architect and editor of the regional architectural magazine Alam Al-Benaa, Abdelbaki lbrahim wrote in 1985, "The Arab architect remains a stranger in his homeland". ${ }^{9}$ There have been separate efforts by authors to construct in Arabic a canon of modern architecture and contemporary practices in the form of a survey, such as Egypt's Mohamed Hammad (Egypt Builds, 1963) and Tawfiq Abd Al-Gawwad (Egypt: Architecture in the Twentieth Century, 1989). - Yet, the limited circulation of these publications meant they have gone untranslated, and buildings featured therein did not make their way into mainstream 


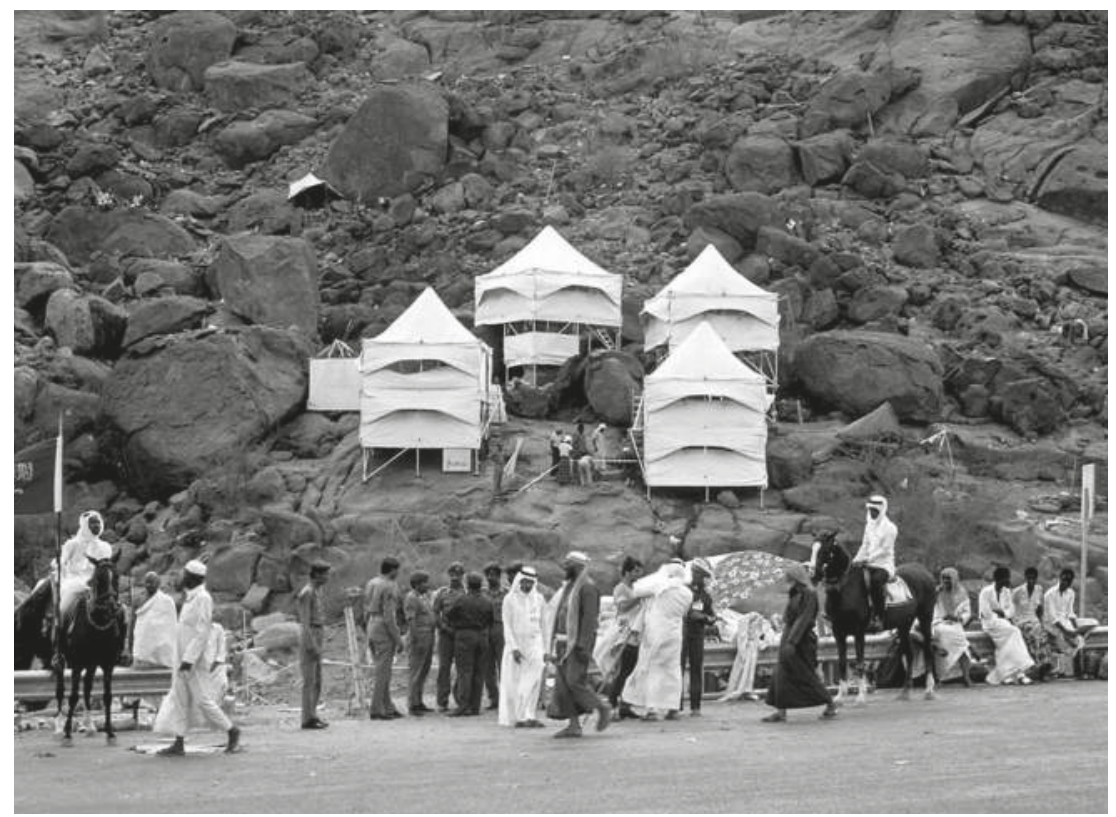

fig.2 Frei Otto, Mahmoud Bodo Rasch and Sami Angawi, Mountain Tents for Hajj Pilgrims, Prototypes in Muna Valley, Saudi Arabia, 1981-82 (Source: Wikimedia - Creative Common License, 2004).

architectural knowledge. As an example, William Curtis' (b. 1948) popular textbook Architecture Since 1900, still in use today with updated editions, has little to offer when it comes to modern constructions in the Middle East and North Africa.

From the 1980s, German-American art historian Udo Kultermann (1927-2013) developed an interest in architectural developments in the Arab world. For him, the revival of tent architecture by German architect Frei Otto for his designs for pilgrims'

fig.2 accommodation for the Hajj (1964-1967) and for Tuwaiq Palace in Riyadh (1983) are considered positive steps in the right direction towards an authentic contemporary Arab architecture. ${ }^{10}$ The endorsement was published in his 1999 book Contemporary Architecture in the Arab States: Renaissance of a Region, the only English-language survey of contemporary architectural production in all Arab states with works spanning four decades. The historian was not interested in the early years of modernism in the region; rather, it was the immediate present that he sought to capture historically, to identify the main architects and their buildings. ${ }^{11}$ In 1980, he wrote, "The emergence of young Arab architects is the first phase of a most recent development of revolutionary importance. Not only do they have to compete with the elite of large international firms, they also have to re-establish 
their identity in an architectural language which is linked to their own tradition". ${ }^{12}$

In this chapter, I explore how writing the history of architecture is related to contemporary architectural practice and potentially informs architectural preservation in Arab states. Udo Kultermann's Contemporary Architecture in the Arab States not only captures a history but also shapes its discourse by identifying a thematic direction for 'history-worthy' contemporary practices as championed by the historian-critic. The book is a product of intellectual debates in the 'West' (mostly the United States, United Kingdom, and Germany) with regards to the status of modernism: what direction should contemporary practice take? To where and led by whom? Kultermann mediated postmodernist thought in the West and the search for a regionally appropriate contemporary architecture for parts of the Arab professional arena. At the heart of this investigation are questions raised succinctly by Anthony Vidler in his study of historical approaches to constructing genealogies of modernism: "What kind of work does or should architectural history perform for architecture, and especially for contemporary architecture", or in other words, "How is history 'related' to design? Is it useful? And if so in what ways?"13

\section{The book}

During his long career, Kultermann published 35 books in German and English on an astonishingly wide variety of subjects, including New Japanese Architecture (1960), New Directions in African Architecture (1969), Contemporary Architecture in Eastern Europe (1985), The History of Art History (1987), and Architecture of the Twentieth Century (1993) in addition to publications on women performance artists, new sculpture, and architecture of the 1970s. By the 1950s, with the provincial limitations of art and architectural histories clearly evident, historians and critics based in Europe and the USA were itching to be the first to conquer new frontiers of knowledge, at least for English speakers. It appears that for Kultermann moving beyond the West meant becoming an expert on everything else. While he was an early proponent of what is now known as "global modernism"14 - expanding the canon of art and architectural histories to include geographies such as Japan, Africa, and the Middle East - his approach was conventional in that it was driven by the architect's point of view and was focused on landmark and state commissions. What cuts diagonally across the seemingly different regional histories is his interest in works by local and foreign architects that explicitly refer to tradition and identity in form or presentation. Given the fervour of postmodernist thought in the moment during which he was writing, his interlocutors were architects, scholars, and politicians who witnessed the rise of the International Style and who looked to move beyond it in favour of regional specificity and identity. 


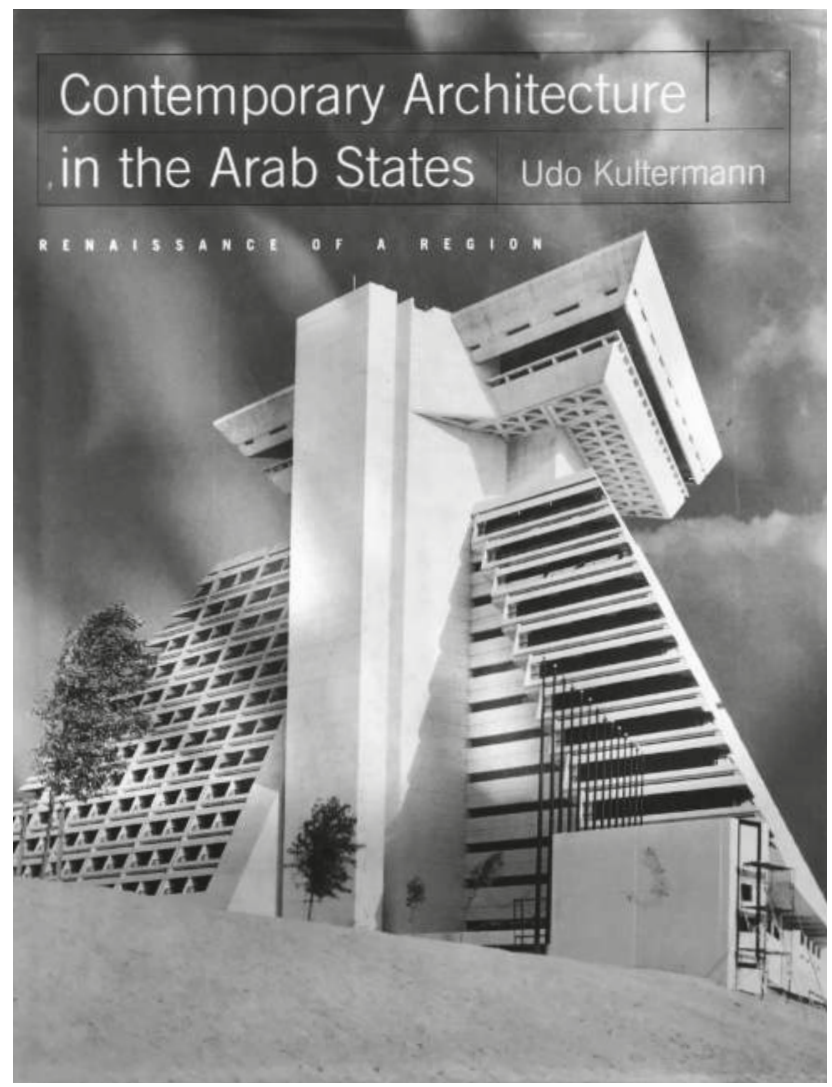

fig.3 Cover of Udo Kultermann's Contemporary Architecture in the Arab States: Renaissance of a Region, McGraw-Hill, 1999.

Kultermann's Contemporary Architecture in the Arab States is composed of 13 country-focused chapters including Egypt, Syria, Iraq, Morocco, Yemen, Saudi Arabia, and one subfig.3 regional chapter focused on the Gulf states. Each chapter begins with a brief introduction and historical background followed by country-specific synopses on political and architectural developments focusing on the post-Second World War or post-independence years. Embedded in these narratives are architectural examples described seamlessly within the text and accompanied by high-quality illustrations. ${ }^{15}$ The architectural descriptions focus on form and the integration or reimagination of traditional references. The book covers four decades starting with the 1950s with the majority of the works built from the 1980 s. ${ }^{16}$ Featured projects were designed by Arab architects such as Abdel Wahed El-Wakil (Al-Sulaiman Palace in Jeddah, 1979), Kamal El-Kafrawi (University of Qatar, 1985), and Mohamed Makiya (Headquarters for the 
Organization of Arab Petroleum Exporting Countries, circa 1983), complemented by projects designed by American and European architects particularly in the Gulf, including Michel Écochard (Kuwait National Museum, 1983), Henning Larsen (Ministry of Foreign Affairs in Riyadh, 1984), and William Pereira (Doha Sheraton Hotel, 1982). $\boldsymbol{\Delta}$ Together, these projects are presented by Kultermann as evidence of a regional renaissance fuelled by modernizing governments with a keen interest in the currency of contemporary design.

The buildings covered in each chapter vary in terms of function. The chapter on Iraq, for example, includes mosques designed by Mohamed Saleh Makiya, Rasem Badran, Robert Venturi, and Denise Scott Brown as well as private residences by Rifat Chadirji and Maath Al-Alousi. There are also banks by Dissing+ Weitling and Makiya, Baghdad University by The Architects Collaborative, and Le Corbusier's Sports Hall. The typological variety and diverse methods and approaches to contemporary Iraqi architecture are well represented. This typological diversity is maintained in most chapters; however, few examples of lowincome housing are included, such as Andre Ravereau's housing in Ghardaia, Algeria (1976). The vast majority of featured projects are state commissions such as ministry and public buildings, museums, airports, universities, parliament buildings, state palaces, and mosques.

The chapter on Egypt demonstrates the historian's bias. The selection of buildings and architects portrays a homogenous picture of the country's post-Second World War architectural production, focusing on Hassan Fathy, Abdel Wahed El-Wakil, and Ramses Wissa Wassef, all rejecting modernist aesthetic values and design approaches. "Foreign technology and architectural traditions have merely been transplanted to Egypt", writes Kultermann as he refers to work by British and American architects in the country such as the international hotels designed by Bruce Graham; Skidmore, Owings \& Merrill; and others. In addition, he echoes critical voices within Egypt opposed to the work of Egyptian modernists, seen as agents contaminating Egyptian architecture with 'Western values'. In this context, the Egyptian architects named above were presented as the vanguard in resisting internationalism in Egyptian architecture. Kultermann's dismissive critique of Egyptian modernists is clear as he writes: "Egyptian architects like Raymond Ayub [Antonius], Sayed Karim and Ahmed Sidky who in their various attempts to remedy the situation [of ugliness in Egyptian cities] with large building programmes modelled after Western structures have not contributed to a viable solution" ${ }^{17}$ In other words, Egyptian architects who represented the mainstream of the profession in Egypt and key modernists such as architect, magazine editor, and polemicist Sayed Karim (1911-2005) are nearly omitted from the narrative all together. 


\section{The context}

In 1970, the death of Gamal Abdel Nasser marked an end to a short-lived pan-Arabism and inaugurated an era of economic liberalism paired architecturally and culturally with a search for identity. That year, a coup d'état unsettled Syria. The 1973 oil embargo changed the trajectory of the region. Two years later, a civil war broke out in Lebanon, and by the end of the decade, Saddam Hussein came to power in Iraq. During that tumultuous decade, the world of architecture was increasingly critical of modernism, by then the architecture of the establishment across Arab states. In the midst of these years, in 1977, Charles Jencks announced the death of modernism in his book The Language of Post-Modern Architecture. ${ }^{18}$ The decade witnessed the rise of the Arab Gulf states which signalled the shift of the region's poles away from Cairo, Beirut, and Baghdad to Kuwait, Doha, and Abu Dhabi. There, vague notions of reviving traditions, centring Islam in public life, and distinguishing between Arab modernity from its universal counterparts were all ideas shaping the discourse on constructing a new Arab identity and Arab exceptionalism. This is what Nasser Rabbat calls the "historical exclusivity and referential reductiveness delimited by the theory of cultural autonomy", which he considers as the most critical root cause "for homogenisation in architectural production in the Islamic world today". ${ }^{19}$

According to the World Development Report 1994, as cited by Kultermann, "The 1992 per capita income in US dollars was \$520 in Yemen, \$640 in Egypt, \$16,150 in Kuwait, and \$16,750 in Qatar". ${ }^{20}$ The drastically different economies across the region manifested architecturally as countries such as Egypt barely provided adequate infrastructure for its growing population while new wealth in Gulf states translated into substantial investment in infrastructure, housing, education, official buildings, and leisure facilities. By the 1990s, the economic unevenness across the Middle East was starkly represented through labour migration within the region and through architecture. ${ }^{21}$ Ageing modernist buildings in the old cities of Egypt, the Levant, and Iraq gave way to new gleaming structures utilizing late modernist but more often postmodernist aesthetics in the new economic, political, and cultural centres of the Arab world. Hotels, universities, government buildings, and other typologies with no precedence in historic architecture were built across the region, often by foreign architects, inventing traditions that are Orientalist and postmodernist but presented to patrons and the public as contextual and regionally modern.

The shortcomings of the post-independence panArabism led by Gamal Abdel Nasser left many countries in political, cultural, and economic disarray. In Egypt, the region's most populous country, dire economic conditions, unchecked corruption, and uncontrolled demographic growth has left the 
bloated Egyptian state perpetually incapacitated since the 1970s. With postmodernism in fashion, international firms seeking to expand their business to Arab clients focused on inclusion of vague symbolic references to traditional or historic architecture handpicked from across the region with a concentration of their constructions in the new Gulf cities. ${ }^{22}$ Arab architects represented in Kultermann's book effortlessly hopped between cities from Baghdad to Kuwait and Amman to Dammam designing what they saw as a regionally specific architecture, moving beyond the nation-state as an identifier and towards the notion of an Arab contemporary architecture.

For the German-American historian, the fast urbanizing terrain of the Middle East in the 1970s to 1990s was a new frontier for architecture, developed not only with designs by international firms eager to gain commissions in a region undergoing immense transformation but also by some local architects who were, according to his reading, mediators between a universal internationalism and regional specificity. Tradition and identity are themes that define Kultermann's survey of architectural developments in a region he frequented from the 1970s, invited by governments such as Morocco, Qatar, and the United Arab Emirates to deliver lectures and to study local architectural developments. Since the 1950s, under the guise of post-independence, states across the Middle East invested heavily in architecture and urban development, fuelled by the politics of post-colonialism in some cases or in other cases by new wealth generated from oil and gas. Architectural developments during those decades reflect the cacophony of changing politics, economics, and culture of the post-Second World War, Cold War Middle East. ${ }^{23}$

As architecture serves financial and political power, the economic unevenness across the Middle East during the period covered in Kultermann's book is evidenced by his selection of buildings. The selection focuses on state and elite private commissions, rendering invisible the widespread building practices excluded from these categories. While he frames the entire book as an investigation of the re-emergence of regional architecture, mainstream architectural practices, populist architecture, and the vernacular of the poor urban majority in all the considered counties are omitted. Thus, not only is the question of identity placed at the centre of the investigation, it is demonstrated with large, expensive commissions from rich states or elites within specific national contexts. This leaves little to discuss in countries with poor economic performance; thus, the chapters on Sudan, Oman, and Yemen are a mere few pages each. Saudi Arabia, in contrast, is the most represented country in the book with mention of government, educational, religious, industrial, residential, and commercial buildings as well as sports, health, and recreational facilities in the kingdom. 


\section{Surveying architecture}

When British-German art historian Nikolaus Pevsner (1902-1983) published Pioneers of the Modern Movement in 1936, he "became responsible for legitimizing the modern movement and providing it with a basis of historical authenticity". ${ }^{24}$ By creating a genealogy, selected contemporary works were given "a provenance of ancestors for modern architecture and design". ${ }^{25}$ After 15 years of British, American, and German historians publishing historical examinations of modern design, by 1940 modern architecture was "fully assimilated into the art-historical canon, and given its place in the history of the "styles". ${ }^{26}$ This "canon" was provincial in conception, considering works and architects operating within limited geographies, yet its claims were universal. By the 1980s and 1990s, when Kultermann was conceptualizing how to narrate the various contemporary architectural developments across the Arab world, the "canon" was decried by a new generation of historians and critics for its hierarchies, its fixed styles and language, its Western-centrism, and its focus on white, male architects. ${ }^{27}$ On the one hand, Kultermann's book is a response to a gap in knowledge; on the other hand, like his predecessors, he provides a partial narrative historically justifying specific contemporary practices he admired. In the absence of other narratives, his stands unchallenged.

Architectural history has been fundamental to the development of the architectural profession since the nineteenth century. ${ }^{28}$ The formalization of architectural education in the United States and various European contexts centred on the study of historical examples, spawning a new era of revival architecture throughout the nineteenth and early twentieth centuries. As Stanford Anderson noted, "From a time of the dominance of academic classicism around 1800, through all the historicisms and eclecticism of the nineteenth century, history was in some way intimately wedded to the practice and teaching of architecture". ${ }^{29}$ This may be true for those contexts, but the relationship between architectural education, practice, and history in the modern Arab states is vastly different and varies from one national context to another. The region's first systematic identification, listing, and documentation of buildings commenced in 1881 in Egypt with the establishment of the Comité de Conservation des Monuments de l'Art Arabe. ${ }^{30}$ It was a task that combined architectural history writing with upkeep and restoration and that also produced a wide array of accurate documentation of historic architecture that spawned a new wave of revival architecture at the end of the nineteenth century. Thus, history writing, heritage identification and protection, and contemporary practice were, for a brief time, intimately wedded. Max Herz Pasha (1856-1919), for example, did all three. The Comité, led by Herz, made parts of Egypt's urban landscape legible by codifying styles, creating genealogies 
of buildings and establishing a canon of 'Arab monuments'. As Nairy Hampikian writes,

In 1881, members of the Comité initiated a list of 'monuments' in which all buildings that were historically, aesthetically, and/or culturally worthy of protection were registered. The chosen buildings were identified as 'monuments' under one category, varying from each other only in the date of their construction. ${ }^{31}$

Such methods were not extended to more recent constructions. In the meantime, architectural education was tied to schools of engineering, originally established by the army in the 1830s, where the history of architecture was not 'intimately wedded' to practice and teaching. ${ }^{32}$ During colonial rule (1882-1952), architectural education shifted towards a Beaux Arts model led by mostly British faculty until the 1940s. The emergence of a new class of Egyptian architects was not accompanied by the emergence of specialized art historians chronicling the production of the present and recent past. Kultermann's Contemporary Architecture in the Arab States does not attempt to link post-1970s constructions with this earlier chapter in the region's history of modernism. Instead, he frames such constructions, regardless of the national origin of the architect, as the 'true' although belated beginning of a uniquely regional architectural language, an 'other' modernism. ${ }^{33}$

Constructions of the nineteenth and twentieth centuries in Muslim societies produced during two centuries of colonialism, industrialization, revolution, nationalism, and modernization rarely appear in architectural canons associated with these periods, nor are they included in surveys of Islamic architecture. ${ }^{34}$ Historians have constructed the history of Islamic architecture following one of two approaches, ordered according to chronology or according to a theme. More often chronology starts with the rise of Islam and ends in the eighteenth century "when the Islamic world is supposed to have become inextricably dominated by the victorious Western culture and ceased to be creative on its own". ${ }^{35}$ The development of Islamic architecture, or the architecture of Muslim societies, was deemed to have had a beginning and an end. This notion, that with modernity the Muslim world became contaminated by the West, is the raison d'être for later projects of revival, of regaining regional identity in art and architecture. Such projects are those embraced by Kultermann as authentic expressions of an Arab modernism that is directly linked to the revival of traditional forms and references centred on Islam. In this worldview, 'Arab' and 'Islamic' become "non-historical" styles rather than responsive, evolving architectures. Kultermann did not veer too far from Sir Banister Fletcher's (1866-1953) view, expressed in his influential A History of Architecture, which "divided world architecture into 'historical' and 'non-historical' styles. While he discussed 
'historical styles' as Western ones that have continuously evolved from Ancient Egypt and Greece to the present, he introduced Indian, Chinese, Japanese, Ancient American and Saracenic architecture as 'non-historical' styles without evolution or succession". ${ }^{36}$

\section{Modernism elsewhere}

Forms and ornaments, or "the tactile and the tectonic" to use Kenneth Frampton's words, "have the capacity to transcend the mere appearance of the technical in much the same way as the place-form has the potential to withstand the relentless onslaught of global modernization". ${ }^{37}$ By the time Kultermann was writing his survey of contemporary architecture in the Arab states, Frampton's ideas on critical regionalism ${ }^{38}$ were already echoed by several key authors such as William Curtis, whose survey Architecture Since 1900 is well established as the textbook for teaching the history of architecture..$^{39}$ Curtis' chapter titled "Modernity, Tradition and Identity in the Developing World" opens with a 1973 quote from Hassan Fathy (1900-1989) that states, "Every people that has produced architecture has evolved its own favourite forms, as peculiar to that people as its language, its dress, or its folklore". ${ }^{40}$ The year of that quote was when Fathy's Gourna: A Tale of Two Villages, originally published in Arabic in 1969 by Egypt's Ministry of Culture, was republished for a wider international audience

fig.4 as the now famous Architecture for the Poor. ${ }^{41}$ For Frampton (b. 1930), a figure such as Hassan Fathy employs a fundamental strategy to "mediate the impact of universal civilization with elements derived indirectly from the peculiarities of a particular place". ${ }^{42}$ Fathy provided an Arab voice that bolstered and further solidified Western-centric narratives about the exclusivity of modernism to the West and the subsequent critique directed towards it. ${ }^{43}$ Curtis' opening lines to that same chapter in which he quotes Fathy provide a compelling but problematic narrative: "Modern architecture was created in Western industrialized countries ... where avant-garde cliques attempted to produce an authentic modern style appropriate to rapidly changing social conditions ... but its results were copied all around the world, and were often misapplied". ${ }^{44}$ For Frampton, Curtis, and Kultermann, Fathy is a convenient example of the singular possibility of a corrective regional modernity that distinctly operates outsides the standards of the West. Kultermann described Fathy's mud-brick vernacularism as "the first steps towards an emerging autonomous Egyptian architecture". ${ }^{45}$ The inclusion of selected 'Global South' figures such as Fathy foreclosed the possibility of considering contending visions. As Keith Eggener later wrote,

It is ironic that writers discussing the places where these designs appeared so often emphasized one architect's interpretation of the region over all others: Tadao Ando for Japan, Oscar Niemeyer for 
Brazil, Charles Correa for India and Luis Barragan for Mexico. In other words, a single correct regional style was implied, or imposed, sometimes from inside, more often from outside the region. ${ }^{46}$

The deeply ingrained notion that Western modernism is authentic, as opposed to modernist expressions elsewhere, is rooted in two convictions expressed by Curtis: that Western modernity developed on its own in the century following the Industrial Revolution and that Western societies have had the time needed to absorb the ideas propagated by the avant-garde cliques that created modernist forms in the twentieth century. He is suspicious of manifestations of modern design outside the West, seen as inauthentic due to two corresponding points: first, given that the world outside the West did not experience an industrial revolution of its own (no mention of European colonialism, slavery, or exploitation), manifestations of modernism in architectural form relied on the West to contaminate the rest of the world with its ideas. Second, the embrace of modernist forms following independence or by post-colonial regimes occurred at a fast pace that did not allow the time needed to make these forms and ideas rooted in such societies. As a counter-argument, one can suggest that global modernism was not possible, in Europe or elsewhere, without the multi-directional circulation of ideas, resources, and labour around the world by networks of expertise, power, and capital including local interlocutors. The Industrial Revolution was not possible without the expansive European colonial projects that exploited geographies far outside Europe. Modernist architecture did not develop in a hermetically sealed Europe but in an interconnected and networked world where the peripheries of empire were often laboratories of innovation and experimentation, with long forgotten local partners.

Throughout the 1980s, Kultermann published a series of articles in Mimar magazine, edited by Hasan-Uddin Khan, on the architecture of Egypt, Iraq, the Gulf states, Saudi Arabia, Morocco, Tunisia, Algeria, Libya, and Jordan. Kenneth Frampton's ideas on critical regionalism are strongly echoed in Kultermann's writings on Arab states. ${ }^{47}$ The introductory essay sets the tone for the rest of the series. Titled "Contemporary Arab Architecture: Toward an Islamic Identity", in it he states that the "common denominator of the architects from these countries is their search for identity, which is a fundamental necessity in order to continue the great tradition of Islamic architecture". ${ }^{48}$ For Kultermann, tradition is only valid when it maintains its relevance and is updated by new generations of architects and builders. This follows Paul Ricoeur's assertion that "a cultural tradition stays alive only if it constantly creates itself anew". ${ }^{49}$ The question is, how will this newness manifest architecturally? Kultermann's answer, informed by the postmodernist zeitgeist, suggests a revival of 'static' notions of Islamic 


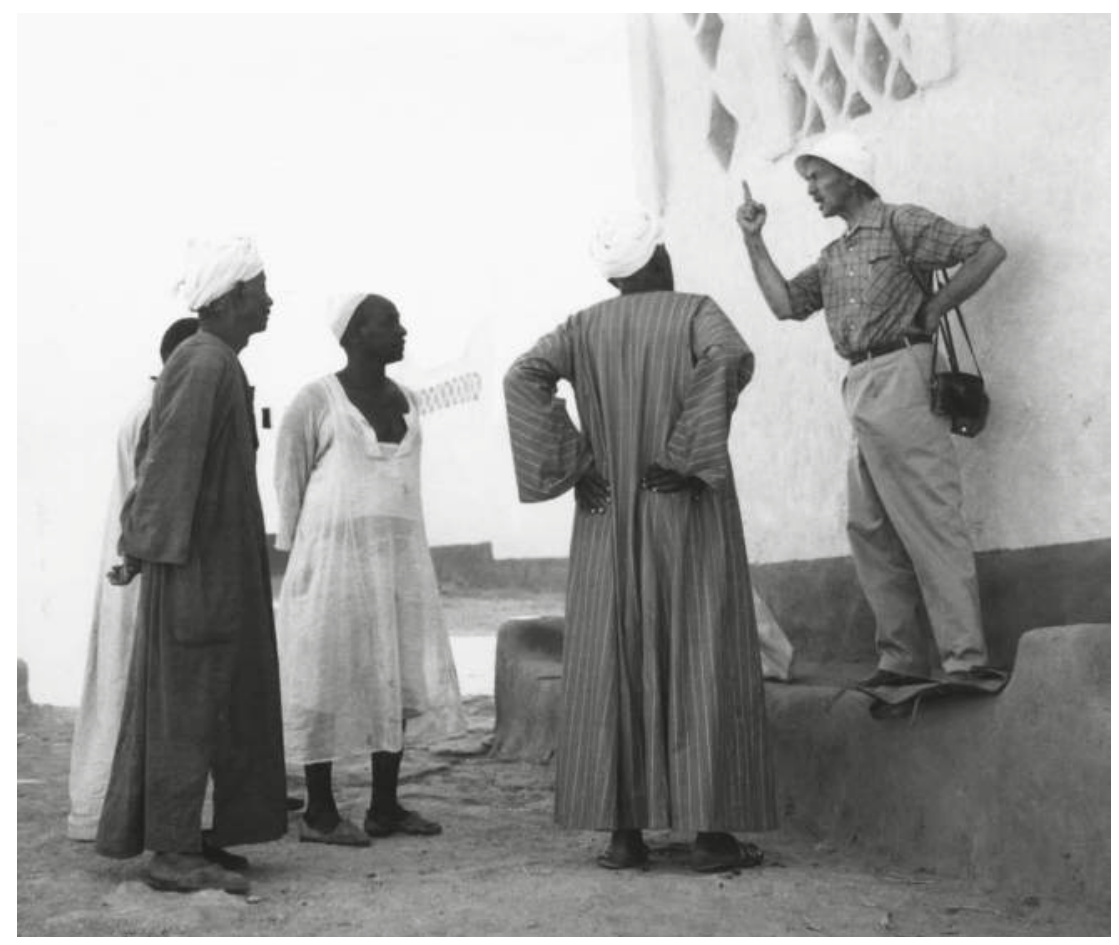

fig.4 Hassan Fathy speaking to builders implementing his New Gourna village design, 1945 (Source: Rare Books and Special Collections Library, American University in Cairo. Reuse not permitted).

and Arab symbols in contemporary architecture. ${ }^{50}$ However, his reference to defining Islamic architecture relies on vague, outdated notions: "the concentration given to the interior space, the continuous experience of the architecture as part of the urban fabric ... [and] the non-representational appearance and the meaningful application of decoration". ${ }^{51}$ Kultermann conflates 'Arab' and 'Islamic'; he emphasizes form and decoration in identifying contemporary manifestations of Islamic architecture as expressions of Arab modernity, even if many of the celebrated projects in the book were designed by American and European architects. Forms and decorations are what Nasser Rabbat considers "tangential" in understanding Islamic architecture. ${ }^{\mathbf{5 2}}$

A contending vision to Kultermann et al. comes from Egyptian architect Sayed Karim in a published lecture he delivered in 1940 at Cairo's Royal Geographic Society: "Architecture within any single region exhibits diversity within a common theme", he said. "For example, Arab architecture slightly differs in Egypt from Iraq or Spain, so too will the new international architecture be expressed with slight and shallow differences on the same theme". ${ }^{53}$ 

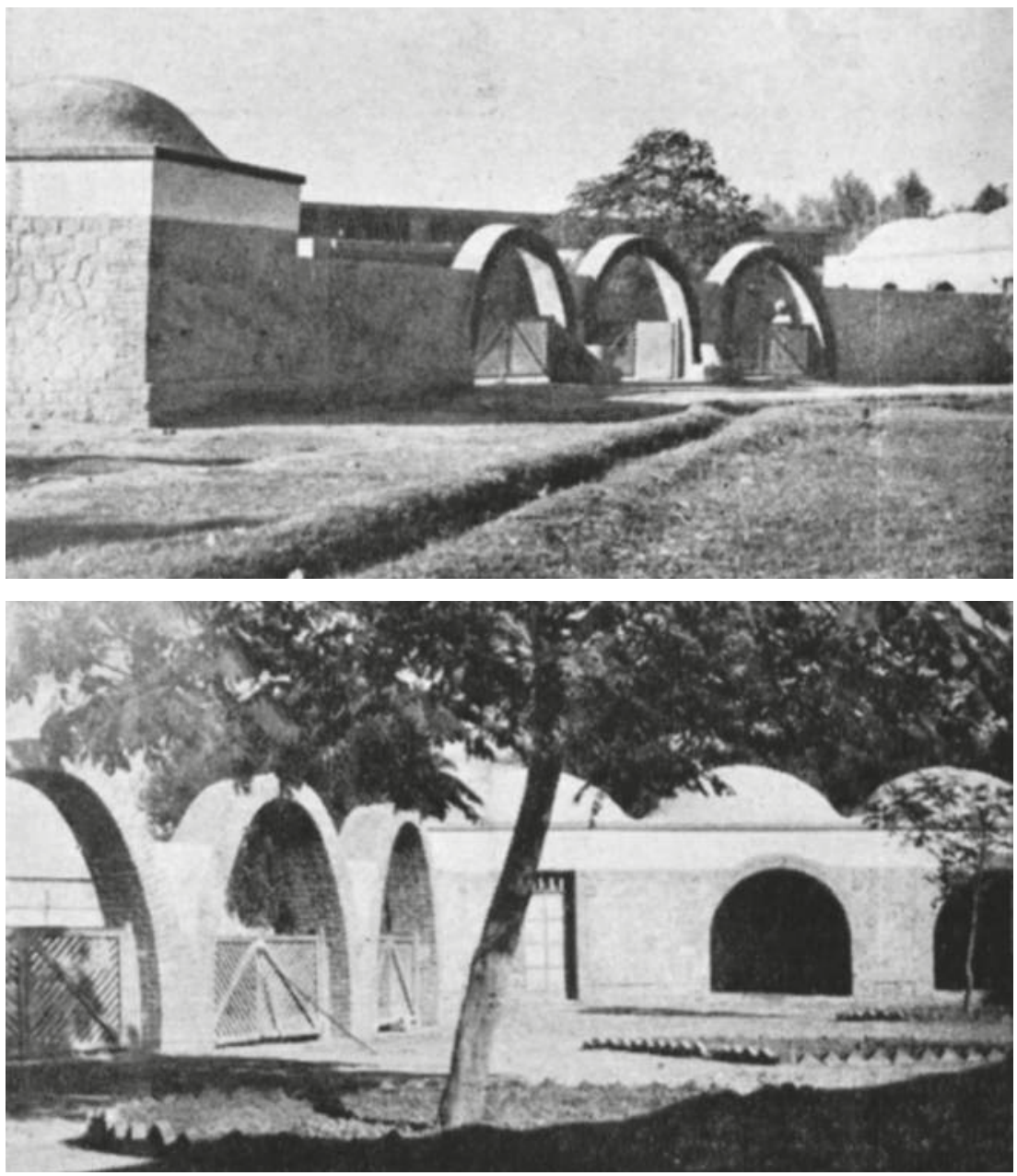

Sayed Karim's Village University, 1945 (Source: Al-Emara magazine, Mohamed Elshahed's personal collection. Reuse not permitted).

Karim advocated a materialist reading of how architecture developed in different national and regional contexts. Historic, vernacular, or contemporary architecture was not described stylistically. For him, contemporary architecture of every epoch responds to contemporary needs with the means, materials, and technologies available to society. ${ }^{54}$ The shapes and sizes of elements that compose a style are, in Karim's view, determined by the construction material, technique, and construction methods. The palate of materials Karim used in his designs includes concrete, brick, wood, tiles, stone, marble, glass, and glass block. With those and other materials that are subsequently introduced, contemporary 
architecture in the Arab region can simultaneously belong to national and regional identity while speaking an architectural parlance that is international, without subscribing to a fixed style.

The assumed, rigid duality between the modern and the traditional, an invention of colonial historicism, does not appear in Karim's discourse. ${ }^{55}$ Karim and his co-editors in Al-Emara, Mohamed Hammad and Tawfiq Abd Al-Gawwad, were not iconoclasts. They did not explicitly reject traditional architecture, nor did they make explicit architectural links between the modernism they produced and specific historical forms or elements. ${ }^{56} \mathrm{Al}$-Emara magazine frequently featured vernacular and historic architecture among the heterogenous modern constructions. Architecture and urban form were measured based on their performance rather than their subscription to certain notions of identity or style. For example, the numerous articles in the pages of Al-Emara regarding village reform did not focus on the rejection of village architecture based on the idea that it was traditional. Rather, reforms were proposed due to sanitation issues and to raise the quality of life of peasants. In contrast with the primitivism of Hassan Fathy's celebrated but failed New Gourna Village (1945), Karim's little-known

fig.5 design for a what he called a 'village university', built the same year, gently inserts modern solutions and amenities, such as a swimming pool, into inherited architectural forms and materials. Similarly, the promotion of modern villas, apartments, and worker housing were not rooted in a rejection of traditional forms of dwelling; rather, they were presented as necessary changes to accommodate social and economic transformations as well as the utilization of new building materials and technologies. In contrast to their European counterparts, some Arab modernists did not legitimize their architectural designs based on an ideological rejection of the past nor a blind embrace of Western models.

\section{Build, write, maintain, remember}

In addition to shaping the discourse on the history of contemporary design, Nikolaus Pevsner's largest body of work, published between 1951 and 1974, is his monumental 46-volume architectural guides Buildings of England. It is a town-by-town, in some cases street-by-street, account of individual buildings across the country, including monuments and vernacular, lesserknown buildings from all periods, all treated historically. His guides have been fundamental to the preservation of England's architectural heritage, in large part by making the architectural landscape legible to the masses. Not only has the publishing of such architectural guides been fundamental to preservation, but also "research undertaken around the practical tasks of restoring and preserving historic monuments and places [is] the backbone of local architectural history". ${ }^{57}$ The uneven development of today's modern world is mirrored in the unevenness of the institutional 
infrastructure required to record the world's diverse and contemporaneous architectural histories and, by extension, in the legibility of the architectural landscape and its potential preservation. Large sections of our collective picture of global modernism are distorted, pixelated, or entirely missing.

The current status of architectural heritage from all epochs is dire across the Arab states, and so too is contemporary architectural practice. The two crises are connected. Recent constructions across the region have fallen into historical purgatory: neither 'historically' legible nor protected, they take with them large swaths of physical evidence necessary for deciphering the region's troubled modern history. The work of Arab architects in Cairo, Beirut, and Baghdad from the 1930s to the 1980s has been defaced by war, deteriorated by negligence, and eliminated by real estate speculation or state-led urban projects. In Egypt, none of Sayed Karim's buildings are on the heritage protection lists, and modernist architecture in general is omitted from the outdated registers of national patrimony. It should be noted that Karim's vibrant career was abruptly ended in 1965 when he fell out of political favour with the Nasser regime. His offices were closed, his assets confiscated, his archive scattered. Although he lived on for another 40 years, he retreated from public life except for the occasional column or essay in a magazine or newspaper, propagating his critique of urban and architectural affairs in Cairo.

Thus Karim, despite his ambitions, is not a modernist 'hero' like those depicted by European and American historians in their early efforts to provide a historical narrative to modern design. What kind of history of modern design does a figure such as Karim afford us? Since the Free Officers proclaimed independence in 1952, Egypt has listed only around 150 Islamic monuments in addition to the 619 already listed, previously recorded, and restored by the Comité. Since then, there has been no methodological approach to writing local histories of the built environment in all its epochs and architectural manifestations including the contemporary, the vernacular, and the anonymous. The perpetual present has been rendered ahistorical.

The focus on identity and its relationship to contemporary architecture in the Arab world, as proposed by Kultermann, has been at the expense of the legacy of an important chapter in the history of global modernism, namely, its manifestations in the Arab world from the start of the twentieth century to the 1970s. George Arbid writes, "In contrast with some quickly concocted 'regional' recipes sometimes legitimized by foreign expertise, many attentive local or foreign professionals designed in response to time and place". ${ }^{58}$ Sayed Karim was perhaps the first "regional" architect; in the decade following the Second World War, he travelled across the Arab states, named in the Egyptian press 'the flying architect', gaining commissions in locations as diverse as Saudi Arabia, 


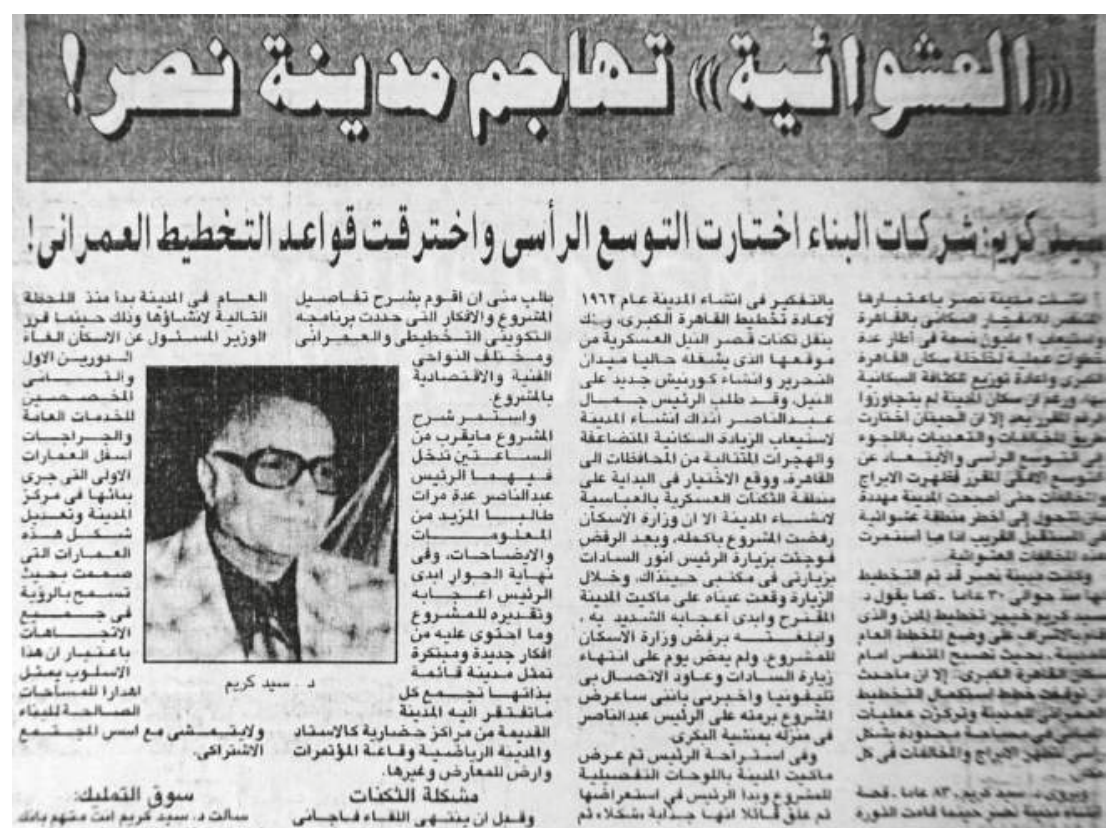

fig.6 While his career abruptly ended in 1965, Sayed Karim published the occasional critique of architectural affairs in the Egyptian press, such as this 1993 column decrying developments in Nasr City, a modernist urban plan he produced for the Egyptian state in 1958 (Source: Al-Ahram, Mohamed Elshahed's personal collection).

Kuwait, and Jordan in addition to his rich portfolio in Egypt. With the exception of a short-lived attempt to document and protect his Cinema Ahmadi in Kuwait, his buildings have not been granted the status of national heritage across the region, where the conditions for a locally institutionalized and methodological approach to the study and documentation of the built environment with the aid of local experts does not exist.

With some rare exceptions, Karim's cinemas, residences, and public buildings in Kuwait City, Giza, Amman, and elsewhere fig.7 have disappeared. No record of this vision of regional modernism has been sufficiently studied or fully archived. In 2015, the modernist block by architect Mahmoud Riad in Cairo - originally built as the city's municipality (1959) and subsequently reused as the political headquarters for Nasser's Arab Socialist Union and then later for Anwar Sadat and Hosni Mubarak's National Democratic Party - was demolished by army engineers who deemed it ugly after it was torched during the 2011 protests. ${ }^{59}$ Nearby, overlooking Tahrir Square, the American University in Cairo's Science Building (1966), one of the earliest experiments in passive solar design in Egypt, was also demolished in $2015 .{ }^{60}$ In 2019, Kuwait's AlSawaber apartment complex (1981) based on a design by Arthur 


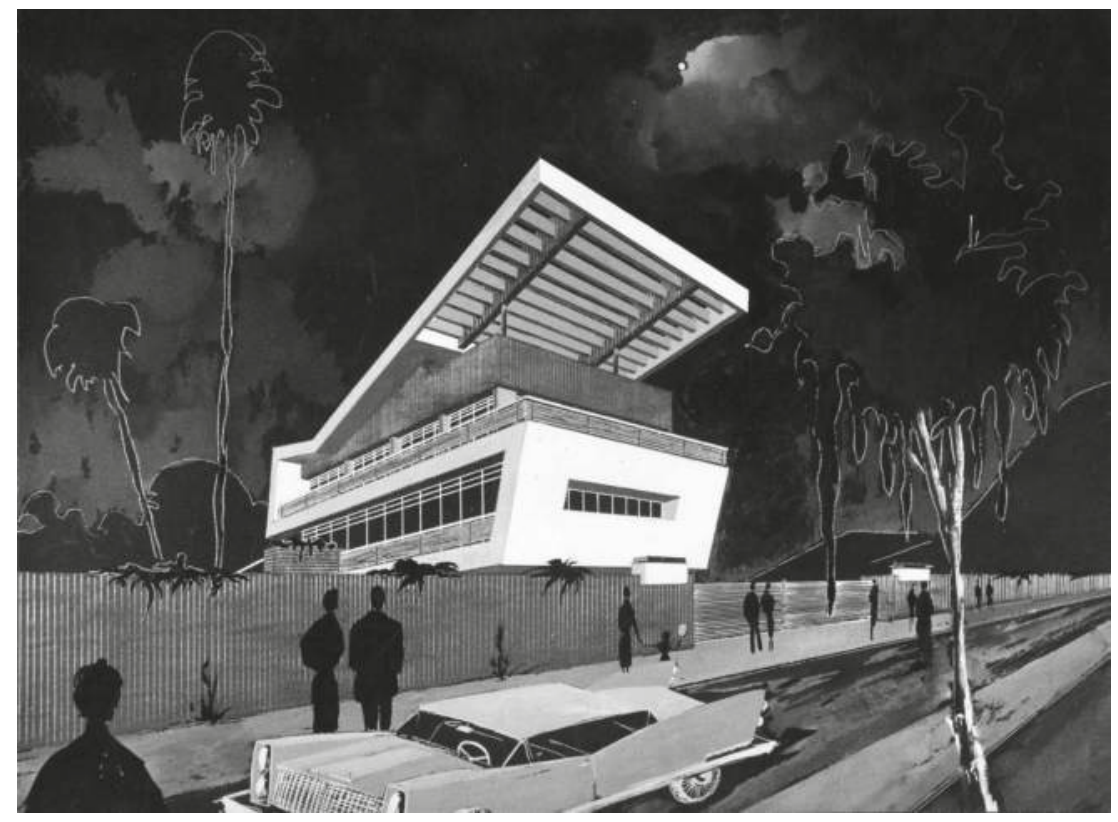

The Al-Qatami Residence in Kuwait, designed by Sayed Karim in 1958 (Source: Rare Books and Special Collections Library, American University in Cairo. Reuse not permitted).

Erikson was also demolished despite efforts by local architects and heritage enthusiasts to save it.

Numerous other examples of historically significant, modern constructions at various scales, from official and large to private and small, have been demolished without ever receiving the attention of historians or heritage institutions, both in short supply in the region. Such buildings are in the blind spot of architectural history, at least the kind championed by Kultermann in his account of the contemporary architecture of the Arab world. The situation is not entirely bleak: in August 2018, Dubai announced a plan to preserve the city's modernist heritage, such as the city's first skyscraper the Dubai World Trade Centre (1979) designed by John Harris. However, rather than singling out iconic buildings for heritage status, Arab cities in constant flux require solidarity in building institutional infrastructure that fosters a body of knowledge and practice, based in the region, linking architectural practice, history and criticism, and architectural memory. 


\section{Notes}

1 Sayed Karim, "Our Architecture and Its National Character", Al-Emara 2, no. 5-6 (1940): 271. Al-'Imara, or Al-Emara magazine as its name is Romanized on its back cover, was the first Arabiclanguage architectural journal focused on contemporary practice in Egypt. It was founded in 1939 by architect Sayed Karim and funded by his father and later his wife. The magazine produced 67 print issues in its 20-year run until 1959.

2 William Curtis, Architecture Since 1900, 3rd edn. (London: Phaidon, 1996), 567.

3 Udo Kultermann, "Contemporary Arab Architecture: Toward an Islamic Identity", in Mimar 3: Architecture in Development, ed. Hasan-Uddin Khan (Singapore: Concept Media LTD, 1982): 77.

4 Kishwar Rizvi and Sandy Isenstadt, eds., Modernism and the Middle East: Architecture and Politics in the Twentieth Century (Seattle: University of Washington Press, 2008).

5 "Research undertaken around the practical tasks of restoring and preserving historic monuments and places [is] the backbone of local architectural history". Andrew Leach, What is Architectural History? (London: Wiley, 2010), 4.

6 Mohamed Elshahed, "Cairo After the Second World War and the Rise of Arab Engineering Professionals", in The Arab City: Architecture and Representation, eds. Amale Andraos, Nora Akawi, and Caitlin Blanchfield (New York: Columbia Books on Architecture and the City, 2016), 79-91.

7 Yasser Elsheshtawy, Temporary Cities: Resisting Transience in Arabia (London: Routledge, 2019).

8 Nasser Rabbat, "Who Was Al-Maqrizi? A Biographical Sketch", Mamluk Studies Review 7, no. 2 (2003): 1-20. Also see Nezar AISayyad, “'Ali Mubarak's Egypt: Between the Testimony of Alamuddin and the Imaginary of the Khitat", in Making Cairo Medieval, eds. Nezar AlSayyad, Irene A. Bierman, and Nasser Rabbat (Lanham: Lexington Books, 2005).

9 Mohamed Abdelbaki Ibrahim,

"Alienation of the Arab Architect in His Homeland", Alam Al-Benaa, no. 53 (January 1985): 3.

10 Udo Kultermann, Contemporary Architecture in the Arab States: Renaissance of a Region (New York: McGraw-Hill Professional, 1999), 4-5. 11 Anthony Vidler, Histories of the Immediate Present: Inventing Architectural Modernism (Cambridge, MA: MIT Press, 2008).

12 Udo Kultermann, "Contemporary Arab Architects and Their Contribution to the Renaissance of Architecture in the
Arab States (extract)", Ekistics 47, no. 280 (1980): 41-44.

13 Vidler, Histories of the Immediate Present, 3.

14 Esra Akcan, "Writing a Global History through Translation: An Afterword on Pedagogical Perspectives", Art in Translation 10, no. 1 (2018): 136-142. 15 The illustration credits reveal Kultermann's direct access to the architects cited, all of whom are the author's contemporaries, as well as to official archives.

16 As a historian, Kultermann shaped the debate - in English and within his elite circle of interlocutors - on what is considered 'contemporary'. He placed his interpretation of present architecture, within an Arab context, in a historical narrative. This parallels Nikolaus Pevsner's project in Pioneers of Modern Design, originally published in 1936 as Pioneers of the Modern Movement. It was, as Pevsner wrote in the book's forward, the "first to be published" as a historical narrative of contemporary architectural practices organized by key architects and their works, setting the tone for future endeavours to narrate the development of architecture. See Colin Amery, "Nikolaus Pevsner's 'Pioneers of the Modern Movement', 1936", The Burlington Magazine 151, no. 1278 (2009): 617-619.

17 Kultermann, "Contemporary Arab Architecture: Toward an Islamic Identity", 77.

18 Charles Jencks, The Language of Post-Modern Architecture (London: Rizzoli, 1977).

19 "For as long as architects responding to the demand for a contemporary Islamic architecture turn uncritically to either the nationalist (and by and large modernist) or the neo-Islamicist (and resolutely postmodern) interpretation of the Orientalist paradigm, the pool of conceptual and compositional possibilities available to them will remain limited". Nasser Rabbat, "Why is Contemporary Islamic Architecture Risking Banality?" in Homogenisation of Representations, ed. Modjtaba Sadria (Geneva: Aga Khan Award for Architecture, 2012), 113-124.

20 Kultermann, Contemporary Architecture in the Arab States, 3. 21 As Nasser Rabbat argues, there are acute discrepancies in identity across the contemporary Middle East due to the unresolved problems of nationalism, persistence of colonial legacies, silenced debates on secularism, absolute rule or dictatorship in most cases, and overall uneven distribution of wealth. These, not a simplified notion of identity built solely on outdated conceptions of 
Islam and its architecture, are at the root of understanding the contemporary architecture of the Arab region. Nasser Rabbat, "Arab Cities and Identity Crisis", in The Arab City: Architecture and Representation, eds. Amale Andraos, Nora Akawi, and Caitlin Blanchfield (New York: Columbia Books on Architecture and the City, 2016), 41-49.

22 As illustrated in the US pavilion of the 2014 Venice Architecture Biennale, titled US Office and featuring one thousand projects built by American offices around the globe, a significant number of projects are in the Arab Gulf states, rending the region an extension of America's global reach.

23 "The Cold War brought about new geographies of collaboration that fundamentally impacted a myriad of locations including West Africa and the Middle East. Yet while Eastern European architects, planners, and construction companies are vividly remembered by professionals, inhabitants, and the general public in Ghana, Nigeria, Iraq, the United Arab Emirates (UAE), and Kuwait, their engagements in the Global South have been almost completely written out of Western-based historiography of architecture". Lukasz Stanek, Architecture in Global Socialism: Eastern Europe, West Africa, and the Middle East in the Cold War (Princeton: Princeton University Press, 2020), 2.

24 Amery, "Nikolaus Pevsner's", 617.

25 Ibid.

26 Vidler, Histories of the Immediate Present, 7.

27 Sibel Bozdogan, "Architectural History in Professional Education: Reflections on Postcolonial Challenges to the Modern Survey", Journal of Architectural Education (1984-) 52, no. 4 (1999): 207-215.

28 Dianne Harris, "That's Not Architectural History! Or What's a Discipline For?" Journal of the Society of Architectural Historians 70, no. 2 (June 2011): 149-152. 29 Stanford Anderson, "Architectural History in Schools of Architecture", Journal of the Society of Architectural Historians 58, no. 3 (September 1, 1999): 282-290. 30 Ormos István, Max Herz Pasha (1856-1919): His Life and Career (Cairo: Institut français d'archéologie orientale, 2009).

31 Nairi Hampikian, "A Decisive Moment for the Survival of Historic Cairo", in Cairo: Revitalising a Historic Metropolis, eds. Stefano Bianca and Philip Jodidio (Turin: Umberto Allemandi \& C. for Aga Khan Trust for Culture, 2004), 209-219. 32 Khaled Asfour, "The Domestication of Knowledge: Cairo at the Turn of the Century", Muqarnas 10 (1993): 125-137.
33 Timothy Mitchell refers to it as the "displacement, deferral, and delay in the production of the modern". See Timothy Mitchell, Questions of Modernity (Minneapolis: University of Minnesota Press, 2000), 23. Also Homi Bhabha, The Location of Culture (New York: Routledge, 2004), 111-115.

34 Zeynep Çelik, "Reflections on Architectural History Forty Years after Edward Said's Orientalism", Journal of the Society of Architectural Historians 77, no. 4 (December 2018): 381-387.

35 Nasser Rabbat, "Surveying Islamic Art and Architecture", in Eothen: Münchner Beiträge zur Geschichte der islamischen Kunst und Kultur, Band 5 (Munich, 2012): 267-274.

36 Esra Akcan, "Postcolonial Theories in Architecture", in A Critical History of Contemporary Architecture, 1960-2010, eds. Elie G. Haddad and David Rifkind (Farnham: Ashgate Publishing, 2014). 37 Kenneth Frampton, "Towards a Critical Regionalism: Six Points for an Architecture of Resistance", in The Anti-Aesthetic: Essays on Postmodern Culture, 2nd edn, ed. Hal Foster (New York: The New Press, 1998), 29.

38 Critical regionalism first appeared in the early 1980 s in essays by Liane Lefaivre and Alexander Tzonis. See also Kenneth Frampton, "Prospects for a Critical Regionalism", Perspecta 20 (1983): 147-162; Kenneth Frampton, Modern Architecture: A Critical History (London: Thames and Hudson, 1980).

39 Kultermann contributed to Kenneth Frampton's multi-volume series World Architecture 1900-2000, with a volume dedicated to central and southern Africa. The volume dedicated to the Middle East in the same series was edited by Hasan-Uddin Khan, a key interlocutor of Kultermann, and published in 2000 , just a year after Kultermann's own survey of contemporary architecture in the Arab states. The two volumes are distinctly different: while Khan's volume consists of 100 buildings selected from across the Middle East, including Turkey, Iran, and Israel, and spans the twentieth century, Kultermann's focuses on the Arab states from the 1960s to the 1990s.

40 Curtis, Architecture Since 1900, 567.

41 Hassan Fathy, Architecture for the Poor (1973, repr., Chicago: University of Chicago Press, 2000).

42 Frampton, "Towards a Critical Regionalism", 23.

43 See Prita Meier, "Authenticity and its Modernist Discontents: The Colonial Encounter and African and Middle Eastern Art History", The Arab Studies Journal 18, no. 1 (spring 2010): 12-45. 
44 Some architects in Egypt would have agreed to this assessment, particularly by the 1990s. By then, the recent death of Fathy had completed his transformation into a sort of deity for some within the increasingly besieged architectural profession, which had distanced itself from modernism after falling out of fashion. In an article about contemporary architecture in Egypt, published in 1998 in the architectural magazine Alam Al-Benaa, architect Abdelbaki Ibrahim critiqued the influence of 'Western theories' transmitted to Egypt via postgraduate Egyptian students who study in Western universities and return to teach in Egyptian universities (such as Sayed Karim). They are accused of contaminating Egyptian architecture with foreign ideas and materials that "reflect Western values". Abdelbaki Ibrahim, "Contemporary Architecture in Egypt", Alam Al-Benaa 199 (1998): 6-8.

45 Kultermann, Contemporary

Architecture in the Arab States, 4-5.

46 Keith Eggener, "Placing Resistance: A Critique of Critical Regionalism", Journal of Architectural Education 55, no. 4 (May 2002): 230.

47 Mimar magazine, first published in 1981 with 43 subsequent issues, was at the time the only English-language magazine concerned with architecture in the 'developing world'. Frampton, "Towards a Critical Regionalism". For recent discussion of Frampton and his critical regionalism, see Tom Avermaete, Veronique Patteeuw, and Hans Teerds, eds., Critical Regionalism Revisited (Rotterdam: NAi010 Publishers, 2019). 48 Kultermann, "Contemporary Arab Architecture", 74-77.

49 Paul Ricoeur, "Universal Civilization and National Cultures", in Architectural Regionalism: Collected Writings on Place, Identity, Modernity and Tradition, ed. Vincent B. Canizaro (San Francisco: Chronicle Books, 2012), 50.

50 As Anthony Vidler notes, postmodernism as a reaction to the apparent failures of modernism's abstraction "posed a problem to historians and critics". He writes, "Historians were in demand ... to provide authorization and depth to present practice. The idea of 'type', to give one central example an idea that stemmed from the need to rethink the tabula rasa planning strategies of the 1950s". Vidler, Histories of the Immediate Present, 2.

51 Kultermann citing Ernst J. Grube, who along with George Michell edited the book Architecture of the Islamic World, published in 1995. Kultermann,

"Contemporary Arab Architecture", 74.
52 "Islamic architecture is of course the architecture of those cultures, regions, or societies that have directly or via some intermediary processes accepted Islam as an integral component of their epistemological and socio-cultural makeup. From that perspective, the term 'Islamic architecture' is still a valid designation for architecture being built today because Islam has never ceased being that constitutive component, even though the ways in which it expresses itself have drastically changed over time and space. The actual architectural forms that those expressions take, important as they are in identifying Islamic architecture, are tangential in understanding it". Nasser Rabbat, "What is Islamic architecture anyway?" Journal of Art Historiography 6 (June 2012): 1.

53 Karim, "Our Architecture and its National Character", 271.

54 Jean-François Lejeune and Michelangelo Sabatino, "North versus South", in Modern Architecture and the Mediterranean: Vernacular Dialogues and Contested Identities, eds. Lejeune and Sabatino (New York: Routledge, 2010), 22. 55 On the invented duality of tradition and modernism, see Anaya Roy, "Nostalgias of the Modern", in End of Tradition? ed. Nezar AlSayyad (New York: Routledge, 2004), 63-86.

56 Alan Colquhoun, "The Concept of Regionalism", in Postcolonial Space(s), eds. Gulsum Baydar Nal-Bantoglu and Wong Chong Thai (New York: Princeton Architectural Press, 1997), 13-23; Keith Egener, "Placing Resistance: a Critique of Critical Regionalism", Journal of Architectural Education 55, no. 4 (2002): 228-237; Gevork Hartoonian, "Critical Regionalism Reloaded", Fabrications 16, no. 2 (2006): 123-129.

57 Leach, What is Architectural History?, 4.

58 George Arbid, Fundamentalists and Other Arab Modernisms (Doha: Bahrain Ministry of Culture, 2014), 8.

59 Mohamed Elshahed, Cairo Since 1900: An Architectural Guide (Cairo: American University in Cairo Press, 2020), 87. 60 Ibid., 94. 


\title{
GARDENS AND \\ GENERATORS \\ Demarcating Dubai's modernization
}

\author{
Todd Reisz
}


In 1947, the British government sought a "gift" of land from Dubai's ruler, Saeed bin Maktoum bin Hasher Al-Maktoum. ${ }^{1}$ The process of selecting, securing, and designing for that land plot established architecture as a key component of the British government's goals in Dubai, particularly to initiate a modernization campaign. On that land grant was to rise the new political agency, future home to both the British political agent and the modernization programme he was appointed to author. After over a century of irregular oversight and efforts to thwart advancement and growth at Dubai's port, the new agency signalled a more dedicated British intervention into Dubai's internal affairs and those of other Trucial States, this time for the proclaimed sake of modernization. The site studies, design process, and construction of the new Political Agency Trucial States would in the end presage how subsequent modernization projects were pursued in Dubai. With references to British public record documents, this paper provides evidence that Dubai's modernization - defined as a centralized authority's project of urban development and technological advancement began several years earlier than many histories suggest. Nearly a decade before Dubai's first hospital and 12 years before the production of Dubai's first master plan - two oft-cited indications of Dubai's twentieth-century advancement - the underlying rationale and guidelines that guided Dubai's modernization were already evident in the creation of the political agency. At the donated site, modern architecture manifested first as a suite of procedures and then as a physical exhibition of modernization's promises; the approach to both of these aspects of architecture was reflected in subsequent modernization projects.

In establishing the Political Agency Trucial States, the British Foreign Office pursued two seemingly contradictory policies: to further embed itself in the affairs of the Trucial States for the British economy's commercial gain and to deny any "special responsibility" by isolating itself from local politics. Modern architecture helped achieve and maintain this paradox. ${ }^{2}$ Even before the eventual concrete foundations of modern bungalows and fence posts asserted the agency's structural fixity, site surveys and drawings helped assemble the British government's "irrefutable documentary evidence" to support its claim, in legal reasoning created for and by itself, that it rightfully occupied and exploited the site. ${ }^{3}$ At the same time, the type of intended construction, namely, a fenced-in compound comprising new buildings and more land than necessary, expressed that the site was cut off from the rest of Dubai, both physically and logically. More specifically, the ordering and administration to be pursued within the circumscribed confines of the land grant were expressed as set apart from everything beyond but nevertheless placed within proximity to the city, its apparent "prestige" intended to influence how future efforts of development would proceed. ${ }^{4}$ In this way, the pursuit of 
the political agency site both asserted Britain's local legitimacy and proclaimed its legal exception.

Today, the city of Dubai is often criticized for its isolated developments, each pursued without apparent concern for creating links to other parts of the city. As this article will demonstrate, such an approach to urban development was already identifiable in the creation of a British political agency in the late 1940s and early 1950s. As early as 1947, architecture helped assert a British claim to a defined portion of Dubai; it also manifested how a designated site could be distinguished from the rest of the city and transformed for political and commercial gain. The acts pursued at the demarcated site presaged how large-scale development would transform the city, not through long-range plans but rather through the piecemeal assignation of meaning to delineated swaths of land. The isolated fixity of the early compound formulated the systems of modernization and ordering intended to be deployed on eventual sites beyond its fencing. Subsequent modernization efforts, increasingly determined by Dubai's leadership more than the British political agency, included the city's first hospitals, schools, a world trade centre, coastal ports, and the city's first 'free zone'.

\section{Choosing Dubai}

Prior to 1947, the British government made its presence known in Dubai and the other Trucial States through navy ships patrolling Gulf waters. British terrestrial control, beyond the sparse camps of oil companies, was limited to the Royal Air Force (RAF) base and a 'political office', both of which were located in Sharjah. The RAF camp was fenced and isolated outside Sharjah's city limits. According to a contract between the British government and Sharjah's ruler, the RAF camp employed local men as guards, instructed as much to keep intruders out as to keep British residents in the compound. In contrast, the political office, consisting of a house and a small assemblage of property unfortified by wall or fence, was located in the city. Here lived the residency agent, usually a foreign Arab in the employ of the British government with which he kept a line of communication via the India Office in Delhi. Proximity to Sharjah's political and economic leadership provided the agent "intimate knowledge" that could be shared with coIonial administrators. ${ }^{5}$ Like the other residents of Sharjah fortunate enough to live in the town's more permanent housing stock, the officer could climb up to his roof to catch a breeze and inspect the city around him. If the weather suited him in cooler months, a white British officer sometimes joined him.

Upon the shuttering of the British Indian government and the creation of the independent Indian state in 1947, British administration of the Trucial States transferred to the Foreign Office in London. The handover made for a moment to review how the British government exerted control in the region. ${ }^{6}$ Within a matter 
of weeks, a redetermination of policy towards the region was deemed "a matter of the greatest urgency", primarily as a means to claim and protect access to potential oil in the region. " "With the development of oil here", the Foreign Office surmised, "the political work of this Agency is more likely to increase than decrease". By no later than 1949, the preferred location for a political office was confirmed no longer to be Sharjah but Dubai "because it is geographically the most central of the Sheikhdoms and it is at present the centre of trade and shipping". ${ }^{8}$ In spite of previous British investment in Sharjah and in restraining regional trade networks, Dubai, "far and away the most important port on the Trucial Coast" with an approximate population of 30,000, exhibited attractive economic potential and, in a historical twist, was no longer perceived as a political threat but an economic advantage in service of changing British policy in the region. ${ }^{9}$ In short, Dubai's success in trading would be capitalized upon as the foundation of the British economy's financial gain. While it might not supply the oil reserves, its accomplished port could supply ongoing expeditions elsewhere. According to the Foreign Office, heightened presence in the Trucial States required that its leading representative no longer be an Arab expatriate; instead, it needed to be a white British officer, whose accommodations became of immediate concern.

\section{Accounting for deficiency}

Before scouting for a new site in Dubai, it first had to be corroborated that the deficient condition of the Sharjah residency necessitated a new home for the future British official. In November 1947, less than three months after India's independence, the British political residency in Bahrain requested that H.S. Walters, a Cairo-based estate surveyor for the British government, inspect the living and working quarters in Sharjah. The request for consultation came with its anticipated findings already well outlined, referring to an index of the office's "amenities, or rather its lack of them". The electricity supply, "generally defective", could sustain only a bulb or two of light on the ground floor; the upper floor's electricity was of a "purely temporary arrangement". Walters was warned that there were no electric fans and no refrigerators. Whereas nearby accommodations for the white residents of the RAF camp and oil companies had "air-conditioned rooms with modern conveniences", the Sharjah premises did not. ${ }^{10}$

Walters arrived in Sharjah on 8 November 1947 and left within 24 hours with his findings. ${ }^{11}$ The property, he recorded, was rented from a landowning family in Sharjah. That meant it was an "Arab style two storied house with courtyard and outbuildings", recognizable as one of Sharjah's most expensive houses. The house was among the minority of Sharjah's housing stock not made of palm fronds and salvaged materials, or as a Foreign Office 
official described it, the "slum of native palm-huts". ${ }^{2}$ Beyond being one of the larger and better equipped houses of Sharjah, the house was also prominently located on Sharjah Creek. Walters found it comprehensively deficient and referred to its "poor construction", but that might have just meant it was made of locally sourced materials, including coral, a local lime mixture, mud, straw, and a sparse use of wood imported from India. The "primitive kitchen (native style)" adjoined a dining room with "no curtains or covering to the mud floor". Furniture was "locally made in Sharjah, and is primitive indeed"; the dining table's two wooden chairs were said to be "borrowed". The bathroom contained little more than a galvanized iron tub. ${ }^{13}$ Walters indexed the discomforts and confirmed Jackson's assessment that Sharjah was "a place where dysentery is endemic and the streets are used by all classes as latrines [and provide] such efficient breeding grounds for flies and fleas". ${ }^{14}$ The environment in sum was "a constant menace to the health of the agency staff". Just getting a sufficient night's sleep, Walters estimated, "must be an ordeal". What was locally considered drinking water was sourced from an uncovered well three miles inland, delivered in petrol cans that added lead and aftertastes of petrol to the already brackish water, "unfit for drinking". For Walters, these conditions were "the worst I have seen yet". Sharjah, he summarized, was "such a dreary place". ${ }^{15}$

\section{Defining the agency}

A white British agent, it was made clear, would "justifiably refuse to work" in the conditions provided for the Arab agent for the last six decades. With "no gardens or recreational facilities whatsoever", this was no place for him to bring his family, who also needed to be accommodated, not because the Foreign Office was mindful of hospitality towards its staff but because families were at least a diversion in a landscape deemed to offer no others. The Foreign Office understood it needed "to provide living accommodation for the European rather than the Arab". ${ }^{16}$ "Any British officer or a clerk, who is posted to such a dreary place, and such a climate, without any amenities, ... will need the very best of accommodations for himself and his wife if he is to maintain his health, or even his mental balance, throughout the summer". ${ }^{17}$ "A new Agency", it was concluded, "must be erected as a matter of the greatest urgency". ${ }^{18}$ Later it was added that it required "the usual amenities - tennis courts and a swimming pool". ${ }^{19}$ The regional environment was defined as barren, brutal, unhygienic, and generally uncomfortable. In order to make the environment amenable, even just bearable, a new environment had to be created within it. The appeal for a "new" agency connoted not only a temporal shift but also a paradigmatic one towards manufactured materials and technologies imported from abroad and away from sources and methods associated with local practices and customs. 
On 4 March 1948, a British architect employed by the Ministry of Works, K.W. Judd, arrived at the Sharjah base to inspect three potential sites in Dubai. ${ }^{20}$ Although Sharjah was supposedly a candidate location, no candidate site there is mentioned. ${ }^{21}$ Equipped with paper, pen, and a camera and driven in a government-owned Land Rover, Judd recorded notes about each site that had been defined and nominated by the British political resident in Bahrain. It is not clear what kind of conversations might have informed Dubai's Sheikh Saeed selection of the potential gift sites, but each was known to be "unencumbered by squatters", which translated to their being under the control of Dubai's ruler. In another seeming paradox, British officials perceived the land as "unencumbered" and "unobstructed" yet also fairly definitively bound by an understanding of property ownership that pre-dated British interest in Dubai's systems of determining land ownership. British officials wrote of having to create administrative systems "from scratch", but there clearly seemed to be a system by which the ruler could distinguish land he controlled from that which he did not.

Two of the sheikh's sites measured about 20 acres, the third measured 5 acres. One was near an outer landmark, Burj Nahar, not far from the Sharjah border, and two others were along Dubai Creek on land beyond the built-up parts of the port and city. The architect created a matrix to analyse each site and to compare it to the others across criteria that included subsoil; "aspect" (views towards the port); "communications" (access to roads, jetties, and telegraph stations); and "surroundings". Judd's reporting also included a local builder's initial estimate of building material costs, though these rates were considered "very erratic" - and the local building industry inadequate for the job. Both materials and labour, it was reported, would have to be imported in order to convert the future site into the new agency. ${ }^{22}$

Some histories claim that Dubai's ruler offered the British government a piece of land beyond the city limits so that the British "should not impinge too closely on the affairs of Dubai's population". ${ }^{23}$ British files contest this reasoning, revealing that British political officers and government-employed architects reviewed at least three sites beyond "the built up areas of Dubai" and "recommended without hesitation" "the most suitable site", referred to as "Site No. 1". The stated preference for distance from the built-up city granted a plot size large enough for a compound; and as Judd's matrix points out, the site afforded "good views" towards Dubai's piers and warehouses, ones "particularly clear and pleasant as sun always behind". From his eventual on-site jetty, the future political agent, amidst his prescribed comforts and conveniences, maintained a comfortable view of the city he was mandated to make a more profitable trade hub. ${ }^{24}$ 


\section{Survey}

Perhaps one of the most foundational documents in tracing Dubai's history of modern architecture is one of the simplest, produced in July 1950 and titled "Site of Proposed Agency - Dubai", a drawing that recorded the survey of the eventual compound. At the risk of "morally [offending] the Shaikh", London officials wanted a more recognizable guarantee, "a detailed aide memoire with a plan annexed", so that the ruler's spoken promise could be more legally recognizable, at least by bureaucrats in London. ${ }^{25}$ The British Ministry of Works created the document for the Sheikh's written approval. It makes no reference to a coordinate system but includes measurements of each side of the quadrilateral site and contextual references to a soon-to-be decommissioned oil-company compound and loose designations of "palms" and a cemetery.

This is not the first surveyed site plan to accompany a land sale or lease overseen by the British in the Trucial States, and it did not mean that all future agreements would always have such a graphic supplement. However, it did precede any known accurate survey of Dubai and its environs, and it signalled the use of surveying to record and document agreements "to be preserved". Whereas textual description relating to the whereabouts of a property continued to be standard throughout the 1950s, the survey drawing signified the Foreign Office's heightened interest in this agreement and others after it. Ten years after the issuance of this drawing, a British architect produced the city's first town plan intended to outline the legal bounds of a burgeoning real estate market universally regulated by such surveying actions. ${ }^{26}$

Modernization projects require borders and the mechanizations that circumscribe, express, and enforce them. More than an aesthetic expression or material manipulation, architecture provides these edges. It is a kit of strategies, including the logistical organizing of capital and labour and, most essentially, of land into 'site'. By the time the survey drawing was made, British officials sought "to secure [the] fairly spacious site". "Secure" in this case can be read to mean 'to acquire', if in rather presumptuous terms, land from other parties who might lay claim to it. A second meaning can suggest protecting the site from unauthorized entrance. The designation of land for a defined purpose, the bounding of allegedly unclaimed terrain into enclosed territory, is perhaps the antecedent to any modernization project. Of course, land was designated, claimed, developed, and fortified before any British interests in Dubai real estate as evidenced in the ruler's ability to claim this site and not others. Having such claim backed by surveys, plans, and other bureaucratic recordings, however, was a crucial moment in negotiations between Dubai's local leadership and the British government towards realizing such administrative acts. Bureaucratic ordering, as much as any physical development 


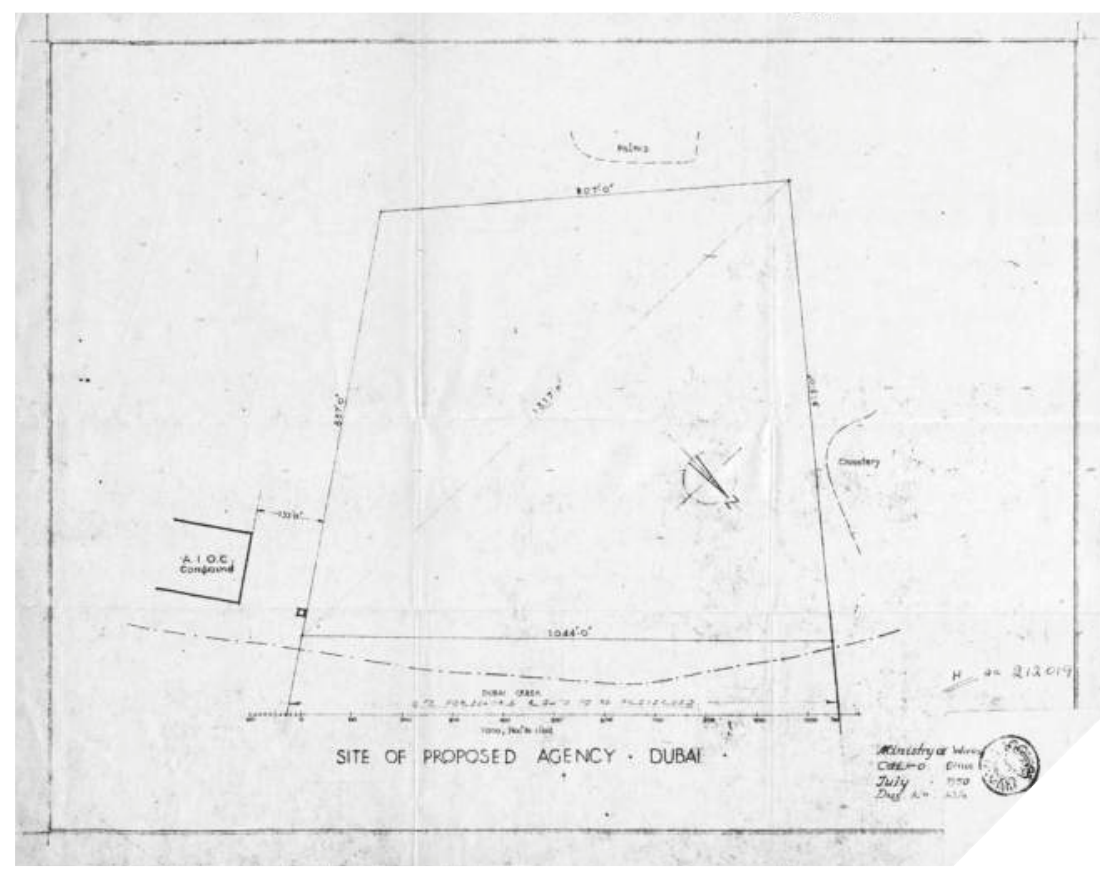

"Site of Proposed Agency - Dubai". Survey drawing based on early surveying of Dubai and created as part of agreement eventually signed by Dubai's ruler Sheikh Saeed bin Maktoum bin Hasher Al-Maktoum, 1950 (Source: National Archives, UK, Work 10/124. Reuse not permitted).

proposals for Dubai's landscape, was integral to initial modernization programmes that British officials pursued in Dubai. With this in mind, architecture was more than a physical manifestation; it was also an administrative ordering, especially evident in the creation of a site plan that is shared with and approved by municipal agencies. Submitting such a plan to the ruler was a precursor to gaining similar approvals from an eventual Lands Department. ${ }^{27}$

In order to prepare it for an administrative understanding both legible to London officials and prescient of bureaucratic reforms to come, the site had to be made void of its potential pre-existing meanings. In finding the site "unencumbered", British officials clearly overlooked signs of cultivation and integration of the land in Dubai's existing society, despite the evidence supplied in their own documentation. K.W. Judd's photographs and notes take account of palms on the site, which can only survive with human cultivation. In addition, there were known wells on the site, therefore providing an essential source of water for Dubai's population. Both the palms and the wells are evidence that the site was used, perhaps necessarily so, by nearby residents. Photographic documentation also captures further use of the site: an anchor, 
a slight wooden wharf, and sails, laid out for drying and mending. These all marked the site as integrated in Dubai's fishing and ocean trade industries. By ignoring the site's role in Dubai's economy, the inspectors endorsed a false narrative that the site was outside Dubai's social and economic existence.

\section{Fence}

In regard to the second meaning of "secure" - to protect the edges from unauthorized entrance - architecture also played a role. While at first the new headquarters was imagined to be a two-storey building outside the city (with living quarters above a ground-floor office), it was rather quickly decided that the agency would take the form of a compound. While an armed "security zone" was deemed unnecessary, it needed to "be reasonably difficult to penetrate". It was well understood that the 20 acres was "a little too large to begin with". Less than a third of the site would be used at first. While "the practice of manning guard towers" was deemed unnecessary, security of the site meant the safeguarding of land for future growth within understood bounds. ${ }^{28}$ It ensured that no other party could claim the land, and future growth within the site would remain unaffected by escalating real estate markets responding to projects the British pursued.

The fenced-off compound as a spatial model had already been implemented by British interests in the region: at the Sharjah air station in 1932 and later by the Anglo-Iranian Oil Company camps, including the one adjacent to the agency compound site. While the political agency was not the first compound, it marked how Foreign Office officials were implementing a form reminiscent of the colonial governor's grounds, or plantation, a historical colonial form of delineation and isolation. ${ }^{29}$ Extending from historical uses of space for power and control, the built form of the political agency expressed, more importantly, the materiality of ordering processes that the agency would urge upon Dubai's leadership and its landscape. Consequently, the processes of defining and creating the political agency informed how large-scale development was pursued in Dubai, with decreasing British political influence but often with increasing influence from British private industry.

The most explicit evidence that the political agency was conceived as a plantation isolated from the rest of Dubai is found in two proposed site plans from 1948.

With slight variations, they reveal a multi-purpose compound on a large site focused on accommodating and serving its white British residents - including housing for British officials, housing for the "natives" who worked on site, a waterside esplanade, tennis courts, flower gardens, a swimming pool, and even a "future hospital". Within the compound, narrow roadways connected various aspects of the site, insulating private areas for high-ranking officials even more in the isolated site. 


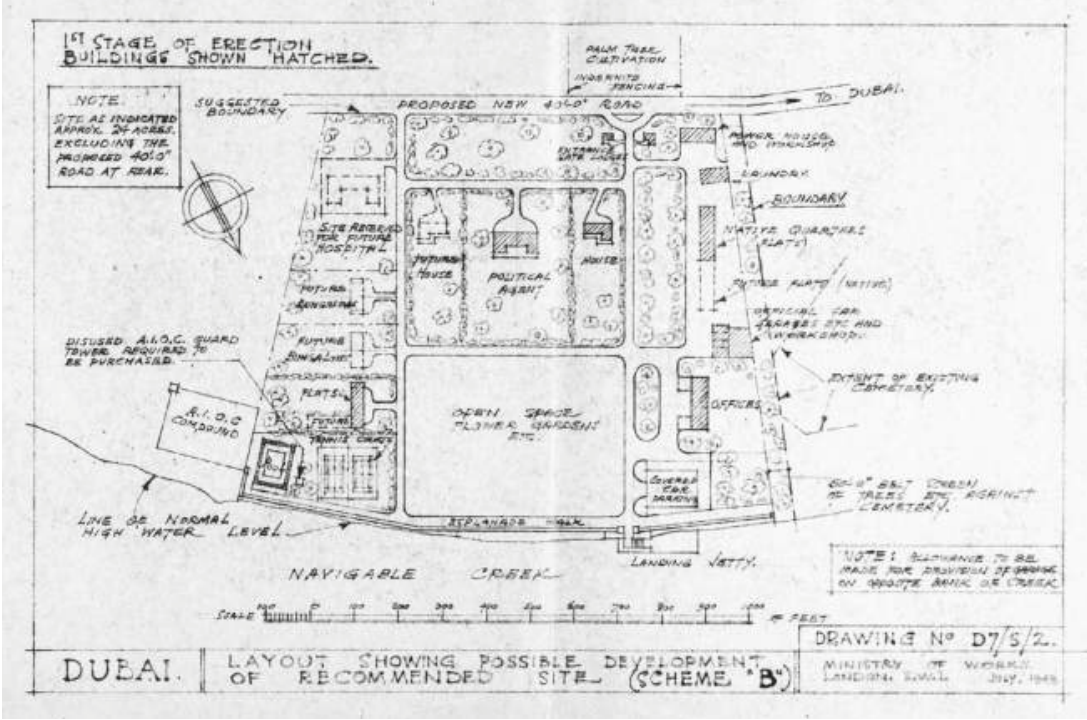

fig.2 One of two 1948 proposed designs for new political agency compound in Dubai. It included a hospital which was eventually scrapped once work began on Al-Maktoum Hospital (Source: National Archives, UK, Work 10/124. Reuse not permitted).

In the plans, one reads a self-sustaining, miniature city that operated on technologies and services not available outside the compound's perimeters. ${ }^{30}$

Neither of the 1948 plans was pursued as they were deemed too extensive for the immediate needs of the agency and too extravagant for the project's limited budget. In place of a oneoff design, the Foreign Office determined that the new quarters would be based on templates, specifically the "Type A Bungalow". Relying on pre-existing templates supplied more than just cost efficiency. It also signified political administrative continuity. "Type A Bungalow" had already been executed in creating housing at the British political residence in Bahrain, the location of the British government's highest-ranking officer in the Gulf region. That the political agency in Dubai was based on a template, and specifically one deployed in Bahrain after oil discoveries there in the 1930s, signalled that what the British government pursued in Dubai, in terms of political control and commercial gain, was systematically connected to its pursuits in Bahrain. Even certain personnel classification codes were connected to the housing type. Architecture substantiated that Dubai, in this way, was a logical continuation of things already underway in Bahrain. Specifically, what was supplied inside the new political agency had more to do with spaces of British political control beyond Dubai than anything occurring just outside the surveyed bounds. ${ }^{31}$ 


\section{Prestige}

As mentioned earlier, the securing of the political agency did not have so much to do with arming the site - it would not withstand any "local upheaval". Rather, it had to do with distinguishing the site from everything beyond it.

"In a country where prestige is a paramount consideration", one official observed, "the offices and quarters of the chief British Political representative for the entire Trucial Coast should show such a ludicrous contrast". In order to manifest that "ludicrous contrast", people other than British officials and their servants had to observe what was provided inside the compound. The political agent's living quarters were adjacent to his offices. Though cost-cutting dramatically reduced the agent's entertaining capabilities, the built premises offered ample spaces for hospitality, including a dining room and living area. Assemblies of Trucial States leaders were held at the house, where leaders could meet the agent and his family, inspect the furnishings and the buildings' "up-to-date lines", enjoy the air-conditioned drafts from "American hermetically sealed room units", and test the running water imported by ships and stored with a week's reserve. ${ }^{32}$ Amidst these dramatically modern interiors and architectural details, the leaders had their first discussions about modernization "schemes" that would eventually supply the infrastructure to sustain such visible enhancements to other parts of Dubai and the region. The agency's fence therefore distinguished the site but did not make it impenetrable.

One important landmark at the agency was the flagstaff that kept the British flag hoisted, perhaps Dubai's tallest structure at the time of its erection. While the bungalows, described by one resident as "low sheds that blended in the surrounding sand", were not designed to be seen from afar, the flagstaff was. ${ }^{33}$ It could be seen from at least a kilometre on the other side of Dubai Creek. It visually marked the British presence in Dubai and, besides that, signalled the existence of another and potentially superseding political power in the city. No local flag flew higher. Sometime after the flagstaff was erected, it became known - whether more than just by word of mouth is not clear - that, if a slave, of which there still were some in the Trucial States, made it through the agency's gate, crossed the gardens, and placed his or her hand on the flagstaff, it was considered as much as a request to the British government by that person to be made free. Part of the political agency's self-determined functions after locating in Dubai was to provide manumission papers for those who made it to the agency flagstaff. ${ }^{34}$ As it was reported that some of Dubai's merchants still trafficked human beings up and down the Gulf coast, the British government professed to work against such trafficking as part of its constraints on regional trade. Broader than the flagstaff's role in ending the practice of slavery, it highlighted the way distinct 
borders defined distinct areas of jurisdiction that could overrule or ignore coexisting ones. The agency's interiorized logic was not only a distinct political space but also a realm that could transform the contractual obligations that occurred beyond its borders, influencing how someone might negotiate his or her life beyond the political agency.

\section{Limits and prestige}

One removed component of the initial design proposals for the compound was a hospital. British officials based in the region were aware of the lack of modern health-care facilities in the Trucial States, whether for the broader public or for the future British staff at the agency. Officials working on the proposal appeared to agree that the suggested hospital would be at least partially accessible to non-British residents. Despite there being "political and prestige value" without "an extravagant contribution" in supplying modest healthcare to Dubai's residents, the hospital proposal was rejected by treasury department officials as too expensive and beyond any British Mandate: there was "no obligation to provide, or help to provide, a hospital for the local inhabitants". ${ }^{35}$

Even before the officials could get internal approvals in order for the simplest of bungalow structures for the agency site, work was already underway on a new hospital at one of the sites rejected for the agency compound. While the hospital eventually received funds from the British government and other British concerns including what was soon known as British Petroleum, the project was launched with proceeds from the ruling family and other wealthy families of Dubai. It was hastily conceived and completed by the single British contractor in the region, with whom the British government could not negotiate the subsequent contract for the construction of the agency. ${ }^{36}$

From his carefully selected venue on Dubai Creek, standing at his private pier, the political agent could inspect the goingson of Dubai Creek, its daily business schedule determined by the ebb and flow of the coastal tide. And beyond, across the water, towards the district of Deira, he could also locate the new, barrackslike building that housed the hospital the British treasury had refused to fund. More important than the agent's view of the hospital, however, was the view from the hospital back at the agency and its waving flag. The visual connection was essential to British power in Dubai. The first structure of Al-Maktoum Hospital, as it was soon called, was not built with British money, but its placement outside the built-up parts of the city allowed it to advance and grow according to the rules set up inside the agency. No later than 1959, a fence encompassed the hospital and a good deal of land around it, once again protecting it less from marauders and more from development into something else. Fortifying future growth potential, the fence was the hospital's most valuable asset until it could 


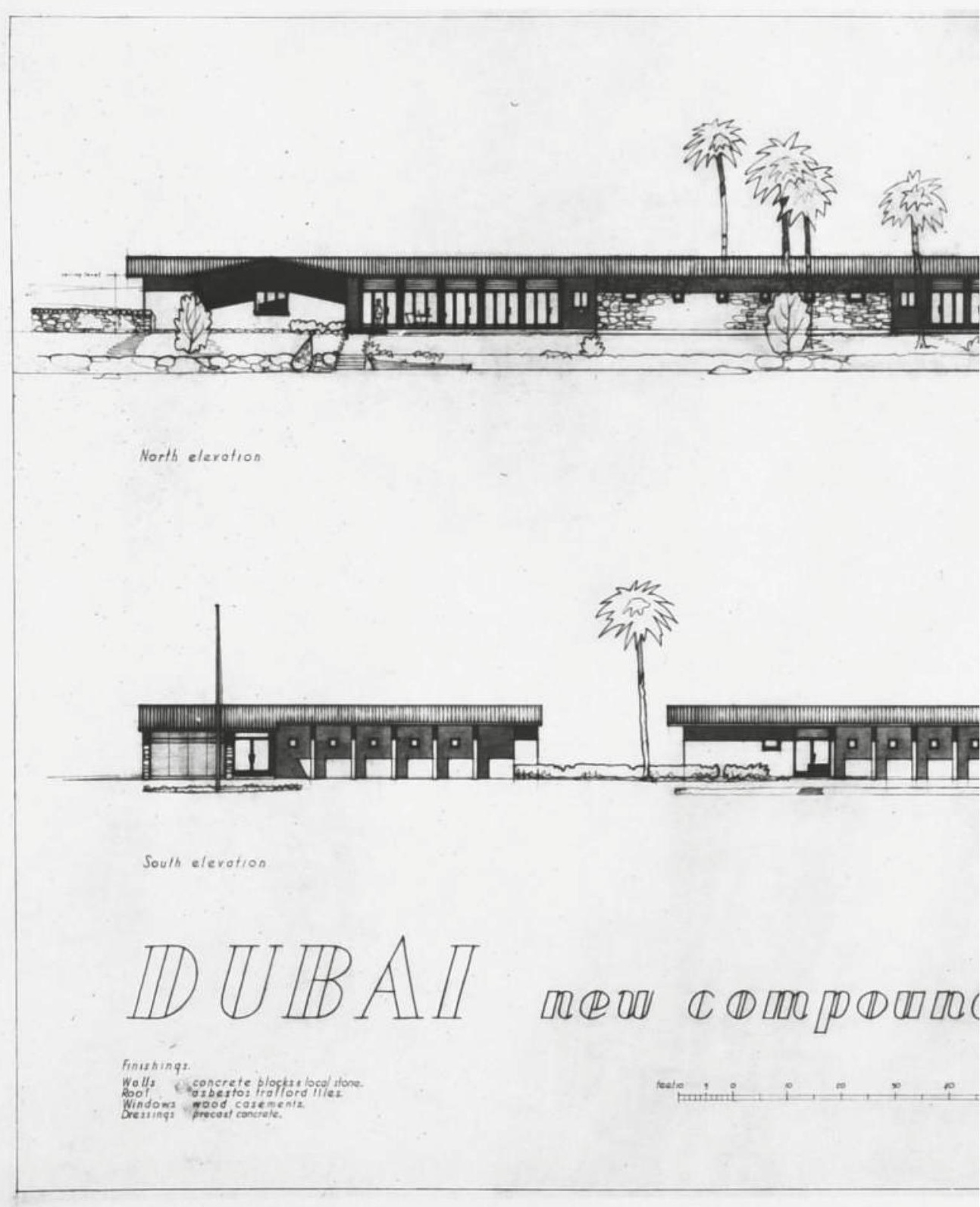



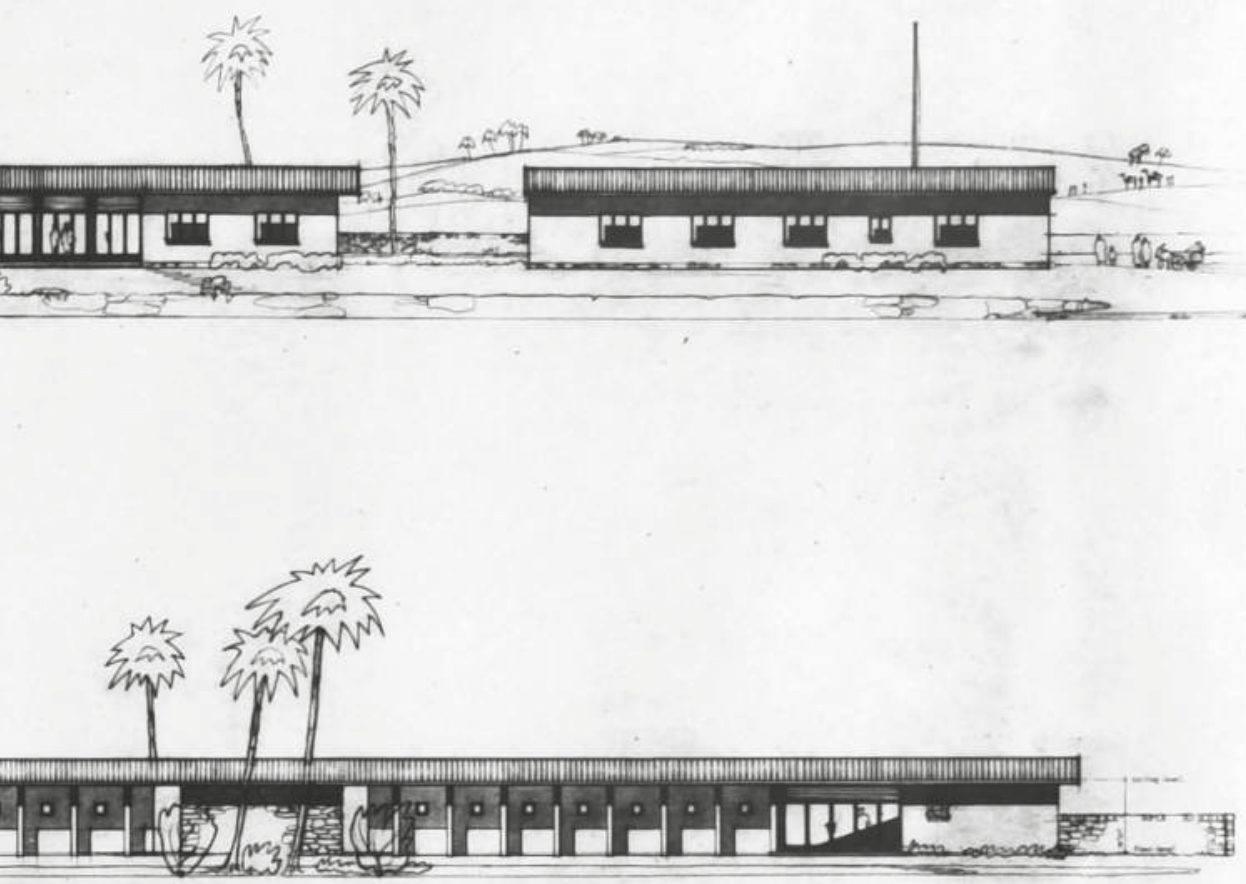

$\pi$

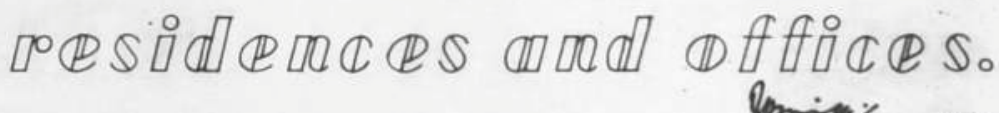
lamina:

R.? Milla, ARIBUSenior Ardifect

H.B. M Ministery of Workit.

May

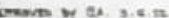


afford to be more than a primitive dispensary. The fence encircled the opportunity for expansion and technological advancement. Without ever fully funding the hospital's development, the British channelled its growth well into the 1960s, overseeing the hiring of medical professionals, supplying the necessary equipment (often second hand), and formulating a master plan for how the hospital would grow as locally sourced funding became available. ${ }^{37}$ At that newly fenced site, beyond the ways and buildings of the built-up part of the cities, modern architecture was manifested as it had been at the political agency, isolated and sealed from its environs and according to discreet contracts and schedules. It would play out once more according to the rules of a British-led modernization. As a result of Al-Maktoum Hospital's fence, other boundaries were made manifest around it, each one distinguishing claimed ownership from the claims surrounding it. In similar fashion, plot by plot, and in manageable swaths that took into account both current and future needs, Dubai "[emerged] from its mediaeval status of a few years ago into the modern world". Whatever was created within the boundaries of a delineated project was expected both to exist upon its own rules and to influence how the rest of the city functioned and grew beyond.

Rather than by sweeping master plans or a coordinated infrastructural strategy, Dubai continued to expand this way, by gradations and delineated allotments. Each component was designed as an autonomy. For each project - a hospital, a district of villas, a resort, an airport - site was defined against what lay outside it. Inside each plot was protected and assured; outside was at best undetermined, and at worst harsh and unbearable. Each swath was a controllable site, its dimensions recorded on cadastre maps, its ambitions limited by the capacity of its contracted expertise, and its funding doled out according to bank documents. Many of these sites contained their own water supplies, power stations, and menus of bespoke amenities that assured users they need not leave. Outside each block, tendrils of new asphalt roads, trimmed in green landscaping, connected new development sites to other ones; the accumulation of sites led the city away from the creek and its compression of people and services towards a vast and seemingly unreachable horizon, easily carved into for new sites of designed environments against the backdrop of an uncherished desert. The city of Dubai would be interiorized. 


\section{Notes}

1 Jackson to Walters, 4 November 1947, The National Archives, United Kingdom (NA), Work 10/124.

2 Neilson to Isaac, 12 September 1949, NA, Work 10/124. Dubai, as well as the rest of the Trucial States, was never a colony within the British Empire. Its status, determined by Britain's unilateral 'truces', was kept undefined though described as a 'protected state'.

3 Note from Thorne, 29 November 1950, NA, Work 10/124.

4 Walters to Turner, 15 November 1947, NA, Work 10/124.

5 Rosemarie Said Zahlan, The Origins of the United Arab Emirates: A Political and Social History of the Trucial States (London: Macmillan, 1978), xv.

6 As early as 1908, there had been profit-minded efforts to convince the British government to build a more significant presence in the Trucial States. See Zahlan, The Origins of the United Arab Emirates, 28-29.

7 Jackson to Walters, 4 November 1947 NA, Work 10/124. This paper is based largely on the correspondence and other documents collected in this folder whose contents span the time period from 1947 to 1955.

8 Undated report ca. 1947, NA, Work 10/124.

9 Hay to Burrows, 30 April 1948, NA, Work 10/124. This assessment of Dubai is further investigated in Todd Reisz, "Writing Sharjah's Landscape".

10 Jackson to Walters, 4 November 1947

11 Trucial Coast News Report No. 21,

8 November 1947, Indian Office Records (IOR)/R/15/4/15.

12 Application for Treasury Sanction, 17 December 1948, NA, Work 10/124

13 Walters to Turner, 15 November 1947.

14 Jackson to Walters, 4 November 1947.

15 Walters to Turner, 15 November 1947.

16 Shepherd to de Norman, 25 July 1952,

NA, Work 10/124.

17 Jackson to Walters, 4 November 1947.

18 Walters to Turner, 15 November 1947.

19 Wilson to Leary, 8 December 1948 ,

NA, Work 10/124.

20 Trucial Coast News Report No. 4, 4 March 1948, IOR/R/15/4/15.

21 Conventional histories often describe the eventual political agency first being situated in Sharjah and then later, in the mid-1950s, moving to Dubai. While there was some kind of British presence in Sharjah from as early as 1892 , the decision in 1947 to advance the British presence in the region was quickly followed with the decision to base it in Dubai.
22 Approx. Prices of Materials in Sharjah/ Dubai, 7 June 1948, NA, Work 10/124.

23 Julian Walker, Tyro on the Trucial Coast (Durham: Memoir Club, 1999), 58. The approximately 20 acres of the political agency are largely the current grounds of Great Britain's diplomatic offices in Dubai. 24 Judd to Turner, 7 June 1948, NA, Work 10/124.

25 Notes, Thorne, 29 November 1950, NA, Work 10/124.

26 See Todd Reisz, "Taking Measures: 1960 Dubai Town Plan", chap. 4 in Showpiece City: How Architecture Made Dubai (Redwood City: Stanford University Press, 2020).

27 The third Political Agent Trucial States, Donald Hawley, advised on the creation of Dubai's Lands Department in 1960. See Reisz, "Taking Measures", chap. 4 in Showpiece City.

28 Judd to Turner, 7 June 1948.

29 Robert Home, "'Planting is My Trade': The Shapers of Colonial Urban Landscapes", in Of Planting and Planning: The Making of British Colonial Cities (London: Routledge, 1997), 38-63. 30 Layout Showing Possible Development of Recommended Site, July 1948, NA, Work 10/124.

31 Historian Stephen Ramos refers to a "regional blueprint" for how British officials responded to local changes as a result of new oil wealth. While there was no actual blueprint - each location required response to local conditions and later actions learned from earlier ones - it is fair to say that preparing Dubai for impending oil wealth, whether within its territory or beyond, learned from previous engagement with regional cities and new wealth.

Stephen J. Ramos, Dubai Amplified: The Engineering of a Port Geography,

Design and the Built Environment Series

(Burlington, VT: Ashgate, 2010), 10.

32 Shepherd to de Norman, 25 July 1952. Harris to Shelley, 7 June 1952, NA, Work $10 / 124$

33 Walker, Tyro on the Trucial Coast, 58.

34 Ibid., 11-12.

35 Neilson to Isaac, 12 September 1949.

36 The agency's first-phase construction was completed by the British government's own labor pools, a practice it would quickly avoid in future projects in Dubai. 37 Reisz, "Piecemeal: Al Maktoum Hospital", chap. 5 in Showpiece City. 


\section{FRAGMENTARIUM Episodes of modernity in contemporary Kuwait City}

Roberto Fabbri 


\section{Introduction}

Jibla, the southwestern quadrant of Kuwait City. Once a traditional part of the pre-oil town, its firjan (neighbourhoods) accommodated merchant family houses and their maritime trades for generations. In the early 1960s, modernity entered the city through the quadrant's gated walls to permanently change the city's landscape. As part of the post-oil urban development, the 1951 master plan designated Jahra Road and Naif Avenue, Jibla's main axes, to become its first modern alleys with shops, arcades, and geometric façades. They pointed to Safat Square, the main public space, adjacent to the first municipal park and surrounded by new concrete structures. Within this triangle, Kuwait's early modern dreams materialized before anywhere else in the city, becoming a recurrent visual theme in government propaganda. Later constructions, such as the Parliament and the National Museum, epitomized a new and different visual representation of local values and traditions. Jibla, however, was also the place in which architectural modernity attempted to come to terms with history. In the heyday of modernization, preservation was not considered an option, demolition was the norm, and tradition was reinterpreted nostalgically, like Behbehani Compound and Youm-Al-Bahar (the Sailor's Day heritage village). In recent years, new redevelopments swallowed the urban fabric of the 1960s, and Jibla became part of a bureaucratic downtown, running nine to five as a service hub. Outside of business hours, it turns into a liminal place chosen by many migrant workers as a meeting point for social gatherings. Lately, it has also been the testing ground for a few examples of reuse and rehabilitation of early modern structures, such as the former American Mission Hospital, known locally as Al-Amricani and the Catholic church, later analysed in this text.

This chapter aims to map a city within a city. Kuwait's modern urbanscape is now but a sequence of fragments, dispersed among shards from different epochs, all reminders of an unaccomplished urban vision: a kaleidoscope of uncorrelated episodes of obsolescence, adaptation, and reinterpretation. By tracing and reading the trajectory of these architectures and questioning the notion that tradition, authenticity, and locality are attributes applicable only to pre-oil structures, this study captures how city and citizens are coming to terms with Kuwait's modern legacy. With its stratified urban history, Jibla offers a sounder and more articulated case study than other parts of the city. In particular, the area allows a comparative reading of the 'strata': the text will initially analyse the urban landscape in today's condition, then trace back the projects, ambitions, and strategies that originated it, and to conclude gauge a few rehabilitative interventions.

The present-day context was assessed through direct fieldwork and a series of photographic sessions of the area during a long-term residency in the country, which also gave me the 


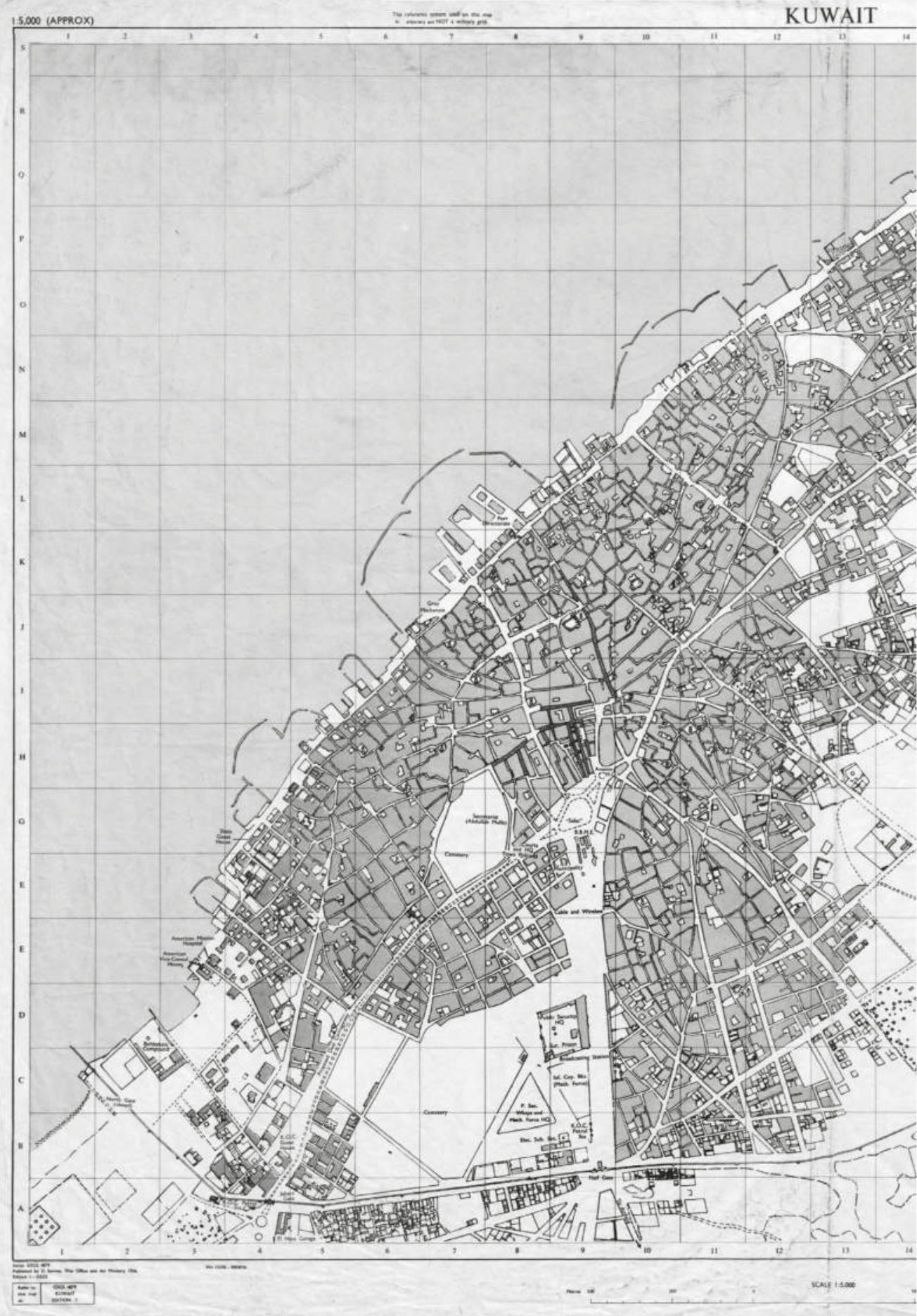

fig.1 "Plans of Towns in Kuwait", D. Survey, War Office and Air Ministry, 1956, surveyed in 1951 (Source: @ British Library Board, GSGS 4879. Reuse not permitted). 


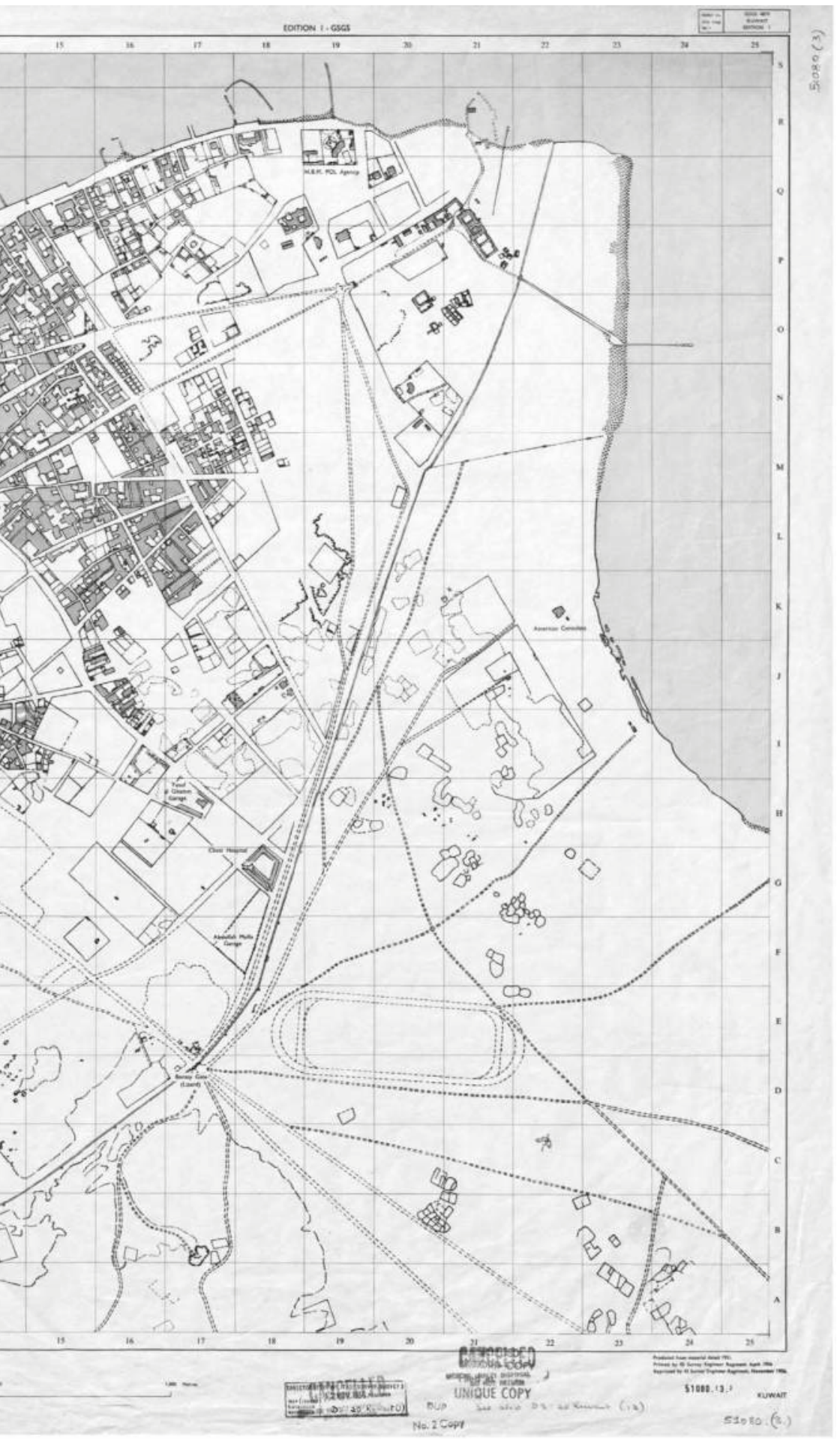


opportunity to actively participate in the rehabilitation project of Al-Amricani. The historical aspects of the chapter elaborate on first-hand material retrieved from the General Hasted's and Kuwait Development Board's papers at the Churchill Archive Centre of the University of Cambridge, United Kingdom, as well as the Dar Al-Athar Al-Islamiyyah archive in Kuwait.

\section{Philipindia}

The very centric wedge, between Kuwait Bay and the streets Soor and Abdallah Al-Salem, is casually referred to as 'Philipindia'. Soor ('wall' in Arabic) is the street that replaced the empty corridor left by the demolition of the old city wall in the 1950s. Fringed by a vegetated buffer zone, the Green Belt, Soor Street delineates the inner urban core from the suburbs while Abdallah Al-Salem Street (once Naif Avenue) runs orthogonally, being one of the radial roads that connects with the outer residential neighbourhoods. This triangle is currently one of the few walkable parts of the city, and in milder seasons, it is commonplace to see groups circulating under the arcade of the bisector Fahed Al-Salem Street (once Jahra Road) or gathering in vacant lots between buildings. Generous sidewalks, usually quite uncommon in Kuwait, and many interstitial plots all lead to the central market area, Souk Mubarakiya, and the bus station: a crucial gateway to the suburban settlements where low-income expats usually reside.

The rather derogatory name of the area does not truly reflect the plurality of accents that can be heard in this central part of the town; while Indians and Filipinos do compose a large portion of migrant workers in the country, Pakistanis, Bengalis, Sri Lankans, other South Asians as well as Egyptians also constitute a significant demographic. ${ }^{1}$ According to the 2011 census, the most recent official data available, around 5,000 non-Kuwaitis reside here, mostly in the run-down apartment blocks erected in the 1960s around Fahed Al-Salem Street. ${ }^{2}$

In addition, a significant number of non-Kuwaitis work in institutions such as small businesses, governmental agencies, and outdated commercial strips that animate this part of town, returning to the suburbs after working hours. Most of Jibla's street levels offer commercial activities related to non-nationals' needs, such as money transfers, currency exchanges, and travel agencies alongside convenience stores, small cafés, and food shops serving until late hours.

The colourful presence of the area's many nationalities does not impress as much as the almost complete absence of locals. According to official data, only 167 nationals live in Jibla; though on a regular day, other Kuwaitis may converge here for work as the majority are employed in the public sector or collect documents from the same offices. Excluding the Salhiya Mall and the adjacent Plaza, Kuwaitis would not pick Jibla as a social space 


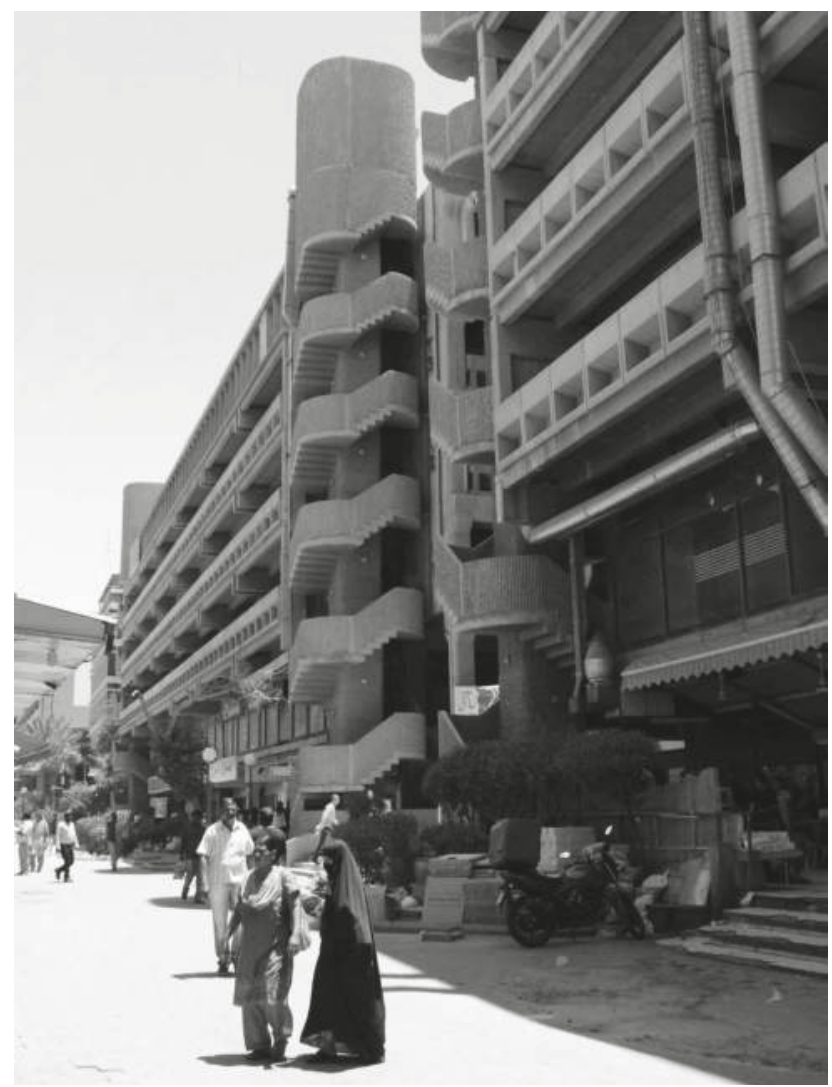

fig.2 Proximity of Fahed Al-Salem Street with Souk Al-Muttaheda on right (Photo: Roberto Fabbri, 2019. Reuse not permitted).

for recreation. It would not be considered appropriate, nor attractive. Since ministries and governmental workplaces typically close at 2 p.m. and the other offices a few hours later, in the evening the area becomes available for other forms of social interaction. In the after-work hours and during weekends, migrant workers and low-income expats reclaim this space for recreational practices and social gatherings. Among the relics of the Kuwait modernist project - the unbuilt plots, uncompleted plans, rejected spaces, and obsolete objects - 'other citizenships' find meaning in a public space that was never intended nor designed for them, demonstrating how the sense of sociality that a place encourages or represents also defines its public life and accessibility more than its property and ownership. ${ }^{3}$

The area does not usually show itself to be appropriate for family gatherings on weekdays as the majority of Jibla's residents are young males, but on weekends the demographics radically 
change. The entire area offers shopping opportunities at affordable prices, and under the arcades of Fahed Al-Salem Street and the squares up to Salhiya Cemetery walls, food shops promise ingredients for 'exotic' cuisines - some say even rabbit or pork can be found around here. ${ }^{4}$ The modernist car parks/souks - such as Al-Mutteheda and Al-Masseel (built by Bonington Partnership, 1973-1979), Al-Watiya (PACE, 1974-1979), and Al-Wataniya (TAC, 1973), $\boldsymbol{\Delta}$ once experimental typologies intended to reintroduce retail and residential functions in the city - today offer inexpensive Chinese goods, household products, luggage, and counterfeit luxury brands as well as beverages and street food in a shaded, air-conditioned interior. ${ }^{5}$

Commerce aside, the main attraction on weekends is the Christian cathedral, which is also a building from the era of modernization. From Friday to Sunday, long lines of people cross the bridge over the First Ring Road and gather in the vacant area around the church's compound. That is the Bishop's seat of the Apostolic Vicariate of Northern Arabia and one of the tangible testimonies of the country's religious tolerance. The church currently serves a congregation of more than 50,000 followers from many nationalities, with services offered in English, French, Latin, Arabic, Tagalog (Philippines), Konkani and Malayalam (India), and Tamil (Sri Lanka).

\section{Jibla's modern project}

Before becoming Philipindia, Kuwait's urban project commenced in Jibla. As early as the 1950s, 'modernity', in terms of urban transformation, entered the city through Jibla's two wallgates, Naif and Jahra, to permanently change the proxemics of the area's traditional fabric. A 1951 survey of the town, redacted by the British War Office and Air Ministry, clearly shows that, typology wise, the only modern buildings in the old town were Edwin Lutyens' British Political Agency in Dasman (1937), the Safat branch of the British Bank of the Middle East (1949), and the American Missionary Hospital (1911-1936), all of which could be considered foreign 'intrusions'. - The rest of the walled town was an intricately woven carpet of traditional courtyard houses and narrow alleyways. The transformation started in 1950 with the rise to power of Sheikh Abdullah Al-Salem and the vision to restructure the country. Unsurprisingly, after 50 years of protectorate status, the political and financial guidance of the modernizing project started under strict British influence. In particular, the entire construction cycle was orchestrated between the Foreign Office in London, regional coordination in Manama, local Agency in Dasman, and Seif Palace (the Amir's office). With the loss of India in 1947, the Gulf became even more strategical for the UK, especially to steer exponentially increasing oil revenues towards British companies. The influence of the Political Agency was sufficient 
to suggest - and by de facto impose - British consultants onto all major design works, starting from the first master plan by Minoprio, Spencely and Macfarlane (MSM), finalized in November 1951. To actuate the plan, the agency encouraged the government to embark on a five-year modernization plan, placing British advisors in key positions in the Ministry of Finance and Development Board. At the same time, a monopoly system secured and distributed the lucrative contacts to five construction firms, precluding open tenders. ${ }^{6}$ The so-called 'big five' were Taylor Woodrow; William Press; Richard Constain; Holland, Hannen and Cubbit; and John Howard, and they operated on a $15 \%$ profit over costs, leaving Kuwaiti partners with only labour provisions. A sixth firm, Ewbanks and Partners, was also active in the country as a specialized consultant in power generation. General William Hasted coordinated the modernization plan, as Chair of the Development Board and Controller of Development. The Board started the first session in January 1952.

Addressing the Amir in the Preliminary Report of February 1952, Hasted set priorities straight. To create "the finest city in the Middle East and the happiest State", he suggested a list of urgent infrastructures to be implemented, such as water and electricity plants, housing, a port, an airport, and industries. He also advised the Amir to carefully locate and design all the public buildings, suggesting to assign them to "architects of repute". ${ }^{7}$ He was reinstating the master plan strategy which, a few months earlier, had suggested placing all the public buildings in the triangle between Naif and Jahra Gate and Safat Square. MSM envisioned "a broad avenue, with garden and trees; lined with public buildings and forming an impressive approach to the town centre", to properly define two arteries converging in the vibrant heart of the city centre. ${ }^{8}$ While Jahra Road was left undefined at this stage, the documents show particular care in detailing Naif Avenue - the gardens, flanks of buildings, as well as water and clock towers at the junction with Safat.

Out of the entire city footprint, the Board identified Jibla's two main axes as an opportunity to showcase the country's progress, and that may have been related to the overall vision of the master plan. In fact, Naif Avenue was intended to serve as the connector between the centre and the southern expansion; it would have led to the airfield in Nuzha, to the new airport further south, and finally to the oil town of Ahmadi. Instead, Jahra Road headed towards the new deep-sea port, new hospital, and technical college, all situated by MSM in the west district of Shuwaikh. It would also have led to the new residential districts of Shamiya and Shuwaikh, where prominent members of ruling and merchant families received residential plots of land. Thus, Jahra Road later assumed a more commercial and retail-oriented role, while Naif was, from the beginning, more institutional. 


\section{Paving the road to modernity}

Following the indication to pursue renowned architects, the Board assigned Naif Avenue's project to Farmer and Dark (F\&D), a British firm founded in 1934 which had successfully partnered with Ewbanks. F\&D specialized in designing industrial and office buildings and, in particular, explored the architectural expression of power plants in UK. In the same period, the British Energy Authority integrated architects into the plant-design teams since the post-Second World War energy plan would have required particular care to incorporate the plants into delicate urban or natural contexts. F\&D's approach soon became popular, not only for a more functional distribution but also for experimenting with 'machine aesthetics': exposed pipes, bright colour schemes, and alternations of cladding material such as aluminium, glass, and concrete. ${ }^{9}$ In September 1947, the Architectural Review published four examples of the firm's latest work: the Stourport, Hayle, Llynfi, and Little Barford power stations. ${ }^{10}$ Meanwhile, during the same period, they collaborated with John Bruce to design Brunswick Wharf on the River Thames, a monumental edifice in bricks and fluted white chimneys, very similar to the Battersea Power Station. ${ }^{11}$

In 1949, the Kuwait Oil Company (KOC) called up Ewbanks and F\&D to design the Fahaheel Power Station, a plant intended to supply electricity to Ahmadi. In 1951, they were charged with the design of the Kuwait Town Distillation Plant and in 1954 with the Town Power Station. ${ }^{12}$ Later, in 1955 and 1956, they also designed a number of school buildings and a palace in Surra for Shaikh Jabir Al-Ali Al-Sabah, head of the Department of Electricity and Water. ${ }^{13}$ At this time, Dark was the only founding member, with six partners, and they operated in the region through the Middle East branch in Beirut, managed by partner William Henderson, who first visited Kuwait in $1952 .{ }^{14}$ Since the mid-1950s, architect Anthony Irving led the Beirut office and was in charge of Kuwait's school project. ${ }^{15} \mathrm{He}$ would later go on to found the Design Construction Group (DCG) in partnership with Gordon Jones, eventually acquiring a reputation for designing bank headquarters and several institutional buildings.

The urban plan for Naif Avenue was a recurrent topic in Hasted's minutes since the Board's early meetings, which often concerned the new governmental headquarters' siting. The general concept was developed by F\&D following the Board's requirements and presented to the Amir in spring $1952 .{ }^{16}$ The project defined a large, dual-carriage, monumental axis, connecting Naif Gate to Safat Square. The central spine was to be a green third-space, with decorative gardens, trimmed grass, trees, and walkways. Sideways, key buildings were positioned creating the avenue's architectural curtain in a scenographic manner, which was meant to culminate in Safat. Following what appears to be 

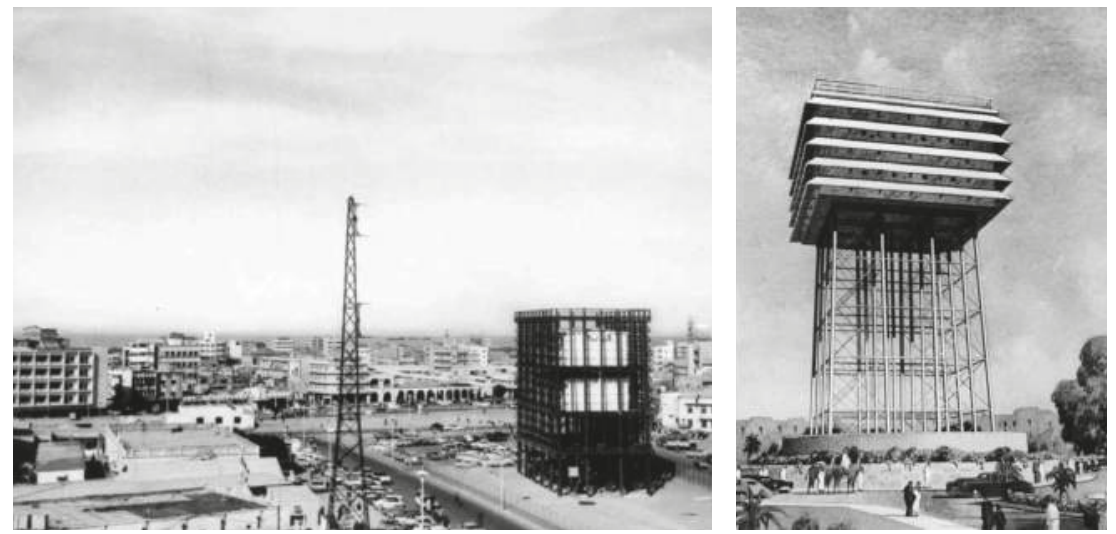

fig.3

Left: view of termination of Naif Avenue with water tower at Safat Square (n.d., postcard). Right: Farmer and Dark's project for the water tower, 1953 (Source: William Henderson, Special Collections and Archives, University of Liverpool D1176/2/7. Reuse not permitted).

common practice in British colonial urbanism, the plan allocated all the key institutions of the country in one stretch, including the Ministries of Health, Education, Marine, Religious Affairs, and Finance; the Departments of Water and Electricity, Security and Public Works; the Chamber of Commerce; and the Law Court together with the fire station, post office, and a large, open-air auditorium. ${ }^{17}$ The axis's main scope was to rhetorically frame access to the civic centre of the city, creating a climax culminating in the strong verticals of Safat, or "Kuwait's Piccadilly Circus", according to F\&D's partner R. L. Banks. ${ }^{18}$

Among these ascending landmarks, the Board and F\&D envisioned both a clock and water tower, though priority was given fig.3 to the latter as it meddled with the water-distribution grid. Cyril Farey's meticulous architectural drawing perfectly renders F\&D's talent in balancing expressive features in technical architecture; the tower has a small circular podium and slender space-frame structure as a pedestal. The latter supports a massive cubic tank protected from direct sunlight by an array of slanted louvres. A viewpoint overlooking the square and the gardens crowns the structure. The whole composition concentrates the masses where they are needed for the correct functionality of the aqueduct yet, at the same time, is careful not to impede the view at street level.

While waiting for the Amir's approval, the Board proceeded to acquire the parcels needed, finding the process more complicated than initially expected due to the opposition of several landowners. ${ }^{19}$ The Amir's endorsement finally came in September 1952, and drawings and maquettes went on display at the municipality for a week. ${ }^{20}$ Together with his approval, Sheikh Abdullah also donated part of the land for the project. 
The situation radically changed in November 1952 when Sheikh Fahed Al-Salem was appointed as the new president of the Development Board by his half-brother, the Amir. In the following years, Sheikh Fahed gradually dismantled the British monopoly in the construction system, opening the market for international consultants and contractors, changing the terms of contracts and tender procedures. In early 1953, he appointed the Syrian engineer Majadin Jabri as head of the Public Work Department (PWD), reducing Hasted's decision power drastically. ${ }^{21}$ Later in 1954, he also appointed the Lebanese engineer Fuad Abdul Baqi as the new Inspector General. ${ }^{22}$ As a consequence, many projects took a different direction, and Hasted finally resigned in frustration in April 1954. Among the affected projects, Naif Avenue fell from one of the top six priorities of the 1953 budget plan to an unaccomplished project; the initial idea was reduced, fragmented, and became known only as a parcellation plan. In February 1953, the Board decided to exclude any architectural or decorative feature from the water tower, which was built a few years later based on a different, resembling scheme. ${ }^{23}$ Similarly, the Board established bylaws for the buildings, based on the code of Heliopolis; but given the actual aspect of the street, these guidelines were probably never implemented. ${ }^{24}$ Nevertheless, the avenue maintained its land-use pattern, and during the years that came, several institutional buildings were erected here. First, the Majlis Al-Ummah (the old National Assembly), inaugurated in 1962 and later converted into the municipality; the only building in the country to sport a cutting-edge curtainwall, it was designed by the Lebanese architect Sami Abdul Baqi, brother to PWD Inspector General Fuad. ${ }^{25}$

While Naif Avenue remained an unaccomplished, bidimensional plan, another coeval urban project led to different results. Jahra Road was on the Board's project-list during the same period as Naif was, mostly as a carriage enlargement to solve frequent traffic congestions. ${ }^{26}$ It eventually turned into a more ambitious project: with 1,000 shops and over 8,000 rooms for Kuwait's new commercial high street. Hamra Street, Beirut's new showplace, was the reference model. On Jahra Road, every merchant family in Kuwait competed to acquire spots to flaunt their businesses, and consequently, land speculation and highly inflated costs of expropriation fuelled the (credible) myth of Jahra as the most expensive mile on the planet.

Given the personalities involved, the project proceeded on the fast lane. The Board appointed PWD to carry on the project in-house, including demolitions, design, and construction supervision. ${ }^{27}$ The project consisted of a dual-carriage avenue, framed by an array of repetitive blocks, notched on the corners to direct the circulation to the side streets. To homogenize the project, PWD established the Jahra Street Façade Committee, which was 
placed in charge of setting the street's norms, heights, colour schemes, and façade elements. ${ }^{28}$

The constructions proceeded fast, and when George Saba Shiber arrived in Kuwait as Director of the Planning Department, the project was already close to completion. He dismissed it as "a wasted opportunity", a cosmetic operation to hide incapacity to articulate inclusive public spaces, a rushed execution that sacrificed construction quality and basic services. In other words, the façade-controlled design approach generated a photogenic backdrop, but the lack of civic principles made the newest street of Kuwait already obsolete. ${ }^{29}$

Soon after Shiber's commentaries, Jahra Road was renamed after Fahed Al-Salem, recently passed. For a decade, it became Kuwait's badge of modernity, depicted in all the postcards, official publications, and international magazines illustrating Kuwait's progress. Later, other prestigious buildings completed the street flanks, such as Sayyed Karim's Thunayan Al-Ghanim Building (1957-1969) and Sami Abdul Baqi's Ministry of Finance (1959-1962). The two, erected face-to-face at the very beginning of the street, acted for years as the new portal to the city.

\section{Modernity by tradition}

Jibla is also one of the places where Kuwait's modernity has tried to come to terms with tradition. In search of a possible historical 'continuity', in times when demolition was the norm, this part of Kuwait has offered few episodes of alternative ways to reach modernity. This is the case of Behbehani Compound, a master plan listed it as one of the nation's few preservation areas. Since "little remains of Kuwait's native architecture, most of which was demolished in the 1950s and 1960s [...] efforts are now being made to preserve what little is left", commented the municipality's chief architect Hamid Shuaib on the occasion. ${ }^{30}$ Despite its pre-oil aesthetic, the majority of the compound was erected after 1956. The 1951 survey previously mentioned, shows the presence of a strip of rowhouses along the south end of the plot, each unit with a small patio. Behind the strip, another cluster of similar houses was accommodated in a square configuration. The rest was built afterward in similar style, replicating the existing typology and implementing architectural features taken from autochthonous and other Arab architectural models. The ground floors were organized traditionally around a central courtyard with the rooms divided by bearing walls, mostly in limestone brick. The upper floors were often made of timber and alternated enclosed spaces with verandas, rooftops, and balconies, with slanted louvres and wooden mashrabiyyas - all 
traditional elements that, a few years later, had to learn to coexist with air-conditioning compressors and antennas, epitomizing the compromises of modernization.

Architectural critic Stephen Gardiner visited the compound in the late 1970s, praising the project as some form of resistance to the modern local patterns: "... nothing extravagant; economy is the hallmark of Kuwait's heritage". ${ }^{31}$ In these dwelling units, he traced some derivative features from Dickson's House, the former British Residency of the 1940s which even today remains one of the most significant examples of pre-oil houses in a good preservation state. In harsh contrast, he found Behbehani Compound in disrepair as the original tenants left for the suburban neighbourhoods. The compound, initially successful, later experienced difficulties but has ultimately found success in recent years, when it became an 'extravagant' residential opportunity for a few Kuwaiti families and wealthy expats. Besides this, endorsing a typical gentrification pattern, it became home to several small restaurants, cafés, artisanal shops, and one art gallery.

We cannot fully consider Behbehani Compound a 'heritage village', having an embedded element of 'pre-oil authenticity'. It portrays an endeavour to explore alternatives to standardized modernity. Similar to the case of Behbehani, Kuwait also tried to amend the demolition of the old urban fabric by enacting lifebefore-oil in the neighbouring Youm-Al-Bahar (the Sailor's Day Village). This small entertainment/theme park was built in the late 1980 s on reclaimed land near Behbehani. The project still operates to this day with questionable success. With a similar intention and even worse results, Kuwait Heritage Village was a 2003 governmental project to be realized around Dickson House; a brand new Kuwaiti fereej built entirely of concrete. The project was part of a series of initiatives to help revamp the city centre that was never completed, a series of empty grey skeletons were left exposed among billboards, inviting passersby to experience the 'authenticity' of a pre-oil life. ${ }^{32}$

Next to Behbehani, in a separate and enclosed compound, there was the Catholic church, built on a plot in the proximity of Jahra Gate once meant to be isolated from the rest of the town. The land was conceded by the Amir Abdullah Al-Salem to bishop Teofilo Ubaldo Stella, founder of the Catholic mission of Kuwait in 1948 and Apostolic Vicar since 1955. In 1956, Monsignor Stella assigned the project to Italian architect Emilio Tenca, who designed a traditional basilica with a central nave, two lower aisles, and a small transept. The general layout and main façade bear close resemblance to the Mater Orphanorum church in Legnano, a town in the outskirts of Milan, also designed by Tenca and completed in December 1955.33 The Kuwaiti version of the project was adapted to the local context through the use of limestone brick rather than clay, and by reducing the aperture it adjusted lighting 


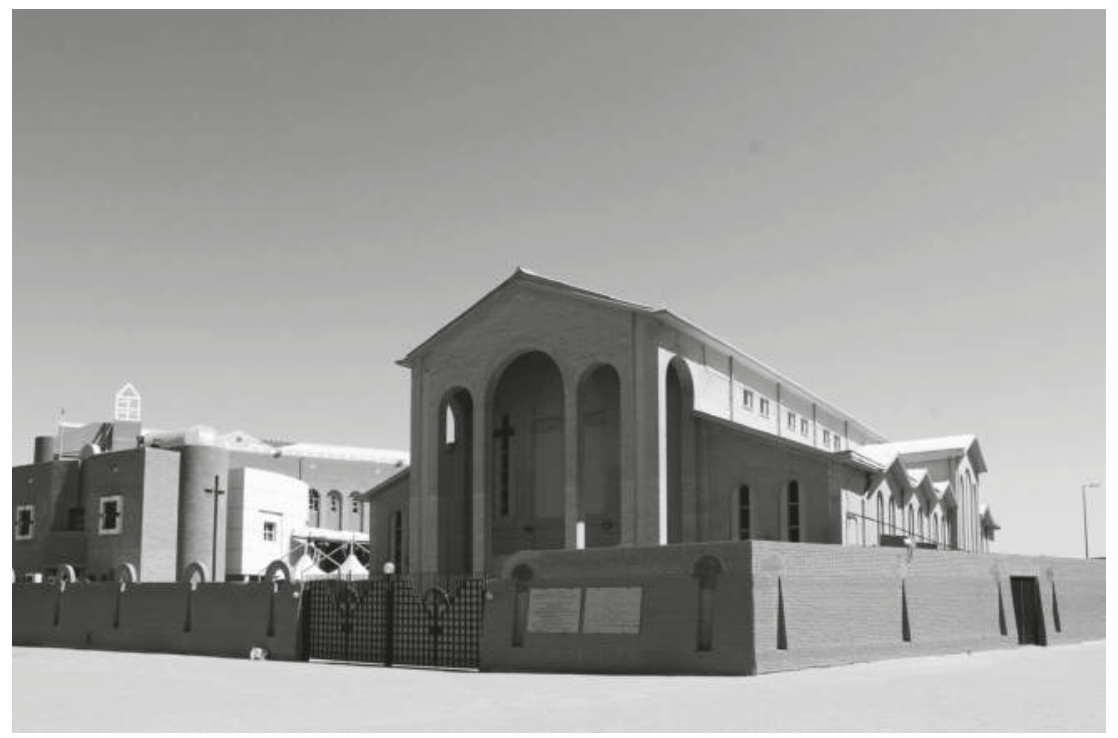

fig.4

"Our Lady of the Desert", church and Apostolic Vicariate of Northern Arabia. On right, the original building by Emilio Tenca, 1957-1961; on left, Krzyztof Wiśnioski's additions, 1997 (Photo: Roberto Fabbri, 2019. Reuse not permitted).

and thermal insulation. Construction commenced in 1957, and the bishop consecrated the church in March 1961 with the dedication to the Holy Family of the Desert. ${ }^{34}$

In the following years, the Christian community of Kuwait grew significantly in parallel with the increasing number of immigrant workers that had joined the country, and by 1997, the Polish architect Krzysztof Wiśniowski was charged with the redesign of the compound. The new project comprised a series of new buildings embracing the church from the west side, including a new bishop's residence, the rectory, the new parish hall, and seven classrooms for catechism. ${ }^{35}$ The additions borrowed the limestone brick and colour palette of the original building, yet the elements were combined to create a more post-modernist language.

In direct opposition to the previous examples, this work offers a reflection on foreign traditions and the symbolic elements that represent it, specifically Christian traditional emblems. In fact, while religious practice is tolerated in the country, Kuwait's law prohibits the public display of non-Muslim religious symbols to avoid potential confrontations. Hence, in Wiśniowski's proposal, the tower bell is here dematerialized, becoming a white spaceframe structure that only alludes to the traditional campanile's silhouette. Similarly, the cross does not stand above the buildings but has become part of the façade design, punctuating apertures, frames, and shutters. 


\section{Redefining modernity/negotiating tradition}

Between Behbehani Compound, the Catholic church, and Youm-Al-Bahar there is a large, vacant plot, occasionally used on weekends for improvised football matches. At the end of the plot stands the Amricani Cultural Center, one of the oldest edifications in the country and one of the most recent examples of adaptive reuse in the region. Just like Behbehani, the Center is a national monument and protected under the 1981 master plan revision, but its history has many folds. It was initially a hospital, and its compound has been an experimental site for the country's modern architecture.

Locally known as Al-Amricani, the American Mission Hospital was built by the Arabian Mission of the Reformed Church of America as a base between their headquarters in Basrah and Bahrain respectively. The land was granted in 1911 by the late Amir Mubarak Al-Kabeer at the far edge of town after a missionary doctor successfully operated on his daughter. ${ }^{36}$ The missionary regarded Kuwait as the door to evangelize Arabia, but their aspiration was met with scepticism from the local population.

The first medical facility was erected between 1913 and 1914 by Charles Shaw and Phillip Heynes of the University of Michigan. The two engineers designed a remarkable-for-the-time structure in steel frames and concrete. They imported all the components from abroad, given the complete and utter lack of construction material in the country, and the technique aroused great interest in a city habitually built in mud bricks. ${ }^{37}$ The hospital was a sleek horizontal body with a pinched roof and deep porch, to protect inpatient rooms from sunlight. The structure allowed for cantilevers, spans, and apertures of an unprecedented size for the country, eventually gaining the name of Glass House. The project was ambitious, and by far the most 'modern' in the region, but the local weather conditions combined with the unskilled labour for such a technique led to several problems, mostly infiltrations, which deterred the mission from replicating the experiment, in Kuwait or elsewhere. ${ }^{38}$ The coeval Physician's and Pastor's Houses were constructed a few years later with local materials, based on the missionary architecture of the region, such as the 1903 Mason Memorial Hospital in Bahrain. ${ }^{39}$

The Kuwaiti hospital initially sheltered men and women, creating predictable inconveniences. Consequently, the missionaries built a new temporary women's dispensary, which would later be replaced by a more significant structure in 1939: Olcott Memorial. ${ }^{40}$ The latter was another effort to experiment with more advanced construction systems, a bearing-wall structure in concrete blocks and reinforced concrete slabs; the cement aggregate was produced on-site in a mixer borrowed from the oil company, and all the resulting surfaces were plastered with cement stucco with a 'special' grouting technique which had been previously tested in 
Lutyens' British Embassy. ${ }^{41}$ Rev. Dykstra and Rev. Barney designed the new hospital, the latter introducing, as an architectural motif, the two-centred arch for windows and verandas. ${ }^{42}$ This feature, outlined by a raised, tuck-joint plaster, provided an 'Arabian' character to a construction which was - in terms of size, services, and typology - quite dissonant with the rest of the city.

The Olcott set a precedent for the last construction in the compound, Mylrea Memorial, meant to replace the 1911 Men's Hospital. Inaugurated by the Amir in October 1955, Mylrea was a bigger, more equipped version of Olcott, featuring the same architectural envelope and a different, more reliable solution for the roof: jack vaults, locally known as the Persian manner. ${ }^{43}$ Lovick, the designer, arranged a $c$-shaped plan facing the sea and extended the arched verandas all around the perimeter.

Despite the 'pre-oil appearance', mostly given by the façades, it could be argued that Al-Amricani is a transitional building in that it reinterprets traditional features; its modernity does not only lay in advanced construction techniques or innovative services but foremost in its spatial design and typology. The two main buildings face the sea aligned on a northwest/southeast axis to take advantage of the sea breeze. The verandas on both principal fronts protect interiors from direct sun exposure and at the same time foster cross-ventilation, as is logical for a modern medical structure. Beyond this, the traditional local typology was the courtyard house, introverted and centripetal towards the inner patio, as can be seen in structures such as coeval Amiri Hospital (1949). In opposition to this, Al-Amricani turns its typology into an open plan, extroverted and facing outward, leaning towards some linear structures that will epitomize Kuwaiti architectural modernity for the following years to come.

\section{Readapting modernity}

Al-Amricani remained operational until 1967 when it was deemed obsolete and subsequently closed. The Mission kept half of the compound, continuing its pastoral and educational services, while the main buildings initially became governmental offices and then abandoned. It was only after the invasion that a new interest for the hospitals arose in relation to the destruction of the Kuwait National Museum (KNM), which was set on fire in 1990 by Iraqi troops, who took the objects to Baghdad, including the Dar Al-Athar Al-Islamiyyah (DAl) collection. ${ }^{44}$ After the Liberation, the United Nations forced the occupants to return the museum's artefacts, but the KNM was unfit to receive the collection, so the reuse utilization of Al-Amricani emerged as a possible solution. In the following years, several UNESCO/UNDP expert missions worked on damage assessment of artefacts and KNM buildings as well as on a feasibility study for the rehabilitation of old hospitals as new DAI headquarters. 


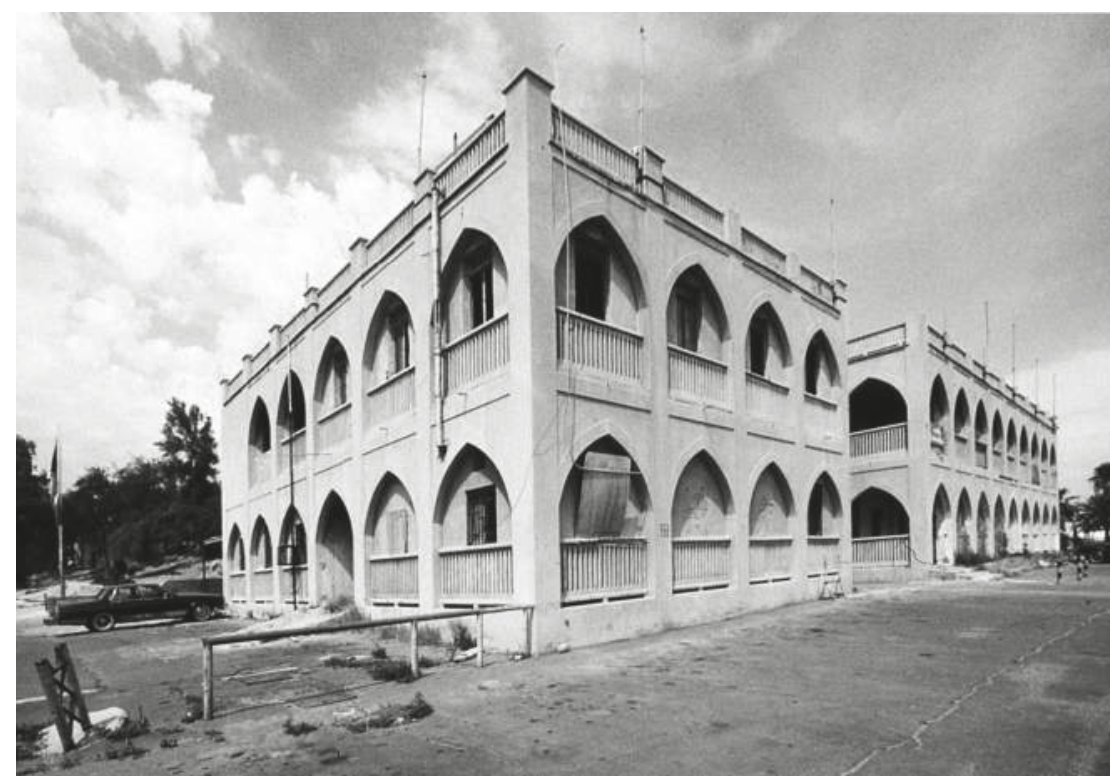

American Mission Hospital, locally known as Al-Amricani,

fig.5 before the renovation (Photo: Abdulkareem Al-Ghadban, 1993. Reuse not permitted).

Since Al-Amricani was on the country's heritage list, the intention was to set a standard for future rehabilitation projects. The UN-led committee, in collaboration with DAI, conducted an in-depth campaign for the buildings which included a dimensional survey, materials and structural assessments, a conservation status, archival research, and a design proposal. This phase was coordinated by Michael Bielinsky with UNESCO consultants Alex Castro as gallery designer, Alan Frost as head of architectural restoration, and Manuel Keen as museum curator. ${ }^{45}$ The team assessed that many sections of the buildings had faced significant structural failures and needed to be replaced, which inadvertently gave a certain level of freedom to the rehabilitation project.

The concept was elaborated in partnership with the Kuwaiti firm KEO, with Nader Ardalan as project director and Ghazi and Abdul Aziz Sultan as the project's "special advisors" . ${ }^{46}$ It proposed that Olcott Memorial could become the new DAl administrative office while the Mylrea, bigger in size, would accommodate the galleries. Hence, the former did not require much alteration, but the latter's distribution changed entirely by the introduction of a wide spiral staircase and new body in the south court. Ghazi Sultan's rendered views depict this space as a triple-high, distributional hinge, protruding above the actual roof with ample fenestration for zenithal lighting. The windows, in this case, were 


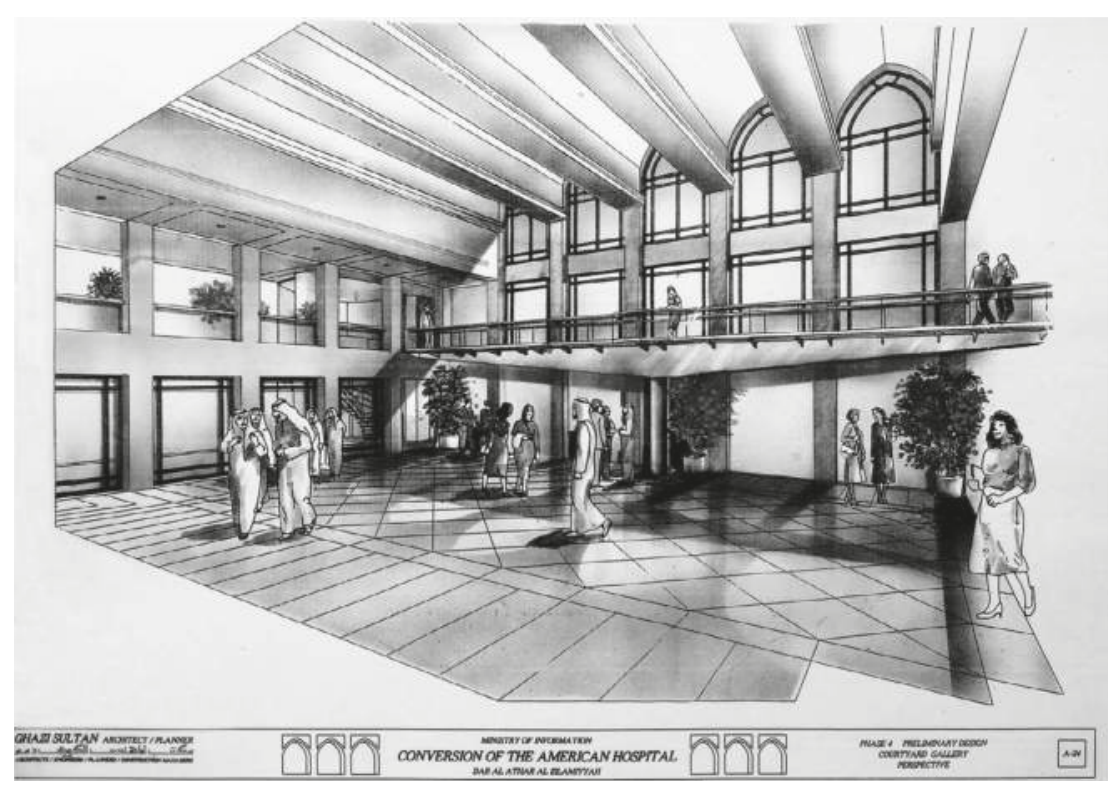

fig.6 Ghazi Sultan and KEO, unbuilt proposal for new lobby of Amricani Cultural Center, n.d. circa 1996 (Courtesy of Aruna Sultan. Source: Dar Al-Athar Al-Islamiyyah, Kuwait. Reuse not permitted).

fig.6 signature element. As an alternative, Ghazi Sultan offered two other versions of the roof: either a tensile membrane or spaceframe structure.

The project in this form never fully materialized as it implied too many modifications of the original structure to be viable. The National Council for Culture, Art and Letters conducted the works in early 2000 as a simplified 'philological' restoration, intended to bring back the construction's original look. Nevertheless, a few years later, the concept of a new hall in the south court came up again following further UNESCO/UNDP missions in 2005, to which the present author was invited to participate as architect. By this time the project had already been approved, and the proposed roof shape was now a concave metal plate with metal trusses, accommodating a large auditorium below. In 2011, DAl finally inaugurated the building as its new exhibition centre and administrative headquarters.

Al-Amricani stands close to one of Kuwait's (modern) architectural symbols: Jørn Utzon's Parliament (1982). The two buildings have been close neighbours for 40 years yet have somehow mutually absorbed architectural elements from one another. From a distance, the Amricani new roof follows, on a smaller scale and simpler manner, the parabolic shape cast over Assembly Hall 
and the sea-view square. Reciprocally, Parliament's north and south elevations retrace the Amricani's façade module, composed by two pointed arches on two floors, framed by two pilasters and a horizontal cornice. The two-centred arches helped Utzon manifest the 'Arabness' of the building, together with the sail and tent metaphors for the roof. The Danish architect refers to his 1959 trip to Iran, with particular regard for Isfahan as one of the most significant historical inspirations for the Kuwaiti building. ${ }^{47}$ On the other hand, Persian influence has permeated Gulf architecture for centuries, was evident in pre-oil Kuwait, and could have also been a known reference for the missionaries.

This episode helps to demystify Kuwait's approach to architectural modernity, often depicted as a predetermined, superimposed, imported pattern. It is, in fact, a more complex and interwoven stratification of historical and contemporary references. The coexisting presence of pre-oil and modern elements reflects the country's traditional openness to external influences, cultural exchange, and trade, embedded in its nature as a port town.

\section{Conclusions}

The present work moved from the analysis of lesser known episodes of architectural modernity that sit at the crossroad of tradition and progress, paraphrasing Harold Rosemberg's definition of modernity as the tradition of deposing traditions. ${ }^{48}$ Examining a series of projects that took place in the same quarter of Kuwait City, Jibla, and in the early days of the country's urban transformation, this chapter attempted to demystify the binaries according to which, in the Gulf particularly, 'tradition' is only 'pre-oil', and 'authenticity' is only regional. Many examples of what is considered heritage nowadays, some of which are discussed here, blend in their architectural form reflections on history, locality, global practices, and external influences, still remaining an authentic expression of their era. These are all the ingredients that compose the country's multifaced society and are mirrored in its heterogeneous urban environment, where global and regional aspects coexist. However, pre-oil architectural manifestations are usually preferred to represent shared values, even if the philological reconstruction or even the 'authenticity' is sometimes questionable, as is the case with some heritage villages or Behbehani Compound, for instance.

In this framework, this study considers how Kuwait's modern urban project contributed not only to the physical reshaping of the city but also to the establishment of a bijective relationship with the past. This connection was not always a conflictual superimposition of foreign narratives or practices. In fact, some projects established a dialogue with the local physical and cultural context despite being drawn by foreign hands. Al-Amricani perhaps captures this concept best, a project argued here to 
represent a sort of archetypally modern approach to architecture, also influencing both the bordering Assembly Hall as well as a more recent example of adaptive reuse in the region.

This chapter also offered a reading of the legacy of modernity in this contemporary city and of how this vision, generated by a top-down practice to target a specific 'user', has radically changed into a liminal space, a theatre for social interaction of completely different citizenships. In contemporary Kuwait, after 5 p.m. and during the weekends, this part of the town is Philipindia, and the rigid 1960s concrete blocks around Fahed Al-Salem Street assume more fluid contours. The rational urbanscape of the 1960s does not appeal any longer to the citizen for whom modernity was acquired, and for this very reason, Jibla is now an open territory in transformation.

In conclusion, this analysis argues how Kuwait's modernist urban project resulted in a 'fragmentarium'. The term metaphorically describes a museological space that collects and accommodates a series of apparently uncorrelated shards that were initially part of cohesive ideas. Now, being incomplete, altered or superseded, these objects can no longer fit into the general narrative of one gallery, just as Kuwait's modernist fragments are currently obsolete in the logic of the contemporary city, waiting to be demolished and replaced or to become heritage and survive. While 'museumification' cannot be a solution for an urban environment, adaptive reuse has shown itself to be the only feasible strategy to repurpose these fragments. 


\section{Notes}

1 The exceptionally disproportionate ratio between local population and migrant workforces in Kuwait, and in the region more broadly, is one of the highest in the world. It often fuels discriminative behaviours based on ethnicity that result in the marginalization and poor living conditions of migrants. The subject has been widely investigated by the press, academia, and international organizations, especially after the widely circulated reports on working conditions in the Qatar 2022 World Cup building sites. For more information, see Fair Migration: Setting an ILO Agenda, Report of the Director General at the International Labour Conference (Geneva: International Labour Office, 2014) and "Labour Migration in the Arab States", official website of the International Labour Organization, accessed October 17, 2020, https://www.ilo.org/beirut/areasofwork/ labour-migration/WCMS_514910/lang--en/ index.htm.

2 Annual Statistical Abstract 2017-2018 (Kuwait: Central Statistical Bureau, 2017), 60. 3 Fran Tonkiss, Space, the City and Social Theory: Social Relations and Urban Forms (Cambridge: Polity Press, 2005), 66. 4 Conversation with C., a Sri Lankan domestic worker, 2015

5 Roberto Fabbri, Sara Saragoça Soares, and Ricardo Camacho, Modern Architecture Kuwait 1949-89 (Zurich: Niggli, 2016), 228-235.

6 Simon C. Smith, "The Business of Decolonization: The Foreign Office, British Business, and the End of Empire in Kuwait and Qatar", in The Foreign Office, Commerce and British Foreign Policy in the Twentieth Century, eds. J. Fisher et al (London: Palgrave Macmillan), 382.

7 Major-General William F. Hasted, Preliminary Report on Development of Kuwait State, February 1952, 2-3, Cambridge University: Churchill Archive Centre, HSTD $3 / 7$.

8 Minoprio, Spencely and Macfarlane, Plan for the Town of Kuwait. Report to His Highness Shaikh Abdulla As Salim As Subah [sic], C. I. E. Ruler of Kuwait, 1951, 4, Cambridge University: Churchill Archive Centre, HSTD 2/1.

9 20th-Century Coal- and Oil-Fired Electric Power Generation (London: Historic England, 2015), 11.

10 "Four Power Stations", Architectural Review 102 (September 1947): 81-84. 11 "Brunswick Wharf", in Survey of London: 43 and 44, Poplar, Blackwall and Isle of Dogs, ed. Hermione Hobhouse (London: London County Council, 1994), 593-600. British History Online, accessed
September 6, 2020 http://www.britishhistory.ac.uk/survey-london/vols43-4/ pp593-600.

12 Fabbri, Saragoça, and Camacho, Modern Architecture Kuwait 1949-89, 38-39.

13 "Palace in the Persian Gulf", Architectural Review 128 (December 1960): 424-428.

14 lain Jackson, "William Antony Henderson (1914-1998): Projects in the Middle East with Farmer and Dark", Transnational Architecture Group (November 20, 2017), accessed July 9, 2020, https:// transnationalarchitecturegroup.wordpress. com/2017/11/20/new-research-williamanthony-henderson-1914-1998-projectsin-the-middle-east-with-farmer-and-dark. 15 Frankland Dark, letter to G.W. Bell, May 28, 1956, "Development Plan for Kuwait”, Arabian Gulf Digital Archive, FO 1016/514/72.

16 Development Board, "Minutes of the Ninth Meeting", April 1, 1952, Cambridge University: Churchill Archive Centre, HSTD 3/7.

17 "Naif Avenue, Kuwait; Buildings to Be Erected", Architectural Review 113 (February 1953): 126.

18 R.L. Banks, "Notes on a Visit to Kuwait", Town and Planning Review 26 (April 1955): 49.

19 Development Board, "Minutes of the 29th Meeting", August 27, 1952, Cambridge University: Churchill Archive Centre, HSTD 3/7.

20 Development Board, "Minutes of the 31st Meeting", September 7, 1952, Cambridge University: Churchill Archive Centre, HSTD 3/7.

21 Smith, "The Business of Decolonization", 383.

22 Foreign Office, "Leading Personality in Persian Gulf", 1958, 27, Arabian Gulf Digital Archive, FO 371/132749.

23 Development Board, "Minutes of an Extraordinary Meeting", February 10, 1953, Cambridge University: Churchill Archive Centre, HSTD 3/7.

24 Development Board, "Meeting at Municipality", June 5, 1952, Cambridge University: Churchill Archive Centre, HSTD 3/7.

25 Silvia Mazzetto and Roula El-Khoury, "Influences and Aspirations in the Production of National Projects in Lebanon and Kuwait: Selected Iconic Projects by Sami Abdul Baki", ArchnetIJAR, Vol. ahead-of-print No. aheadof-print (2020), https://doi.org/10.1108/ ARCH-06-2019-0159.

26 Development Board, "Minutes of the 56th Meeting", February 23, 1953, Cambridge University: Churchill Archive Centre, HSTD 3/7. 
27 Ibid.

28 George Saba Shiber, "The Newest 'New Street' of Kuwait", in The Kuwait Urbanization, George S. Shiber (Kuwait: Governmental Press, 1964), 398.

29 Ibid., 399.

30 "New Towns Plans Underway", Kuwait Monthly Review 34, no. 9, (May 1984): 9.

31 Stephen Gardiner, Kuwait: The Making of a City (New York: Longman, 1983), 103.

32 Abdulnasser Al-Aslami, "Heritage

Village Project Reflects the Execution

Failure 14 Years after Launch", The Arab Times, August 8, 2019, accessed June 14, 2020, https://www.arabtimesonline.com/ news/heritage-village-project-reflectsthe-execution-failure-14-yrs-after-launch.

33 Daniele Berti, "La Mater Orphanorum", blog on the local history of the city of Legnano, accessed March 1, 2020, https:// danielebertisindaco.blogspot.com/2018/ 01/la-mater-orphanorum.html.

34 "Holy Family Cathedral Parish, Kuwait City", official website of the Apostolic Vicariate of northern Arabia, accessed May 1, 2020, http://www.avona.org/kuwait/ cathedral_kuwait.htm\#.XIBhOpNKhOt. 35 Krzysztof Wiśniowski, Krzysztof Wiśniowski, Anna Wiśniowska, Magdalena Wiśniowska, Jan Wiśniowski. 1968-2006 (Warsaw: Muzeum Architektury, 2006), 24. 36 Alfred DeWitt Mason and Frederick J. Barny, History of the Arabian Mission (New York: Abbott Press, 1926), 145. 37 Ibid., 153.

38 "It is not be advisable to put up another building of that construction". Letter to Mrs. W.I. Chamberlain from Frederick J. Barny (July 3, 1912) reporting the technical comment by Rev. Edwin Calverley. Calverley followed the construction after the steel frame was erected when engineers Shaw and Hayes abandoned the project. The episode is cited in Sandra Shinn, American Mission Hospital: Kuwait, UNESCO Report (Paris: UNESCO, 1996), 31.

39 Shinn, American Mission Hospital, 34.

40 Eleonor T. Calverley, "A Letter from Kuwait”, Neglected Arabia 102 (1917): 13.

41 Evelyn Simos Ali, quoted in Shinn, American Mission Hospital, 38.

42 Mary C. Van Pelt, "The Olcott Hospital - Nearly Complete", Neglected Arabia 185 (April, May, and June 1939): 10.

43 Haidar Khalifah, quoted in Shinn, American Mission Hospital, 42.

44 Roberto Fabbri, "A Museum without Walls: Dar Al-Athar Al-Islamiyyah's

Cultural Diplomacy", Journal of Islamic Architecture 7, no. 2 (2018): 291.

45 Michael Bielinski, Conversion of the American Mission Hospital in Kuwait into Kuwait Museum of Islamic Art, UNESCO Report (Paris: UNESCO, 1997), 2.
46 Archie Walls, Dar Al-Athar Al-Islamiyyah (American Mission Hospital), Report No. 3, UNESCO Report (Paris: UNESCO, 1996), 6.

47 Richard Weston, Utzon: Inspiration, Vision, Architecture (Hellerup: Edition Bløndal, 2001), 300-333.

48 Harold Rosenberg, The Tradition of the New (New York: Horizon Press, 1959), 81. 


\title{
INDUSTRIAL PROMISES Speculative thinking for Sharjah's industrial districts
}

\author{
Jason Carlow
}




\section{INTRODUCTION}

\section{An urban overview}

As the oil rich cities of the Gulf continue to grow and develop, many governments have taken steps to diversify their economies through real estate development, global tourism, financial services, and industrial production. Through the segregation of various industries and land uses into separate urban developments linked by high-speed, vehicular transportation systems, cities in the United Arab Emirates have used a top-down, modernist, urban planning model to structure and control urban growth. This twentieth-century attitude towards the development of the twenty-first-century city has led to the clumping of many residential districts away from commercial and industrial zones and a reliance on automobile-driven transportation systems fuelled by inexpensive petroleum.

The gleaming towers, expansive shopping malls, multilane highways, and luxury villas of the Gulf region are examples of what urban sociologist Richard Sennett might call a 'closed' urban system. The closed nature of parts of Dubai and similar cities is in part due to the legacy of modernism through the "overdetermination, both of the city's visual forms and its social functions". ${ }^{1}$ These closed systems have been built and are serviced by crews of migrant workers from across the Global South who do not have equal access to the closed city in which they live, given the segregation of the city into autonomous clusters based on programme and social class. Further complicating the urban context of the UAE, workers in the construction and service industries in the UAE and other countries have immigrated over the past decades to find work and careers far from home. The number of workers that have immigrated to the UAE far outnumbers the country's population of permanent citizens. As rapidly developing cities like Dubai are built on industries - real estate, tourism, and finance-driven by global capital, a very large income gap between the wealthy and the working class has subsequently developed, affecting the built form of the city.

As a component of social equality and economic mobility and as a tenant of the modern city in many parts of the world, the accessibility of affordable housing is an issue of growing importance in a country with a large expatriate, working class population. Although developable land is seemingly limitless in the UAE, the demand for comfortable, affordable housing for working class expatriates is significant due to tight governmental control over land policies and a relatively high cost of living in urban centres. ${ }^{2}$ Many working class individuals are forced to live in cramped, corporately owned dormitories or within industrial areas of the city that offer few public amenities or open space. On a positive note, Dubai and other cities in the Gulf region have acknowledged this 
problem and are working on new initiatives to provide better housing for low-income residents. The government of Dubai has recently enacted policies to formally address the socio-economic stratification of income groups and to address the desperate need for affordable housing. ${ }^{3}$

In reaction to the lack of public amenities, open spaces, and space for leisure, the working class residents of the UAE's industrial zones have altered and re-inhabited the fabric of the modern city. In reaction to the rigors of modernist planning, the working class has in effect constructed, developed, and inhabited an informal layer of leisure spaces between factories, in vacant lots, and at the urban periphery of the city.

Presented through the lens of Sennett's definition of urban 'openness', this chapter features a historical and urban overview of the industrial areas in the Emirate of Sharjah as well as design research carried out by an undergraduate architecture studio at the American University of Sharjah. The student work outlines the ways in which the industrial areas have the potential to become models for mixed-use, urban development while maintaining the physical infrastructure of the modernist city. Through site research, including the mapping of new uses for industrial spaces, and with proposals to graft new forms of housing into these zones, student design projects provide compelling, new ideas that address the modernist legacy of the 1980 master plan by Sir William Halcrow \& Partners for Sharjah. The following sections also describe architectural and infrastructural strategies for the transformation of Sharjah's industrial districts into repurposed sites that are able to support a more equitable urban environment based on Sennett's definition of an 'open city'.

\section{Worker demographics and housing}

Given the nature of available work opportunities and of policies prohibiting low-income workers from obtaining sponsorship visas for family reunification in the emirates, a large percentage of this working class is relatively young and male. Male expatriate residents who want to bring their families into the country must earn a minimum monthly salary of 4,000 Emirati dirhams, ${ }^{4}$ preventing many workers from living together with their families. Subsequently, a significant demographic shift towards large percentages of young men working in the emirates has skewed the make-up of residential communities and lifestyles. Tendencies of groups of young men to sublet and subdivide residential housing stock to make it more affordable has led to animosity from local residents and also generally put a strain on housing conditions. ${ }^{5}$

Housing regulations that control where migrant workers may reside have become stricter in recent years. The Emirate of Sharjah, bordering Dubai, is home to many low-income workers who have sought more affordable housing than Dubai has to offer. 
In Sharjah, government agencies have forbidden young, single, working class men, commonly referred to as 'bachelors', from living in family-designated areas. Instead, bachelors are forced to live in industrial areas, surrounded and bound by buildings dedicated to storage, logistics, and manufacturing. ${ }^{6}$ Due to twentiethcentury, modernist-planning ideals, these zones were initially devoid of public amenities or open spaces for recreation based on the fact that they were not planned as residential areas.

\section{Learning from informal development}

The informal occupation of the interstitial and peripheral zones of the rapidly developing, twenty-first-century city by the working class reveals potential for the design of strategic, infrastructural amenities and new forms of affordable housing. This opportunity led to the establishment of an undergraduate, architectural design studio at the American University of Sharjah to further study this urban condition and to provide design proposals for urban interventions to accommodate affordable housing. Methodological site analysis and speculative design work were employed to explore ways in which the industrial districts of Gulf cities can offer viable urban fabric and infrastructure for a more open and equitable society.

The goals of the research and design investigations undertaken relate to what Sennett refers to as the open city: "The cities everyone wants to live in should be clean and safe, possess efficient public services, be supported by a dynamic economy, provide cultural stimulation, and also do their best to heal society's divisions of race, class, and ethnicity". ${ }^{7}$ Design proposals build on the informal, hybrid, and mixed-use nature of Sharjah's industrial districts to propose opportunities that offer an open system of public amenities and social and economic mobility to the residents. In opposition to the typical clearance of old urban districts to create a tabula rasa for new programmes, employed throughout the developing world, the studio sought to keep the built form of the modernist industrial infrastructure in place while working to create new layers of amenity over, under, and in-between buildings.

\section{URBAN DEVELOPMENT IN SHARJAH}

With a land area of 2,590 square kilometres, Sharjah is the third largest emirate in the UAE. It shares borders with Dubai to the south and with Ras Al-Khaimah to the north and wraps around a part of Ajman. Sharjah is a significant manufacturing centre for the country as $40 \%$ of the total number of industries in the UAE are based in Sharjah. A large portion of these companies include petrochemical, textile, leather, and food-production service providers as well as basic, non-metal businesses. ${ }^{8}$ 
According to the Department of Statistics and Community Development in Sharjah's 2015 census, the total population of the emirate is 1.4 million. Expatriates constitute approximately $87 \%$ of the total population; about $79 \%$ of the population is under the age of 30; and more than two-thirds of the expatriate population is male. ${ }^{9}$

The Emirate of Sharjah is zoned into five, major, land-use categories: residential, industrial, commercial, agricultural, and free trade zones. Of these land-use categories, Sharjah's industrial areas are particularly interesting from an urban perspective as they are the most complexly layered in terms of programme and use. While the industrial zones were originally planned with architecture and infrastructure dedicated to warehousing and manufacturing, over time commercial and residential uses as well as informal spaces dedicated to other modes of dwelling, urban agriculture, and recreation emerged organically within them.

\section{Sharjah's industrial zones}

As Sharjah's oil and gas reserves are not as large as those of other emirates or Gulf states such as Abu Dhabi or Bahrain, economic diversification has played a role in the formation of the city. Industrial districts have been in place for decades and were an early part of urban and economic growth in Sharjah since the formation of the UAE in 1971. Large tracts of land were zoned for industrial use which have helped to provide products and resources for a growing city and region. These parcels were inland of the coastal historic centre of Sharjah and positioned along Sharjah's southern border with Dubai.

The industrial zones' position near the Dubai border helps not only to expedite the movement of goods and services to the larger, more rapidly developing emirate to the south but also creates a buffer zone of sorts between the two emirates. Likewise, on the Dubai side of the border, the airport and a mountainous landfill (Dubai's solid waste dumping area) are pushed against the Sharjah municipal boundary.

A pair of twentieth-century master plans for the expansion of Sharjah contributes significantly to the legacy of modernism in the emirate. The 1968 plan by the British civil engineering firm Halcrow \& Partners allowed the urban area concentrated along Sharjah's coast to extend inland in a more rectilinear, increasingly gridded manner. The plan, like many mid-century urban plans across the Western world, emphasized vehicular connections at the expense of traditional neighbourhood fabric. ${ }^{10}$

Over the course of the next decades, Sharjah's rational layout of gridded blocks was furthered as the emirate developed. A subsequent master plan, drawn in 1980 for Sharjah's land use until the year 2000, extended the city's rectilinear urban grid and assigned programmatic uses to the large blocks of land defined by 


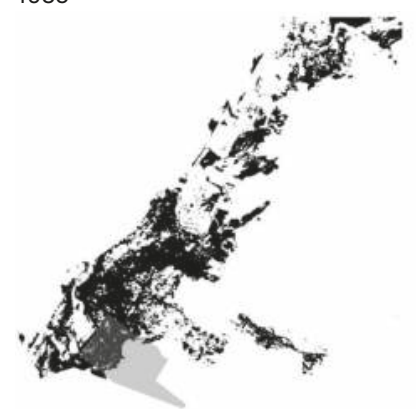

2005

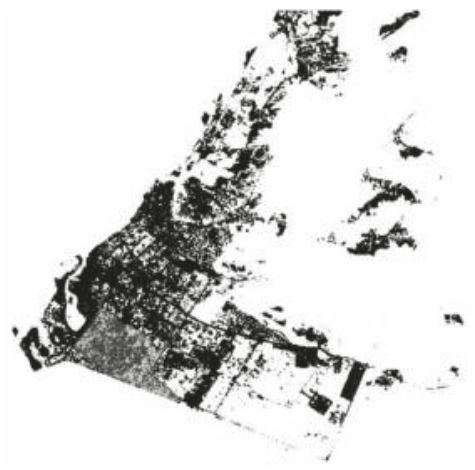

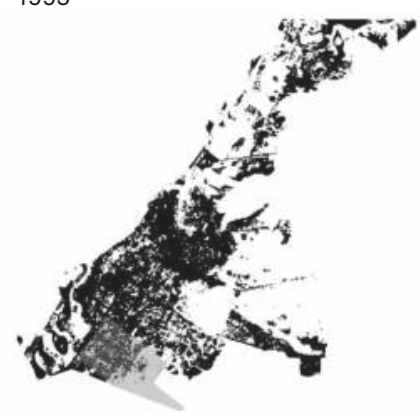

2015

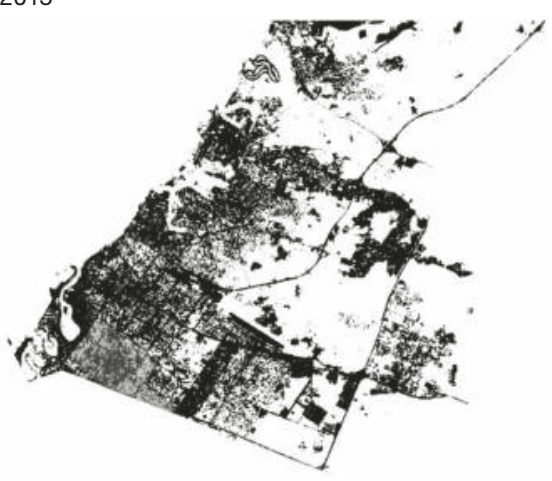

fig.1 Development of the urbanized area of Sharjah in five-year increments from 1985 to 2015 , showing present-day industrial areas enveloped by growing urbanization (Source: Jason Carlow, 2020. Reuse not permitted).

the matrix of vehicular roads. This zoning map identified a series of industrial areas running from the coastline along the border with Dubai towards the southeast. Instead of being pushed out to the periphery of the city, Sharjah's industrial zones were allowed to remain relatively close to the urban centre. The execution of the master plans of 1968 and 1980 has left a significant modernist imprint on the Emirate of Sharjah that not only defined the urban form of the city but also determined the architectural form of the industrial zones.

Given that Sharjah's industrial areas have been an important district for production and dwelling in the city for over forty years, they have been imbued with complex layers of informal infrastructure that other districts - which developed more rapidly or under tighter controls - lack. Workers and their families have built a community within the industrial districts that offers a host of commercial amenities and supports a variety of 
socio-cultural groups. Districts are mixed-use with barbershops and convenience stores nestled between the factories and warehouse buildings. The district is also closely connected to the urban and transportation infrastructure of the city.

According to Sennett, the organic growth of a city is a significant factor in its degree of 'openness' and social, cultural, and economic success. ${ }^{11}$ Because they were not originally designed as residential enclaves and have been somewhat neglected by high-end, Dubai-style redevelopment funded through global capital, Sharjah's industrial zones have grown and developed over a significantly longer time span when compared to other urban neighbourhoods of the UAE. They were not designed and built through top-down methods in a short period of time but have grown, adapted, and evolved slowly.

\section{Industrial zone redevelopment}

Sharjah has begun an initiative to re-establish its industrial zones farther inland, away from the city centre. Sharjah Asset Management, the investment branch of Sharjah's government, announced the launch of a new industrial zone, Al-Sajaa Industrial Oasis, in 2015. The project comprises one of the largest industrial zones in the region and is part of Sharjah's economic diversification masterplan. Located in close proximity to Sharjah International Airport, Emirates Road highway, and Al-Hamriya Port, Al-Sajaa Industrial Oasis will provide 353 building plots on over 130 hectares of land. ${ }^{12}$ In addition to plots for industrial use, Al-Sajaa will also have facilities for worker housing and new amenity hubs provided for workers. An entertainment and shopping centre will be constructed in order to provide retail outlets, banks, and other services for the workers living in the new industrial area. The complex is planned to include leisure facilities and a movie theatre. ${ }^{13}$

The establishment of a new industrial area on the outskirts of the city suggests that the emirate will somehow update the existing production zones. A number of questions are raised by the potential relocation of manufacturing in the city. What kind of industrial or post-industrial legacy should these areas have? Should they be redeveloped, re-zoned, or repurposed?

Industrial zones in other cities have made successful transformations into vibrant urban zones though the re-adaptation of modernist sectors of the city. Buildings in New York City's SoHo district, previously used for textile production, are now repurposed for high-end retail uses and luxury loft apartments. Culver City in Los Angeles County, with industrial lots originally built for aircraft production and film studios, now hosts retail boutiques, art galleries, and restaurants. Even the Al-Quoz industrial zone in Dubai is showing signs of urban transformation with the repurposing of industrial warehouses for indoor children's playgrounds, organic 
supermarkets, and creative industry compounds like Al-Serkal Avenue. With their mixed-use fabric, open-grid street network, and connections to urban centres, Sharjah's existing industrial zones hold much promise for becoming model developments based on the concept of an open city. The largest problems within the zones are the lack of public spaces as well as recreational and institutional support systems to further encourage socioeconomic development.

\section{OPENNESS/CLOSED-NESS}

In his book Building and Dwelling: Ethics for the City, Sennett dedicates a chapter to "Five Open Forms", which are attributes of an open city and therefore resist urban 'brittleness', a quality attributed to many urban designs of the modern era. Through their existing urban fabric and complex layers of occupation and use, Sharjah's industrial districts have the promise of operating much more 'openly' than typical residential and commercial enclaves that have been developing through Dubai-style, top-down planning. Sennett's attributes of open urban forms include the terms "Synchronous", "Punctuated", "Porous", "Incomplete", and "Multiple". ${ }^{14}$ These terms can be used to measure Sharjah's industrial areas' degree of openness to better understand how well the districts perform from social and urban perspectives and where there are still shortcomings to remedy.

\section{Synchronous forms}

In Sennett's description of synchronic urban spaces, "The Bazaar is a synchronic space, while the stadium is a sequential space". ${ }^{15}$ In other words, a better, more open city is one that allows and encourages events to happen spontaneously and simultaneously. Though the industrial districts were zoned in a top-down manner for a singular use, the fact that they accommodate residential and production programmes activates them in ways different than those of other industrial zones. Their occupation over time, the insertion of additional forms of housing, and the evidence of informal economies and leisure activities has converted sequentially planned space into a synchronic environment.

The result is a set of neighbourhoods that have benefitted from the informal layers of commerce and occupation in symbiosis with the production infrastructure of factories and warehouses. Vegetable markets and modest retail outlets line the networks of paved and unpaved streets. Cricket pitches pop up in vacant lots on Fridays, and clusters of used furniture are found in the shade of trees and along alleyways. 


\section{Punctuated forms}

Similar to the way in which urbanist Kevin Lynch theorized about the legibility of urban systems through their form, Sennett uses the metaphor of grammatical punctuation as a way to discuss the importance of strategically placed, urban elements such as street grids, monuments, and even street furniture to add legibility and character to space. ${ }^{16}$ Without unique character, Sennett argues that parts of cities planned with a modernist ideology become indistinct, homogeneous, interchangeable, and therefore "closed". ${ }^{17}$

The lack of 'punctuation' of Sharjah's industrial areas through meaningful monuments, markers, and public spaces is one of the area's shortcomings. Along with the development of parks and leisure facilities at the Al-Sajaa Industrial Oasis on the outskirts of Sharjah, the emirate is planning for the introduction of new, landscaped park spaces in Industrial Zones 3 and $12 .{ }^{18}$ However, in the meantime the districts rely instead on informal means of urban adaptation to imbue the spaces with character and liveability. Adhoc volleyball courts are constructed in empty lots, and secondhand upholstered furniture is gathered together into makeshift, outdoor living rooms in alleyways. Sharjah's informal networks of publicly accessible leisure space that punctuate the interstitial spaces between industrial buildings have the capacity to become a more meaningful network of spaces and perhaps even enrich the grammar behind Sennett's definition of urban punctuation.

\section{Porous forms}

"The closed boundary dominates the modern city". ${ }^{19}$ Sennett proposes that a building or neighbourhood with a flow between the inside and the outside is inherently more open. ${ }^{20}$ In comparing membranes and boundaries, he notes that membranes are more porous and allow material to pass through easily whereas boundaries represent tightly controlled and regulated edges. Sharjah's industrial zones have edges that are mostly porous in that they are not gated or situated in private estates. They are part of an open, street-grid system that allows entry in from every direction. In contrast to the enclaved labour camps in the Muhaisnah district of Dubai, the residential housing within Sharjah's industrial zones is in a programmatically mixed and varied district. An open grid of streets and alleyways designed for the efficient transportation of commercial and industrial goods creates a neighbourhood that is not bound or isolated as an enclave. After decades of urban development during which Sharjah's urban planners extended commercial and residential zones farther inland, Sharjah's industrial zones now occupy a relatively wellsituated, central territory in the overall city. With access to bus lines to Sharjah's city centre and to the Dubai Metro system, the industrial zones are relatively well connected to transportation infrastructure and proximate to developed urban areas. 

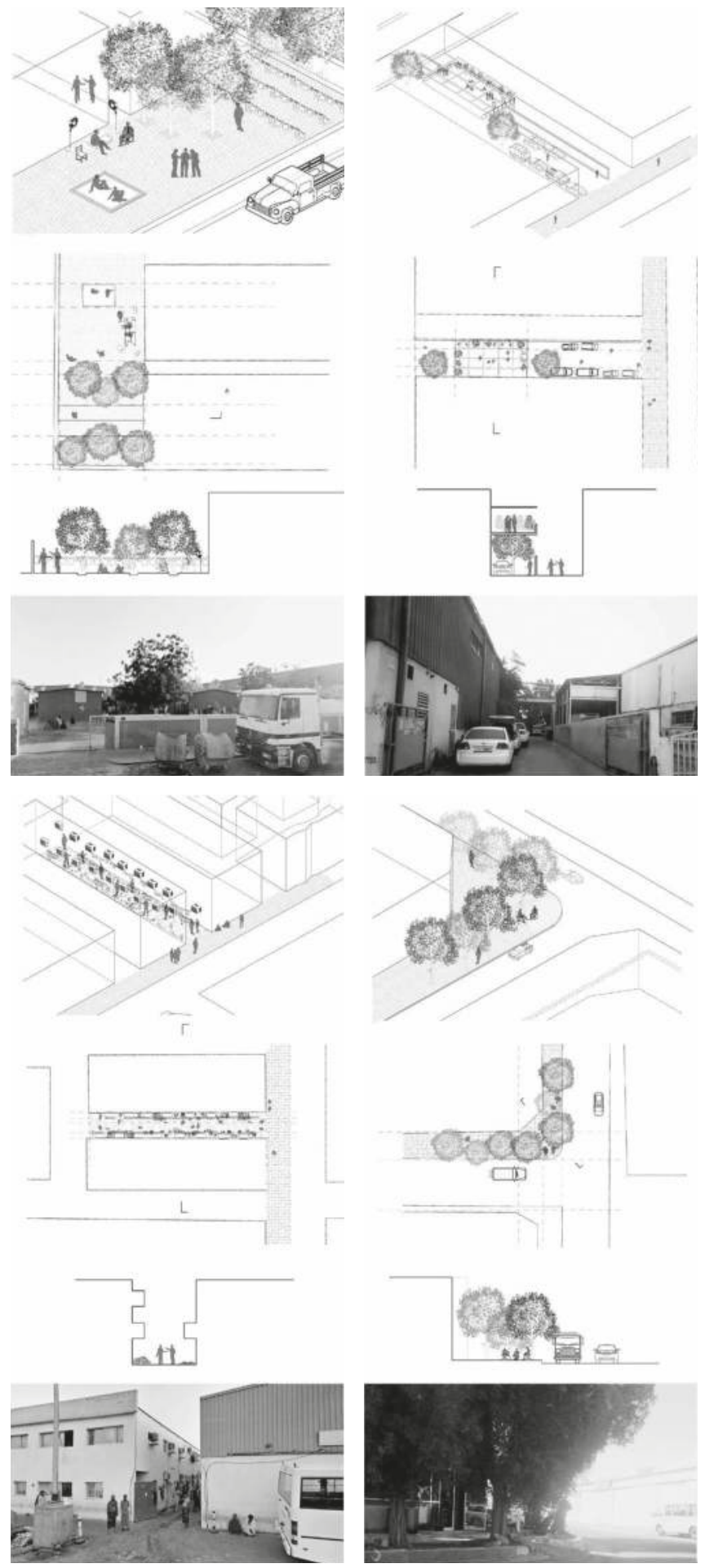

fig.2

Diagrams show informal occupation of spaces between buildings and in empty lots for leisure activities by foreign workers residing in industrial areas. Drawings by Mona Moussalem and Maha Abdelsalam (Source: American University of Sharjah, 2018). 


\section{Incomplete forms}

Sennett praises cities that allow residents to become their own architects, cities that are allowed to adapt and change over time without total reconfiguration or redevelopment. He also refers to a strong "type-form" as a necessary device to create an urban fabric within which to adapt and vary. "A type-form is a piece of urban DNA which takes on different shapes in different circumstances.... In the realm of buildings, the type-form is open to substitutions as well as variations". ${ }^{21}$

Sharjah's industrial areas are largely made up of large warehouse buildings; low-rise housing blocks; linear commercial strips along major roads; and unbuilt lots. Though they may be artefacts of modern, single-use planning, the generic warehouse buildings that cover much of the industrial zones are highly flexible in their potential uses. In the Al-Quoz industrial area of Dubai, there are multiple instances of warehouses repurposed as art galleries, indoor children's play areas, co-working office buildings, and shopping centres. Existing housing stock can be easily adapted from predominantly shared, bachelor apartments to family units or renovated to suit a wider range of residents from more diverse income groups. The unbuilt lots are direct evidence that the districts are incomplete and therefore adaptable to socio-economic changes through the addition of new buildings and open spaces. Sharjah's industrial zones have been incomplete and programmatically flexible for decades and remain ready to take on new forms and uses.

\section{Multiple forms}

The last of the five open forms that Sennett suggests are part of a more liveable and equitable city is multiplicity. That is, instead of grounding urban form on a singular master plan that distributes urban functions and amenities based on relative efficiency, cities should allow for multiple and redundant uses to spring up wherever they are needed. ${ }^{22}$

Sharjah's industrial zones were laid out in the aforementioned 1980 master plan for land use in Sharjah but never internally planned. Despite being demarcated zones, designated for production within the overall city master plan, lots and associated building uses have no overall, top-down logic guiding their internal composition. Developed over time as the city grew, informal economies, social networks, and dwelling patterns have added greater multiplicity to the zones by adding functionality to sub-zones and residential neighbourhoods on an ad-hoc and market-driven basis.

Through the recognition and strengthening of these five aspects of the industrial zones in Sharjah, the districts as hybrid neighbourhoods built on a modernist infrastructure hold much promise to serve as an urban model for new forms of development and to "create the material conditions in which people might thicken and deepen their experience of collective life". ${ }^{23}$ 


\section{EXPERIMENTS IN HOUSING DESIGN}

The research and design work presented in this section has been in a sense triggered by recent governmental efforts to address the problems and challenges of affordable housing in rapidly developing Gulf cities such as Dubai and Sharjah. The work represents an effort to identify key issues in the development of affordable housing for the UAE and presents new housing solutions through design iterations.

As previously mentioned, the urban analysis and design work featured in this section was carried out within the context of an undergraduate design studio in the Department of Architecture at the American University of Sharjah. The studio title - Over, Under, In-between - not only refers to the activation and occupation of space for housing within the city but also to how affordable housing must work above, below, and in spite of socio-economic obstacles within the global culture and local space of industrial production. How can architecture move beyond the mere provision of shelter and allow residents opportunities to advance their livelihoods and improve the overall built environment? The pedagogical goals of the studio are tied to Sennett's definition of the open city. "The cities everyone wants to live in should be clean and safe, possess efficient public services, be supported by a dynamic economy, provide cultural stimulation, and also do their best to heal society's divisions of race, class, and ethnicity". ${ }^{24}$ Design solutions seek opportunities to offer an 'open' system of public amenities to the industrial zones and in turn social and economic mobility to the residents.

\section{Studio context}

The urban contexts chosen for the studio participants to map and investigate were Industrial Areas 10 and 11 in Sharjah, along the border of Dubai. The development of housing prototypes for the 'bachelor class' in this complex site came from various types of urban analysis. Students were encouraged to search the complex industrial zones for dynamic issues based on urbanist Andrea Kahn's theories of the definition of urban sites, namely, that they "are dynamic rather than static, porous rather than contained". ${ }^{25}$ The studio recorded patterns of flows, movement, mass, void, economic exchange, production, and habitation through the invention of analytical maps and diagrams. Students created drawings, diagrams, and maps to represent economic, social, and spatial issues. The identification of these key urban issues aided the definition of more specific, strategic sites for architectural and urban intervention.

\section{Design projects}

In order to grapple with the artefacts of modernist urban planning and activate new types of space within the industrial areas, students developed design projects at the architectural 

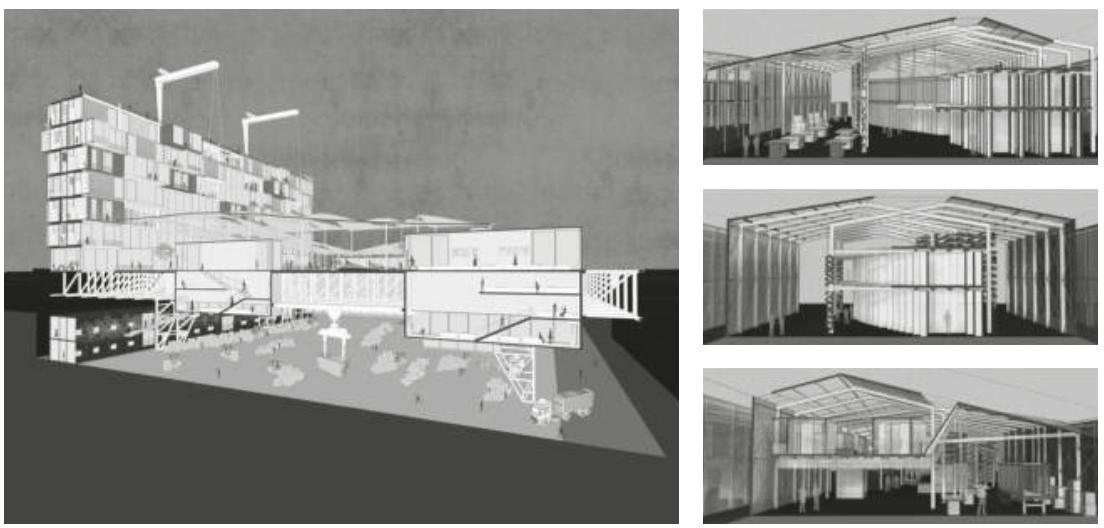

Student projects represent 'typological interventions' in buildings within Sharjah's Industrial Zones. "Reframing Industrial Housing" by Farah Kazali and Joanna Fattal (right) reconfigures the ubiquitous Butler Building frame to hybridize spaces for working and dwelling while the "Elevating Industrial Living" project by Mona Moussalem and Maha Abdelsalam (left) suspends leisure and public open spaces above a factory yard (Source: American University of Sharjah, 2018).

scale to test sites, programmes, and opportunities for affordable housing. New type-forms for living are designed to be flexible in nature and respond to environmental, social, economic, urban, and architectural conditions uncovered in the urban analysis phase of the semester. The projects therefore challenge the singularly programmed, residential-housing types and gated communities of the contemporary Dubai region. Conversely, residential programmes are inserted into and between industrial buildings to create new opportunities for dwelling. Projects with common strategies are categorized and presented in the following sections.

\section{Category 1: Typological interventions}

The first series of projects propose to create new space for housing through additions and alterations to the modernist building types within Sharjah's industrial zones designed for production. Sharjah's industrial areas contain numerous abandoned or unused warehouses. The project by Farah Kazali and Joanna Fattal, titled "Reframing Industrial Housing", o proposes the reconfiguration of a standard, Butler Building, ${ }^{26}$ structural frame to accommodate current and future uses and in so doing introduces possibilities for new economies and changes to the overall urban fabric. The project proposes to interweave indoor and outdoor production zones with residential units. The dwellings could be utilized by both residents of the neighbourhood and workers in the same building. The Butler Building structure is transformed into a site for investigation, enabling residential units to exist over, under, next to, and in-between the frames that support the warehouse. 
The generic nature of the project site and the ubiquitous Butler Building frame allow the proposal to potentially be implemented in any industrial context in the world, thus affording the scheme impact on a global scale. Its flexible design allows for integration with existing or even incomplete Butler Building frames. Structural adjustments to the building frames allow for different spatial configurations which subsequently alter the organization of the interior. Strategic manipulation of the frames yields multiple new building types. The project anticipates future fluctuations in the live/work nature of the site and amplifies the existing conditions within the industrial areas by formally hybridizing production and residential zones in a single building.

The second project in this group, titled "Elevating Industrial Living", was developed by Mona Moussalem and Maha Abdelsalam. - The team's site analysis of the ad hoc leisure spaces built by the migrant workers of Sharjah revealed a need for improved communal spaces for workers within Sharjah's industrial zones. Through the project, the team explored the exploitation of air space above warehouses and factories as a new potential site for dwelling and leisure space. The space directly above and adjacent to an existing building of workers' housing was chosen as a project site.

The project proposes a new, vertical, structural frame that contains affordable housing units with communal spaces suspended above a new factory and production space below. The project provides a mega-structural, cantilevered space frame to house a number of reconfigurable residential units. The reconfigurability of units enables different programmes to be inserted, removed, or adapted according to future programmatic needs. A floating landscape of leisure spaces is visible from the production spaces below, providing a hybrid ecosystem of domestic and work zones through the interpenetration of architectural volumes. With the potential to be reproduced across the UAE's industrial zones, the building type has the capacity to provide local amenity hubs for the large population of expatriate workers.

\section{Category 2: Dwelling with industrial artefacts}

Sharjah's industrial areas are characterized by clusters of empty lots, warehouse buildings, and housing facilities mixed together with an array of commercial outlets and informal social spaces. Bishoy R. Girgis and Nermin Sherif Hegazy's "Mechanized fig.4 Urbanism" project investigates the capacity of a community to be formed by the large-scale equipment found around typical industrial zones. The proposal seeks to develop a reconfigurable building prototype that combines the site's three programmes of production, housing, and leisure in a setting where they can coexist and function in a dynamic network. Like shipping containers at a port, the various modular components of the project can be 

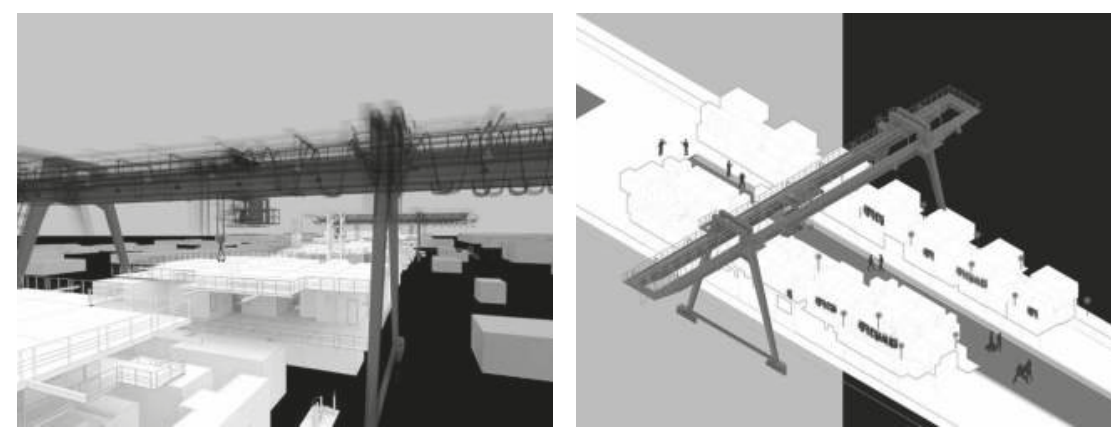

A community formed and adapted by a production-line gantry by Bishoy R. Girgis and Nermin Sherif Hegazy. Incorporating machinery like the gantry as an organizer of social space and provider of services makes it a socioeconomic asset to the entire area (Source: American University of Sharjah, 2018).

mechanically configured by the residents to create adaptive combinations of housing, production, and amenity. Like many of the projects in the studio, the proposal challenges the separation of dwelling and production in the city and instead combines living with working together in a prototypical community. The appropriation of machinery like the gantry by the workers themselves transforms industrial capital into an instrument capable of organizing of social space and providing services. Equipment dedicated to industrialist production by day becomes a socioeconomic asset to the entire community in off-hours.

\section{Category 3: Appropriating vehicular infrastructure}

Two student teams developed proposals that seek to activate surplus space at the fringes of vehicular infrastructure. The teams found inspiration in precedent projects such as Le Corbusier's Plan Obus for Algiers with linear housing blocks running under a highway and Paul Rudolph's Lower Manhattan Expressway proposal for a new city built around a motorway. Azmiha Raza and Misbah Baig's project, titled "Median Strip", proposes to build a linear, multifunctional building above a roadtraffic, divider line within Sharjah's industrial zones. The project piggybacks affordable housing on a vocational training institution to provide local workers with improved access to educational opportunities. This new institution, hovering above vehicular infrastructure, would provide the community with improved socioeconomic mobility. Students sought to create opportunities to attract and sustain a diverse international workforce in the UAE by introducing a training campus in the industrial area. The institution could also function as a space for leisure, informal economic activity, and communal gathering for workers in the area. The ribbon-like building complex is designed with the potential to 

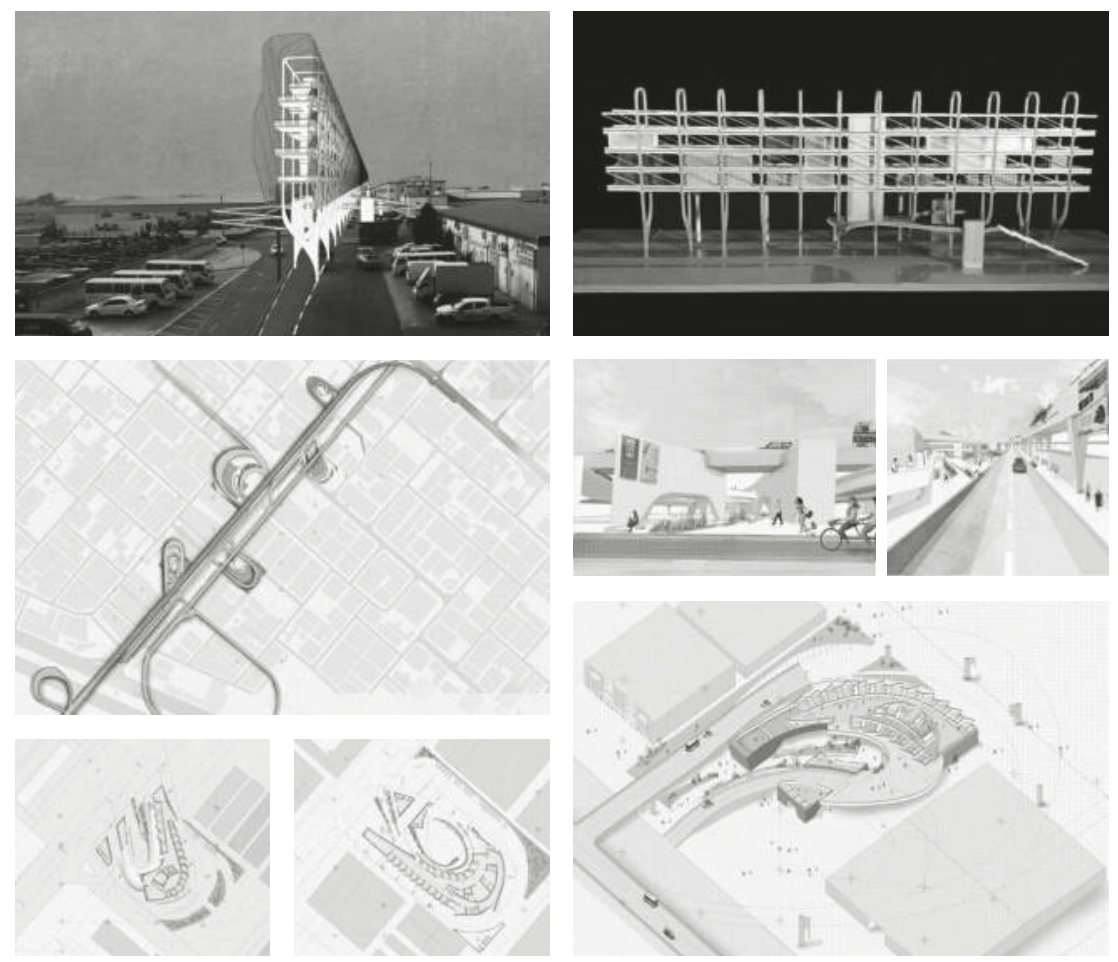

fig.5

Design proposals appropriate vehicular infrastructure. "Median Strip" by Azmiha Raza and Misbah Baig (above) proposes a multi-functional linear building above the roadway median strip in Sharjah's industrial zones. The "Urban Loop Holes" project by Jumanah Abbas and Sarah Al-Adayleh (below) introduces a new strand of vehicular infrastructure to better connect Sharjah with Dubai (Source: American University of Sharjah, 2018).

fig.5

expand and grow along the vehicular infrastructure of the industrial zones while contributing to the growth of Sharjah's economy by creating a stronger and more educationally advanced workforce.

Based on a critical urban analysis of Sharjah's industrial zones, the "Urban Loop Holes" project by Jumanah Abbas and Sarah Al-Adayleh 0 is a proposal for greater symbiosis between architecture and infrastructure, specifically focused on mobility for vehicles and socio-economic mobility for workers. By integrating affordable housing and public amenities within elevated roadways and looping on- and off-ramps, the project not only improves vehicular mobility between Sharjah and Dubai but also uses a large-scale investment in highways as a platform to offset the cost of social infrastructure. By elevating existing roadways and embedding the curved off-ramps into new buildings on empty lots, the project is able to reclaim the existing ground level as public space. Situated above, below, or adjacent to the roadways, the architectural geometry and building typology of housing is 
adapted to the curvature of the highway off-ramps. Considering the project at a global scale, "Urban Loop Holes" provides a new design methodology to integrate architecture with vehicular infrastructure that could be deployed in similar urban conditions across the world.

\section{Category 4: Anticipating future economies}

The students responsible for designing this series of projects made predictions about the social and economic development of Sharjah, Dubai, and the Gulf region. Beyond the mapping of urban form, projects used publicly accessible governmental policies, newspaper articles, and white papers concerning the growth of the UAE as research material to shape their proposals. The subsequent projects investigate how speculative planning for the future needs of a city might consider the spatial side effects of industrial automation or global tourism as drivers of urban development.

"Housing Mass Tourism", by Shaimaa Mostafa Genidy, was developed in response to one of Sharjah's strategies for economic development and global recognition to attract more than ten million tourists per year. The project proposes to introduce a series of thick parking platforms as a support system for the growing tourism industry. The platforms would be strategically placed adjacent to existing and future sightseeing routes for a new fleet of tour buses. An elevated datum of parking decks, built for housing the vehicular by-products of mass tourism, would hover above the industrial landscape and would double as a host for affordable housing and public amenities. The 500-metre-long, corrugated structures - inspired by the typical cross section of pre-cast concrete, vehicular viaducts - merge infrastructure and habitation, parking and housing, as well as vehicles and people through varying the profile of the folded structural slabs. Folded surfaces serve to create inhabitable spaces with seamlessly integrated floor, wall, and roof planes. The project creates spaces that accommodate different types of functions, ranging from small housing units to communal dining rooms, from landscaped parks to decks for bus parking and cricket matches.

Tasnim Al-Tinawi and Uthra Varghese's project, "AgriIndustrial Housing", explores a radical layering of food-production systems and affordable housing within an industrial site. The project is inspired by the fact that many expatriate inhabitants of Sharjah's industrial districts supplement their income and diet by growing vegetables and raising livestock between factory buildings. The formalization of these various programmes at a larger scale has the potential to create a new urban environment that combines space for housing and leisure with urban farming, storage, and distribution. New, elevated, residential dwelling units are situated within large, structural space frames along the edges of an existing 

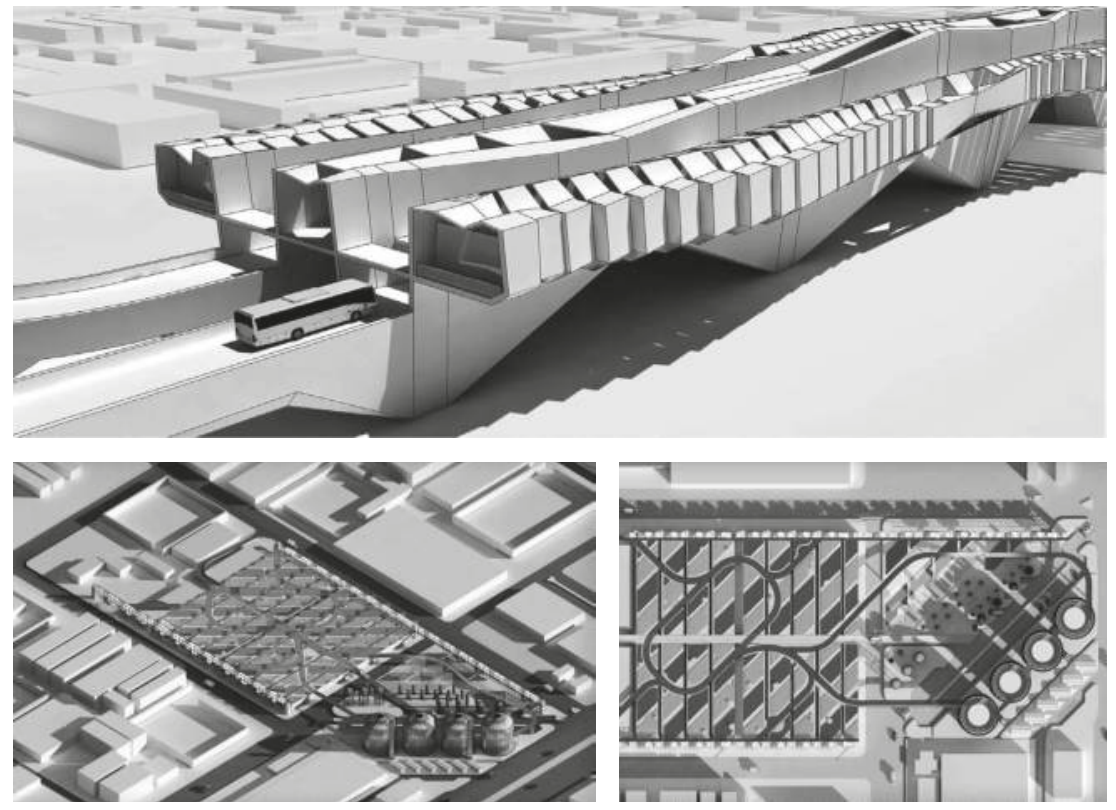

fig.6 Projects anticipate future economies within Sharjah's industrial zones. "Housing Mass Tourism" by Shaimaa Mostafa Genidy (above) proposes integrating housing and public spaces with elevated parking decks for tourist buses. "Agri-Industrial Housing" by Tasnim Al-Tinawi and Uthra Varghese (below) proposes rooftop farming, leisure zones, and market spaces layered on top of existing worker housing, with new market housing at the periphery (Source: American University of Sharjah, 2018).

worker-housing complex. The new community is positioned at the periphery of a new layer of rooftop farms. Units provide unexpected views that offer residents a green zone of pastoral respite from the industrial nature of the surrounding districts. Through a relatively straightforward, architectural intervention, the project seeks to elevate the socio-economic mobility of the residents by creating an independent agricultural industry where the working class can farm their own food and sell their produce in the marketplace. The proposal for providing urban farming on the rooftops of existing buildings aims to create an amenity that can be later incorporated in other housing areas on site.

\section{CONCLUSIONS}

The industrial districts of cities like Sharjah present an interesting opportunity in the development of open, more equitable cities in the Gulf region. Originally planned as single-use zones for manufacturing and production during the modernization of Sharjah, through the addition of layers of corporate and informal 
dwellings they have grown into dynamic, mixed-use urban districts brimming with culture and activity. Over the decades of economic development in the UAE, the population of working class residents has grown dramatically in Sharjah. Measures to restrict working class bachelors from living in residential areas has further burgeoned industrial zone populations through shared, market-rate apartments and informal dwellings. Somewhat ironically, the regulatory effort to remove working class labourers from higher-class residential areas and to isolate bachelors within the fixed boundary of the industrial zones of the city has led to the creation of an 'open' and fluid urban fabric in the districts. In contrast with the urban character of Dubai's labour camp neighbourhoods, Sharjah's industrial zones provide a richer, more diverse urban context.

The speculative design proposals presented here as new prototypes for affordable housing are based largely on augmenting the positive urban aspects of Sharjah's manufacturing districts. Studio projects aim to transcend typical housing types and topdown, neighbourhood planning strategies often employed in the Gulf region by responding more thoughtfully to the existing social, economic, environmental, temporal, urban, and architectural conditions in Sharjah. The work in the form of speculative design contends that only by amplifying the scope and vision of housing to the scale of urban and regional infrastructure can architecture begin to provide public amenity and social mobility to affect flows of people and capital. Only through envisioning architecture at larger scales and across longer spans of time can architects and urban designers start to foster a trend towards openness and to formulate strategies for the repurposing of the modernist cities of the Gulf.

\footnotetext{
Acknowledgements

The author would like to acknowledge the work of the participating students in the ARC502 studio, Over, Under, In-between: Affordable Housing for Sharjah. Thanks to Jumanah Abbas, Bishoy R. Girgis, Maha Abdelsalam, Tasnim Al-Tinawi, Sarah Al-Adayleh, Pooja Annamaneni, Omar Badran, Amine El Kaddouri, Joanna Fattal, Shaimaa Genidy, Nermin Hegazy, Misbah Shehreen, Hidayathullah Baig, Farrah Kazali, Mona Moussalem, Azmiha Raza, and Uthra Varghese for their hard work and their development of important new ideas for the future of housing in the region. Thanks to Nermin Hegazy and Alaa Elsheikh for developing new maps and providing research assistance for the development of this chapter and larger research project.
} 


\section{Notes}

1 Richard Sennett, "The Open City", in Towards an Urban Age (London: Cities Programme The London School of Economics and Political Science, 2006), accessed October 17, 2020, http:// v0.urban-age.net/0_downloads/UA Summit_Berlin_Newspaper.pdf, 6. 2 Jason F. Carlow, "Over, Under, In-Between: Worker Housing within an Industrial Ecology", in Conference Proceedings, ACSA 2018 International Conference: New Instrumentalities (Washington, DC, Association of Collegiate Schools of Architecture, Forthcoming).

3 "Dubai's Housing Policy for LowIncome People", Gulf News, March 13, 2017, https://gulfnews.com/opinion/ editorials/dubai-s-housing-policy-forlow-income-people-1.1993181.

4 "Sponsoring Residency Visa by Expatriates", The United Arab Emirates' Government Portal, accessed July 23, 2018, https://www.government.ae/ en/information-and-services/visa-andemirates-id/sponsoring-residencyvisa-by-expatriates.

5 Afkar Abdullah, "Sharjah Wants Bachelors Out of Residential Areas", Khaleej Times, October 30, 2017, https://www.khaleejtimes.com/nation/ sharjah/sharjah-wants-bachelors-outof-residential-areas-.

6 Afkar Abdullah, "Leave Family Areas, Sharjah tells Bachelors", Khaleej Times, October 30, 2017, 6.

7 Sennett, "The Open City", 1.

8 "Overview of Sharjah", Sharjah Airport International Free Zone Authority, accessed May 24, 2019, http://www.saifzone.com/en/About/Pages/Sharjah.aspx. 9 "About Sharjah", The United Arab Emirates' Government Portal, accessed May 14, 2019, https://www.government.ae/ en/about-the-uae/the-seven-emirates/ sharjah.

10 Hassan Radoine, "Sharjah, UAE", in Architecture and Globalisation in the Persian Gulf Region, eds. Murray Fraser and Nasser Golzari (London: Routledge, 2016), 201.

11 Richard Sennett, "The Open City", 6.

12 Mary Sophia, "Sharjah Launches New 14 Million sq ft Industrial Zone", Gulf Business, October 22, 2015, https:// gulfbusiness.com/sharjah-launches-new14-million-sq-ft-industrial-zone/. 13 "New Recreation Parks Part of Efforts to Raise Labour Standards", Sharjah Update, October 26, 2016, accessed May 20, 2019, http://www.sharjahupdate.com/ 2016/10/new-recreation-parks-part-ofefforts-to-raise-labour-standards/.
14 Richard Sennett, Building and Dwelling: Ethics for the City (New York: Farrar, Straus and Giroux, 2018), 207.

15 Ibid., 207.

16 Ibid., 213.

17 Ibid., 213.

18 "New Recreation Parks", Sharjah Update.

19 Sennett, Building and Dwelling, 220.

20 Ibid., 218.

21 lbid., 231-232.

22 Ibid., 236.

23 Ibid., 241.

24 Richard Sennett, "The Open City", 6.

25 Andrea Kahn, "Defining Urban

Sites", in Site Matters: Design Concepts, Histories and Strategies, eds. Carol Burns and Andrea Kahn (London: Routledge. 2005), 286.

26 The term 'Butler Building' is a brand name for a building system developed by the Butler Manufacturing Company. The term refers to the generic, long span, rigid metal buildings typically used for warehouses and factory buildings. 
PART II 


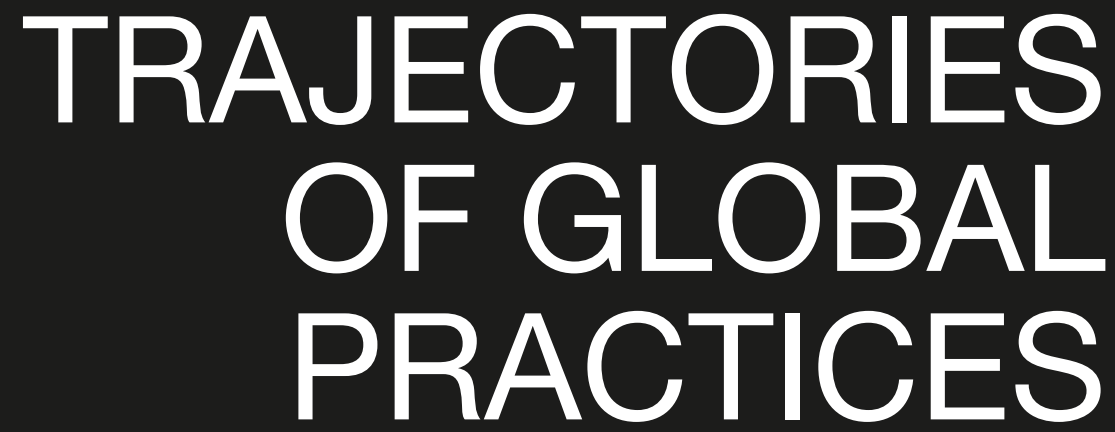




\section{BUILDING IDENTITIES Transnational exchange and the authorship of modern Gulf heritage}

Michael Kubo 
Among the discursive dichotomies that have governed interpretations of the architecture of Gulf cities over the last half century - constructs like tradition versus modernity, universality versus identity, and image versus 'authenticity' - the binary of 'local' and 'foreign' has served as a uniquely persistent trope. This has been especially true for the built legacy of urban modernization programmes after the 1960s, which often brought international firms based in the USA and Europe into the building economies of the Gulf for the first time. These exchanges reached their peak during the boom in crude oil prices from 1973 to 1983 as a direct corollary to the economic constraints these firms suffered in their domestic practices 'at home', a period in which US-based firms in particular were heavily involved in pursuing and developing commissions throughout the region. Paradoxically, post-colonial critiques of such work as alien (at best) or Orientalizing (at worst) insertions into the local context have often served to preclude a more detailed account of the sustained, reciprocal influence between local consultants and engineers, team-based foreign design practices, and the transforming economies of the Gulf states.

Despite the complex history of these large-scale commissions, which were typically produced through transnational networks of designers, clients, builders, and laborers, the localforeign trope assumes that the design signatures of such buildings can be definitively assigned, based on the primary figures, or authors, whose names are (or can be) attached to their creation. This binary further assumes that such presumptive authors can themselves be easily labelled as 'local' or 'foreign', via classifications that are often based on simplistic assumptions of national or cultural identity alone, regardless of where a building's protagonists were trained; with whom or for whom they practiced; where, within which discourses; and through which networks of actors, among other complicating factors of history, geography, and relation. In this sense, a central stake in recent discussions of modern architectural heritage in Gulf cities has been the difficult question of authorship that surrounds many significant buildings of the 1960s and 1970s.

Inevitably, these assumptions can lead to simplifications and omissions of cultural history that complicate and obscure, rather than enable, more nuanced discussions of heritage in relation to modern architecture in the Gulf. As Sultan Sooud Al-Qassemi and Roberto Fabbri note in their call to assess the modern heritage of Gulf cities, many major landmarks of urban and social transformation in the region over the last half century have been "blamed for allegedly superimposing foreign narratives to local customs", with the result that "people and institutions have demonstrated disaffection and a low sense of belonging to the 1960s-1970s city". ${ }^{1}$ In these arguments, the presumed foreignness of such works is tied to a dismissal of their value as deviations 
from truer or more 'native' cultural expressions, with which a city's inhabitants might have a more natural affinity, and which would thus be regarded as exemplars of modern heritage more worthy of preservation. In particular, the theoretical framework of 'critical regionalism' - in which a supposedly universalizing and uncritical modernism is seen to demand forms of resistance only possible from local architects rooted in more 'authentic' regional cultures - has often served to obscure a more detailed account of the reciprocal influences between locally based consultants and engineers, international design firms, and the networks of material, labour, and expertise through which much of the post-war urbanization of Gulf cities took shape. ${ }^{2}$ In what follows, I argue that this failure to accurately historicize such transnational practices in the Gulf has erased precisely those questions of exchange that would allow a fuller discussion of heritage around built works of this period and expand what we can mean by 'local' cultural significance.

\section{Local constructs}

To gain a sense of the performance of the local-foreign binary within discussions of authorship in Gulf modernism, we might look to a recent article on urban heritage by Yasser Elsheshtawy, "We Need to Talk about the Modernism Fetish in the Gulf", that exemplifies the operation of this mode of argument. ${ }^{3}$ As one of the most prominent voices on urban heritage in Gulf cities, in this article Elsheshtawy frames his opposition to the indiscriminate "fetishization" of modern architecture from the second half of the twentieth century, implicitly led by a foreign "modernist brigade" that values these buildings for their aesthetics only rather than for their deeper connections to place or local identity. ${ }^{4} \mathrm{His}$ primary example of this phenomenon is the Abu Dhabi Central Bus Terminal (1989), designed by Bulgarproject, a Bulgarian state design and construction firm that was responsible for hundreds of projects throughout the Middle East and Africa during the Cold War. $\Delta$ Elsheshtawy claims that, in the eyes of outside observers, the bus terminal "has acquired ... a kind of respect and reverence usually associated with Gothic cathedrals", whereas in his view the building lacks a meaningful connection to the life of the city.

Elsheshtawy's narrative is pervaded by his account of his participation in a conference in New York on Abu Dhabi's modern architecture and - in his retelling - his heroic stand in the face of an imported or alien modernist dogma from outside, or what he describes as "an angry mob" of preservationists that would seek to keep these buildings at any cost. He takes notable care to highlight the "gasp from the audience" that followed his sanctioning of the demolition of the bus terminal, or to claim that only a single person, "in a face-to-face conversation after the event ... praised [his] bravery for refusing to turn the city into some sort of fossilised version of itself". ${ }^{5}$ 


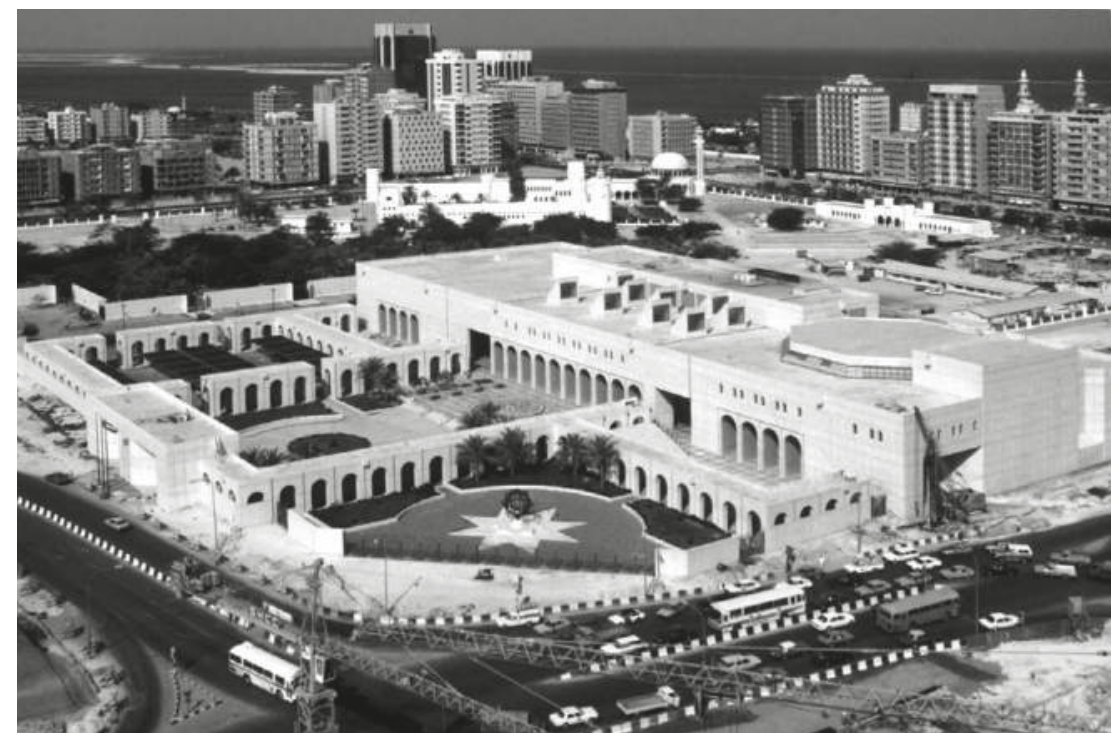

fig.1 The Architects Collaborative, Cultural Foundation - Abu Dhabi National Library and Cultural Centre, 1974-1979, and Qasr Al-Hosn at upper left (Source: Aga Khan Trust for Culture, courtesy of the architect, 1985. Reuse not permitted).

What is crucial in Elsheshtawy's account is the foreignness of the building's Bulgarian architects and, by implication, the foreignness of both the building and those who would presume to judge its architectural value in the present. In contrast, he advocates for paying more attention to more prosaic, less iconic structures, such as Abu Dhabi's gas stations, for their more meaningful connections to the life of the city rather than as exemplars of stylistic categories imported, in his view, from outside. Such buildings, he claims, belong more authentically to "an Emirati Vernacular ... rather than a top down version of an expatriate architect's fantasy about what constitutes Emirati identity". ${ }^{6}$

As a counter to the ways in which the binary judgment of local and foreign plays into this sort of narrative, we can compare the rather different appearance within Elsheshtawy's argument of another building: the Abu Dhabi National Library and Cultural fig.1 Centre, or the Cultural Foundation, as it is known today. Located on a culturally charged site directly adjacent to Qasr Al-Hosn, the Cultural Foundation was recently restored and reopened to the public in 2018 as a beloved cultural monument but only after surviving years of neglect, closure, and the threat of demolition to make way for the redevelopment of the site.

The Cultural Foundation was designed between 1974 and 1981 by The Architects Collaborative (TAC), based in Cambridge, Massachusetts, with branch offices in Kuwait and Rome. TAC 
was a key actor in modernization and nation-building efforts in Iraq, Kuwait, the United Arab Emirates, and Saudi Arabia among other Gulf states after the late 1950s. Yet despite the ostensible foreignness of its architects and unlike the bus terminal whose demolition he favours, Elsheshtawy fully supports the preservation of the Cultural Foundation, which he describes as a modern structure that was "not simply an object to be acquired ... [but rather] performed a significant role in the life of the city". ${ }^{7}$

A subtle construction of authorship underlies these differing assessments. While the bus terminal is dismissed as an alien insertion, designed by Bulgarian expats, the Cultural Foundation, Elsheshtawy tells us, was designed not by TAC, a US firm, but rather by a 'local' to the Gulf, even if not directly to the Emirates: namely, in his words, by "Iraqi architect Hisham Ashkouri, who was a part of TAC". In other words, in this argument the Cultural Foundation can lay a plausible claim to the city's modern heritage in part because it was seen to be authored by a 'local' architect, thus sanctioning its modernism and thereby making the building available to be counted as part of an Emirati "modern vernacular". ${ }^{8}$

I dwell on Elsheshtawy's article not to contest his argument about what should or not be preserved - I am equally in favour of preserving the gas stations, bus terminal, and Cultural Foundation as important elements of Abu Dhabi's modern heritage - but to point to the ways in which the binary judgment of local and foreign plays into such contested questions of authorship. In fact, the history of the Foundation's design is more complex than would be suggested by the claim that Ashkouri was the building's author or by the use of this claim to boost arguments for the building as an example of 'local' heritage. The design competition for the Cultural Foundation began in 1973, a year in which Ashkouri worked at TAC in between finishing his master of architecture at the University of Pennsylvania (1973) and a master in urban design at Harvard (1975). The previous year, Ashkouri had left the office of Hisham Munir (TAC's long-time collaborator on projects in Iraq), and Munir later claimed that he implored TAC to hire the young Ashkouri, as a student in need of work in order to continue his studies in the USA. ${ }^{9}$

The competition entry that was presented in Abu Dhabi the following year was a highly articulated composition of three volumes containing the library, exhibition space, and theatre, arranged in a trefoil (or three-leaf clover) pattern around a shared entry court in the northern quadrant of the Qasr Al-Hosn site. Two of these three volumes (likely those containing the auditorium and exhibition space) were designed as quatrefoils in turn, each with one longer bar of programme connected to three shorter ones around a central crossing in plan. The TAC job files do not record Ashkouri's specific role on this scheme among others in the office who worked on the project, including Basil Hassan, another Iraqi expatriate and a job captain for many of TAC's projects in Kuwait 
by 1973. Nor do his initials appear on any of the drawing sets I have been able to find, a fact that leaves unsettled the question of his role within the competition team. ${ }^{10}$ In any case, Ashkouri was at the time a new employee working under an experienced senior architect, Perry K. Neubauer, who operated in turn under the direction of Louis McMillen, the partner-in-charge for much of TAC's extensive work in the Gulf states after the firm's commission to design the University of Baghdad in 1957.

Of more significance for the question of authorship is the fact that the competition version of the project bears little relationship to the design that was ultimately built after TAC won the commission in 1974. According to Neubauer, the client's first statement to TAC following the competition was that the master plan would have to be changed completely since it gave the unavoidable impression of a Latin cross, a connotation that was evidently unacceptable for the project. ${ }^{11}$ Under the direction of McMillen and Herbert Gallagher as partners-in-charge, Neubauer and lead designer Michael Gebhart produced an entirely new scheme, organizing the three programmes of library, exhibition space, and auditorium in a single block, relocated to the eastern corner of the site. Each of the three main programmes occupied roughly a third of this rectangular volume, with an arcaded entry court leading to a central exhibition space flanked by the library to the left and a free-standing, octagonal auditorium to the right.

Neubauer credits Gebhart with both the decision to consolidate the programme into a single bar and with the idea of introducing a diagonal slice in the plan that frames a direct view of the Qasr Al-Hosn tower and serves as an orienting device through the library portion of the block. ${ }^{12}$ Gebhart produced dramatic renderings of this second scheme that were presented to the client in 1975, showing a long, horizontal volume with stacked decks under a projecting frame. Neubauer argues that it was McMillen who insisted on the introduction of semicircular arches into the building's exterior expression, an interest that extended from his work on the University of Baghdad through the firm's numerous projects in Kuwait after 1968. ${ }^{13}$ The building's exterior was later simplified even further to form a largely monolithic concrete volume, animated by a monumental arcade and punctuated by narrow openings topped with semicircular arches.

By the time of this second scheme for the Cultural Foundation, Ashkouri had already left TAC to pursue his postgraduate studies at the Harvard Graduate School of Design. Though he later dismissed TAC's redesign as "essentially about the exterior expression" rather than a more fundamental reconception, Neubauer has characterized the second scheme more accurately as "essentially a brand-new design", with a new location and site plan, a different layout and exterior massing, and a conceptually distinct interior organization focused on views to Qasr Al-Hosn. ${ }^{14}$ 


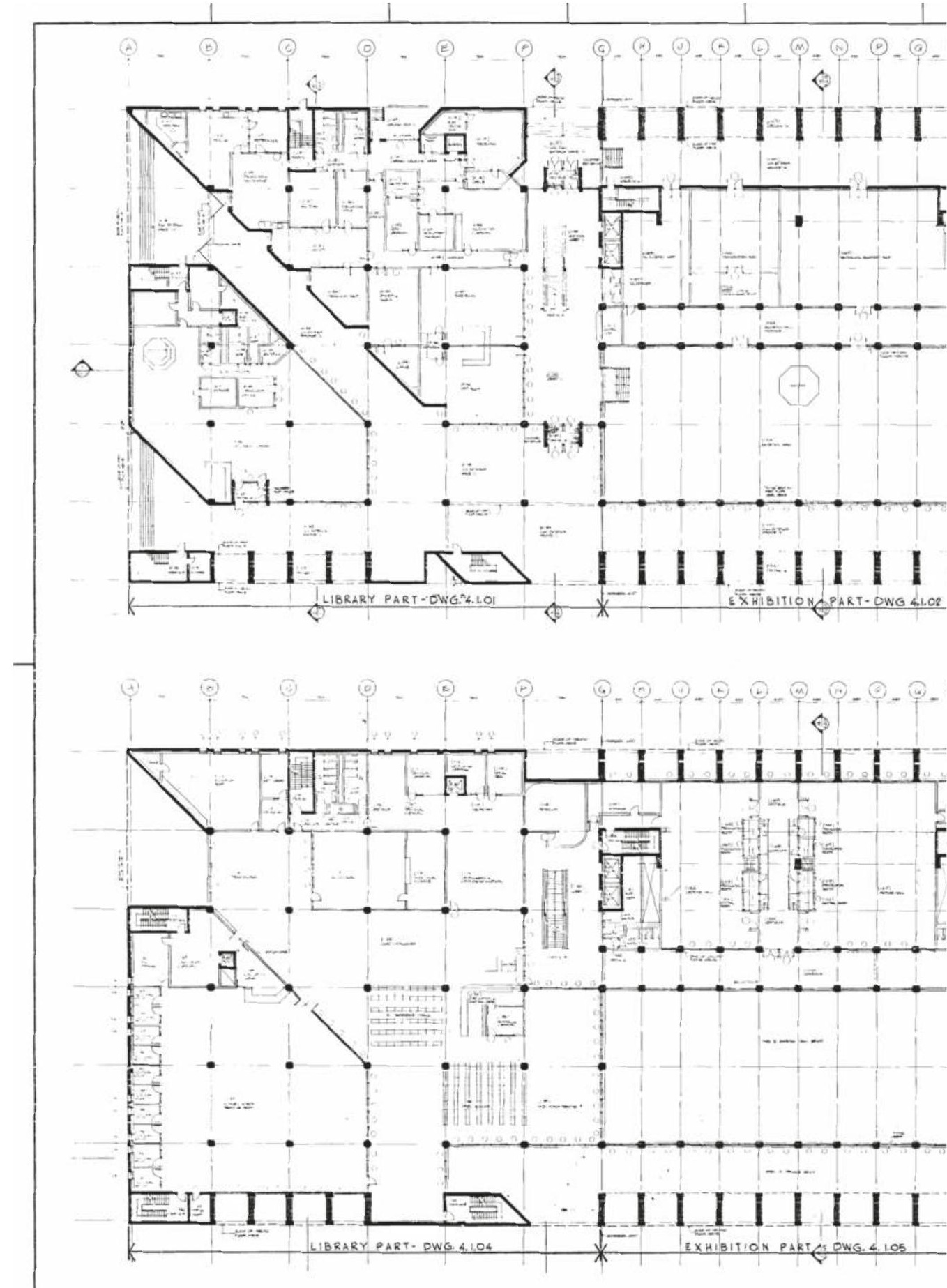




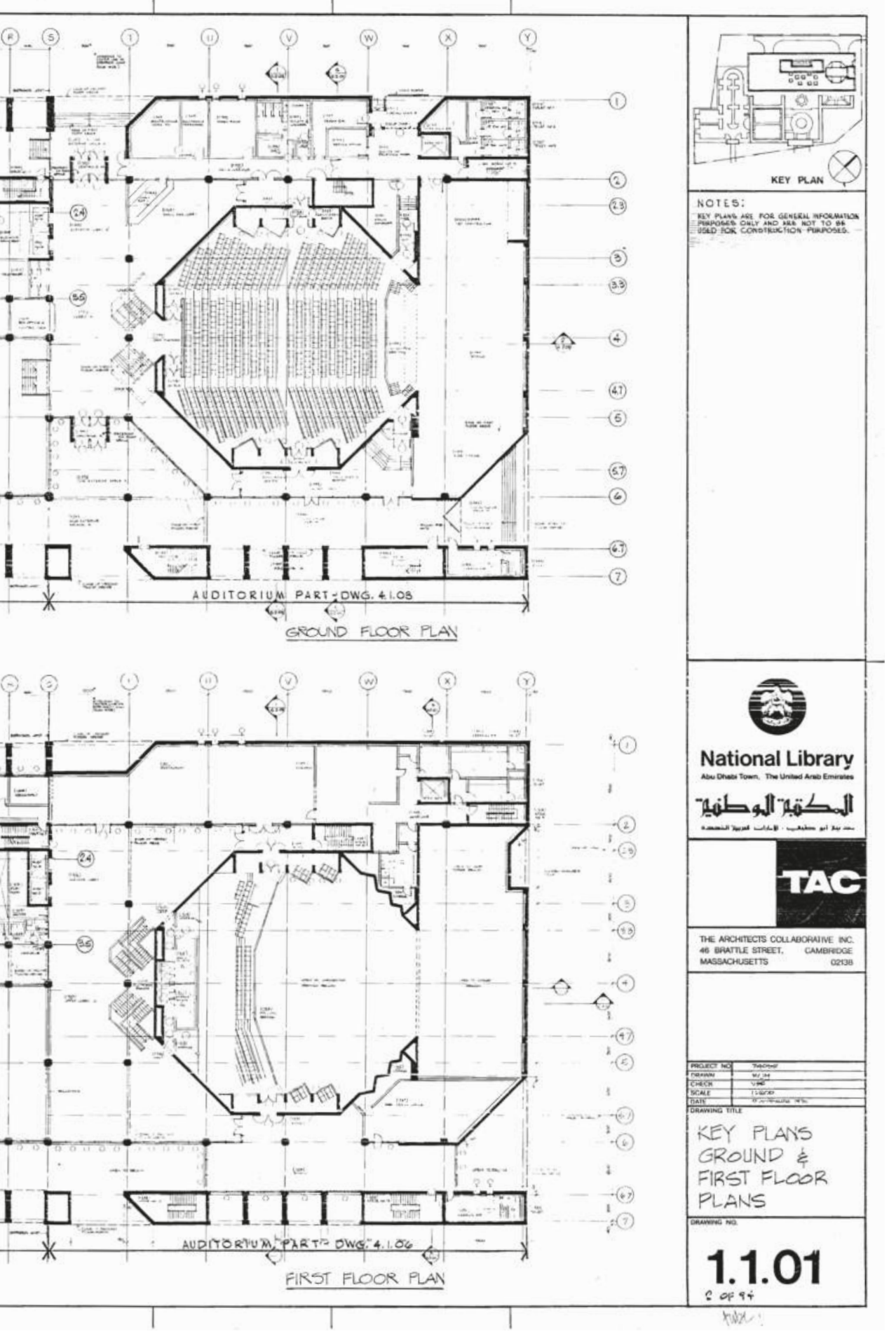


By the time Ashkouri returned to TAC around 1975, the development of this second scheme was well underway, directed by Neubauer (who personally assisted on various detail drawings of Arabesque light fixtures and other key functional elements that doubled as references to traditional Islamic architecture) and including Gebhart and Hassan among other team members. While Ashkouri may have additionally claimed that Louis McMillen tasked him upon his return to TAC with redesigning the Abu Dhabi scheme again "in keeping with Islamic ideas and principles", there is little evidence to support this idea. ${ }^{15}$

In light of this more detailed excavation of the Cultural Foundation's design, it becomes clear that its status as an Emirati building designed by a 'local' architect has rested almost entirely on claims made by Ashkouri in order to promote himself as the building's singular author, an argument that stands largely in contrast to the available evidence. This image of authorship has been propagated uncritically in turn in the popular press and in extant accounts of modern architecture in the Gulf. Ashkouri's argument, by simplifying the public version of this history, cannily exploits the dynamics of the local-foreign dichotomy as a means to claim sole credit for the conception of the Cultural Foundation, while critics and historians alike have been only too content to accept such claims in order to reinforce the sense of the Cultural Foundation as a 'locally' designed building within current heritage debates.

By this point, it should be clear that the simplistic dichotomy of local and foreign precludes the ambiguities of authorship through which the material reality of the Cultural Foundation took shape. Nor can these categories allow us to capture the broader production networks and forms of exchange through which such buildings were produced in these decades. In the case of the Cultural Foundation, these included the difficulties of adapting US construction protocols in concrete to the hot climate of the Gulf, for which locally specific techniques for cooling had to be developed in conjunction with Korean contractors - in some cases employing Koreans who were completing their national military service by working on building projects in the UAE. ${ }^{16} \mathrm{~A}$ thorough history of these dynamics would also encompass the cultural history of the materials that make up the building's concrete, including aggregate mined in Ras Al-Khaimah, created through state changes in land-tenure arrangements that displaced communities of tenant farmers there in favour of industrial sites for gravel extraction. ${ }^{17}$ So too, it would attempt to account for the role of other actors in the building's creation like Dr. Ezzeddin Ibrahim, a trusted advisor to Sheikh Zayed; of Egyptian origin, Ibrahim co-founded the Abu Dhabi Documentation and Research Centre (later the National Archives) and established the Cultural Foundation as an institution, and Neubauer credited him as a 'guiding light' in the development of TAC's design. ${ }^{18}$ All of this suggests that we could use the social 


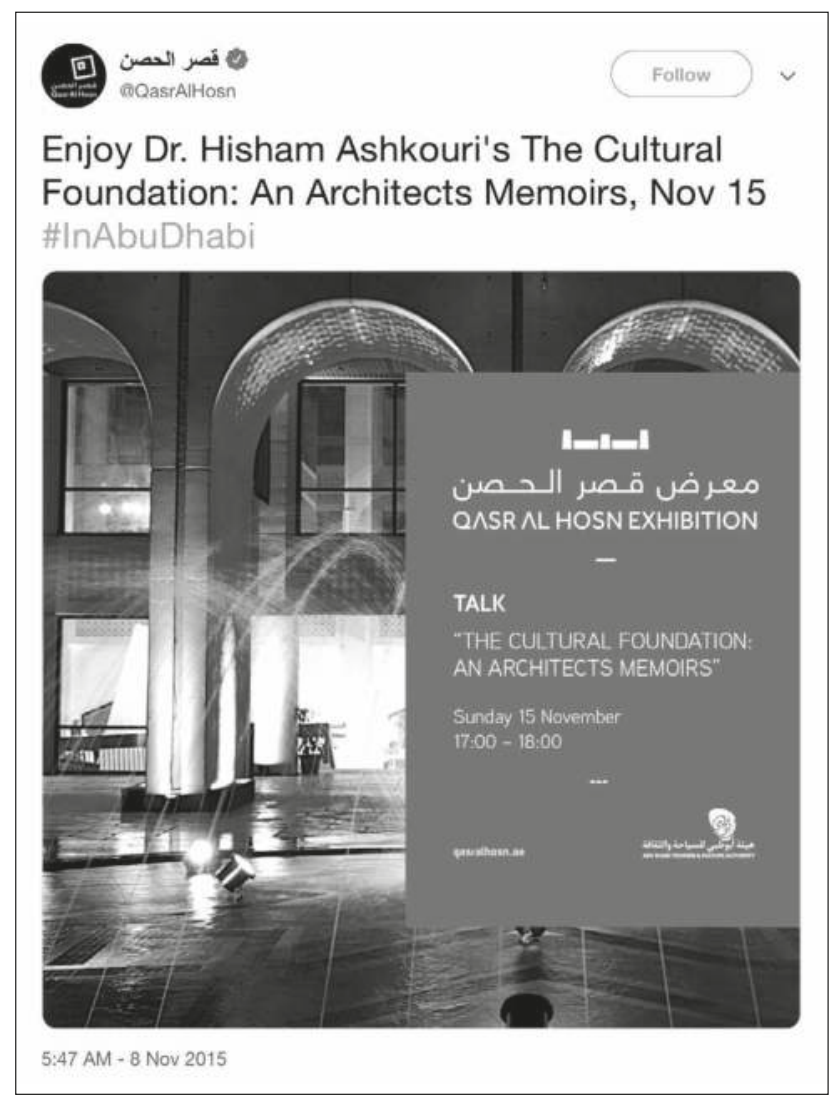

fig.3 Qasr Al-Hosn, announcement of talk by Hisham Ashkouri on design of Cultural Foundation, November 8, 2015 (Source: @QasrAlHosn, Twitter post).

and material constructs of these buildings to piece together a very different and expanded idea of the 'local', one that might build a heritage discussion around these histories of matter and labour rather than solely around tropes of identity or authorship.

\section{Concrete exchanges}

A more nuanced picture of what this sort of heritage discussion might look like beyond the local-foreign binary emerges when we shift our attention from Abu Dhabi to TAC's work in Kuwait, the centre of its transnational practice in these decades. In particular, it is here that we can trace TAC's relationship with Pan-Arab Consulting Engineers (or PACE), established in 1968 by Kuwaiti architect and planner Hamid Shuaib, Palestinian architect and planner Charles Haddad, and Kuwaiti engineer Sabah Al-Rayes. PACE was one of the largest construction firms in the 
Gulf by the 1970s, and its presence was crucial for TAC's work in the Gulf as the consultant for nearly all of their projects in Kuwait as well as those of other large US firms in the country. ${ }^{19}$

In the same year as PACE's founding, TAC received its first commission in Kuwait, to design the headquarters of the Kuwait Fund for Arab Economic Development (1968-1974), an entity established shortly after national independence as the major lender of development aid within the Arab world. When TAC engaged PACE by the end of 1968 to provide consulting services on the Kuwait Fund project, the two firms initiated a sustained collaboration that lasted nearly two decades: the cooperation stands as one of the earliest examples of shared expertise within an emerging network of partnerships between local consultants and foreign firms. ${ }^{20}$ The inauguration of the first Kuwait Fund building in 1974 began a 30-year period of sustained work in Kuwait for TAC, one which subsequently served as the hinge point for later built and unbuilt projects in the UAE, Saudi Arabia, Egypt, Jordan, and Oman. TAC and PACE's joint projects in Kuwait over these decades ranged from iconic cultural and institutional buildings - including the Kuwait Institute for Scientific Research (1979-1983), Kuwait News Agency (1981-1987), and Kuwait Foundation for the Advancement of Science (1982-1986) - to more anonymous infrastructures, most significantly including a series of commercial parking garages commonly referred to as modern 'souks' - combining ground-floor shopping with parking, offices, and housing (1973-1979). ${ }^{21}$

The partnership between TAC and PACE challenges the conventional narrative of their joint commissions as purely 'foreign' buildings, or what Al-Qassemi and Fabbri have described as a persistent tendency to show such modernization efforts as "a onedirectional phenomenon, a West-to-East technical knowledge export and not a bijective relationship". ${ }^{22}$ PACE's presence was key to TAC's proficiency across as many as 50 built and unbuilt projects in Kuwait from 1968 through the collapse of the oil boom in 1983, a body of work that fuelled TAC's own rise to become the largest dedicated architecture firm in the USA by the 1970s. The success of these projects led TAC to create a branch office in Kuwait in 1976 to pursue work in the Gulf, known as TAC Middle East. Conversely, PACE's early growth was due in large part to its involvement with TAC, a relationship that PACE's founders credited for the firm's rapid acquisition not just of professional drawing and detail standards but also of managerial protocols in its formative years. ${ }^{23}$ The TAC-PACE partnership anticipated the physical expansion of PACE's offices in Kuwait: the firms collaborated on an apartment complex for Sheikh Jaber Al-Ali Al-Sabah (1974-1976) on what subsequently became the site of the vast Nugra project, designed by PACE for the same client in multiple phases from 1975 to 1986, the last of which included its own purpose-built headquarters. ${ }^{24}$ 


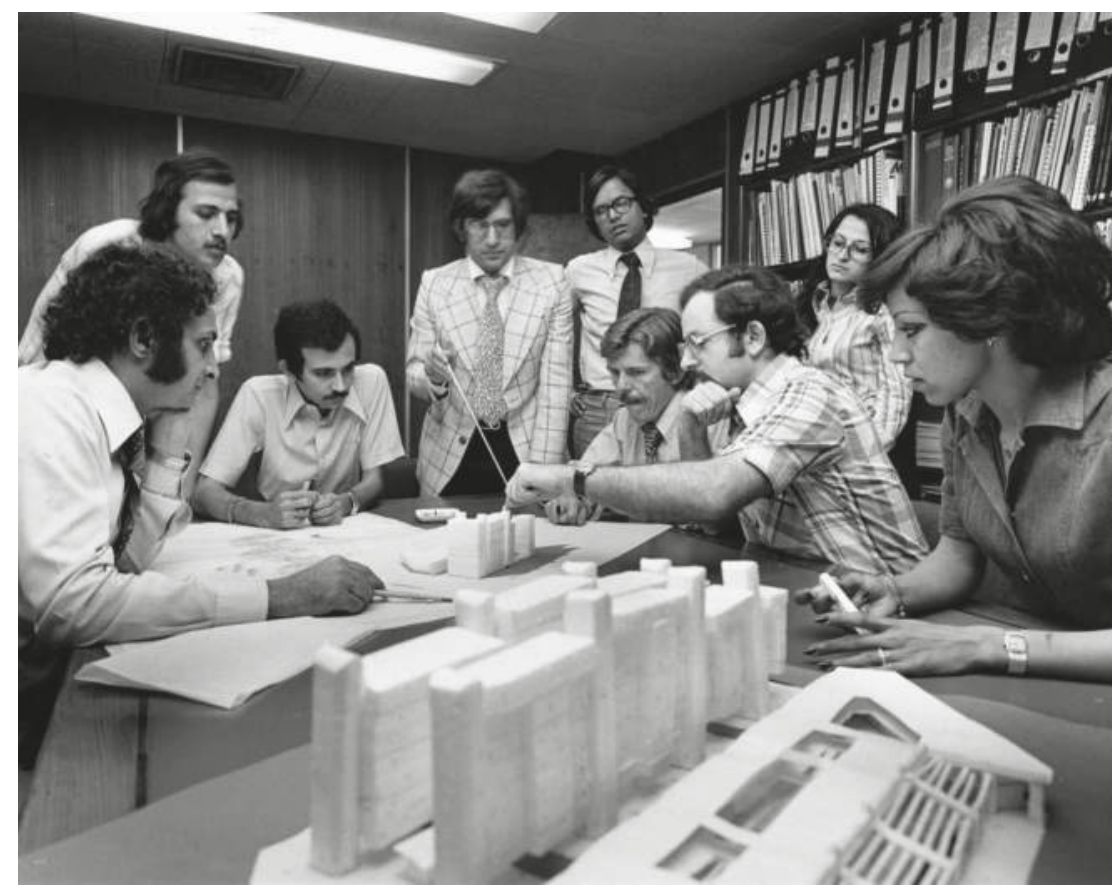

fig.4 PACE (Pan-Arab Consulting Engineers), Kuwait City offices with model of Nugra complex in foreground, c. 1970s-1980s (Source: PACE, Kuwait. Reuse not permitted).

The imbrication between the two firms extended to TAC's design of the logotype, stationary, and office interiors for PACE (1976) and later signage and graphics for PACE International (1977), a branch office established in Cambridge, Massachusetts, by partner Charles Haddad in response to the firm's large volume of commissions with TAC. ${ }^{25}$

The evolving relationship between PACE and TAC can be divided roughly into two phases. While the first began with their collaboration at the Kuwait Fund, a second, more developed stage began around 1973 with the initiation of a series of TAC-PACE projects through the framework of the joint venture, a newly mandated legal structure which required foreign architects seeking to practice in Kuwait to form partnerships with local firms. This body of work included numerous, large-scale residential and commercial developments throughout Kuwait for wealthy private clients combining a variety of housing types with retail, office, and other programmes - as well as major institutional headquarters for clients including the Kuwait Foundation for the Advancement of Science (1981-1987), Kuwait Institute for Scientific Research (1979-1989), and a tower addition for the Kuwait Fund (1975-1981) adjacent to its original building. 
Throughout their partnership, TAC and PACE developed a recognizable repertoire of forms and details in precast and pouredin-place concrete, transacted through the shared bureaucratic language of standardized drawing protocols and technical specifications in both English and Arabic. These material exchanges began in 1968 with TAC's engagement of PACE to act as its local partner in the design of the Kuwait Fund, the first major landmark of a collaboration that became increasingly centred on assessing the quality of concrete as a material measure of the evolving relationship between the two firms. While it remains unclear what first led Kuwait Fund director Abdulatif Al-Hamad to commission the US firm to design its building or how TAC first came into contact with PACE, by May 1969 the Kuwaiti office had been contracted to prepare bills of quantities, specifications, and contract documents for the building, followed by an agreement in August 1970 to undertake construction supervision. ${ }^{26}$ The mutual congeniality between the firms continued into the construction phase of the project: after visiting the construction site in December 1971, McMillen wrote to Al-Rayes to commend PACE's work, noting that he had been "very impressed with the excellent quality of the concrete and by the general handsome look of the building as it is beginning to merge [sic] from the foundation". ${ }^{27}$ In its annual summary of progress on the project later that month, PACE explained that the achievement of such results relied on raising the standards of Kuwaiti contractors as much as on its own work: "While the quality of the reinforced concrete work has been an achievement on its own", the firm wrote, "the most important aspect has been the overcoming of the difficulty of getting the Contractor to accept the quality expected and to co-operate with the Consultants in trying to achieve a high standard". ${ }^{28}$ Al-Rayes reiterated in a monthly report sent to TAC the following July, a year prior to the opening of the building, that "the construction is quite new to any contractor in Kuwait". ${ }^{29}$

In this sense, the Kuwait Fund's importance as a benchmark for the developing construction industry in Kuwait was well understood even before the project was complete. In July 1972, a year before the inauguration of the new building, Adnan Ghantous, TAC's job captain in Kuwait, wrote to inform McMillen that the chairman of the financial committee of the Kuwaiti Parliament had offered praise to Abdulatif Al-Hamad, the director of the Kuwait Fund, for its choice of architect as well as for the quality of its new headquarters. Ghantous reported not only that the chairman had "commended [The Kuwait Fund] on the good workmanship that they have introduced to Kuwait" but also that he had been sufficiently impressed to implore the Ministry of Public Works "to consider our building as the standard for workmanship and supervision that should be followed" for all future construction projects in the country. "I0 "It seems", Ghantous 
concluded, "this job will constitute a turning point in construction work in Kuwait". ${ }^{31}$

A significant element of this development of a shared concrete language through these early projects was the material's unique capacity to signify as alternately local and foreign in the Kuwaiti context, as a hybrid in which imported details and on-the ground matter and labour were synthesized. Edward O. Nilsson, the project architect for Souk Al-Manakh and Souk Al-Wataniya - two of the TAC-PACE projects that immediately followed the completion of the Kuwait Fund - later recalled that, for the poured-

fig.5 in-place concrete in these buildings, "It was necessary to have a specialised consultant design the concrete mix, because one could not use the local sand as it was". ${ }^{32}$ In other words, technics from abroad were required to mediate the insufficiency of using Kuwaiti raw materials in the making of 'Kuwaiti' concrete. ${ }^{33}$ Beyond such material constraints, the concrete mix at Souk Al-Wataniya was required to accommodate a complex hybrid of structural systems, including cast-in-place concrete girders, a Freyssinet precast framing system allowing up to 20-metre spans without columns, and steel roof framing for the residential units at the upper levels of the building.

Stylistically, however, concrete was implicitly required to sublimate the transnational mixture of structural and material technics through which it was formed, solidifying this aggregate into the image of a 'local' architectural expression. Such images were built through a language of forms that included semicircular arches, opaque walls with narrow openings, deep window sills and horizontal sun shades, and other elements intended to situate these new building types within Kuwait's rapidly changing urban conditions. Yet despite these efforts, TAC and PACE's buildings and their monumental forms in concrete were often admired by local architects as examples of a properly modern Kuwaiti architecture more for their technical sophistication than for their stylistic attributes.

\section{Joint ventures}

The local-foreign binary is challenged in particular by an examination of the more dedicated joint-venture framework that developed between TAC and PACE after 1973, as an example of the changing legal and financial relationships between local firms and foreign architects seeking to operate in the Gulf. In the same year, a circular was issued to all government departments by Abdulatif Al-Hamad requiring all non-Kuwaiti firms to team with local offices in order to work in the country, as a counter to governmental bias towards foreign companies. ${ }^{34}$ Henceforth, firms like TAC would be obliged to form joint-venture partnerships with Kuwaiti engineering and construction conglomerates, as offices like PACE became newly empowered mediators of imported technical expertise and 


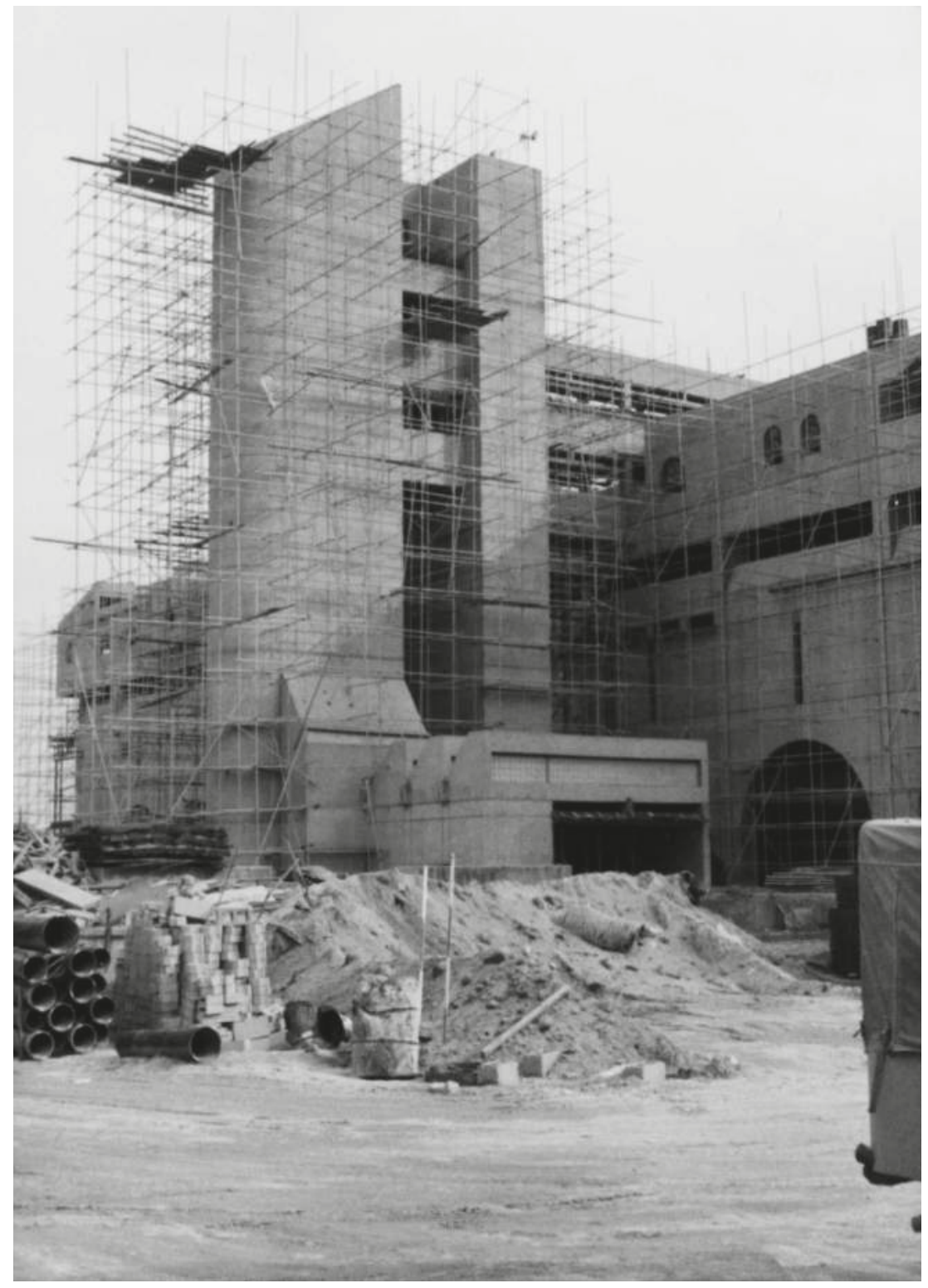

fig.5 The Architects Collaborative with PACE, Souq Al-Wataniya, Kuwait City, 1974-1979, construction photograph (Source: PACE, Kuwait. Reuse not permitted). 
design details with on-the-ground regulations and building protocols. The draft of a single, joint-venture contract covering all future TAC and TAC-PACE projects dates from August 1975, after which the team was officially renamed the TAC-PACE Supervisory Establishment. ${ }^{35}$ By the end of the decade, PACE's repertoire of services, as rendered in an office portfolio produced around 1978, had expanded to include structural, mechanical, electrical, civil engineering, architectural, and interior design as well as urban planning, quantity surveying, photography and graphic design, and construction supervision and management. ${ }^{36}$

By the time of the TAC-PACE joint-venture agreement in 1975, the pair's work extended to a wide array of large-scale residential and commercial projects in Kuwait designed primarily in concrete, including the Salmiya (today Al-Anjari) Commercial Complex (1974-1978), designed for the Kuwait Investment Company as part of the development of Salem Al-Mubarak Street after 1970, and the unbuilt Northeast Sawaber Housing scheme (1977), designed for the National Housing Authority. ${ }^{37}$ Yet within a few years the ties between these two firms had apparently begun to fray under the pressure of market competition to design Kuwait's new concrete landmarks. Their relationship suffered in particular after the Joint Banking Centre competition, in which Sabah Al-Rayes had backed the winning entry of Skidmore, Owings \& Merrill (SOM) over Charles Haddad's allegiance to TAC. Other fissures were exposed in the process of designing the Kuwait Fund addition, a project that TAC may have initially intended to develop independently prior to PACE's insistence on the joint-venture framework after 1975. By the time the tower went into construction, PACE had consolidated all structural as well as mechanical, electrical, and plumbing design for the project in its offices for the first time, presaging its ability to execute similar commissions without the US firm.

By 1976, TAC had begun to pursue commissions in Kuwait and elsewhere in the Gulf states in earnest through its TAC Middle East branch while PACE developed both its independent design practice and its partnerships with other US firms in the wake of the Joint Banking Centre. Some of PACE's projects apart from TAC, like the United Arab Shipping Company (1980), were unconvincing attempts to imitate the forms of the Kuwait Fund, perhaps to channel the aura of the institution that had established the reputation of both firms at the outset of their practices in Kuwait. Others, like the Nugra complex and high-rise buildings including the Behbehani (1978-1982), Imad (1979-1983), and Al-Khaleejia (1981-1984) Towers, better exemplified PACE's in-house expertise in concrete by the end of the 1970s, extending the techniques of sand-blasting and bush-hammering that the firm had learned from TAC despite their stylistic variance. ${ }^{38}$ As the landscape of commissions in the Gulf shifted for US firms after the end of the boom in 
crude oil prices in the 1980s, PACE went on to gain its own significant commissions in the region prior to the interregnum of the First Gulf War in 1990-1991 and the economic recovery that followed. These commissions were no longer developed in partnership with TAC, however, but rather in-house or else with other US firms like SOM, which collaborated with PACE in designing the United Gulf Bank (1981 - 1987) in Manama, Bahrain.

For its part, TAC's increasing presence in the region after its arrival in Kuwait quickly reaped benefits in other booming construction markets across the region, including projects in Iran, Saudi Arabia, the UAE, Oman, Jordan, and Egypt by the early 1980s. In these projects, pursued separately from PACE, TAC often employed concrete forms and motifs that it had developed in their shared work in Kuwait. Unable to continue this steady stream of work following the end of the boom in crude oil prices and the collapse of the Souk Al-Manakh stock exchange - a financial crisis precipitated from one of the commercial parking garages built at the height of the TAC-PACE partnership - TAC largely divested itself of its work in the Gulf states and its relationship with PACE and other Arab consultants after 1983. By the time of its tentative return to working in Kuwait at the end of the decade, its collaborations with consulting firms like Archicentre and Kuwait Engineering Bureau proved to be short-lived, definitively concluded by the Iraqi invasion in 1990.

\section{Cultural foundations}

In the present context, a handful of TAC and PACE's institutional buildings in Kuwait have achieved prominent places within contemporary understandings of modern Kuwaiti heritage. Chief among these is the Kuwait Fund headquarters, a building that symbolized the newly independent nation's outsize economic power within the Arab world and has continued to be well maintained by its private owners, even if it remains largely inaccessible to the public. Yet many of the buildings from this period involving international architects have fared far less well within recent discussions of built heritage and cultural memory. This is particularly true of the concrete souks built by TAC-PACE and other joint ventures: these structures are uniquely local building types that have, nevertheless, had a markedly different reception history than that of cultural icons like the Kuwait Fund - or the Abu Dhabi Cultural Foundation - in the decades since their construction. Despite their central role within the history of Kuwaiti urbanization - as crucial elements of the city's modernizing urban fabric and as prominent examples of the new, hybrid, building types that marked the transformation of the city centre after the 1970s - the souks have remained generally neglected within discussions of Kuwait's modern heritage, leaving them highly vulnerable to recent threats of demolition or alteration. They have been commonly regarded - if 
they are regarded at all - simply as anonymous elements of the city's infrastructure, despite their provenance from the same collaborators (and featuring many of the same design techniques and motifs) as signature icons of Kuwaiti nation-building like the Kuwait Fund. In this respect, their cultural status today is not unlike that of the bus terminal in Abu Dhabi whose demolition Elsheshtawy favours, regarded as marginal to the city's modern history even if they have been fundamental to its lived experience.

I would argue that the marginalization of the Kuwaiti souks has been exacerbated by the popular impression of these buildings as either unauthored and anonymous, or else - if granted authorship in critical debates - as 'foreign' insertions into the traditional building fabric of the old town, designed by non-Kuwaiti architects and thus dispensable with regard to the construction of a 'local' urban identity. Indeed, the material history of such buildings, as complex transnational products of labour and matter, escapes not only the tropes of the local-foreign binary but often the conventional assignation of authorship altogether. As such they have remained largely devalorized by critics as well as by the public, even though to my mind they were no less important in shaping the cultural experience of Kuwaiti modernization after the 1970s than were more prominent public buildings like the Abu Dhabi Cultural Foundation in the UAE.

In this sense, a comparative study of the production and reception of the Abu Dhabi Cultural Foundation and Kuwaiti souks offers valuable lessons for the broader history of transnational design networks that shaped the construction of modern Gulf cities after the 1960s, a persistent omission within histories of both modern architecture at large and heritage discussions in the Gulf in particular. By unpacking the differing assessments of value which I argue have conditioned the contemporary status of these buildings in the midst of ongoing preservation challenges and heritage debates, we might develop new tools to understand the distributed mechanisms of authorship and exchange through which such emblems of Gulf modernism took shape. 


\section{Notes}

1 Sultan Sooud Al-Qassemi and Roberto Fabbri, "Re-Engaging with the Gulf Modernist City: Heritage and Repurposing Practices", call for 10th Annual Gulf Research Meeting, Gulf Research Centre, Cambridge, UK, July 2019, 2, https:// gulfresearchmeeting.net/documents/ 1584361672Desc\&AbstractWS10.pdf.

2 See in particular Kenneth Frampton,

"Towards a Critical Regionalism: Six

Points for an Architecture of Resistance", in Hal Foster, ed., The Anti-Aesthetic:

Essays on Postmodern Culture (Port Townsend, WA: Bay Press, 1983), 16-30. 3 Yasser Elsheshtawy, "We Need to Talk about the Modernism Fetish in the Gulf", Dubaization, December 26, 2017, http:// dubaization.com/post/168964409563/ we-need-to-talk-about- the-modernismfetish-in-the-Gulf.

4 Ibid.

5 Ibid.

6 Ibid.

7 lbid

8 lbid.

9 Hisham Munir, interview with author, Washington, DC, August 20, 2015. According to Munir, Ashkouri also later falsely claimed credit for projects by Hisham Munir Associates, including the Amanat Al Asima in Baghdad (1982-85), designed after Ashkouri left the office. 10 Nick Leech, a journalist in Abu Dhabi, claims implausibly that "Ashkouri was assisted" by Hassan, working as an "associate architect" on the project. Like similar claims, this account appears to come solely from Ashkouri himself, whom Leech interviewed for this and other articles. Leech, "Abu Dhabi's Cultural Foundation to be revitalised", The National, February 12, 2015.

11 Perry Neubauer, presentation on the history of TAC International with Michael Gebhart and Deborah Bentley, Boston Society of Architects, June 10, 2016. The resemblance of the competition scheme to a Latin cross may cast further doubt on Ashkouri's claim that he was lead designer of the competition scheme, since the Iraqi architect presumably would have been aware of this iconography and its unsuitability for the project.

12 Neubauer presentation, June 10, 2016. 13 Ibid. On TAC's commission to design the University of Baghdad after 1957, see Michael Kubo, "'Companies of Scholars': The Architects Collaborative, Walter Gropius, and the Politics of Expertise at the University of Baghdad", in Ines Weizman, ed., Dust \& Data: Traces of the Bauhaus Across 100 Years 1919-2019 (Leipzig: Spector Books, 2019), 496-515.
14 Neubauer quoted in Leech, "Abu Dhabi's Cultural Foundation to be revitalised".

15 Ashkouri quoted by Mark Kyffin, Head of Architecture for the Department of Culture \& Tourism Abu Dhabi and director of the revitalisation projects for the Cultural Foundation and Qasr al Hosn, interview with author, May 23, 2016. Extant construction drawings of the Cultural Foundation in the MIT Museum archives, dated to October 1976, include the initials of team members including Vladimir S. Florek, Perry Neubauer, and William J. Higgins, but Ashkouri's initials do not appear on any available drawings.

16 Neubauer presentation, June 10, 2016. TAC used white cement for the Cultural Foundation concrete, as the firm had in its Kuwait Fund for Arab Economic Development headquarters (1968-74), the first use of white cement in Kuwait. 17 See Matthew Maclean, Spatial Transformations and the Emergence of 'the National': Infrastructures and the Formation of the United Arab Emirates, 1950-1980 (PhD Dissertation, New York University, 2017).

18 Ibid. According to Neubauer, Ibrahim's influence on the design included sending members of TAC to Cairo to study the Egyptian National Library, an important precedent for the Abu Dhabi project. 19 Much of what follows in this section is abridged and adapted from Michael Kubo, "Concrete Ventures: TAC, Pace, and Transnational Exchanges in the Construction of Modern Kuwait", forthcoming in Dalal Musaed Alsayer, Ricardo Camacho, Sara Saragoça Soares, ed., Pan-Arab Modernism: The History of Architectural Practice in The Middle East (Barcelona: Actar, 2020).

20 The project number given to the Kuwait Fund project by PACE was 68006 , with the first two digits indicating the year of the commission, indicating that this was the sixth project the firm undertook in the year of its founding.

21 See Edward Nilsson, "History, Memory, and Narratives of the Past and Future: The New Souks in Kuwait", 180-197, in this volume.

22 Roberto Fabbri and Sultan Sooud Al-Qassemi, "Introduction: Re-Engaging the Modern", in Urban Modernity in the Contemporary Gulf: Obsolescence and Opportunities, eds. Roberto Fabbri and Sultan Sooud Al-Qassemi (Abingdon: Routledge, 2022), 12.

23 Tarek Shuaib, current head of PACE and son of founding partner Hamid A. Shuaib, interview with author, August 1, 2012. 
24 PACE information sheets on the TAC scheme for H.E. Sheikh Jaber Al-Ali Al-Sabah suggest that the project may have originally been located in Fintas circa 1974 prior to being moved to the later Nugra site in Hawally. Drawings by TAC in the PACE archives clearly show the Hawally site, indicating that TAC initially remained involved with the project after its relocation. 25 Haddad claims that by the mid-1970s TAC preferred to develop these projects in-house according to their own requirements rather than working in Kuwait, requiring PACE to establish an office in Cambridge, MA close to TAC's headquarters. This was an inversion of the arrangement Haddad described for the Iraq Consult projects and TAC's work on the Kuwait Fund in PACE's early years, in which each firm sent an architect to work with PACE in Kuwait, with PACE paying their salaries and maintaining a say in the final design. Interview with Charles Haddad in Essays, Arguments \& Interviews on Modern Architecture Kuwait, 110-114. 26 PACE, letter to Louis A. McMillen, May 23, 1969. Louis McMillen, letter to Sabah Al-Rayes, received August 24, 1970. PACE Archives.

27 Louis McMillen, letter to Sabah Al-Reyes [sic], December 10, 1971. PACE Archives.

28 "Monthly Report No. 5 with an Annual Summary, KFAED HQ Office Building", December 31, 1971, 1. MIT Museum Archives.

29 "Monthly Report No. 11, KFAED HQ Office Building", enclosed with letter from Sabah Al-Rayes to Louis A. McMillen, August 13, 1972. MIT Museum Archives. 30 Adnan Ghantous, letter to Louis A. McMillen, The Architects Collaborative International Limited Inc., March 13, 1972. MIT Museum Archives.

31 Ibid.

32 Interview with Edward Nilsson, in

Essays, Arguments \& Interviews on Modern Architecture Kuwait, 178.

33 TAC hired a U.S. firm, Concrete Associates Inc, to develop these specifications for the concrete mix.

34 Rod Sweet, ed., SSH Design: The First 50 Years, http://issuu.com/sshdesign/docs/ 50_years_book, 47. Sweet claims that Abdulatif Al-Hamad was a government minister responsible for finance and planning at the time, though officially Al-Hamad was Minister of Finance and Planning only from 1981 to 1983 . SSH, already one of the largest consultants in Kuwait, claimed that this requirement came as the result of lobbying by partner Salem Al-Marzouq, a U.S.-educated civil engineer then in the Ministry of Public Works and a member of the National Assembly.
35 "TAC/PACE Supervisory Establishment Joint Venture Agreement", August 26, 1975. PACE Archives.

36 The Pace Story: Pan Arab Consulting Engineers, office portfolio c. 1978.

PACE Archives.

37 The Salmiya Commercial Complex project began in 1974 according to the TAC job number (74022), and the latest drawings available for the design are dated to August 1978 (MIT Museum Archives). The construction dates for the project remain unclear.

38 Interview with Sabah Al-Rayes in Essays, Arguments \& Interviews on Modern Architecture Kuwait, 69. 


\section{CHANGING FAÇADES IN GULF CITIES Identity, icons, and lamentations of loss}

Kevin Mitchell 
At the beginning of the twenty-first century, the significant inflow of foreign direct investment into the Gulf and competition among cities to establish centres for commerce and tourism fuelled extraordinary expansions of the built environment across the region. International Monetary Fund (IMF) data reveals that the number of employees in real estate during the most recent building boom in the United Arab Emirates, supported by the rapid growth of Dubai, more than doubled from 42,000 in $2000^{1}$ to an estimated 97,000 in $2008 .^{2}$ During the same period, the number of people involved in the construction industry rose from 287,000 in $2000^{3}$ to 757,000 in $2008 .{ }^{4}$ The extraordinary increase in employees in the real estate and construction sectors is an indicator of the rapid development of the built environment in the city, now recognized as an exemplar of unbridled growth among the Gulf Cooperation Council (GCC) member states.

While the latest phase of development that propelled Dubai ahead of its neighbours was notable in terms of scope and scale, other cities also experienced major transformations of the built environment at various times following the discovery of oil. For example, Kuwait grew rapidly to accommodate a growing population that increased from 262,000 in 1960 to 750,000 in 1970 , and then to nearly 1.4 million in $1980 .^{5}$ The plan for Kuwait signed by Minoprio, Spencely and Macfarlane presented in 1951 and the subsequent plans by Colin Buchanan \& Partners (1968) and Shankland \& Cox (1976 and 1981) guided growth and resulted in continual redevelopment of areas of the city through demolition and rebuilding, a practice that remains common in many Gulf cities.

The building booms that have transformed the built environments throughout the Gulf have often been accompanied by elegies lamenting the loss of a past perceived to be superior to the present. In The Kuwait Urbanization, published in 1964, Saba George Shiber reacts to the destruction of parts of the city to facilitate new construction:

The new city is undoubtedly a startling new machine that has been assembled in an astonishingly short period of time ... By profound urban and architectural concepts, Old Kuwait is a classic. Many of the top architectural and urban authorities that I have had the occasion to discuss new Kuwait at length with are unanimous in their opinion that it is not: at least not yet from the urbanarchitectural significance points-of-view. ${ }^{6}$

Shiber goes on to describe connections between the urban organization of what he terms "Old Kuwait", domestic architecture, family structures, social norms, cultural values, and religious practices. 
The unease, precipitated by the abandonment of "profound architectural and urban concepts" that in Shiber's estimation are people- and place-specific, is related to contemporary claims that Gulf cities have lost their identity; though, 'identity' is rarely defined and often invoked when the pace of change is perceived as a threat to prevailing norms. In her article "The Islamic City Historic Myth, Islamic Essence, and Contemporary Relevance", Janet Abu-Lughod addresses the challenges associated with approaching cities in the Islamic world in essentializing terms by raising a series of critical questions related to the challenges of reproducing historical forms that emerge from context-specific circumstances and may no longer have relevance. Abu-Lughod maintains that cities are processes rather than products, arguing that there are three conditions that influence the urban form of Arab-Islamic cities: "(1) juridical distinctions between Muslims and/or citizens and outsiders; (2) segregation by gender and a virtually complete division of labour according to it; and (3) a fully decentralized and ex post facto system of land use and governmental regulation of space". ${ }^{7}$ Although Abu-Lughod maintains that none of the conditions exist today, she nevertheless concludes that measures could be taken to encourage processes to enhance cities in the Arab-Islamic world and advocates for learning from the achievements of the past:

The historic Islamic city often achieved community, privacy, and beauty. It would be wise to seek the same goals, even though the old means are no longer available to us. We can only encourage growth in the desired direction, but since cities are living processes rather than formalistic shells for living, they cannot be built by us, we can only encourage them to grow in a desired direction. Can we nurture neighborhoods that are supportive but not defensive? Can we foster privacy for women alone but not for households? Can we guard the rights of neighbors while still applying laws consistently? This is the task Arab city planners must set for themselves. ${ }^{8}$

A survey of urbanism in the region indicates that planners continue to face challenges in achieving a sense of community, privacy, and beauty. Abu-Lughod's makes for a convincing and strong case, but the assertion that cities are processes rather than products is, arguably, only partially correct. Cities are processes and products: the individual works of architecture that make up cities are physical products with particular qualities and attributes. They function in specific ways according to formal structure, spatial organization, and overall appearance. Individual buildings can also take on meaning and be contested in significant ways that lead to destruction and/or alteration, and this is one of the reasons for the renewed interest in mid- to late twentieth century architecture in the Gulf. 
While both Shiber and Abu-Lughod recognize the complex relationship between the built environment and the broader social, cultural, and religious context, the calls for preserving and maintaining buildings constructed during the period from the 1950s until the beginning of the twenty-first century have tended to focus on outward appearance rather than the specific qualities or particular approaches to space, form, and context that would be the basis for assessing the significance of a work of architecture. The tendency to focus on façades is perhaps due to the rather substantial challenges of addressing the complex socio-cultural contexts of Gulf cities informed by the diversity of inhabitants and their respective communities. Demographic structures may vary greatly depending on the city and on investor-driven models of urban development. These models promote demand for generic commercial and domestic space with the broadest possible appeal for rental and resale. There are a number of compelling reasons for preserving and maintaining buildings from the more recent past, ranging from reducing the resources required for demolition and new construction to the architectural significance of the work; however, the continued emphasis on the outward appearance of buildings can be detrimental as it propagates the assumption that architecture begins, and ends, with the façade.

The indiscriminate concern for outward appearance has been important in the brand-building competition among cities - seeking to attract the inflow of capital, corporations, and tourists - as evident in the demand for "icons" that must always aspire to be bigger and better. Leslie Sklair, in The Icon Project: Architecture, Cities and Capitalist Globalization, writes that

\footnotetext{
Icons emerge at the meeting point of power, meaning, aesthetics, and taste, where the power of those who dominate the global economy, the meanings produced by its ideologues, and the aesthetics produced by architects create the condition in which the Icon Project thrives. One of the consequences of capitalist globalization is the need to transform the social production, marketing, and reception of iconic architecture. These processes are largely driven by those who own and control most of the land and other resources all over the world, conceptualized here as the transnational capitalist class (TCC). The TCC is organized in four overlapping fractions - corporate, political, professional, and consumerist. In most societies, the TCC has the lion's share of economic resources, political influence, and mass media attention. ${ }^{9}$
}

One manifestation of the emphasis on the iconic in the Gulf is participation in the global contest to build higher. At the turn of the twentieth century, projects like Al-Faisaliyah Centre (2000) and Kingdom Centre (2002) in Riyadh or Burj Al-Arab (1999) and the twin Emirates Towers (2000) in Dubai were nearly one-third 
taller than other high-rises in the region at the time they were completed, in spite of a surplus of available land, the expense associated with building taller, and an oversupply of leasable space. In 2010, Dubai secured the distinction of world's tallest building with the 828-metre-high Burj Khalifa; the Jeddah Tower planned for Riyadh, and currently under construction, is estimated to reach 1,000 metres. Dubai's latest contribution to super tall structures is the Dubai Creek Tower, announced in 2016. While the final height of the building has not been made public, the developer's website promises a superlative-worthy icon:

\begin{abstract}
Set to be the 21st Century's [sic] new global icon, Dubai Creek Tower soars up from the heart of Dubai Creek Harbour into the clouds above. Designed by the renowned neo-futuristic Spanish architect, Santiago Calatrava, this gravity-defying structure is inspired by the lily flower and traditional Arabian minarets. A product of great vision, innovation and construction excellence, it will add to Dubai's significant skyline and elevate the city's position as a world-leading metropolis of the future. ${ }^{10}$
\end{abstract}

While the design and construction of the Burj Khalifa and the Kingdom Tower have advanced technical knowledge and fulfilled client demands for an iconic presence, there have been few attempts to consider how high-rises could respond to the Gulf climate and context.

In spite of the lingering repercussions of the post-2008 financial crisis, which included the sudden cessation of construction activity and the promise of more considered approaches to the built environment to address the excesses associated the unchecked speculation in real estate, fondness for the iconic and for appearance remains. At the beginning of October 2019, Dubai announced a series of initiatives that included "to design and implement a clear architectural identity that makes Dubai different from other international cities. This identity can be placed on public and private buildings". ${ }^{11}$ Although details related to the actual implementation were not explained, there is the implication that "architectural identity" would result from an applied façade treatment.

The assumption that "architectural identity" can be reduced to the façade treatment of a building is indicative of the increasing focus on appearance. By tracing the development of the Central Bank of Kuwait (CBK) buildings - from the Arne Jacobsen-designed structure completed in the 1970s to the most recent headquarters designed by HOK in collaboration with PanArab Consulting Engineers (PACE) - and comparing the CBK highrise to the National Commercial Bank (Jeddah; completed 1983) designed by Gordon Bunshaft and Skidmore, Owings \& Merrill (SOM), this paper examines the shift in emphasis from formal 
structure, spatial character, and climate responsiveness to a concern for iconic expression. The paper also addresses ways in which terms like 'context' and 'identity' are challenged and problematized with respect to the production of architecture in Gulf cities competing to establish themselves as legitimate nodes within global networks that facilitate the flow of commerce and culture.

Acceptance, rejection, and a turn towards the iconic As part of a major building programme in Kuwait, Danish architect Arne Jacobsen was invited to develop a proposal for a new building to house the CBK in 1966. Although Jacobsen died prior to the initiation of construction in 1973, the building was completed by Dissing+Weitling, an office initially founded by Hans Dissing and Otto Weitling to carry out Jacobsen's work following his death. Dissing had been with Jacobsen's office since the early 1950s, and Weitling joined in the mid-1960s.

The selection of a Danish architect known for a minimalist approach to form and the rejection of applied ornamentation was a bold choice for the CBK but not necessarily surprising given the outward orientation of Kuwait following independence in 1961 and ratification of the constitution in 1962. In a broader historical context, Denmark's connections extend back to the Danish Arabia Expedition (1761-1762), which was later chronicled by Carsten Niebuhr, the only member to survive the trip. In the more recent past, Barclay Raunkiær led a Royal Danish Geographical Societysponsored expedition that included Kuwait in 1912, and Danish archaeologists organized the first excavations in the Gulf region and have been active in Kuwait since 1958. While the academic exchanges would have brought exposure to Denmark, the trade ties between the two countries were strong as evidenced by companies such as the Kuwaiti Danish Dairy Company established in 1962.

The design of the CBK exhibited the formal clarity and minimalist approach to detailing that characterized Jacobsen's fig.1 work.

There were also clear lessons drawn from the National Bank of Denmark (NBD) project in Copenhagen, on which Jacobsen had begun work in 1961 after being invited to participate in a closed competition. ${ }^{12}$ Like the CBK, the final stages of the NBD project were completed by Dissing+Weitling after Jacobsen's death. The sites for CBK and NBD were both trapezoidal, which created particular challenges. In both instances, Jacobsen filled nearly the entire site by establishing a consistent street wall. In the case of NBD, the boundary wall maintains a one-storey height and a block, containing an additional five storeys, appears to float above a one-storey wall expressed as a solid plinth on the façade. The north and south façades of the block are divided into vertically oriented sections clad in marble, and the solid portions of the 


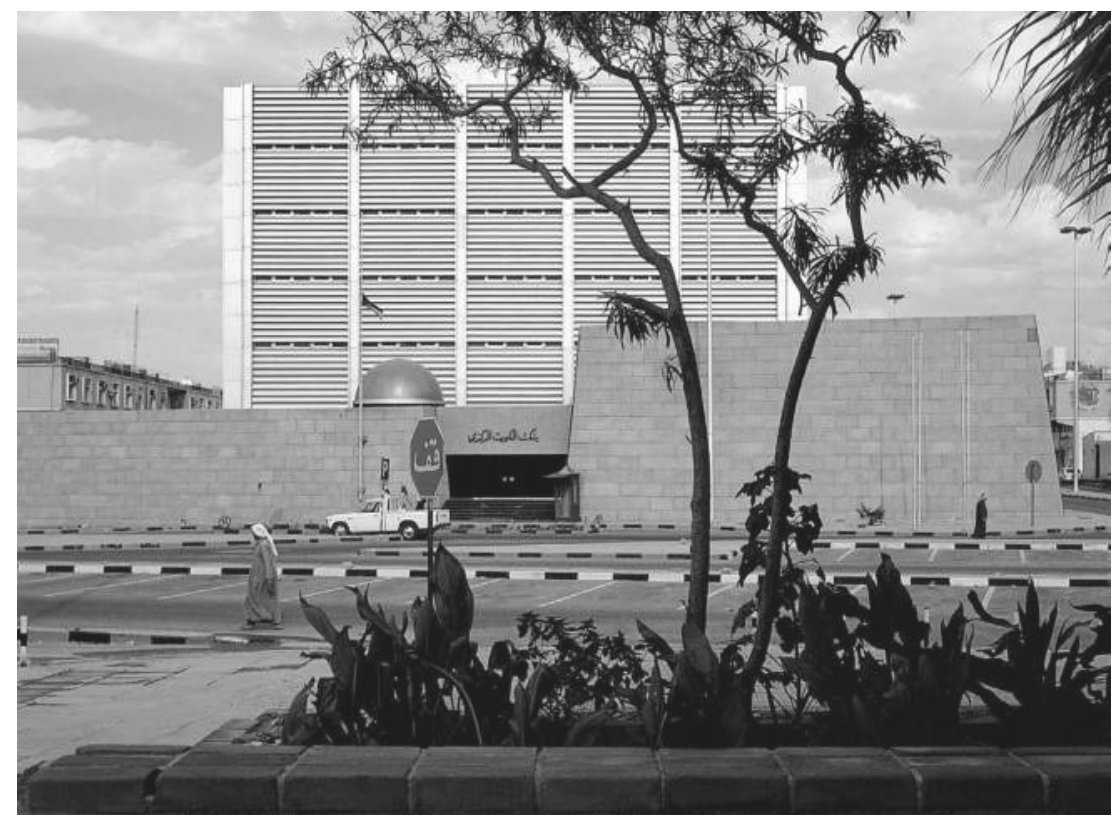

Central Bank of Kuwait, prior to renovation. The building was design by

fig. 1 Arne Jacobsen in 1966 and constructed by Dissing+Weitling from 1973 to 1976 (Source: Dissing+Weitling. Reuse not permitted).

façade are separated by recessed windows that serve to create a gap, reinforcing the appearance of verticality. The long east and west façades are sheathed in curtain walls that maintain the same rhythm of the solid panels covering the north and south façades. Typical of perimeter blocks characteristic of Copenhagen's urban fabric, interior courtyards have been created to allow for narrower floor plates and access to light. Perhaps the most striking aspect of the NBD building is the 20-metre-high lobby containing a staircase that appears to be suspended with no visible means of support. Like the site itself, the lobby is a trapezoidal plan, and visitors enter into the narrowest part of the plan underneath a low plane and then emerge into the space facing the stair. In terms of formal structure and spatial configuration, Jacobsen explored some of the same ideas developed in the NBD in the design for the CBK; however, the ideas were transformed in fundamental ways to respond to the context of the Gulf.

As mentioned above, the plot for the CBK was irregular and, as in the site response for the NBD project, Jacobsen proposed a low building that extended to the plot boundaries. While the site strategies were similar, there were subtle but significant differences beyond the response to the irregular plot: the boundary wall enclosing the CBK site has a slight vertical slope, and one 


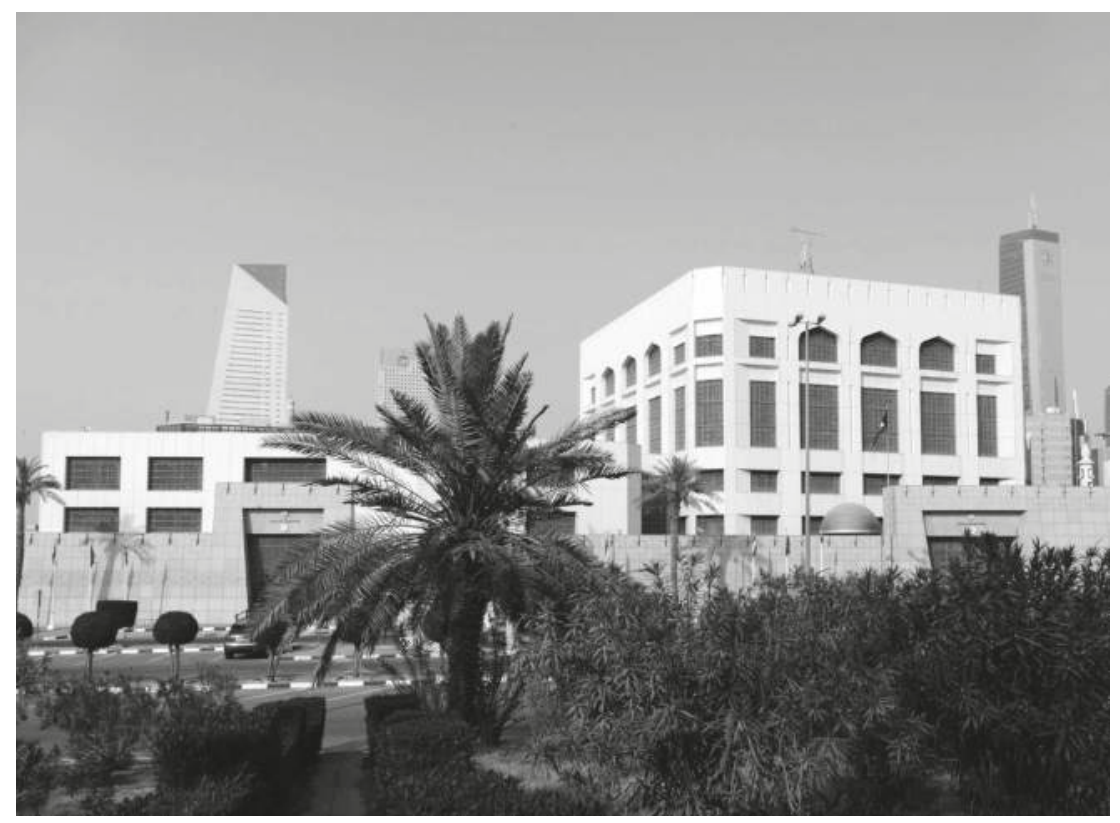

fig.2

Central Bank of Kuwait, Kuwait City, following renovation with Central Bank of Kuwait Headquarters shown beyond on left (Photo: Kevin Mitchell, 2020. Reuse not permitted).

corner is defined by a mastaba-like, two-storey mass adjacent to the main entry. Given the degree of formal abstraction employed throughout the project and the fact that the mastaba form was found in other parts of the Middle East and North Africa (MENA) region but not indigenous to Kuwait, the treatment of the wall raises questions regarding the way in which Jacobsen considered the relation between building and context. In an interpretative leap, one could argue that the sloped wall surface is a reference to buildings such as Qasr Al-Ahmar. However, as discussed below, the visual reference to potential precedents was not enough to prohibit an intervention that substantially altered the interior integrity and exterior appearance of the project.

While both the NBD and the CBK rely on a one-storey building expressed as a plinth and a taller structure to house essential functions, in terms of overall organizational strategy the CBK differs substantially. The tower for the Kuwait project is based on a square plan comprised of five structural bays in each direction, rendered visible as vertical columns on the façade. A central, courtyard-like atrium extending across three bays rises five storeys; the atrium is bounded by a single-loaded corridor that leads to open plan offices. Similar to the NBD, the entry sequence for the CBK is planned to provide experiences of compression 
and expansion; in the case of Kuwait, the sequence extends, and visitors pass through a series of distinct spaces, including a thickened wall at the entry and the service zone, before entering the atrium. In response to the harsh sunlight in the Gulf, Jacobsen filtered light into the atrium using roof lights. The façade responds to the climate through a system of horizontal louvres spanning between the vertical columns expressed on the façade, which results in the tower block appearing as a light volume that contrasts with the massiveness of the solid boundary wall.

The façade treatment of the CBK could be viewed as an adaptation of the mashrabiyya used to control light and reduce glare in some parts of the MENA region. However, the extensive renovation of the building that occurred in the mid-1980s clearly revealed that the mashrabiyya-like devices were not enough like mashrabiyya for some. In addition to drastically altering the appearance of the building, the renovation negated the conceptual clarity evident in Jacobsen's original building.

The façade was radically altered as the louvres were replaced with precast panels intended to invoke 'traditional' architecture with arches and dark-coloured, lattice-like screens that replicated, rather than recalled, mashrabiyya. The interior was not spared as the atrium was filled in, and decorative flourishes and a poorly executed extension of the building left the project muddled in terms of massing. There were also significant changes to the interior that affected both formal clarity and functional efficiency. As Dana Aljouder has pointed out, the political climate in Kuwait in the 1980s was tenuous, and the conservatism that impacted the political sphere also impacted the reception of what were viewed as "Western" ideas. ${ }^{13}$ The fact that the CBK building was altered so dramatically from Jacobsen's original design indicates perhaps not so much a rejection of the building per se but rather a rejection of the fact that a public building such as the CBK was not stylistically derived from what was considered to represent what some deemed to be 'appropriate'.

The oscillation between acceptance and rejection of architectural expressions perceived to be from abroad tended towards positive reception of 'imported' models at the time that the CBK required a new headquarters. HOK in collaboration with PACE was awarded the commission in 2003 following a limited competition. The 40-storey tower has a triangular floor plan; a diagrid exoskeleton supports a glazed façade oriented towards the north to provide views of the Gulf while the remaining two façades are clad in stone and treated as solid planes with small punched openings.

The orientation of the building itself could be considered a climate-responsive measure to protect from heat and glare. The overall appearance of the building indicates that the demand for visual references, a demand which resulted in the renovation of Jacobsen's original building for the bank, were no longer 
necessary. Instead, it was vital for the building to have an 'iconic' presence as indicated by the following quote from a CNN broadcast that is highlighted on HOK's website: "Kuwait City is soon to welcome an iconic new landmark to its skyline". ${ }^{14}$

The emphasis on the iconic evident in the new CBK building has become a dominant concern in architectural production in the Gulf since Dubai's ascendancy at the beginning of the twenty-first century. Projects across the GCC, with the notable exception of Oman, reflect the competition for investment and prestige that could serve to attract capital, enhance reputation, and support the effort to gain regional economic and political prominence. While some projects seek to instantly buy legitimacy through importing institutions rather than building foundations through enhancing capability and capacity over time, there have been others that seek to lead in terms of technological development. For example, the Burj Khalifa has led to a number of advances in engineering for tall buildings. However, the global race to build ever higher is not necessarily fuelled by the need for increased density in urban areas but rather by aspirations to merely prove that a city or nation possesses - or can secure - the financial resources necessary to compete in the race to build higher. As I described in "Restricted by Scarcity, Striving for Greater Bounty: The Role of Architecture in Making Dubai", the status-enhancing potential associated with boasting the world's tallest building is deemed to be more important than the monetary costs of construction and continued maintenance:

When considering the relationship between architecture and economy, the physical attributes and architectural aspects of the Burj Khalifa are less important than the way in which the building was part of a larger strategy aimed at establishing Dubai as a major city capable of competing on a global scale. The extent of media attention garnered by the Burj Khalifa and the appearance of the building in films from Bollywood to Hollywood have contributed to promoting Dubai across the world. Unlike the exchange value of International City, which is established by the resale through 'flipping' apartment units and rental returns, the Burj Khalifa has enhanced Dubai's status in the region and beyond..$^{15}$

While attaining the moniker 'iconic' for the Burj Khalifa and the new CBK may fulfil a client's desire, there are few high-rise buildings in GCC countries that consider how the typology could be transformed to respond to the particular climate and contexts in the Gulf. ${ }^{16}$

As mentioned above, the new CBK does respond to the climate of the Gulf through building orientation and façade treatment to counter solar radiation, but ultimately the reliance on familiar contemporary tropes such as the diagrid, tapering, and 


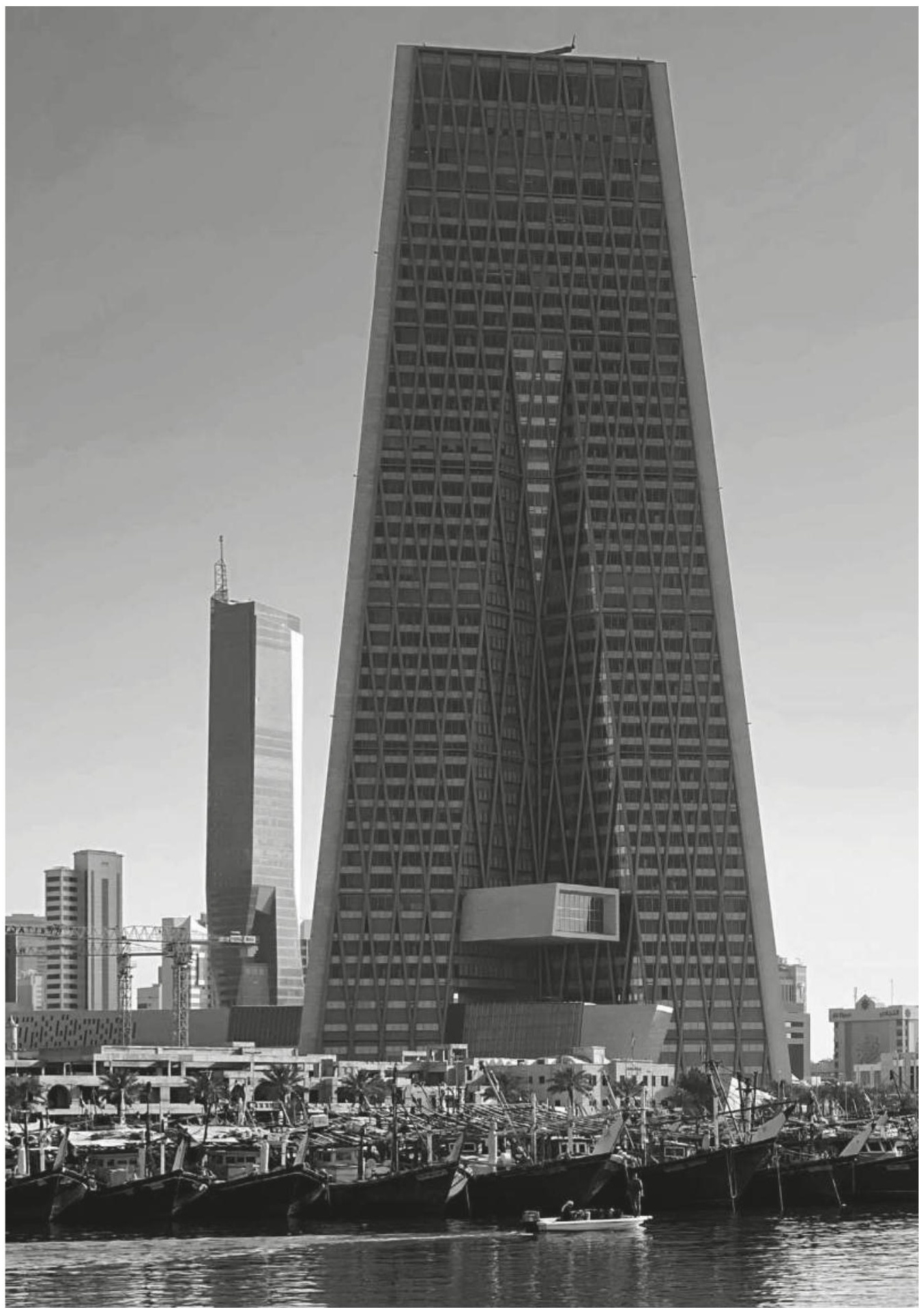




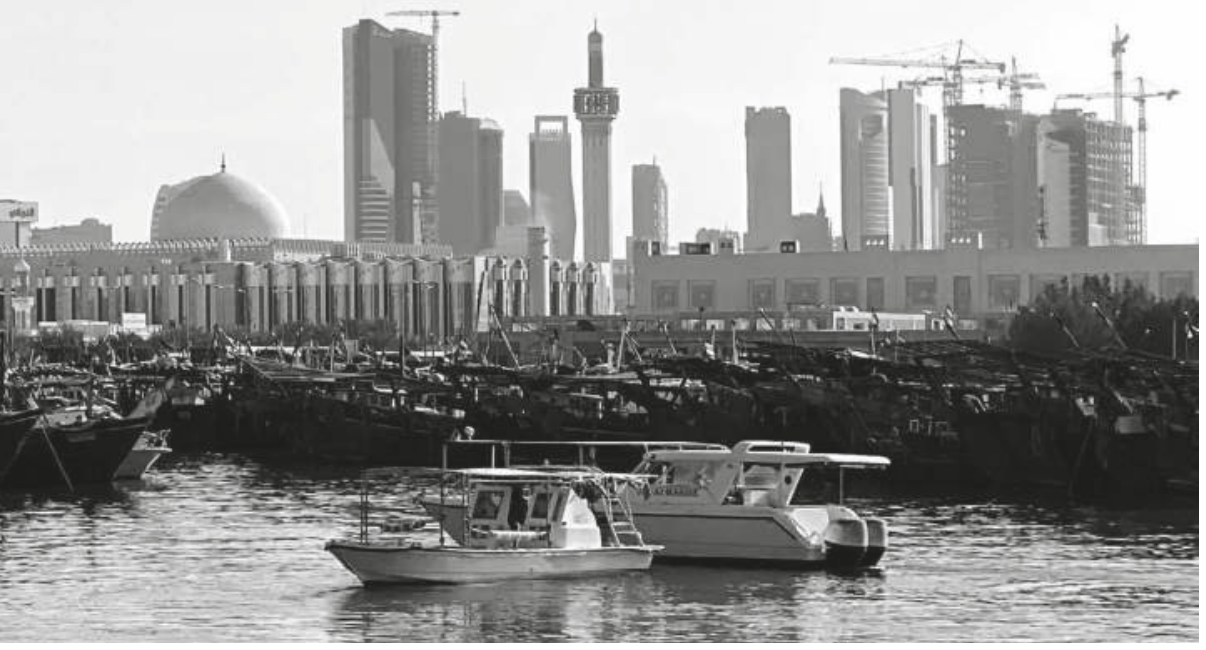




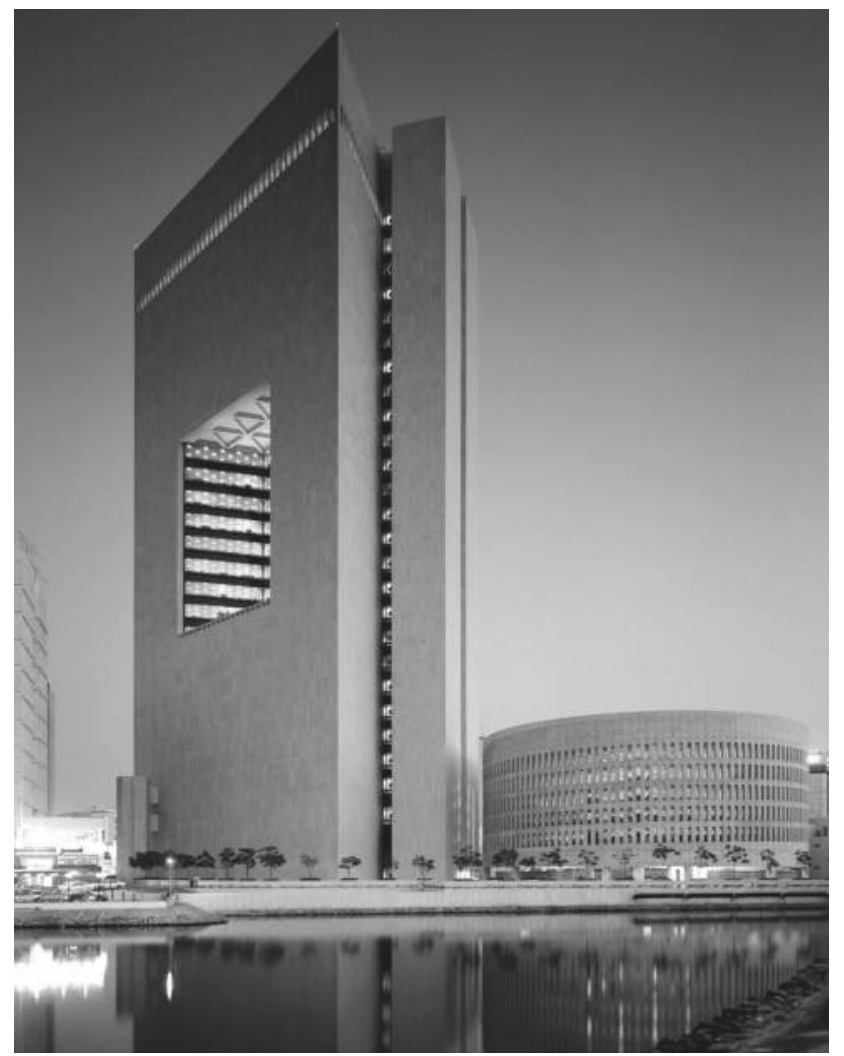

SOM, National Commercial Bank, Jeddah, Kingdom of

Saudi Arabia, completed in 1983 (Source: (c) Wolfgang Hoyt/Esto,

1985. Reuse not permitted).

cantilevered volumes ensure an iconic presence without the need for exploring spatial or formal strategies that could differentiate the building in terms of its architecture. In contrast, the National Commercial Bank (NCB) in Jeddah, Kingdom of Saudi Arabia (KSA), designed by Gordon Bunshaft and SOM and completed in 1983, provides an example of a building that derives its iconic presence from a clear, rigorously executed architectural idea with a concern for climate and context.

The NCB occupies a prime site adjacent to an area of Jeddah known as Al-Balad, which contains buildings of historical significance, and at the juncture between Al-Manqabah Lagoon and the Red Sea. Since being declared the official port of Makkah in the seventh century AD, Jeddah has grown in size and stature and attracted a cosmopolitan population that brought building traditions from other parts of the MENA region. In spite of the deterioration of a number of buildings of historical significance, 
a portion of Al-Balad designated "Historic Jeddah, the Gate to Makkah" was inscribed on the United Nations Organization for Education, Science and Culture (UNESCO) World Heritage List in 2014. Although all of the criteria for inscription were not met, the Advisory Board Evaluation concluded that Historic Jeddah did meet requirements related to architecture. With reference to criterion (ii), which requires that nominated properties "exhibit an important interchange of human values, over a span of time or within a cultural area of the world, on developments in architecture or technology, monumental arts, town-planning or landscape design", the Advisory Board noted the following:

\footnotetext{
Jeddah was for centuries the most important, the largest and the richest among these settlements, and today Historic Jeddah, the Gate to Makkah is the last surviving urban site along the Red Sea coast still preserving the ensemble of the attributes of this culture: commercial-based economy, multicultural environment, isolated outward-oriented houses, coral masonry construction, precious woodwork decorating the façades, and specific technical devices to favouring internal ventilation. ${ }^{17}$
}

The site of the NCB was significant within Jeddah and the location on the Red Sea at the mouth of Al-Manqabah Lagoon was prominent. As the building could be viewed from Historic Jeddah, Bunshaft and his colleagues were faced with the challenge of addressing how it should respond to the immediate context.

When comparing the architecture of the NCB in Jeddah and the new CBK building in Kuwait, there are superficial similarities as both are based on triangular floor plans; however, Bunshaft's seemingly simple plan belies a spatial complexity derived as a result of a $v$-shaped subtraction from the plan, rotated in seven-, nine-, and seven-floor increments, to create a vertical triangular void through the centre of the building that functions as a courtyard. The wall surfaces that result from the $v$-shaped subtraction are glazed to allow views, but the windows are shaded from direct sunlight. A 15-metre-high, public banking hall with a mezzanine level fills the triangular floor plan and forms a solid base for the tower; executive offices on the top level of the building also occupy the full triangular floor plan and serve to create a solid cap, visually lightened by alternating vertical openings around the perimeter of the building. A separate six-storey, circular parking garage is connected via a rectangular service and vertical circulation core, distinguished as an independent element through the use of deep reveals.

The NCB in Jeddah was shortlisted for the Aga Khan Award for Architecture, and a comprehensive technical review was completed in 1989 as part of the award process. The technical review included a local report to "evaluate some of the socio- 
cultural aspects" of the building. ${ }^{18}$ As part of the research carried out for the report, a questionnaire was developed in order to gather information regarding the perceptions of employees, customers, and neighbours in the vicinity. Feedback was also obtained from a group of professionals, architects, and planners practicing in Jeddah. The questionnaire asked respondents to consider the compatibility between the NCB and the context; and employees (75\%), customers (83\%), and residents who lived nearby $(76 \%)$ reported that they found the building to be homogeneous with the traditional buildings in the surrounding area. Given that the building was shortlisted for the Aga Khan Award for Architecture presumably because of some degree of sensitivity to the context, it is interesting to note that only $20 \%$ of the professionals surveyed perceived the building to be homogeneous in terms of its relation to the buildings of Historic Jeddah. Equally interesting are the findings related to exterior appearance and general impression of the building. Those surveyed were asked to respond to the question related to appearance by stating whether they "like", "dislike", or "do not know". For this question, $63 \%$ of employees, $44 \%$ of customers, $60 \%$ of professionals, and $52 \%$ of nearby residents indicated that they "liked" the exterior. The question related to general appearance asked respondents to express whether they "admire very much", "admire", or "do not know"; $86 \%$ of employees, $94 \%$ of customers, $80 \%$ of professionals, and $84 \%$ of nearby residents stated that they "admire very much" the general appearance of the building. ${ }^{19}$

The Aga Khan Award for Architecture is one of the few award programmes that carries out multistage reviews of shortlisted buildings; and although one could question the formulation of the survey questions or the validity of results based on the number of respondents, the results provided in the local report for the technical review of the NCB raise issues related to elusive notions of 'identity' that permeate discussions of the built environment. Surveying various approaches to architecture in the Gulf through projects for the CBK and the NCB serves to frame a discussion related to identity. Rapid growth, the lack of a coherent unified approach to urban design and planning, and the overwhelming demand to deliver visually arresting icons to attract the attention of investors has led to criticism that Gulf cities 'lack identity'. The criticism stems from an essentialist position that assumes that cities in the Gulf have lost an 'essence', once manifest in the appearance of buildings and in the urban fabric, such as that found in extant buildings in Historic Jeddah and in restorations and reconstructions in Dubai's Al-Fahidi, Doha's Souq Waqif, and Sharjah's Al-Mareija neighbourhoods.

Adopting an essentialist position relative to Gulf cities denies of the complex interplay of forces that have shaped architecture and urban form, assumes that all Gulf cities developed 
according to a similar trajectory and were subject to the same forces, and fails to recognize the impact of exchange of knowledge and practices through extensive networks across the Gulf, Red Sea, and Indian Ocean. It is perhaps more useful to consider architecture and urbanism in the Gulf in terms of the acceptance of or resistance to ideas that that have been adopted and, in some cases, adapted. Even adopting ideas without adaptation is an explicit choice from among the myriad of other possibilities. Writing on adoption or adaptation in relation to the formation of personal identity, lan Hacking has written that

\footnotetext{
[People] can make tacit or even explicit choices, adapt or adopt ways of living so as to fit or get away from the classifications that have been applied to them. These very choices, adaptations or adoptions have consequences for the very group, for the kind of people that is invoked. What was known about people of a kind may have become false because people of that kind have changed in what they believe about themselves. ${ }^{20}$
}

Tracing the development of the buildings for the CBK, and a comparison with the NCB headquarters in Jeddah, provides insight into the ways in which the adoption and adaptation of architectural ideas reveals changing views related to the built environment. It also suggests that the reception of architectural ideas is contingent upon both time and place.

\section{The problems of reproducing the past}

The diverse approaches to architecture in the Gulf are evident in the range of stylistic tendencies observed within and across the major cities, from the calligraphy-covered Museum of the Future in Dubai to the windmill-bearing Bahrain World Trade Center. As noted in the introduction, successive building booms have transformed the built environments throughout the region, and periods of extraordinary growth have often been followed by lamentations over the loss of a past perceived to be superior to the present. As noted in the introduction to this chapter, Saba George Shiber, who is increasingly quoted in relation to his cogent critique of the changes in Kuwait in the late 1950s and early 1960s, expressed concern over the absence of "profound urban and architectural concepts" in the projects replacing "Old Kuwait". And Janet Abu-Lughod has cautioned against Orientalizing tendencies that give rise to essentialist claims about cities in the Islamic world while advocating for learning from the past and also recognizing that the conditions which gave rise to cities in the region have fundamentally changed. While both Shiber and Abu-Lughod were writing with acute awareness of the complex relationship between the built environment and the broader social, cultural, and religious context, the calls for preserving and maintaining buildings 
constructed during the period from the 1950s until the beginning of the twenty-first century have tended to focus on outward appearance rather than the specific qualities or the particular context-specific responses that are important considerations when assessing the significance of a work of architecture.

The desire to acknowledge the value of mid-twentiethcentury buildings is warranted, and there are numerous examples that demand serious consideration and critical assessment. While the CBK building from the 1970s and the NCB designed by Gordon Bunshaft and SOM are rather insensitive to the urban context, perhaps necessarily so given their function, there is evidence of a considered approach to formal structure, spatial character, and climate responsiveness. The fate of the Jacobsendesigned CBK resulted from a lack of recognition of the value of the building and from broader societal forces, rejecting the appearance of the original façade in favour of what was deemed to be 'traditional' expression.

The early twenty-first century fascination with mid- to late twentieth-century buildings, if limited to a concern for outward appearance, ultimately devalues the potential of architecture and perpetuates the pervasive view that the 'identity' of cities can be made - or remade - by constructing icons or making stylistic choices. Jacobsen's design for the CBK and the NCB demonstrates how façades can be used to mitigate the impact of solar radiation, and the buildings also illustrate how the treatment of façade is commensurate with strategies related to, for example, the distribution of interior space, location of service zones, and design of structural systems. If one begins, and ends, with the façade of notable precedents in the region, then there will be reason to lament the loss of lessons that could be learned from the recent past to inform the development of more sensitive approaches to architecture in the present and future. 


\section{Notes}

1 International Monetary Fund [IMF], United Arab Emirates: Statistical Appendix, IMF Country Report No. 06/256

(Washington, DC: 2006), 15.

2 IMF, United Arab Emirates: Statistical Appendix, IMF Country Report No. 09/120 (Washington, DC: 2009), 9.

3 IMF, United Arab Emirates, 2006, 15.

4 IMF, United Arab Emirates, 2009, 9.

5 The World Bank, https://data.worldbank. org/indicator/SP.POP.TOTL? locations=KW.

6 Saba G. Shiber, The Kuwait

Urbanization (Kuwait: Kuwait Government Printing Office, 1964), 74.

7 Janet Abu-Lughod, "The Islamic City - Historic Myth, Islamic Essence, and Contemporary Relevance", International Journal of Middle East Studies 19, no. 2 (May 1987): 172.

8 Ibid., 173.

9 Leslie Sklair, The Icon Project: Architecture, Cities, and Capitalist Globalization (Oxford: Oxford University Press, 2017), 2-3.

10 "Dubai Creek Harbour", accessed August 15, 2019, https://www.emaar.com/ en/our-communities/dubai-creek-harbour/ dubai-creek-tower.

11 "Unique Cultural Visa Aimed at Turning Dubai into a Cultural Hub", Gulf News, October 1, 2019, https://gulfnews.com/uae/ unique-cultural-visa-aimed-at-turningdubai-into-a-cultural-hub-1.66822670. 12 For a discussion of the National Bank of Denmark, see Carsten Thau and Kjeld Vindum, Arne Jacobsen (Copenhagen: Arkitektens Verlag, 2002), 508-521.

13 Dana Aljouder, "Monologues with Bureaucracy", in Acquiring Modernity, ed. Noura Alsager (Kuwait: National Council for Culture, Arts and Letters, 2014), 10-12.

14 Ibid.

15 Kevin Mitchell, "Restricted by Scarcity, Striving for Greater Bounty: The Role of Architecture in Making Dubai", in Economy and Architecture, eds. Juliet Odgers, Mhairi McVicar, and Stephen Kite (London: Routledge, 2015), 222.

16 Roberto Fabbri, "IconiCity: Seeking Identity by Building Iconic Architectures in Kuwait", Gulf Affairs (Autumn 2016): 13-16. 17 The International Council on Monuments and Sites [ICOMOS], Historic Jeddah, the Gate to Makkah (Kingdom of Saudi Arabia) No 1361, 94, http://whc. unesco.org/en/list/1361/documents. 18 Serge Santelli, Aga Khan Award for Architecture, 1989 Technical Review Summary: National Commercial Bank, 0684.SAU, unpaginated, https://s3.useast-1.amazonaws.com/media.archnet. org/system/publications/contents/736/ original/FLS0746.pdf?1384748560.
19 Ibid.

20 lan Hacking, The Social Construction of What? (Cambridge, MA: Harvard University Press, 1999), 34. 


\title{
THE CORNICHE The representation of Doha's waterfront and its institutional buildings
}

\author{
Jumanah Abbas
}


On the night of February 22, 1982, the Sheraton Grand Doha Resort \& Convention Hotel opened its doors to the residents of Qatar. The then ruler of Qatar, Sheikh Khalifa bin Hamad AlThani, and his advisors in addition to pioneering prime ministers, leaders, and respected officials of the Gulf region attended the official opening of the hotel. The ceremony was grand and broadcasted on national Qatari TV. The show host described the programmes and facilities of the hotel, including a bowling alley, health and fitness centre, multiple tennis courts, swimming pool, gift shops, restaurants, multipurpose exhibition space, and convention centre. Towards the end of the broadcast, the camera zooms out to capture an aerial view of the hotel, glistering in light on an empty land. Built on a reclaimed coastline, the hotel served to reflect the nation's progress towards independence and political autonomy from British rule. As such, the Sheraton would represent the ideal type of architecture for future planning of the waterfront, known as the Corniche. ${ }^{1}$ The ziggurat-shaped structure, its bold terraces, and strips of punctured windows introduced progressive standards of modern architecture to Doha, the capital city of Qatar. The prefabricated materials and construction methods were new forms of technology, distinct from local building practices. Many residents likened the hotel to a spaceship that had slowly landed on a new reclaimed area, known as Al-Dafna (Arabic for 'the buried') district, and inaugurated the development of the Corniche. ${ }^{2}$ One observer was Sophia Al-Maria, the American-Qatari artist and filmmaker, who narrated an account wherein the hotel as a "mothership", a "herald of the future and a promise to the past", in her dystopian fictional memoir. ${ }^{3}$ In the novel The Girl Who Fell to Earth, Al-Maria portrays the Sheraton as a luxurious monument that represents the onset of Doha's modernization period. These two different modes of documentation, the televised and the fictional, reflect the ways in which the Sheraton was a microcosm of Doha as a modernist city emerging in the 1970s. Throughout the late twentieth century, the state of Qatar was committed to the modernization of the Corniche that accompanied the construction of the Sheraton. ${ }^{4}$

The Corniche is a man-made semi-circular road and promenade that connects the city's port to today's Al-Dafna business district. Signalling the start of the Corniche, the port on the south was once a site for customs exchange and for facilitating the flow of goods, information, and knowledge. ${ }^{5}$ Rectangular settlements and cement buildings marked the land behind the port, which served to embody the old part of the city. After Qatar gained independence in 1971, the newly founded state would draw on architectural, infrastructural, and urban projects to establish itself as a nation. The Corniche would be the ideal site for such large-scale investment and for the state to use the aesthetics of modernism to display power. The state's intentional choice to place modern institutional buildings along the waterfront, not in 
the historic part of the city, elevated the architectural status of the newly established, central, administrative state as modern, independent, and physically disconnected from the city's old urban fabric. The waterfront promenade and road became characterized by state-funded projects, geared towards modernization of the city's infrastructure, housing, and public services. ${ }^{6}$ In this chapter, I focus on the making of Doha's Corniche and the processes behind the modern state-institutional buildings - the Sheraton hotel, the Ministry Complex, and the Museum of Islamic Arts - that marked the waterfront's architecture landscape. Against an urban examination of the undertaken strategies to define the modern architecture along the Corniche, I trace how the built environment was integral to political ambitions and nation-building. To do so, I use archival material, official documents produced by the Ministry of Urban Planning, sketches, and realized or unrealized proposals for the waterfront. Such study serves as a reflection of the complex relations between the governments, local consultants, and agencies building the image of the nation. Whereas the existence of a nation requires geographical boundaries and borders, it is crucial to situate the nation as a set of ideas, processes, and power relations in my analysis and to identify how architecture was an essential medium in the production of the nation and its architectural landscape. With that goal, I situate the reclamation project as at once a nationalist and a futuristic endeavour, one that endured the city's incongruous development.

The burgeoning discourse examining urban planning in Doha may provide a comprehensive overview of contemporary as well as historical analysis of the city's intensive urbanization. These studies mainly explore the evolution of the capital city from a fishing village to a prime regional and international hub. They are predominantly about the oil economy and consist of narratives on the oil industry that mobilized the spatial transformation of Doha; they often map the transition of the city's urban infrastructure from a pre-oil settlement to a post-oil global city. Described as "an emerging regional metropolis" by Ashraf Salama and Florian Weidmann, Doha is a city depicted as an important global capital capable of positioning and reinventing itself on the map of international architecture and urbanism. ${ }^{7}$ In Demystifying Doha, the authors meticulously document and analyse, on the one hand, the city's models of urban governance and, on the other, the effects of placemaking strategies and branding mechanisms as by-products of the global condition: they provide a unique, inclusive overview of the city's architecture and urban transformation. In addition, scholar Khaled Adham draws an interconnected relationship between the city's economic transformation and its emerging urban scenes across three different eras. The first one is centred on the pearling industry, territorial disputes, and implications of British geopolitics to curb colonial interests in the region in the 1930s. 
Adham emphasizes that two interrelated socio-economics forces, tribal affiliation and the pearling industry, influence urban structure during the early decades of the twentieth century. ${ }^{8}$ The second era covers the modernization of the city and its transition from a British protectorate to an independent nation-state and from a pearl- to an oil-based economy. In the third and last era, from the 1990 s to the present, Adham states that the sea was treated as a commodity space captured by an increasing, global, real estate market. For any urban scholar examining the transformation of Doha, the Corniche is an important site of inquiry. The reclaimed land has been the locus for the articulation of social, spatial, and symbolic structures across different stages of the city's growth and remains an important site for the state until today.

Contributing to this rich literature on Doha's urbanism, my analysis of the Corniche registers the processes behind the waterfront's urban governance as a way to map the past and future pathways of the Corniche's urbanism. My contribution to the architecture and urban discourse is focused on the figures involved and the mediums used in the spatial articulation of the Corniche. In what proceeds, this chapter is divided in three sections, focusing on the myriad of architecture along the Corniche and the negotiations behind the built landscape. Each built structure reveals a particular narrative about the dynamic interaction between certain figures and local agencies. Taken together, they illustrate the numerous strategies embedded in personal invitations, design briefs, and international competitions, launched by officials in the government to build the city's future.

\section{Reclaimed land and local agencies}

The formation of a central government and administrative system led by Sheikh Khalifa, coupled with the onset of the oil industry, catalysed the city's architectural transformation starting in the early 1970s. The introduction of a centralized administration signified a shift in Doha's urban fabric. ${ }^{9}$ As the Sheikh stepped in as ruler, a formal institutional environment was enshrined, and the responsibility for urban planning was distributed among specialized branches of the growing bureaucracy. Annual British reports on Qatar discuss the improvements in the structure of the government in the early 1950 s, stating that a comprehensive government system was formed in the mid-1970s. ${ }^{10}$ There thus emerged mainly two ministries tasked to administer Qatar's urbanization: the Ministry of Municipal Affairs and Agriculture and the Ministry of Public Works. Both were responsible to build the image of Doha as the "Modern City Centre". ${ }^{11}$ In the article "Dressing up Downtown: Urban Development and Government Public image in Qatar", Sharon Naggy indicates that urban interventions and proposals for the Corniche would be one of the many consequences of the state's bureaucratization procedure and discovery 


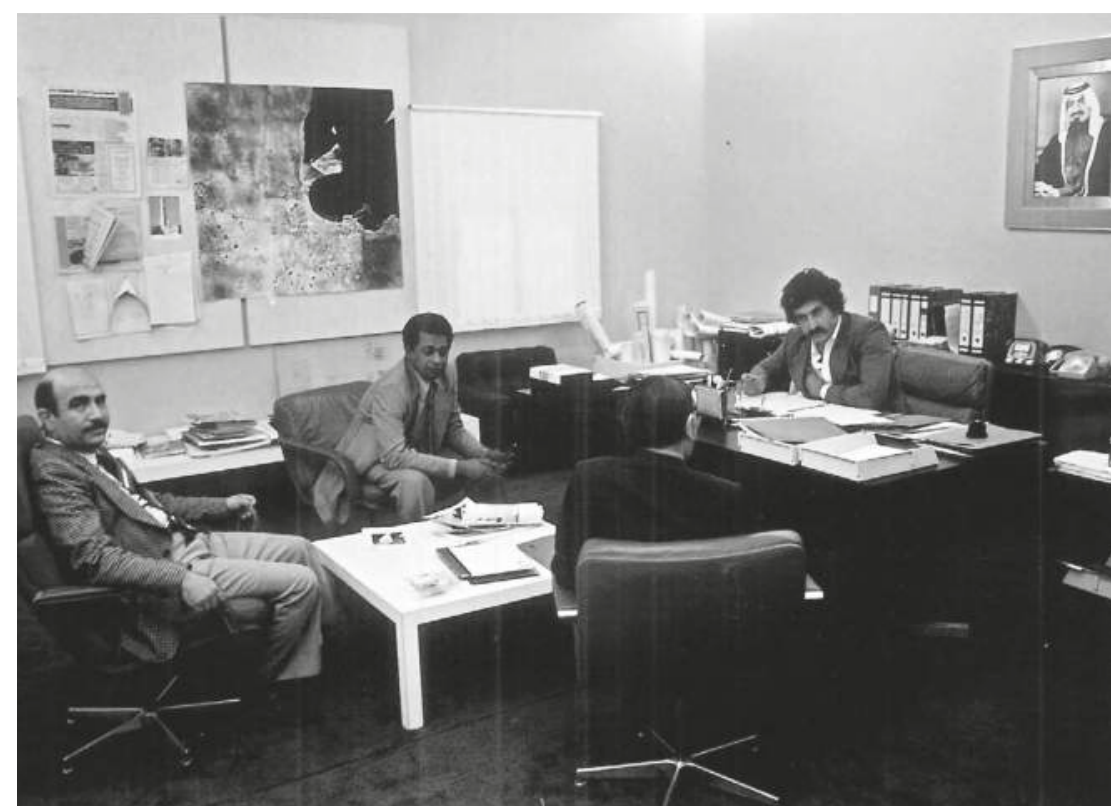

Hisham Qaddumi at the Amiri Diwan, 1976 (Courtesy of Hisham Qaddumi. Source: Atlas Bookstore. Reuse not permitted).

of oil. She provides a critical account of the ideologies and technologies recommended by foreign consultants and demonstrates how they transformed existing local infrastructures. Such drastic urban reformations were not fully embraced by government officials; one official criticized this form of urbanism, stating that "we have caught all of [your] Western social ills". ${ }^{12}$ However, the procedure involved far more than consulting foreign architectural and urban firms. When the Amiri Diwan (the state's governmental house) would step in to take charge of a particular high-profile project, relations within and between the different ministries were complicated, especially in the case of the Corniche: the project of conjuring land from the sea was executed by the Amiri Diwan throughout the 1970s and1980s.

The development of Doha's Corniche was coordinated through a network of ministries, local figures, foreign architects, and urban planners - all working together. There was a dedicated urban planning office at the Amiri Diwan, mainly responsible for the development of major urban schemes. Hisham Qaddumi, the president and founder of the architecture consultancy Arab Architects in Jordan, - was appointed as the planning and development advisor at the Amiri Diwan and the director of the Diwan's technical office in Qatar. While working with the government from 1974 to 1987, Qaddumi was not only responsible for supervising 


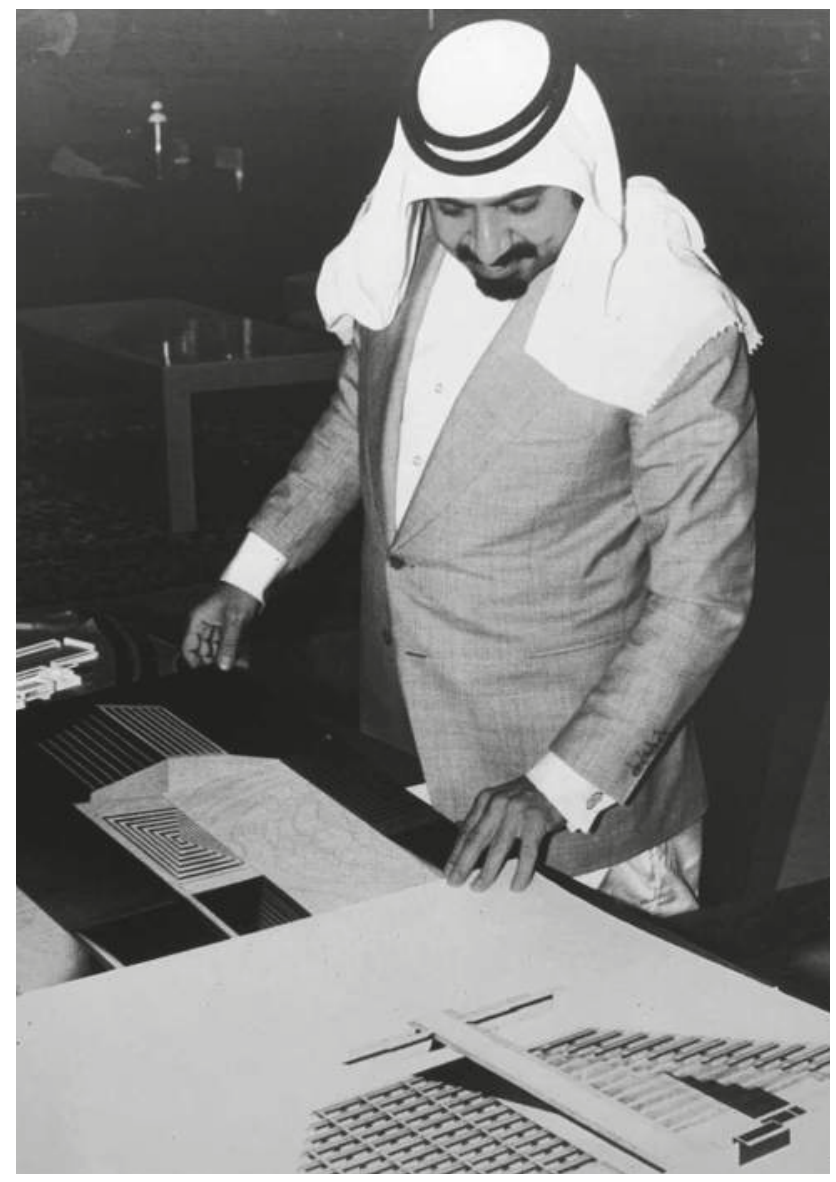

fig.2 The former Emir of Qatar, Sheikh Khalifa, looking at an elevation drawing of the hotel, n.d. (Source: Ministry of Public Works, Qatar. Reuse not permitted).

the design and construction management of projects along the Corniche, but he was also a key figure in developing national and regional plans for Doha as well as defining necessary strategies. For instance, as he held graduate degrees in economics and in architectural engineering from the University of Texas, he was involved in producing, reviewing, and evaluating the national budget for the city's urban development. In an interview during the 2014 Global Art Forum in Dubai, Qaddumi spoke about his fascination with William Pereira's work while studying architecture in Texas. ${ }^{13}$ He describes coming across the American architect's photo on the cover of Time, accompanied with the September 6, 1963, article title "Vistas for the Future" on the left side of the cover, while he was working at the Amiri Diwan. Qaddumi remembers calling the 
firm based in California in 1975 right after reading the Time article and commissioned Pereira to design the planned Sheraton. He indicates that two weeks after the phone call Pereira arrived in Doha. The American architect was enthralled by the size of the city, in particular the undeveloped part that would be later known as New Doha, consisting of the Corniche and Al-Dafna districts. Sheikh Khalifa had a clear vision of the Corniche as an important site to build the city's new infrastructure, and Qaddumi was entrusted with a role to execute the vision. The planning office run by him overrode the jurisdiction of any other ministries involved in planning the Corniche, gaining full control and supervision of the development of the Corniche.

Subsequently, the local planner, the foreign architect, and the government engaged in a series of epistolary exchanges, outlining that the architectural proposal was to be initially designed by Pereira, supervised by Qaddumi, and then approved by the government. According to Qaddumi, Pereira was neither an influential architect nor a leading pioneer of the modernist movement; nevertheless, he was a prolific architect who produced over 400 projects during his lifetime. ${ }^{14}$ William Pereira and Associateshad in 1976 designed a training facility in Iran and would later design the Baghdad International Airport in 1978. In addition, Pereira's architectural practice had a bland connection with the modernist narrative; his pioneering futurist visions, reflecting his synergetic design, appealed to the Jordanian architect. When the American architect came to Doha in 1975, Qaddumi referred to Pereira as a young architect eager to be part of building the image of a new nation. His contribution would be of excitement, confidence, and change. Pereira shared his unrestrained enthusiasm with Sheikh Khalifa as he would partake in attuning to the visions of the urban planners and architects; Qaddumi was equally excited because Pereira was "simply rooted in the modernist movement". ${ }^{15}$ Both would draw future plans for Doha starting from the Corniche, which would be the main backbone connecting different parts of the city together. This period in Doha's urban planning was marked by optimism and determination, reflecting the patron's willingness and determination to develop the architecture of the waterfront promenade. The government's direct interference in the Corniche's public sphere was crucial since the reclamation project was not subject to the same financial and bureaucratic limitations as other sites.

In 1976, the main focus in the urban planning of Doha was the reclamation project that began from the northwest of the city, the site of the new Sheraton. The deep water was dredged, and the total project area covered 2,000 hectares. In planning the execution of the project, Pereira indicated that the newly constructed and engineered "city edge" would be the "defined interface between the land and the sea", one that would "not [be] ambiguous". ${ }^{16}$ To execute this vision, Qaddumi and Pereira 


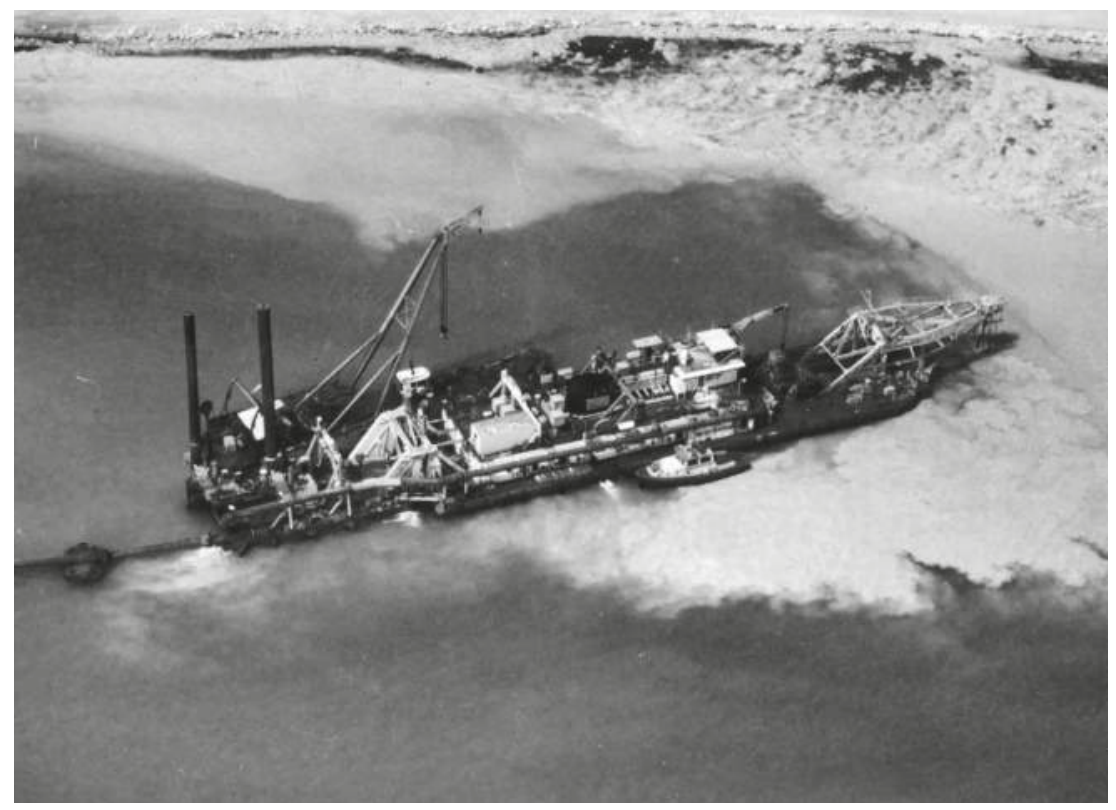

fig.3

Shaping Doha Bay, 1976 (Courtesy of Hisham Qaddumi. Source: Atlas Bookstore. Reuse not permitted).

took long walks along the Corniche and discussed how to plan the waterfront border. They conversed about the genesis of the Corniche and its uses for the future, speculating on what type of public space would attract the citizens and residents of Qatar and what the private use of the reclaimed land would be like. Qaddumi alluded to the body of water as the "generator" and any other institutional buildings as "magnets". ${ }^{17} \mathrm{He}$ outlined three objectives to develop the Corniche. The first objective was to distil the nearby water from any impurities. The second was to complete the semicircular sweep of the Corniche. The last aim was to increase the availability of lands at a reasonable price to accommodate different 'magnets' along with the 'generator'. Both Qaddumi and Pereira drafted over 40 different sketches of the Corniche. In these sketches, Pereira proposed to position the Sheraton at the southern end of the Corniche and a national university around the northern outskirts of the city, a location intended to encourage the future growth of the city. Pereira proposed a potential location for another important landmark to be built. The location would be in front of the port at the southern end of the road, and he suggested to design two grand buildings, marking the start and end of the waterfront promenade and road. Evident in the sketches, there were many propositions for the future growth of the Corniche and visions of how the reclamation project could act as a gateway for 

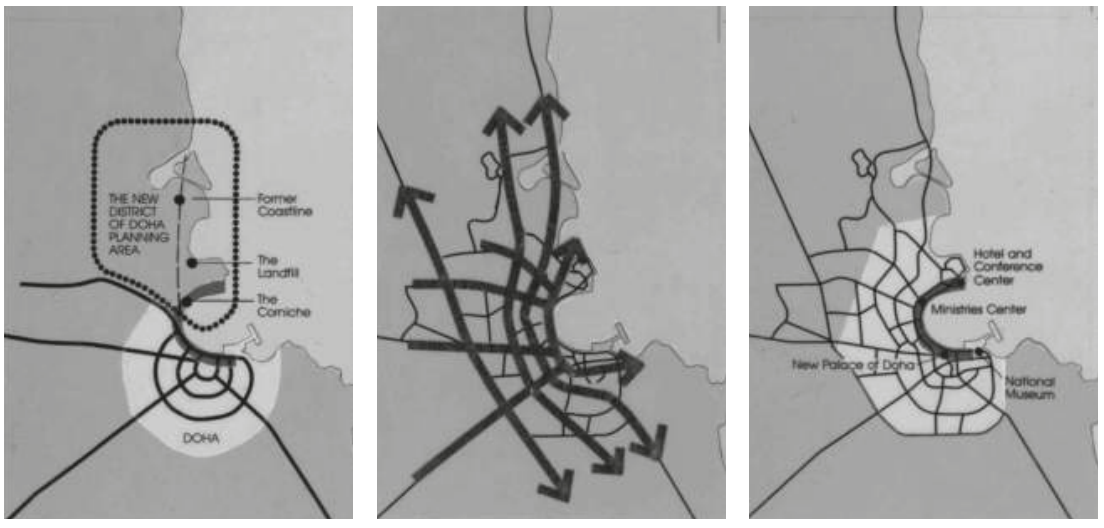

William Pereira, concept diagrams for the Corniche, n.d.

(Courtesy of Johnson Fain, Los Angeles. Reuse not permitted).

the city's future development and circulation. ${ }^{18}$ The Corniche road would consist of five consecutive roundabouts: each would connect to the neighbourhood surrounding the bay and would extend to potential developments on the outskirts of the city.

The Corniche underwent intense urbanization and represented the materialization of the nation. The project would also showcase advanced mobility in the city. The goal was to create a road linked to the movement of the city: of people, of goods and cargo moving from and to the port, and of the circulation between neighbourhoods. Both architects agreed that the transformation of the waterfront was linked to the representation of the city as consisting of and functioning through the Corniche's networks of circulatory systems. ${ }^{19}$ In addition, another objective was to populate the road with a series of 'magnets' and form a Ministry Complex. Across different stages of design and development, Qaddumi would work towards achieving these two goals. He was a key figure in coordinating the planning of the Corniche as he would mediate between the ruler's vision to establish the physical infrastructure for the independent nation and the architect's practices affiliated with modernism. As such, a reading of the dialogues behind the construction of the Corniche highlights the role of local actors in mobilizing the waterfront's development, often overshadowed by the attention casted on the urban transformation of the city from barren land to a modern one.

\section{The hotel and ministry complex}

The development of the Corniche was isolated yet also crucially connected to the rest of the city. The Corniche became a place of site of experimentation and architectural invention, distinct from the rest of the city. Whereas William Pereira was the 
main urban planner of the Corniche and the newly reclaimed area, other urban planners were later invited to develop other parts of Doha. ${ }^{20}$ Unlike other neighbourhoods, the Corniche would consist of megaprojects, such as ministries and government branches, which would reflect the state's political and economic investment in modern architecture. The hope was that these modern state institutions would change the perception of the city as well as afford it global status. Hence, the urban position, programmes, and function of the buildings as well as the architectural motifs and visual language were critical strategies considered by the technical planning office when they articulated the design brief for the government's physical infrastructure. For instance, the position of the buildings forming the Ministry Complex and the governmental palace would be parallel to the arc of the Corniche at a straight angle; the Sheraton was to be built on a distinct man-made island, strategically designed to accommodate the hotel's exterior programmes and landscape design. According to Qaddumi, the position of these ministries in relation to the hotel was carefully planned by him and Pereira. ${ }^{21}$ The ziggurat shape, in this context, and the building's unprecedented shape and scale would contrast strikingly with the uniform line of the rest of the governmental buildings, forming a visual backdrop to the Sheraton. The construction of the hotel took more than five years, due partly to the introduction of pre-fabricated concrete panels and steel structures. The interior of the Sheraton was a space of modern luxury; the spacious grand atrium was identified by many locals and residents as 'the majlis' as it functioned as a social gathering space. Qaddumi would speak highly of the hotel as the emblem of the Corniche, using the analogy of the Sheraton as a spaceship that inaugurated the rapid modernization and growth of the Corniche.

At the same time the Sheraton was under construction, a brief for the Ministry Complex was distributed to many international architects already visiting the Gulf and designing projects for these newly independent nations. The content of these briefs stressed the importance of designing institutional/governmental branches with a modern, formal language. From there, Qaddumi would direct the architects about the scope of these projects, the given opportunities, and the limitations, emphasizing the maintenance of a specific cultural element to drive the design concept. In Hisham Qaddumi's personal archive, many submitted proposals for the Corniche visualize the Ministry Complex differently and engage in various ways with modern aesthetics. For instance, in October 1976, Kenzo Tange presented a proposal for the Ministry Complex to the technical office of the Amiri Diwan. In his proposal, Tange accommodated the various operations and functions of the ministries in a logical and systematic manner by consulting with each ministry representative about the ministry's main operations. He intended on forming "an inter-ministerial and 


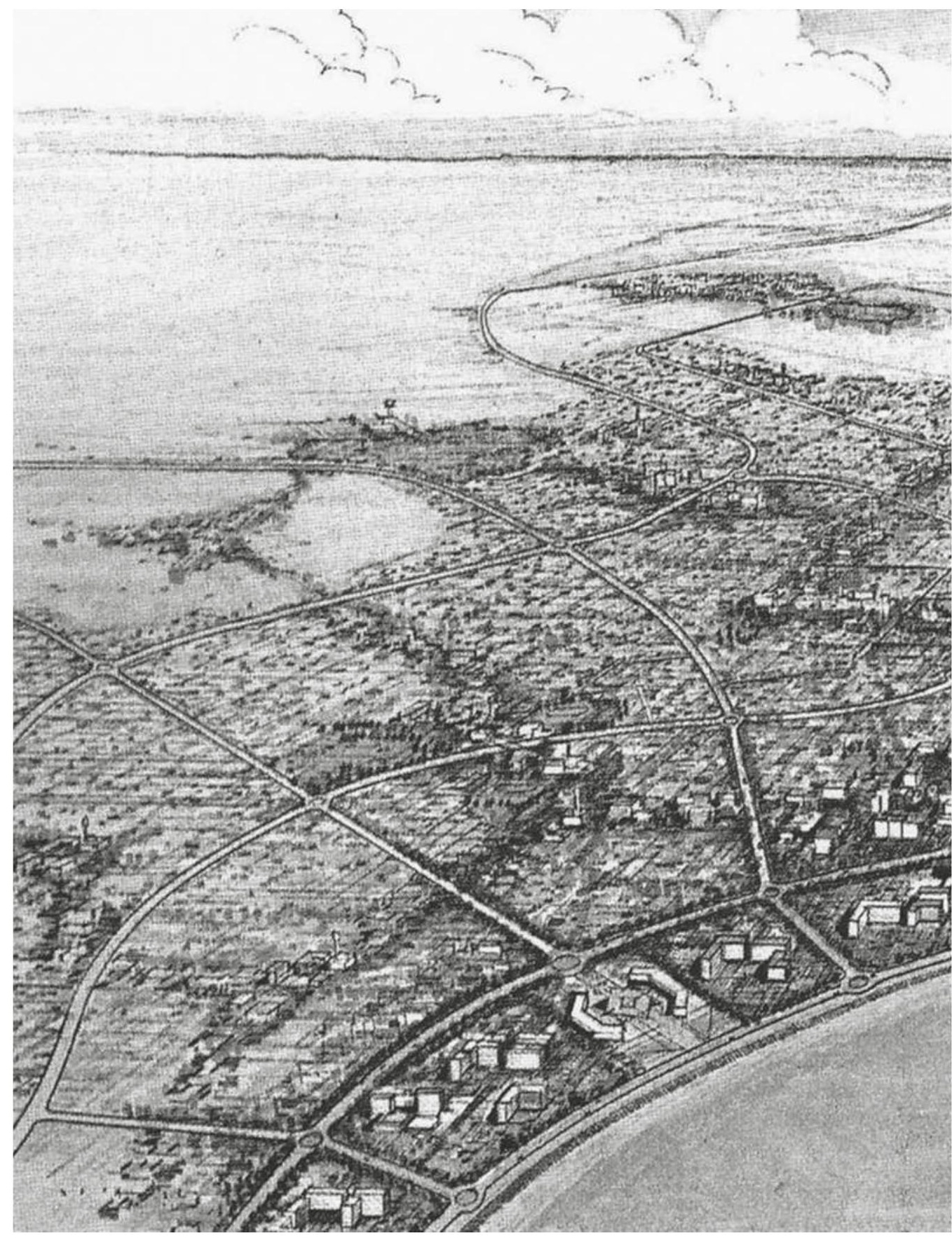

fig.5 Master plan by William Pereira showing north district of Doha, n.d.

(Courtesy of Johnson Fain, Los Angeles. Reuse not permitted). 

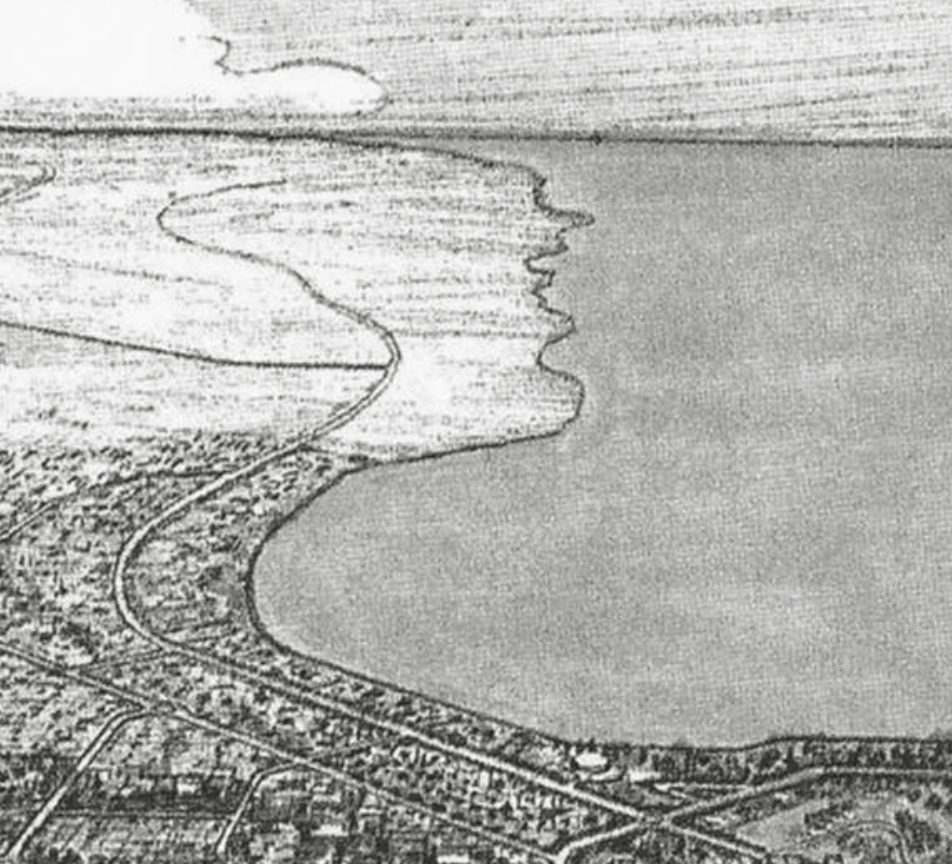

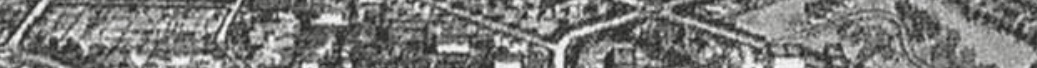
6.7.2. 15.

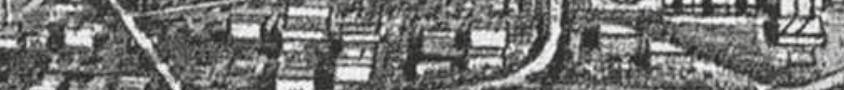

\section{9

\section{(2)}

atso. (5)

anterist

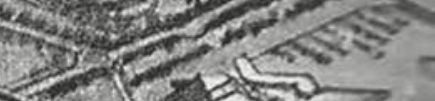
(1)
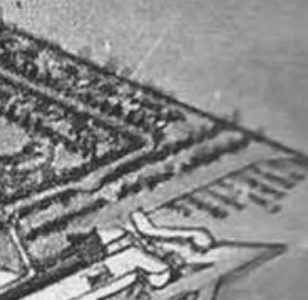
intra-ministerial function to help identify the respective needs and requirements" and on generating a "well trailed program". ${ }^{22}$ Therefore, the resolution for the Ministry Complex design was dependent on adapting a modular system along with a series of plazas and enclosed pedestrian walkways in conjunction with the inter-ministry complex. Such design would be flexible; it would accommodate any unaccounted facilities as well as any potential reorganization and extensions according to future demands. Studying the relationship between each ministry and the Amiri Diwan, Tange was way highly critical of the significance of the Corniche as "the ceremonial boulevard serving the Government Centre". ${ }^{23}$

However, the state did not have enough funds to execute the construction of Tange's ambitious proposal. Instead, the Ministry Complex was built by a wide range of international architects whom Qaddumi invited, reflecting how architecture had become a vehicle for the application of Qatar's state sovereignty. The Ministry of Finance was designed by Kenzo Tange while the Ministry of Information and Communication Technology and the National Theatre were designed by Triad Cico. The post office, a building that embodies the essence of Doha's global communication network, was designed by Twist Whitley Architects and ComConsult. The four sides of the tapered roofs are carried by a semi-monocoque series, mimicking the traditional means of delivering messages. Moreover, two housing structures by George Candilis, one at the Corniche and the other one at Umm Said north of Doha, were designed to accommodate 216 international staff persons. The social housing at Umm Said is still present whereas the second one behind the post office was demolished in 2003. Qaddumi indicated that social housing at the Corniche was "very problematic" since the modular design was a hasty response to accommodate the increasing government staff and the influx of immigrants. ${ }^{24}$

Here, I want to highlight that the ministries of the Ministry Complex are not only representative of the modernization project but also stand until today as important landmarks and artefacts. Naggy indicated these buildings consolidated the public's appreciation towards the government's investment in this form of architecture, stating that "the public overwhelmingly applauds the Diwan's role in 'preserving a Gulf architecture'". ${ }^{25}$ In addition, the aim behind the intentional preservation of these modernist buildings, as Trinidad Rico sets forth in her overview of preservation practices across different parts of Doha, does not align with dominant policies of preservation that consider materiality and cultural values. $\boldsymbol{\Delta}$ Instead, the survival of these buildings reflects 'informal ways' for keeping a certain visual language and preservation practice. ${ }^{26}$ They, in addition, promote certain powerful narratives about nationalist agendas to maintain grand institutional projects. On 
that account, encountering the architecture of these government branches is not about encountering certain aesthetics and affiliated designers. These buildings also set the groundwork for the spatial infrastructure of the current and upcoming generations of the nation's architecture. The landscape of the waterfront promenade is now populated by a series of governmental buildings contrasting against the background of the city's incongruous commercial and business towers located in West Bay.

\section{The museum}

The bloodless coup and the change of Emir in 1995, coupled with the reorientation of Qatar's economy towards expanding its economic tier, led the state to invest over $\$ 130$ billion dollars in the city's architecture. Adham states that these changes mark a turn in the urban growth of Doha, concurrent with many political and economic transformations in the 1990s. ${ }^{27}$ Malls, skyscrapers, gated residential communities, iconic museums, and the new stadium and sports facilities represent the urban and real estate explosion. These emerging urban scenes and their "phantasmagorical architectural forms", as described by Adham, were fulfilling Doha's visions to be a global city - museums in the Gulf region, in particular, played a strong role in the creation of a public sphere and in marking an entry to the global stage. ${ }^{28}$ To accommodate these new ideals, the Corniche still visibly remained as a site for expansion and investment in architecture and the image of the nation. It would set the context for these emerging architectural forms as the Corniche presented itself with a rich history and multiple narratives.

In 1997, the Aga Khan Trust for Culture announced an architectural competition to design a Museum for Islamic Arts, on the side opposite the Sheraton, in coordination with the urban planning ministry. At that time, the main architectural features of the Corniche's landscape were the Sheraton, the state ministries, and a social housing structure by George Candilis accompanied by a few commercial buildings and future proposals. One of these future projects was the Tower of Doha by Pereira, to be built at the southern edge of the Corniche. The building's terraced landscape would seep into the edges of the sea; the main circulation core would act as a supporting system for the suspended volume, holding programmes such as an observation deck, a plant conservatory, restaurant, and a museum. Another was the Qatar National Library, proposed by Arata Isozaki to be built by the end of the twentieth century, characterized by the suspended terraced slabs and three supporting piers. The library would be the second-largest building on the Corniche because of its unprecedented form and height. Next to the library would be another two eminent projects: the first one was a theatre space by Isozaki with a prominent pristine sphere floating above ground, the second by Zaha Hadid who 
proposed a design for an exhibition space. ${ }^{29}$ Even though these projects were unrealized due to the lack of state funding and the decrease of oil production in the early 1990s, these proposals do not only showcase the different visions for the Corniche but also reveal the different stages of the Corniche's development at the nexus of nation-building and architectural invention. Most importantly, these unrealized projects were conceived as part of the Corniche's built landscape, which the assigned architect had to acknowledge and respond to as part of the exiting spatial environment and infrastructure.

The six finalists were Richard Rogers, James Wines, Zaha Hadid, Rasem Badran, Oriol Bohigas, and Charles Correa. ${ }^{30}$ At the end, the jury selected Charles Correa and Rasem Badran as the finalists, choosing Badran as the final winner of the competition. His design focused on creating a dialogue between the citizens, city, and museum. Badran's concept was centred on certain principles of Islamic architecture. For instance, each mass was oriented around a courtyard, while both, the courtyard and the mass, were covered with a structural skeleton and wood panels, recalling older parts of the city. However, Badran's project did not move forward; Luis Monreal, general manager of the Aga Khan Trust for Culture in Geneva, who was part of the original jury of the competition, later persuaded the Emir that I. M. Pei would be a good fit to design the museum. ${ }^{31}$ Moreover, the Museum of Islamic Arts would hold more programmes than originally planned, for the Emir wanted to establish a cultural and education centre in conjunction with the museum. The change of the architect and brief reflects how ongoing discussions between the ruler and officials can unforeseeably dictate the physical structure of the Corniche.

Concerned by future projects overshadowing the museum, the Chinese-American architect changed the location from territorial to reclaimed land 60 metres from the shore, at the southern end of the Corniche. Similar to the hotel's site, the position of the museum was physically isolated on a man-made island so that the building would be visible against the city's skyline. The formal composition of the museum was inspired by the eminent Mosque of Ibn Tulun in Cairo, misplacing one culture and reconnecting with another one. This form of cultural displacement contributes to the homogeneity of Islamic architecture; it serves as a "principal unifier" that legitimizes the museum as the premier vessel of Islamic art and artefact. ${ }^{32}$ This was in favour of the architect as his intention for the design was to embrace different cultural narratives. ${ }^{33}$ The conceptual design of the museum would, nonetheless, align with the new regional development conditions that consolidated the city in an international network based on personal interests. Moreover, the landscape of the museum mimics the semicircular shape of the Corniche and acts as an extension to the Corniche's promenade. Writ large, the museum serves as 
another critical landmark contributing to the waterfront's modern institutional buildings. The overall transformation of the Corniche is rooted in accumulated strategies and projects led by figures within Qatar's governance and leadership. The Corniche landscape was built by representatives of different architectural styles, symbolic actors invited by certain figures, representing the capital city as an international hub comprised of different values, cultures, narratives, and identities.

\section{Corniche's future pathways}

The Corniche is a place of layered historical imaginaries and visions. It's a place of an idealized past and possible future. To analyze the Corniche is to reveal a history rich with stories, concepts, and aspirations. This narrative of the hotel, Ministry Complex, and museum dominating the landscape of the Corniche aims to contribute to the existing literature about Doha's urbanism and to expand the tools used for these studies. Architecture and urban discourse are multifaceted and can be enriched with personal anecdotes, design briefs, forgotten proposals, or competition entries. Such narratives and tools can promote the exchange of ideas and values between different actors as well as reveal the mediums essential in building Doha's Corniche.

In this chapter, I highlighted the practices and strategies behind the Corniche's built landscape. In foregrounding the historical context of the government's structure and ways of executing projects, the present development of the Corniche is apparent. The Corniche would be constantly revisited and replanned by other architects, urban planners, and designers. Their proposals would be driven by government and private investment. In 2003, another competition by the same Aga Khan board was launched in coordination with the government. The aim of the competition was to design a new multipurpose venue, the International Arts and Culture Centre, emphasizing an innovative landscape design for the promenade of the Corniche. The brief stressed the importance of the institutional buildings that hold a prestigious place in Doha's modernist landscape. The finalists were Kamel Louafi, Martha Schwartz Partners, Patrick Berger, Jean Nouvel, and Zaha Hadid. However, a final winner was not selected, and the project remains unrealized. These competition entries are, arguably, an epitome of the dynamic ways in which the urban planning and architecture of the Corniche grow and transform according to different visions, institutional figures, and political ambitions.

As previously noted, the investment in the waterfront's architecture can shift according to capital concentration and power relations. The Corniche was once empty land occupied by few cement buildings eventually demolished and replaced by new, modern, and potentially 'Gulf' architecture that reflects the agency and role of the Diwan office in articulating Doha's waterfront. The 
constellation of the Corniche's institutional buildings signposts a corresponding history between the visions of the government and the purpose of these modern buildings, a relationship important for future developments. As the Corniche is becoming progressively characterized by commercial and real estate projects, the modern buildings linger as the skeleton of the waterfront's built environment. The spatial infrastructure of the Corniche remains as it is, and these buildings' persistent existence sets the stage for further growth. The Sheraton, Ministry Complex, and Museum of Islamic Art are symbolic representations of progress as well as political and economic independence. They form a body that endures through time and into the future: these buildings are inscribed in a vehicle of political aspiration that mediates between a forged past and potential futures. They captured the Corniche's form of future that the city would long live with.

\footnotetext{
Acknowledgements

I would like to thank Eva Schreiner and Ziad Jamaleddine for providing generous feedback to the first draft of this text. Trinidad Rico gave insightful comments and critiques on later drafts, together with Sultan Al-Qassemi, and Roberto Fabbri. Lastly, I would like to express my deep gratitude to Fatma Al-Sehlawi for sharing the pictures and materials used in the research.
} 


\section{Notes}

1 See Sharon Nagy, "Dressing up Downtown: Urban Development and Government Public Image in Qatar", City and Society 12, no. 1 (2008): 125-147; Khaled Adham, "Rediscovering the Island: Doha's Urbanity from Pearls to Spectacle", in The Evolving Arab City: Tradition, Modernity and Urban Development, ed. Yasser Elsheshtawy (Abingdon: Routledge, 2011), 218-257.

2 Amongst those who identify the hotel as a spaceship are Sophia Al-Maria, author of the fictional novel The Girl Who Fell to Earth, and Hisham Qaddumi. 3 For more on the description of the Sheraton Hotel, see Sophia Al Maria, The Girl Who Fell to Earth: A Memoir (London: Harper Perennial, 2012).

4 Nagy, "Dressing up Downtown", 125.

5 Mehran Kamrava, ed., Gateways to the World: Port Cities in the Persian Gulf (Oxford: Oxford University Press, 2016), 3. 6 Adham. "Rediscovering the Island", 228.

7 Ashraf Salama, and Florian Wiedmann, Demystifying Doha: On Architecture and Urbanism in an Emerging City (Farnham: Ashgate, 2013), 1-5.

8 Kaltham Al-Ghanim, Al-mogtama' al-Qatari men al-ghawss ila al-tahadour (Doha: Dar Al-Sharq, 1997), 222.

9 Florian Weidman, Ashraf Salama, and Alain Theirsteins. "Urban Evolution of the City of Doha", Metu Journal of the Faculty of Architecture 29, no. 2, (2012): 46. 10 Nagy, "Dressing up Downtown", 128-129.

11 Ibid.

12 Ibid.

13 "Global Art Forum 8: 1972-82:

Spaceship Sheraton and the Making of Doha's Masterplan", Art Dubai conference with Hans Ulrich Olbrist, Shumon Basar, Hisham Qaddumi, Sophia Al-Maria, May 8, 2014, accessed March 25, 2019, https://www.youtube.com/watch?v= OG4QdVR8JWc.

14 Ibid.

15 lbid.

16 William Pereira Associates, New Doha Planning Studies: Project Book (Los Angeles, 1975), 3.

17 "Spaceship Sheraton and the Making of Doha's Masterplan."

18 William Pereira Associates, New Doha Planning Studies, 14.

19 "Spaceship Sheraton and the Making of Doha's Masterplan".

20 For instance, Qaddumi hired the British-based firm Llewelyn Davis from 1975 to 1977 , which conducted several statistical studies and estimated the increase of population in the upcoming years. The firm proposed changing the urban layout of the city by adding a series of consecutive roundabouts. He later commissioned the Lebanese firm Dar Al-Handasah and design consultancy firm Shankland Cox in the late 1970s. 21 These comments were made by Hisham Qaddumi in the Modern Qatar: Architecture \& Planning public talk at Museum of Islamic Art on 31st of March, 2018.

22 Office of the Emir, Master Plan for Government Centre by Kenzo Tange (Doha: September 1977), 40-41.

23 Ibid.

24 "Spaceship Sheraton and the Making of Doha's Masterplan".

25 Nagy, "Dressing up Downtown", 142. 26 See Trinidad Rico, "Modernism in Qatar: Survival through Reuse", chapter 12 in this volume.

27 Adham, "Rediscovering the Island", 237.

28 For more on the museum bloom in the Gulf linked to global developments, see Sonja Atassi and John Scwhartz, eds., "Introduction: Challenges and Directions in an Emerging Field of Research", in Archives, Museum and Collecting Practices in the Modern Arab World (New York: Routledge, 2016), 1-33.

29 This set of proposals was on display in the Making Doha exhibition at the Qatar National Museum, which was curated by Fatma AI Sehlawi, Samir Bantal and Rem Koolhas. The exhibition was on view from March 28 through August 30, 2019. 30 "International Competition for the Museum of Islamic Arts Doha, Qatar", Medina Magazine, April-June 1998, 104-111.

31 Oliver Watson, Museum of Islamic Art: Doha, Qatar (London: Prestel Publishing Ltd, 2008), 25.

32 Amale Andraos, "The Arab City in Representation", in The Arab City:

Architecture and Representation, ed. Amale Andraos and Nora Akawi (New York: Columbia Books on Architecture and the City, 2016), 15.

33 Watson, Museum of Islamic Art, 18. 


\section{OPERATIONAL PLANNING An alternative view of Doxiadis' project in Riyadh}

Faisal bin Ayyaf Al-Mogren 


\section{Introduction}

By the twenty-first century, a number of Gulf cities have become regional powerhouses, competing on the global stage economically, socially, culturally, and politically. This has not always been the case, though; the region's urban construct was different throughout much of the twentieth century when it was distinctly nonurban. In the case of Saudi Arabia, for example, only $10 \%$ of the population lived in urban areas in 1950, compared to $70 \%$ in 1985 and a staggering $85 \%$ by $2005 .{ }^{1}$ The typical historical dynamics of the region dramatically transformed during the second half of the twentieth century, largely motivated by the discovery of oil in commercial quantities and by the subsequent economic prosperity, which triggered major regional social, political, and economic changes. What had been a series of small, isolated, self-sufficient towns evolved into today's sites of global practices, contemporary architecture, rich culture, and economic affluence. A common scenario unfolded across the region: Western planners, arriving with full support and considered as a bridging force towards modernity, guided urbanization and modernization efforts. Typically, the planners came with clear tasks: to transform the organic fabric of old cities into a 'modern' one, often associated with Western images of modernity. The trend was region wide: The first ones were Minoprio, Spencely and Macfarlane in Kuwait in 1951. Then A. M. Munro devised Manama's plan in 1968, and later Katsuhiko Takahashi developed designs for Abu Dhabi in 1971. Llewelyn Davis came to Doha in 1974; John Harris made a plan for Dubai in 1960 and 1976; and most recently, $\mathrm{CH} 2 \mathrm{M}$ Hill \& CEG were engaged to plan Dammam in 1980. While all had a substantial influence in the development of the region, the present chapter focuses on the 1972 master plan of Riyadh, developed by the Greek planner Constantinos Doxiadis, known for its experimental urban design aspects.

Doxiadis' first introduction to Riyadh was in 1968, and timing was an important factor that increased his influence on the city's future development. Riyadh was, at that time, on the brink of development in a critical moment in the city's history that marked its transformation from a small town into today's largest Gulf city. However, there was little in place that would guide and plan this growth. The Greek planner filled that gap, producing the city's first masterplan in 1972, a tool that remained influential in shaping Riyadh's urbanity for the subsequent decades and its growth to become a modern city with global reach. Since its official implementation, the plan has become a subject of debate among urbanists, scholars, policy makers, and citizens. Few extol the plan; most scholars critique it, negatively.

The aim of this chapter is to explore Doxiadis' master plan and his legacy in the city and to provide an alternative understanding to the way he approached planning and influenced Riyadh's urban future. Before examining the project, it starts by 
discussing the site and reviewing Riyadh's pre-Doxiadis urban situation. Then, it provides an account of the Greek planner's introduction to the city and the planning process he conducted there. After detailing the plan's characteristics, the plan is critically examined from two contrasting perspectives, that of Doxiadis' adherents who highlight the pros of the plan and that of his critics, who mention the cons. The chapter concludes by considering the legacy of Doxiadis' work, exploring how, in spite of many practical limitations, the 1972 master plan is today still a major guiding force in Riyadh's growth. In addressing this point, the present text suggests that urbanists discussing the project often have a limited lens, resulting in a reductionist perspective that ignores Doxiadis' attitude and understanding of the field. Almost all planning efforts around the world are assessed as spatial exercises and according to physical criteria, be the planner Haussmann in Paris, Moses in New York, or even Harris in Dubai or Munro in Bahrain. Doxiadis' plans to modernize Riyadh are often discussed in a similar manner with a focus on the spatial components of the plan. This chapter, however, argues that the key to understanding the plan is to recognize the process it initiated: it created a flexible mechanism of growth that adapted to changing situations, allowing the city to territorially expand in the years to follow. This aspect reflects Doxiadis' theoretical position towards planning: understanding cities as living organisms that should not be bounded, he believed that the planner's role is not that of a builder or creator per se but rather that of a guide and facilitator for growth. This chapter takes Doxiadis' theoretical position into consideration to provide an alternative reading of the plan, suggesting that its adaptability is one reason why the plan has endured for decades. Rarely is Doxiadis credited for adopting a different approach to urban planning.

\section{The site}

The story of Riyadh's urban growth can be divided into distinct phases marked by clear critical moments of transformation. The early era is of Riyadh as a small, semi-isolated town. The first reliable record of its urban condition dates to 1902 when it had an area of one square kilometre and a population of 8,000 inhabitants. ${ }^{2}$ Construction of the Murabba Palace in 1938 marked a significant moment in Riyadh's history, not only because it led to Riyadh's expansion beyond its walls but also because, for the first time, it employed motorized vehicles in the construction process. People used to depend solely on mud for construction, but now they were able to transport other materials from different places, making buildings more stable and radically transforming the city's morphology. ${ }^{3}$ Another significant urban force was a programme to help Bedouins settle in urban areas. Banned at that time from residing within city walls, they resorted to constructing 


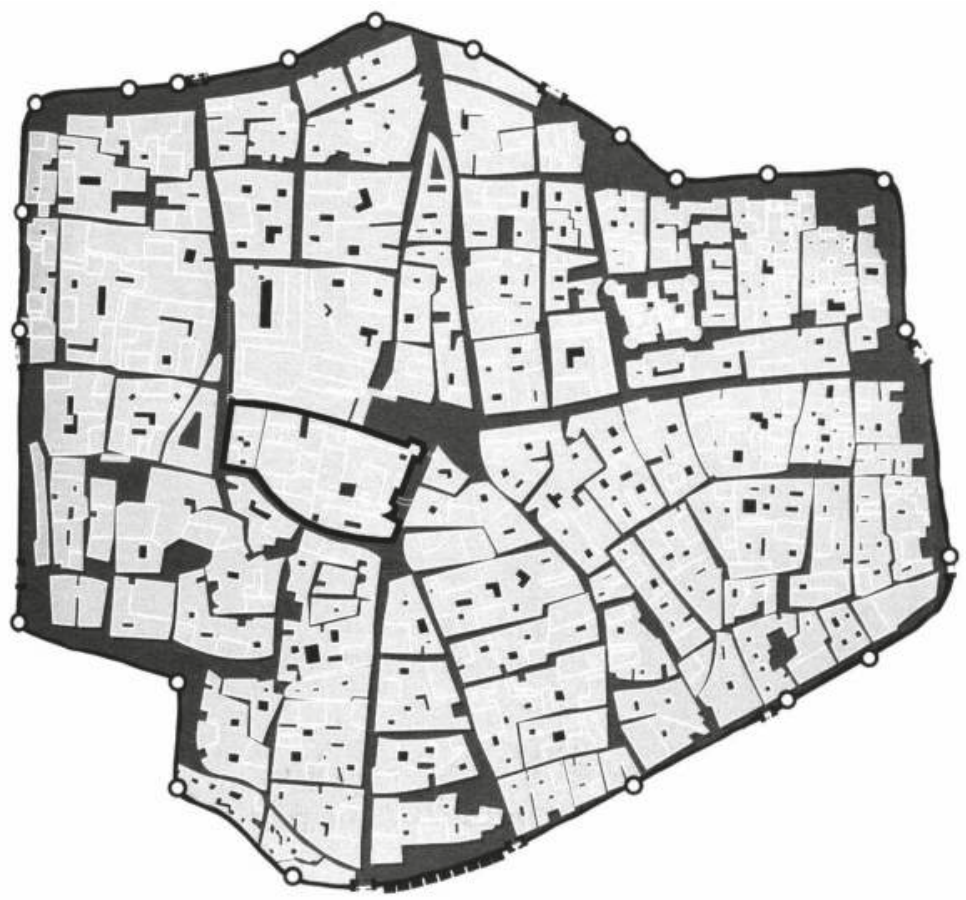

fig.1 Map of Riyadh, 1939 (Source: Arriyadh Development Authority. Reuse not permitted).

their own agglomerations just outside the walls and called them Al-Hilal. Clearly, the city was expanding and growing although in a slow manner. Riyadh's territorial growth was relatively limited, reaching around $3.5 \mathrm{~km}^{2}$, and it was only inhabited by about 50,000 people in the 1940 s, with a density similar to that of $1902 .{ }^{4}$

1952 was a watershed moment. What was originally a small town would develop into a major global city, a transformation catalysed by two simultaneous key events for the nation. First was the decision by the late King Saud to declare Riyadh as a new location of governmental agencies, issuing a royal decree that ordered their relocation to the city within two years. (In reality, the process took four years according to scholar Yousef Fadan.) ${ }^{5}$ The second moment was when Saudi Arabia signed an oil profit sharing agreement with the United States. A year earlier in January 1951, the Saudi government agreed to a fifty-fifty profit share with Aramco, leading to enormous economic wealth, expansion in the job sector, and intense urbanization processes.

These national dynamics unfolded powerfully in Riyadh and transformed its urban reality. The capital city became the hub of internal and external migration and the country's official portal 
to the world, and modernization efforts were impelled by a desire to command higher status and to represent a paradigm shift. Riyadh's territory grew to accommodate the population wave and soon reached $6.5 \mathrm{~km}^{2}$ : while the old town remained static, the new neighbourhoods, such as Al-Malaz, Al-Nasserya, and Al-Fouta, sprawled outward and blurred the boundaries of the old city. The population of the city also increased considerably: the growth rate hovered around 4.5\% between 1930 and 1950, but it almost doubled, reaching $8 \%$ between 1950 and $1970 .{ }^{6}$ As a consequence of this modernization effort, as a reflection of these new economic and social changes, and to accommodate the population influx, Riyadh became a large construction site with development projects in various areas of the city.

The initial pace of modernization efforts did not decrease in the coming years. Consequentially, Riyadh changed dramatically: it was reconfigured from a small city with high density and tight fabric to a new pattern with one-fifth the previous compactness and a street allocation scheme three times greater than before. ${ }^{7}$ Between 1930 and 1968, Riyadh's population grew elevenfold from 27,000 inhabitants to about 300,000 , with an urban footprint reaching $24 \mathrm{~km}^{2}$ that absorbed the airport, originally located eight kilometres outside the centre. ${ }^{8}$ Saudi Arabia, as a whole, was experiencing a rapid migration to urban centres, especially to the capital Riyadh, the major stakeholder in this dynamic. A significant development early in these efforts was the aforementioned Al-Malaz, a neighbourhood and housing project financed and constructed by the national government in 1953. That project represented the first time that Riyadh experienced the use of a grid as an urban strategy and of the villa as a building unit. Thus, it effectively set a precedent for development of Riyadh as well as of other major cities in Saudi Arabia.

Between the construction of Al-Malaz in 1953 and Doxiadis's arrival in 1968, many projects were under construction simultaneously across a city aiming to control its growth. Developers were arriving from all over the region, and the pace of urbanization increased exponentially. The fundamental challenge during this period became how to develop institutional management frameworks in the face of rapid growth and an increasing demand for services. Also, the definition of a holistic vision for the entire city, that could combine various and sundry efforts into a single whole, proved to be critical. ${ }^{9}$ Aware of these challenges, the government took multiple, consecutive steps to address these issues: the Ministry of Interior created the Directorate of Municipalities in 1953, later upgraded to become the Department of Municipal Affairs (DMA) in 1962. In December 1967, in the face of these new challenges, DMA signed a contract with Doxiadis Associates to commission the city master plan. This decision turned out to be a major moment in the city's urban development path. 


\section{The planner}

In 1959, Constantinos Doxiadis, a graduate of the Faculty of Architecture at the University of Dresden, Germany, was hired to devise a new capital for Pakistan. The city of Islamabad would be constructed from scratch to grow gradually. In planning Islamabad, Doxiadis employed design elements similar to the ones he would later implement in Riyadh despite the staggering difference in the scale of the two cities: Islamabad's project area was about $1,165 \mathrm{~km}^{2}$, making it almost four times the size of Riyadh. He conceptualized a grid using a two-by-two-square kilometre 'superblock,' the same unit with which he would experiment again later, as a modular system to cover the larger extent of the city. The Islamabad plan featured a trademark central business spine, the ability to indefinitely expand, and a prominent natural element, in this case the national park, all aspects similar to those that Doxiadis later envisaged for Riyadh. His project in Baghdad contained the same features. He was contracted at a time when Iraq was in the throes of popular movements and social unrest, and he was brought partially to set the disputes. Hiring the Greek planner indicated political will for change. The Baghdad commission was based on a planning model that emphasized growth, control, and efficiency, principles which would later become the hallmark of his work elsewhere and would be critical to his Riyadh project.

Besides ekistics, or the science of human settlements, Doxiadis had a number of key planning principles that he maintained throughout his projects, and they are evident in Riyadh and elsewhere. He always predicted that cities would grow much larger, anticipating that the world's urbanized population would expand from $33 \%$ in 1960 to over $97 \%$ in $2100 .{ }^{10}$ As a response came the idea of dynapolis, with the prefix 'dyna' indicating growth or development. It expresses the planner's view of the city as a living organism that should not remain static. He proposed that cities should be permitted to grow, their expansion unfolding along a single transportation axis that alleviates pressures of traffic, without bounds or limits in lockstep with the requirements of an increasing population.

This concept clearly echoes his belief in the 'linear city,' a concept and topic of tendentious debate among planning professionals at that time. To him, the linear city was an attempt to depart from the old, inefficient, static towns built around a centre since, in the current age of the automobile, this obsolete design tended to choke with overuse and traffic. Additionally, much like many of his modernist colleagues at that time, Doxiadis' plans adopted the renowned concept of the 'superblock,' which created neighbourhoods wherein internal vehicular access was controlled or prohibited. This offer of retail and services in close proximity allowed residents to fulfil their daily needs without stepping into a car. Moreover, the superblocks were surrounded by broad highway networks, able to process the traffic of a modern city. 


\section{The project}

Doxiadis' involvement in projects in South Asia and the Middle East made him known as a modernization agent in economically developing contexts, and this reputation is probably what led him to Riyadh. His initial contact with the Saudis occurred in 1962, but his first formal engagement was not until 1966 with the Ministry of the Interior. In 1968, Doxiadis opened his first office in Al-Malaz neighbourhood in Riyadh. The office's sole focus for the subsequent years became gathering data and information. A milestone of this research was the 1969 production of the first planning document, titled "Riyadh, the Current Conditions". ${ }^{11}$ It mainly consists of data analyses describing the city: the current situation in Riyadh, physical and social characteristics of the city, and most urgent challenges. Notably, there is neither mention of future plans nor previsions of what would happen in the coming years or of how Riyadh would or should grow. The scope of this document was to study the context before starting to envision the future.

By July 1971, Doxiadis finally disseminated the results of earlier efforts in a document titled "Riyadh, the Masterplan", a scheme that was formally approved by the Cabinet of Ministers in early 1972 and aimed to guide and control the city's growth until 2000.12 This plan was emblematic of the firm's main planning principles, clearly advocating for the idea of a dynapolis, where the physical growth was imagined in a linear pattern. The plan's physical footprint of this ideal city was about $304 \mathrm{~km}^{2}$, an area large enough - it was thought - to accommodate Riyadh's growth until the turn of the century, by which point Doxiadis anticipated that it would host 1.4 million residents. The document identifies two primary objectives. The first is to improve transportation and circulation at a desired speed, ameliorating transport connections and allowing people to move from base points to their destinations in the easiest and most efficient manner. The second goal is to divide the city into a number of smaller sectors or neighbourhoods, with each sector clearly defined, easy to manage, and selfsufficient in terms of services and uses with some unique aspects. The document has three key elements: highway catalogues that circumscribe superblock typologies and community classes; cityscale regulations that take into account density, zoning, type, height, and other characteristics; and a detailed design for individual action areas within the city centre that explains how the plan would be carried out in those locations, as they were imagined to serve as a model for other areas to follow.

Physically, the plan's scope consisted of a main northsouth commercial and transportation axis or spine along which the city could grow in a linear manner. The plan justified the decision to direct the expansion of the city towards the north, citing environmental, economic, historical, political, and social factors. From this commercial spine, residential areas would branch out in 


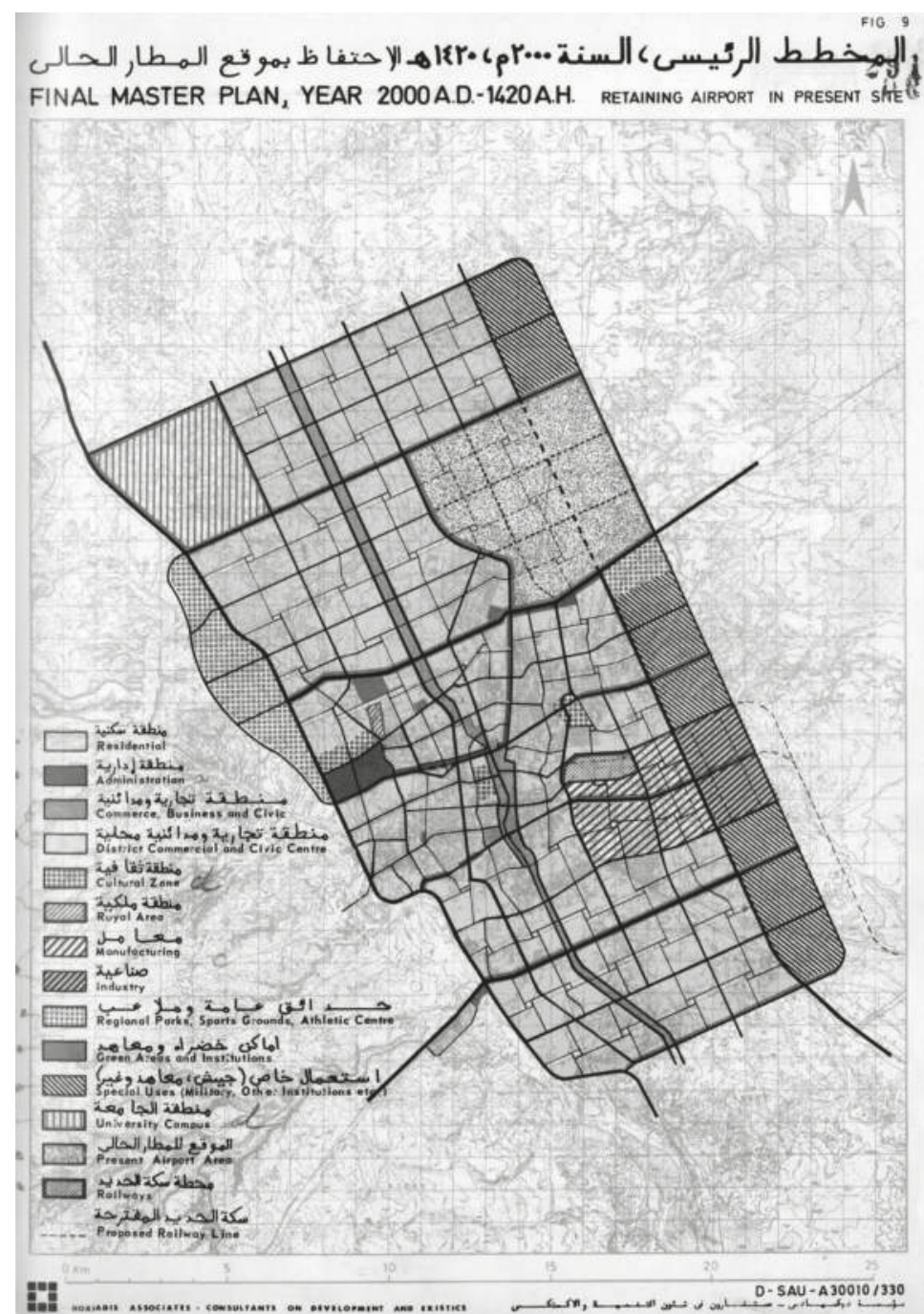

fig.2 Doxiadis Associates, 1972 Final Master Plan: Regulations (Source: Constantinos and Emma Doxiadis Foundation, Athens. Reuse not permitted).

a repetitive manner along the flanks by means of the two-by-twokilometre grid. The latter is Doxiadis' main physical legacy in the city, in which each constituent of the grid forms a superblock surrounded by highways that enable through traffic.

Each block represents a self-contained neighbourhood restricted to pedestrians, with services at a walkable distance and tailored for the residents. These blocks demonstrate Doxiadis' ideas of different class communities and their relationships to one 


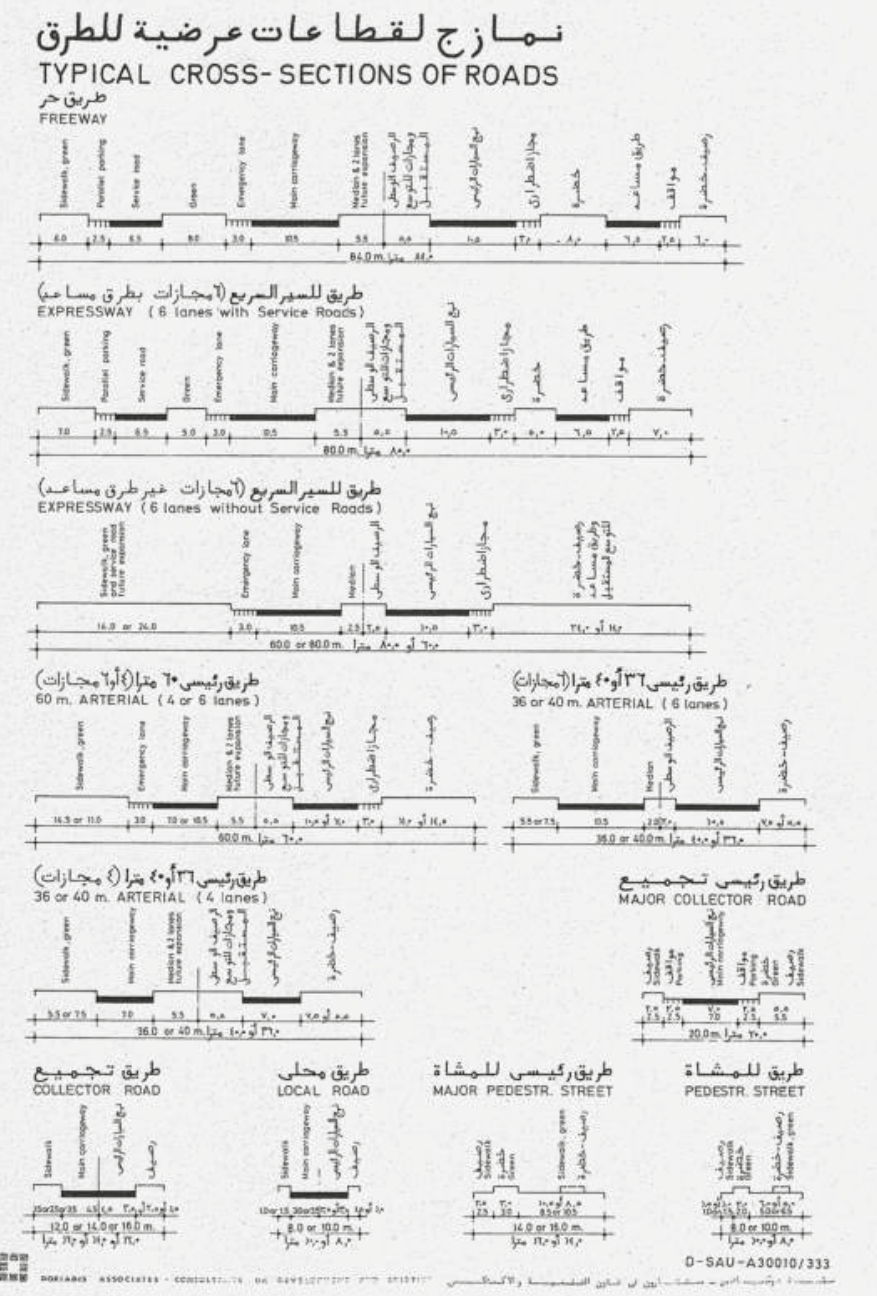

Doxiadis Associates, 1972 Final Master Plan: Highway catalogue, typical cross-sections of roads (Source: Constantinos and Emma Doxiadis Foundation, Athens. Reuse not permitted).

another. One of the plan's main considerations was to carefully design and allocate new roads, featuring a hierarchy and outline of functions for each one. It proposed a comprehensive road network with a total length of $457.8 \mathrm{~km}$; the streets would be configured on the grid to define and bound each block. This network was intended to connect the organic lineaments of the old city pattern to the new and highly regular grid, allowing for seamless transit between different parts of the city. Likewise, the built-up area of Riyadh was divided into three density levels: the further one 
progresses from the central spine, the lower the density becomes. The proposal's recommendations are also divided into three phases: the most immediate before 1975, the medium-term before 1980, and the long-term scenario envisioned for the year 2000. At the very end of the document, in just a small paragraph, the plan discusses issues of social and practical implementation.

\section{The debate}

As the subject of vigorous debate, Doxiadis's legacy in Riyadh is often judged cynically. On the one hand, his few adherents portray him as a hero to the city; the plan was a much-needed tool that arrived at a critical juncture in the city's development and aided its growth. ${ }^{13}$ At that time, Riyadh was expanding rapidly, and this expansion was occurring in a haphazard manner with little planning. According to Abdulaziz bin Thenayan, then mayor of the city:

Many people are building everywhere, they ask for permits, which they are given, but we do not know whether they should really build there, or whether they should go higher up. I cannot stop the people, there are no regulations, no zoning. ${ }^{14}$

Clearly, it was a critical moment, and a plan was urgently needed as intense growth was unfolding despite the lack of any clear direction. The new plan was successful in filling that gap and providing a framework for the unplanned growth to follow, and this is the point often emphasized by his supporters. Furthermore, the plan was effective in achieving the criteria that the architect targeted, regardless of the validity of that criteria. It was a plan that aimed to accommodate the city's rapid growth and to allow for a smooth, automobile-dependent, circulation pattern.

On the other hand, the master plan received fierce criticism from Riyadh-focused urbanists such as former Deputy Mayor of Riyadh Faisal Mubarak who often portrayed it as a major source for many of the city's current urban challenges. Their critical perspective wasn't utterly unjustified; much like many modernist planning efforts, Doxiadis' plan did lead to a number of adverse effects on the city's urban construct. It embodied International Congresses of Modern Architecture (CIAM) ideals of a utopian, post-industrial city model, where the built morphology is geared towards achieving efficient circulation and where its public spaces were dominated by automobiles. The plan's proposed form for Riyadh, while accomplishing the desired modernist efficiency, can be seen as extremely detached from the context, generic, and obsolete. Similarly, it also devotes little attention to Riyadh's natural traits. While the data collection phase included a thorough study of the city's topography and natural features, this study had minimum impact on shaping the urban strategy. The plan also contains negligible allocation 
of green open spaces; it specifies their significance as an element "of modern developed towns", yet it designates less than $2 \%$ of the city's territory to that use in one of the future scenarios. ${ }^{15}$

The plan's limitations were not only evident in physical aspects, but the planning process that Doxiadis employed was also itself extremely flawed. He was commissioned to plan for Riyadh up to the year 2000, and a careful, retrospective analysis reveals that it contained a number of misguided assumptions and predictions. In 1970, while Doxiadis' team were in the process of planning the city, Riyadh was home to 355,000 inhabitants. They predicted that the city's population would grow to reach 1,400,000 citizens by the year 2000 . Unbeknownst to them at the time, by 2000 Riyadh would count $3,800,000$ residents, more than twoand-a-half times their estimates. The team also predicted that in 1980 , the city would be home to only 685,000 inhabitants, but the city in fact reached that figure close to 1976. Likewise, their predictions of a 1990 population of 1,050,000 were surpassed before 1980. The planners underestimated not only the city's growth in terms of population but also its physical expansion. It was predicted that the city's footprint would reach $304 \mathrm{~km}^{2}$ by 2000 , but the city in fact reached $400 \mathrm{~km}^{2}$ by 1976 , just four years after the plan was issued. ${ }^{16}$

On the one hand, this underestimation is understandable. What Riyadh witnessed in the coming years was an unprecedented boom that rarely occurred in the planner's experience, making it extremely difficult to anticipate. On the other hand, these unsound assumptions were extremely problematic for the plan and disastrous to the city's future urban construct. These impacts were accentuated not only because of how far off they were from reality but also because of Doxiadis' own planning strategies and the way he approached the task in Riyadh. Doxiadis' talent as a practitioner depended heavily on his ability to generate data and analyse it, and this is extremely clear in the case of Riyadh. It seems that he positioned himself vis-à-vis the city more as a predictor than a designer. His main contribution was in his ability to collect and produce the data and then to analyse and predict the future based on this collection. For instance, the report clarifies its scope in Riyadh in a number of points: to predict growth possibilities and the estimated size as well as to predict and divide the stages of growth through particular future dates. It uses the word 'predict' to express its objective and goal, highlighting the role of the team and the way they were positioned. The first document on Riyadh's current situation was a 429-page report of enormous detail; but the third report, Doxiadis' actual design proposal, was a relatively scant 171 pages. Even in the shorter document, it is not until page 119 that he moves from local data to the actual plan, when he starts discussing the future density of the 

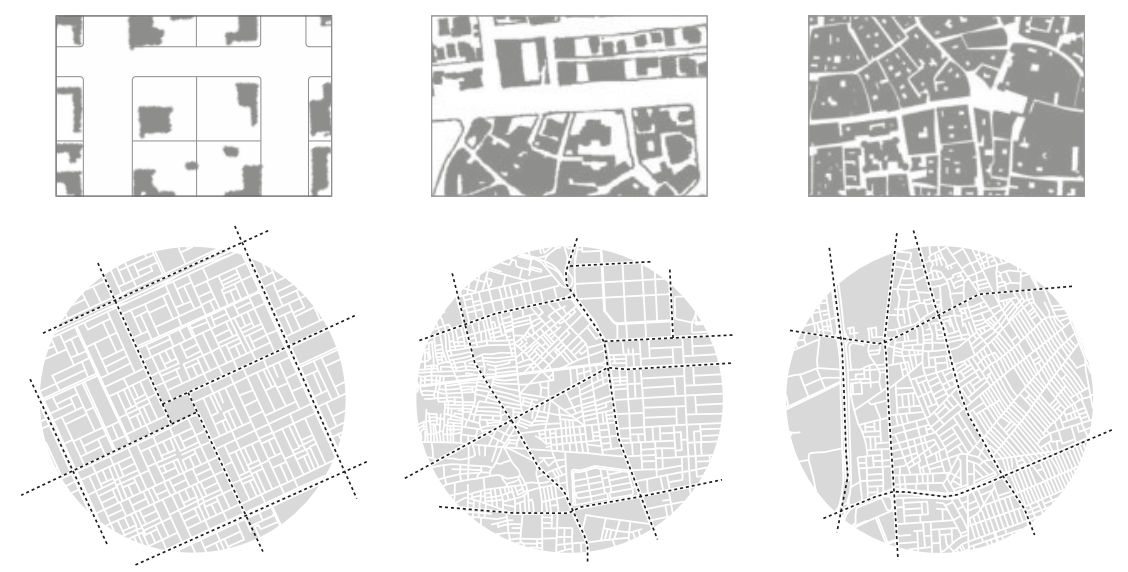

fig.4 Doxiadis' legacy in Riyadh. Left: newer neighbourhoods; centre: neighbourhoods designed immediately after 1972 plan; right: parts of old Riyadh (Source: Faisal Al-Mogren, 2020. Reuse not permitted).

city. The way he positioned himself, and this sheer dependency on data, makes the inaccuracies of his estimates disastrous to the plan and hence the city.

\section{The conundrum}

Despite the divergence of perspectives on the plan, the two sides agree on the fact that it played a critical role in shaping the urban growth trajectory of the city. Doxiadis' legacy is evident not only in the city's older parts, which were constructed during the plan implementation phases of the 1970s and 1980s, but also

fig.4 in more recent developments. To date, new neighbourhoods are being built according to a strategy similar to that of Doxiadis.

The plan's continuing relevance in Riyadh's current urban environment is a puzzling phenomenon, especially if one considers that the original scope was imagined to guide the city until 2000. Thus, 20 years after the plan's expiry, the city would be expected to have moved beyond the framework that the Greek planner put in place. Certainly, the city has had other subsequent masterplans. For instance, the French company SCET produced a plan in 1978, and the urban strategy MEDSTAR was devised by the development authority in 2008 . Nevertheless, apart from simple alternations and updates, the city was not able to escape the original plan's influence and construct, operating within the urban structure that was envisioned for the city in 1972.

This chapter's main aim is to analyse this phenomenon and to propose a different view of Doxiadis' project, a reading alternative to what is common in current Gulf urban discourse. The continuing relevance of the 1972 plan reveals a different approach 
for which Doxiadis' plan is rarely credited. A typical understanding of any master plan is as a physical unit, where the role of the planner is to design the large picture of what the city ought to look like: its physical size, the locations of its components, the densities and heights, the different pieces and their relations to each other in addition to other physical attributes. Scholars and urbanists discussing Riyadh often focus on that aspect, treating the project as a physical construct and investigating measures such as density, transportation circulation, or territorial expansion; however, this article argues that the aforementioned approach is not entirely able to accommodate the whole complexity of the plan.

Doxiadis' plan likely remained relevant due to its construction of a dynamic growth model, unleashing a process which allowed Riyadh to grow and expand indefinably, even beyond the physical boundaries that were set in the plan. Treating the urban environment as a living creature, the planner provided city officials with the ingredients needed to guide Riyadh's growth, with little regard to the mix of these ingredients. In the masterplan, he suggests that Riyadh will face qualitative and quantitative transformations, and hence

it is necessary to develop a framework that is able to grow and connect the different kinds and levels of functions in an organized manner, and is able to absorb both the anticipated and the unexpected transformation from now. This is what Riyadh needs first and foremost to solve its current and future problems. ${ }^{17}$

To that end, he devised spatial tools that are adaptable; they could be incorporated in a number of different plans and could be applied irrespective of the specific or physical placement of urban elements. These strategies extended the life of the plan and heightened its adaptability to various geographical locations. The plan, which could adapt and operate in a city of 500 citizens just as well as it could function in a metropolis of five million, remained relevant despite all of its inaccurate, initial assumptions.

The mechanisms, such as the modular grid, initiated by the 1972 plan remain embedded in the urban fabric of the city, and it is how Riyadh continues to grow to this day. This grid of two-by-two-kilometre superblocks delineated exact parameters according to which each unit could be endlessly regenerated, regardless of the direction or location, creating a system to ensure a hierarchy of streets and an associated catalogue of street types to follow. In addition, the plan also created a ratio between certain typologies, densities, heights, and setbacks based on their proximity to certain elements, allowing for these parameters to guide growth in any direction or shape. "The suggested pattern should be open-ended", reads the report, "it should allow the city 


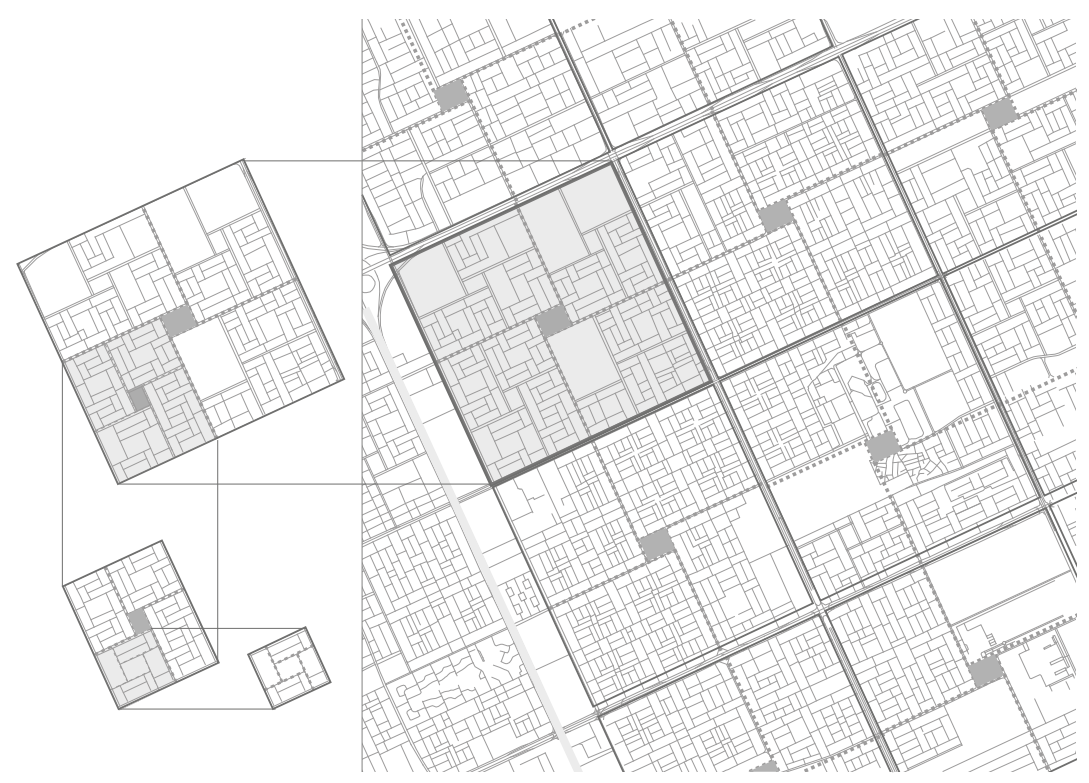

1972 masterplan. Right: detail of the two-by-two km grid. Left: growith mechanism of the superblock (Source: Faisal Al-Mogren, 2020. Reuse not permitted)

to grow as much as the population increases". ${ }^{18}$ Doxiadis also set a formula to determine the percentage of public spaces relative to density and access and created a complex system of connections and networks. All of these specifications exemplify how the plan operated as an enabling tool for growth rather than a detailed physical implementation of a vision.

A major aspect of adaptability is that the plan, while extremely detailed in some respects, is designed in a vague manner in others, leaving certain aspects completely open to interpretation. Though this trait often has negative connotations, it is not the case in this context, where it turned out to be one of the reasons that the plan was able to adapt and remain relevant. In the plan, Doxiadis laid out the general framework for how the city should develop. He believed strongly in certain principles and, as a result, was particularly specific at describing them, such as the limits and characteristics of the superblock or the length and hierarchy of streets. By contrast, there are many other aspects of the plan left purposely vague. These could thus be implemented in several different ways based on the given circumstances and according to interpretation. In Riyadh, and through the different stages of its development, it was apparent that the same elements in the plan were read, interpreted, and applied differently based on the changing situation and the needs of that specific time. This was enabled by the plan's vagueness. For example, the plan's 
description of "a neighbourhood centre" is open for interpretation as it could mean an open space, civic space, religious space, recreational space, transportation hub, or a hodgepodge of these elements. Another example is that the plan dedicates a section to advocating for the preservation of the city's unique architectural style, yet neither the nature of this style nor the required modes and mechanisms are clarified. This wide room for interpretation is a key aspect that helped the plan to endure. It meant that the plan could remain flexible and adaptable, that it could always be reinterpreted by local agencies to serve new purposes while keeping the general framework intact.

These characteristics of the plan, its adaptability and its dynamism, should not be considered as a coincidence or as if they are isolated phenomenon; rather, they are conscious and deliberate planning moves that fit within Doxiadis' ideals and theoretical convictions about cities. The dynapolis model allowing for indefinite growth is translated into the mechanisms proposed in his plan for Riyadh, and even though the city outgrew his vision's anticipated boundaries, these parameters and tools were designed in a way to allow for unlimited territorial expansion. In the report, Doxiadis suggests that understanding Riyadh as a living organism is the grounds on which he based the two, main planning principles: the linear pattern of growth and the arrangement of neighbourhood units. Riyadh is treated in his plan, indeed, as a living creature, a true dynapolis. 


\section{Notes}

1 Faisal bin Ayyaf Al-Mogren, "Turning Points: City-Building in Riyadh and the Gulf" (master's thesis, Harvard Graduate School of Design, 2016), 26.

2 Abdulaziz Mohammed Bin-Ayyaf Al-Mogren, Riyadh: A Paradigm:

Enhancing the Human Dimension in Saudi Municipal Work (Riyadh: Tarah International, 2017), 24.

3 Saleh Al-Hathloul, "Urban Evolution of Riyadh in 100 Years (1902-2002)", (unpublished material, 2014), 2-3.

4 Saud Al-Oteibi, Allen Noble, and Frank Costa, "The Impact of Planning on Growth and Development in Riyadh, Saudi Arabia, 1970-1990", GeoJournal 29, no. 2 (1993): 163-170.

5 Yousef Mohammed Osamah Fadan, "The Development of Contemporary Housing in Saudi Arabia (1950-1983): A Study in Cross-Cultural Influence under Conditions of Rapid Change" (PhD diss., Massachusetts Institute of Technology [MIT], 1983), 73.

6 Shaibu Bala Garba, "Managing Urban Growth and Development in the Riyadh Metropolitan Area, Saudi Arabia", Habitat International 28, no. 4 (2004): 593-608.

7 Abdul Aziz Abdullah Alkhedheiri, "Urban Infill: A Rational Policy for Land Use in the Kingdom of Saudi Arabia", (master's thesis, MIT, 1991), 45.

8 Yusuf Aina, J. H. Van de Merwe, and H.M. Alshuwaikhat, "Urban Spatial Growth and Land Use Change in Riyadh: Comparing Spectral Angle Mapping and Band Rationing Techniques", in Proceedings of the Academic Track of Free and Open Source Software for Geospatial (FOSS4G) Conference, (Cape Town, South Africa, 2008).

9 Garba, "Managing Urban Growth and Development", 593-608.

10 Ray Bromley, "Doxiadis and the Ideal Dynapolis: The Limitations of Planned Axial Urban Growth", Ekistics 69, no. 415-417 (2002): 317-330.

11 Doxiadis Associates, "Riyadh, the Current Conditions, Final" (unpublished manuscript, Athens, Greece, July 1968). 12 Doxiadis Associates, "Riyadh, the Masterplan, Final" (unpublished manuscript, Athens, Greece, July 1971)

13 Zahir Othman, "Doxiadis, the Defamed", Alriyadh City no. 29 (June 2002): 24-25.

14 Pascal Menoret, Joyriding in Riyadh: Oil, Urbanism, and Road Revolt (Cambridge: Cambridge University Press, 2014), 91.

15 Doxiadis Associates, "Riyadh, the Masterplan", 129.
16 Joyce Hsiang, "The Doxiadis Effect", Al Manakh 2 (Amsterdam: Stichting Archis, 2010), 248.

17 Doxiadis Associates, "Riyadh, the Masterplan", 5.

18 Doxiadis Associates, "Riyadh, the Masterplan", 101. 


\title{
HISTORY, MEMORY, AND NARRATIVES OF THE PAST AND FUTURE The new souks in Kuwait
}

\author{
Edward Nilsson
}




\section{Introduction}

Worldwide, post-war modernization in the outward form of 'urban renewal' often included wholesale demolition of neighbourhoods, a policy later regretted because of the loss of historic fabric. While the typical mid-twentieth-century world view focused on the future, a common response to twenty-first-century globalism in countries going through change is a growing interest in past histories. In the case of Kuwait, the loss of its inner-city housing was unfortunate because its historic urban heritage provided guidance, not necessarily to recreate the original but to preserve an understanding of the holistic and unified lifestyle of the vibrant pre-oil era.

Recent years witnessed the growth of literature in preservation studies throughout the Gulf area, one that reflects and is driven by an interest in the identity, sense of place, and meaning of architecture. ${ }^{1}$ However, the recent demolition of the Al-Sawaber complex, a 500-unit residential development in Kuwait's inner city, designed by Canadian architect Arthur Erickson, demonstrated the surprising vulnerability of a heralded modern structure of the 1970s economic 'Golden Era' of social and environmental change. To many people, preserving a segment of that project would have been an appropriate addition to Kuwait's historical narrative, one that could transmit the optimism and spirited vision of that progressive decade. Muhannad Albaqshi, assistant professor at the College of Architecture, Kuwait University, notes:

One may regret that the demolitions of the 1950s were not more carefully handled; however, they did usher in a new era and spirit. Kuwait City is not a place frozen at a particular moment in history. The history of Kuwait's urbanity continues to unfold, but the memory of the old city will always be there guiding the future. ${ }^{2}$

A total erasure of a 1970s building on a site of an earlier demolished medina, or old town, is a second erasure of historical urban heritage, and such a loss challenges the relationship between past and present. Rising land values in Kuwait's inner city have increased the demand for new and larger structures that entails the threat to demolish urban fabric built during the latter half of the twentieth century. The situation has spurred the architectural and preservation community to research the 'memory images' of the city's pre-oil past, before the 1950s modernization. In addition, the community aims to draw attention to late twentieth-century structures, now also vulnerable due to physical deterioration or to the perception by some of their lack of cultural meaning. This can play out in the transmission of culture from one era to the next by consciously or unconsciously designating buildings for either preservation, restoration, rehabilitation, adaptive reuse, or demolition. 
Kuwait's written framework to protect its built heritage is the Law of Antiquities (1960), requiring a property to be at least 40 years old as part of its classification process. ${ }^{3}$ In the United States, the country where I work as an architect, a similar, commonly accepted threshold within the field of historic preservation is the '50-year rule'. Properties that have achieved significance and are more than 50 years old are generally considered eligible for listing in the National Register of Historic Places. Selection standards such as these to protect properties have contributed to a growing awareness of mid- to late twentieth-century modern architecture. Less explicit reasons why buildings of this era may capture our interest include a natural response to increasing globalization that tends to standardize and commodify design worldwide. In the early years of the International Style, architectural schools embraced the Bauhaus legacy of the functionalist approach to architecture, and it was thought conceivable that someday buildings everywhere might be the same with regional differences handled by increasing reliance on new technology, that is, climate control and structural innovations. Since then it has become widely accepted that a building's function should also recognize and respond to regional differences, not only for economic efficiency and sustainability but also so that the language of forms - the expression of individualized dwelling units, spaces for social gathering, or even the shape of windows in a façade - can correlate with established cultural and institutional meanings.

An earlier article by the author presented a case study of a building type illustrative of Kuwait's Golden Era: the multipurpose souk. ${ }^{4}$ The study offered an example of the traditional housing type and ancient souk found in the Old Town, combined in modernist form by The Architects Collaborative (TAC), the firm where the author served as lead design architect for Souk AlWataniya project. The present chapter builds on that study, showing how memory can play a part in urban design by forming a reinterpretation of history and by reintroducing traditional Arabic architectural features in contemporary design. How are the layers of past, present, and future defined in the development of urban fabric? As noted by Asseel Al-Ragam, associate professor at the College of Architecture, Kuwait University, "A critical appreciation of history can resurrect old meanings and also generate new ones". ${ }^{5}$ This chapter then also looks ahead with an example of how this building type could be repurposed to extend its useful life to sustainably accommodate the social needs and market demands of the twenty-first century while preserving links to its recent past.

\section{Background}

Settled in the early eighteenth century, Kuwait grew from a tradition of fishing, pearling, shipbuilding, and trade. Following the discovery of oil in 1938, the city's rapid environmental transformation 

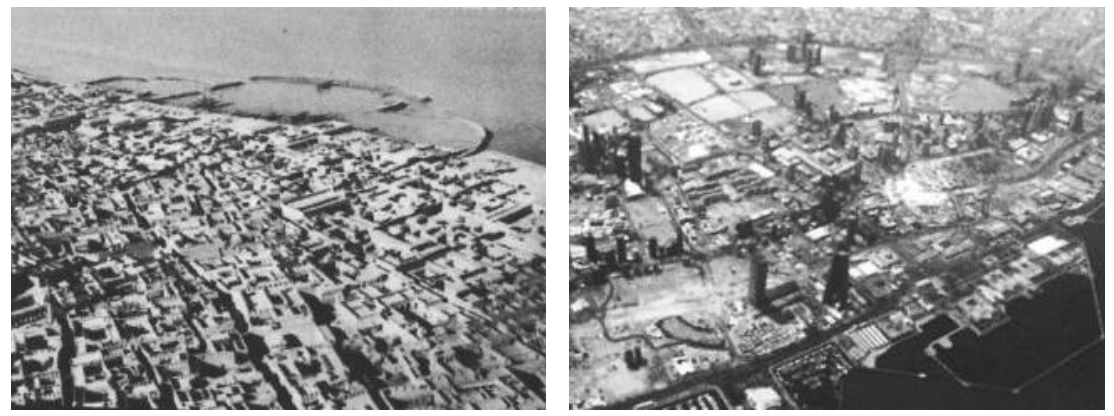

fig.1

Left: 1940s aerial view of pre-oil housing (Source: Kuwait Oil Co. archives. Reuse not permitted). Right: view of inner-city, high-rise development and vacated land (Photo: Edward Nilsson, 2016. Reuse not permitted).

of Old Kuwait began after the Second World War and was soon guided by its first master plan in 1951. Led by the British firm Minoprio, Spencely, and Macfarlane, the plan was driven by the needs of transportation access and land-use development. Nearly all of the Old Town's pre-oil era residential district was demolished during the 1950s and 1960s to make way for the new governfig.1 ment and commercial structures. To achieve this, residents were encouraged through economic incentives to relocate to new suburban villas developed outside the historic inner city.

The resultant erasure of urban fabric for modernization was regretted by many as the promises of new construction did not meet expectations of maintaining their cultural heritage. In response to the loss of the Old Town, the city's Advisory Planning Committee (APC) in 1968 solicited design proposals from four internationally recognized architects and planners to guide major development and expansion that would hopefully restore continuity to Kuwait's urban heritage. BBPR (Banfi, Belgiojoso, Peressutti \& Rogers) from Italy; Peter and Alison Smithson from England; Candilis, Josic \& Woods from France; and Reima and Raili Pietila from Finland were chosen. Each of the four proposals focused on a different segment of the city, and all were charged with exploring the creation of identity by reconciling architectural form with a wider social and cultural Kuwaiti context. The APC did not wish to recreate the lost city but rather to revitalize the now emptying city centre with new connectedness to its heritage. Georges Candilis noted that, before oil, Kuwait's main urban quality was diversity. There was a close association of the different "functions of the city life" - habitation, commerce, worship, and administration. ${ }^{6}$ These corresponded to the physical integration of houses, markets, mosques, streets, and squares. Each of the four proposals advocated for the expansion of the souk areas and the return of housing to the city centre. 


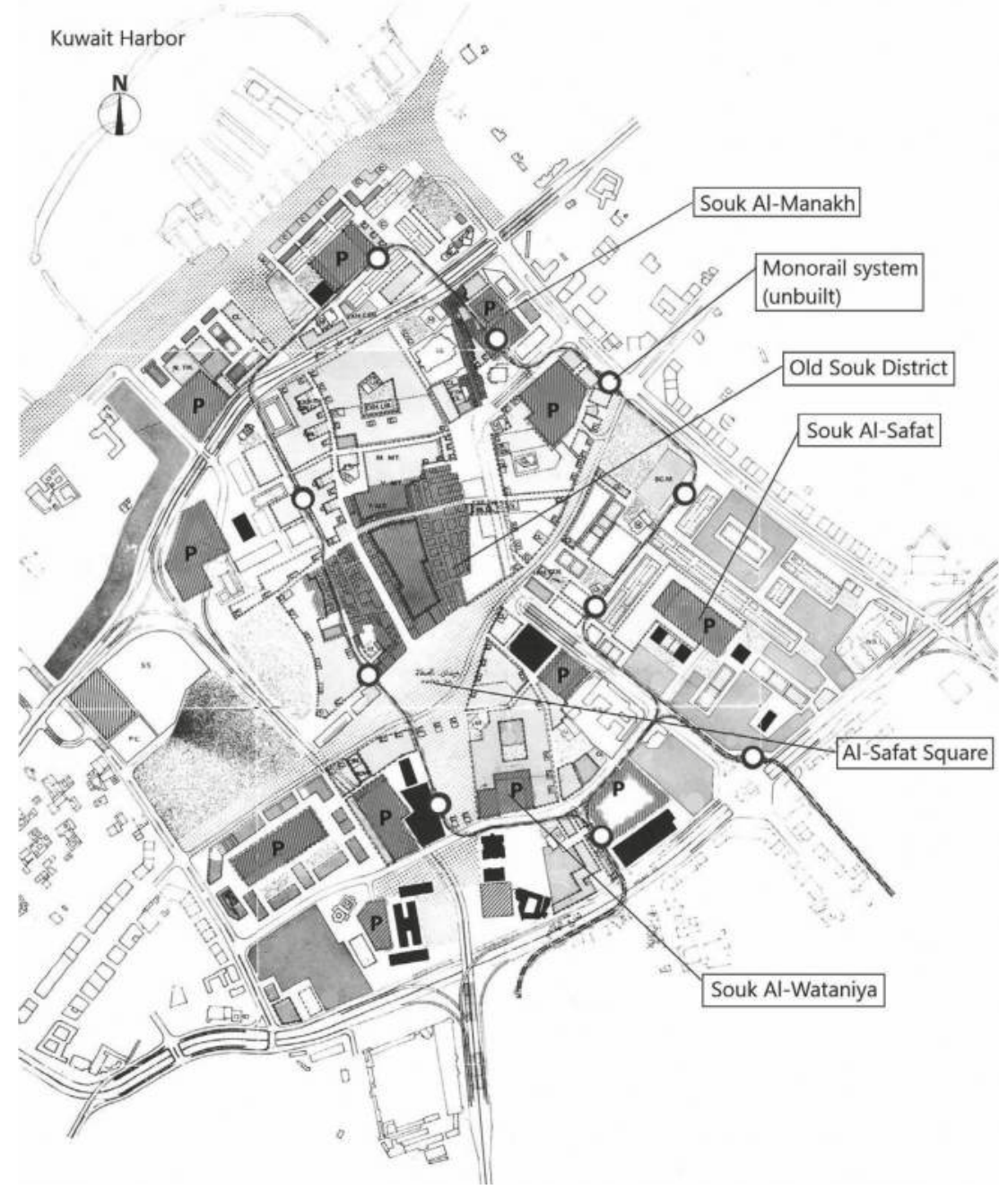

fig.2 1973 BBPR urban design plan of Central Business District showing carparks (P), or 'new souks', and monorail system looped around the Old Souk District (shaded darker gray). Stations marked as open circles by author (Source: Edward Nilsson's personal collection. Reuse not permitted). 
The 1951 master plan gave primacy to the automobile over the pedestrian. More than a decade later as the city grew, new proposals projected that up to 44 car parks were needed in the wider Old Town to reduce congestion. The 1968 BBPR proposal focused on the Central Business District (CBD), and their plan was the most detailed of the four proposals. The submittal included a multilevel zoning plan and emphasized a new framework of pedestrian walkways - sheltered from the weather, running northsouth between the Dhow Harbour and historic Safat Square - that would link the waterfront with the city centre. The final report with an updated plan was presented in April 1973 showing integrated transportation, land use, and building massing.

In addition to conservation of the nearby Old Souk District, the BBPR plan indicated a dozen large car parks, or new souks, in the CBD. These were connected via an elevated monorail, linking pedestrian open spaces and a system of primary and secondary roads. The following year, the BBPR plan provided guidance for TAC in the conceptual design of the new souks. Sara Saragoça Soares observes, "The consolidation of urban and architectural values was understood mainly by Kuwait's rulers as an essential vehicle for preserving social cohesion, attributing and distributing land, and reinventing ancient typologies, like the souk". ${ }^{7}$ This assortment of such large megastructures created a supporting infrastructure in the CBD by providing space for different uses at basement, ground-floor, and rooftop levels and also by generating potential linkages with later projects in the undeveloped or under-developed parcels between these structures.

\section{Construction of TAC's new souks}

Of the eight car parks constructed during that period, three were designed by TAC: Souk Al-Manakh, Souk Al-Safat, and Souk Al-Wataniya. These structures were called souks for the retail function, which was upgraded to an air-conditioned experience in proximity of the old, traditional open-air souks, or street markets. Moreover, the projects integrated the function of car park and office or residential space. TAC's first project in Kuwait began in 1968 with the design and construction of the Kuwait Fund for Arab Economic Development (KFAED) office building. This project was well-received and led to the Kuwait Investment Co. (KIC) in 1973 to commission the firm to design two of the multi-use souks, Souk Al-Manakh (CBD Area 5) and Souk Al-Safat (CBD Area 9). ${ }^{8}$ Within a year, TAC was retained also by the National Real Estate Co. (NRC) to design two additional buildings of this type, Souk Al-Wataniya (CBD Area 10C) and a fourth design, Souk Al-Watiya (CBD Area 15), a project that was subsequently revised and eventually designed by others. 
The three new souk structures were developed under the Build-Operate-Transfer (BOT) system. In exchange for constructing the car park (containing an average capacity of 1,000 vehicles), real estate shareholding companies were offered the right to lease out space within the building for a specified period, following which the lease would be transferred back to the municipality or be renewed. The rising value of inner-city real estate at the time gave incentive to the developer to repurpose the spaces if a more favourable lease could be obtained for alternate uses.

Souk Al-Manakh's relatively small, constricted, and irregular shaped parcel surrounded by banks and offices suggested a poured-in-place concrete structure, one that would accommodate smaller building elements and variations in the building footprint. The site's proximity to the Old Souk District also suggested a synergy between the historic souk and the commercial shops on the ground-floor and mezzanine level of the new souk. Each level of the building had its own distinct use: the programme's 600 parking spaces were distributed within the two basement levels and three levels above the shops, and the sixth (rooftop) level was designated for Kuwait Investment Co.'s own corporate offices.

A significant feature of the building from an urban design perspective is a structural provision to accommodate the city's proposed monorail system, which would pass through the building with a station at one of the upper parking levels, linking Souk Al-Manakh to the surrounding financial centre and other parts of the inner city. This feature demonstrated how the car parks and other elements of the BBPR plan, such as the Old Souk District, were meant to be integrated utilizing an inner-city transit loop. Unfortunately, the monorail system has yet to be built. Another example of the expectation of continued growth then that did not come to fruition occurred shortly after completion of the building in the late 1970s. At the request of the client, the upper of the two basement levels had sufficient space and headroom enabling it to be repurposed into an unofficial stock market. The market's subsequent collapse in 1982 triggered widespread economic loss, thus giving the event the moniker "Souk Al-Manakh stock market crash". ${ }^{9}$

In contrast to the cast-in-place framing system of Souk Al-Manakh, the larger and more regular shaped footprint of Souk Al-Safat was an appropriate application of the locally available Freyssinet system. This elegantly simple, structural framing system is comprised of prefabricated, prestressed concrete l-beams spanning approximately 18 metres between cast-in-place concrete girders, the typical distance needed for column-free parking decks. Connecting each single or paired I-beam, a five-centimetrethick, precast concrete slab is placed as a form to receive a fivecentimetre, finish concrete topping. In addition to its long span, the importance of this system was its cost-effectiveness and speed 


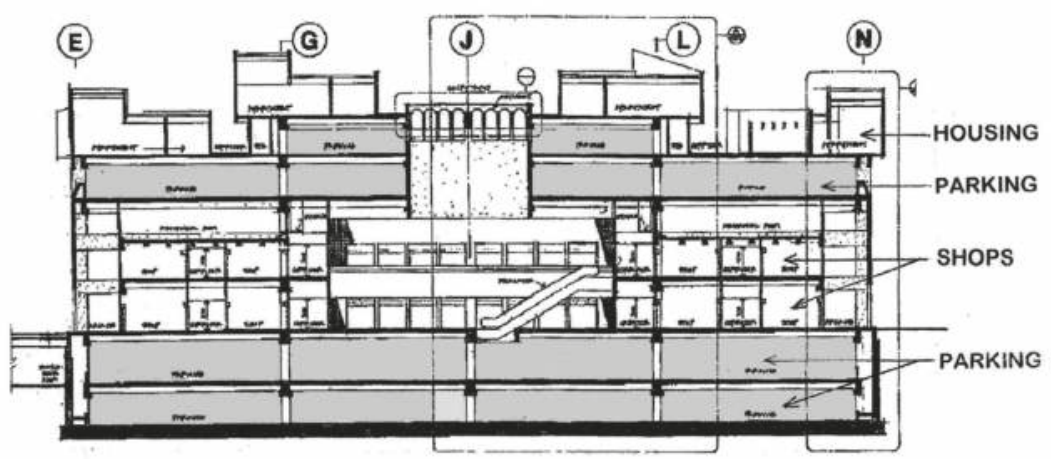

fig.3 Souk Al-Wataniya - section. TAC working drawing modified by author, n.d. (Source: Edward Nilsson's personal collection. Reuse not permitted).

fig.3 above the shops.

The largest of the three souks, Souk Al-Wataniya, differed from the other two by including 50 residential courtyard units at the roof level in lieu of offices. This rectangular building also utilizes the Freyssinet system except for the rooftop residential units. Here, load-bearing masonry party walls, 4.40 metres on centre and sitting atop doubled-up, prefabricated concrete I-beams, are spanned by steel I-beams and metal roof decking. Except for the ground-floor commercial level, the building's 1,000 parking spaces are distributed throughout all levels of the building, including one of the two residential levels where many residents could drive to and park within metres of their apartment.

Concrete and masonry were the principal building materials utilized for all three buildings. The exteriors are comprised of large expanses of cast-in-place, 'bush-hammered' (textured) concrete, selected both for durability and for thermal mass to absorb midday heat. Similar to Souk Al-Safat, the two basement levels extend approximately nine metres below grade, at that time well into the water table, requiring a reinforced concrete basement slab more than one metre thick to counter the uplift effect from groundwater pressure. By today's standards, these materials represent a large quantity of embodied carbon energy, which could be a significant factor in evaluating sustainable alternative uses in the future. For flexibility to make future changes in the layout, the shopping levels at grade and mezzanine are subdivided by non-bearing, masonry walls into hundreds of three-by-six-metre shop modules. These are leased in single or multiple modules with mezzanines and often clustered into groupings of similar 
product type as in the traditional souk. In observing the historical nature of the souk, Magdy Tewfik, dean of the erstwhile Faculty of Engineering \& Technology at the University of Jordan notes, "The souk in its various traditional aspects created a perfect environment for social intercourse and active economic vitality, both of which were the outstanding factors in the Arab city of the past". ${ }^{10}$

\section{Souk Al-Wataniya and traditional design elements}

In the summer of 1974 the architectural team from TAC and their consulting engineers delivered to the client the final drawings for Souk Al-Manakh and Souk Al-Safat and began research for the two new projects, Souk Al-Wataniya and Souk Al-Watiya. Local impressions and architectural references were observed in the densely packed markets of the Old Souk District; in the clustering of dhows (traditional sailboats) at the old port; in buildings with cementitious exterior finish and internal courtyards; in vernacular residential neighbourhoods on the outskirts of the city, in arched fenestration and other traditional motifs (decorative screens, for instance); and in shaded colonnades and crenellations such as those atop the historic city gates. After touring the nearby, precast concrete plant, the team conferred with colleagues at Pan Arab Consulting Engineers (PACE), the local consulting firm TAC partnered with for all three souk projects, among other projects in the Gulf. ${ }^{11}$ Meetings were also held with representatives of the fire brigade and municipality to discuss specific requirements, such as which of several possible building codes would be utilized for the projects.

The preliminary sketches for Souk Al-Wataniya reflected a horizontal layering of different uses as suggested by the BBPR 1973 urban design plan previously mentioned. Design decisions were made primarily at TAC's office in Cambridge, Massachusetts; feedback from the client was also part of the process and led to significant modifications to the building's appearance. One such suggestion was that the exterior colonnade contain traditional arched instead of larger rectangular openings as initially proposed. The increased wall area of the arched form would also provide additional shade in the colonnade. To visually integrate the arched forms, narrow slit openings were added just above the arch to provide a limited amount of additional natural light to the upper part of the shaded colonnade and to visually disarm the otherwise load-bearing attribute normally associated with the arched form. This allowed the colonnade façade to appear more as a decorative shade screen and not as a structural wall supporting the building above.

Following initial results of the feasibility study, ${ }^{12}$ the preliminary design was presented and approved by the client in the autumn of 1974. The detailed working drawings and specifications were completed by early summer 1975, and the bid 


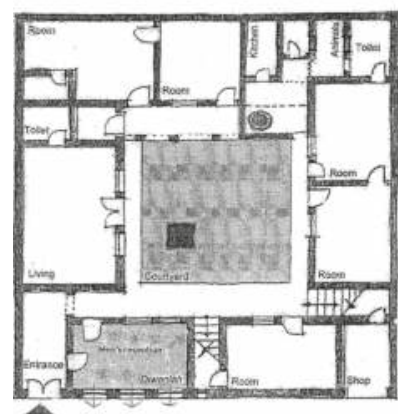

A

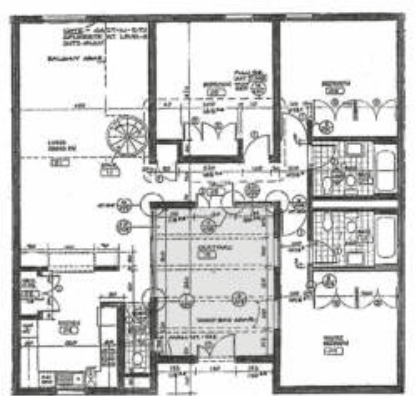

B

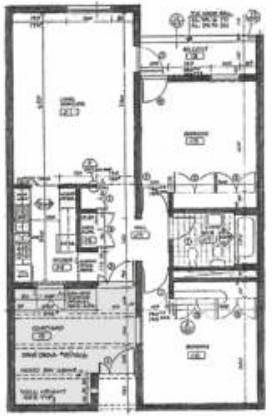

C

fig.4

Plans of a traditional courtyard house (A) (Source: Mohammed Alajmi. Reuse not permitted), and Souk Al-Wataniya three- and two-bedroom units (B and C), TAC working drawings, n.d. (Source: Edward Nilsson's personal collection. Reuse not permitted).

documents and presentation model forwarded to Kuwait the following November. The existing site prior to construction was a partly unimproved and half-paved parking lot. The dimensional boundaries of the parcel were not clear from the reference surveys obtained from the municipality. As the government owned the building site and surrounding land, slight adjustment of the lot boundary was possible to more readily fit the programme requirements and design. PACE consultants translated TAC's documents into a locally familiar format suitable for bidding and for interfacing with local authorities having jurisdiction. After a lengthy round of pricing proposals, the Korean firm Hanyang Construction Co. was selected as general contractor for the project.

During the early 1960s, a major goal of noted Kuwait municipal planner Saba George Shiber was to see "a significant modern architecture created in the post-oil period by studying the simplicity of the structures erected in the pre-oil era". ${ }^{13}$ Planner Shiber "demanded a planning uprising ... that would resist the widespread development programs that eroded ... traces of the traditional urban fabric". ${ }^{14}$ As requested by the client NRC and outlined in the economic feasibility study, Souk AI-Wataniya was to include courtyard residences, perhaps the most common

fig.4 Arabic architectural element. - The courtyard was an essential space-creating, space-forming feature.

This traditional house-type of the region, in addition to enhancing privacy, regulates the environment by trapping cooler evening air and redistributing it into the house during the daytime. If desired, the front bedroom of the Al-Wataniya apartments could serve as a diwaniya, or traditional reception room, accessed from fig.5 the outside walkway or the private courtyard. At the uppermost level of the building, the residences are clustered around a large 

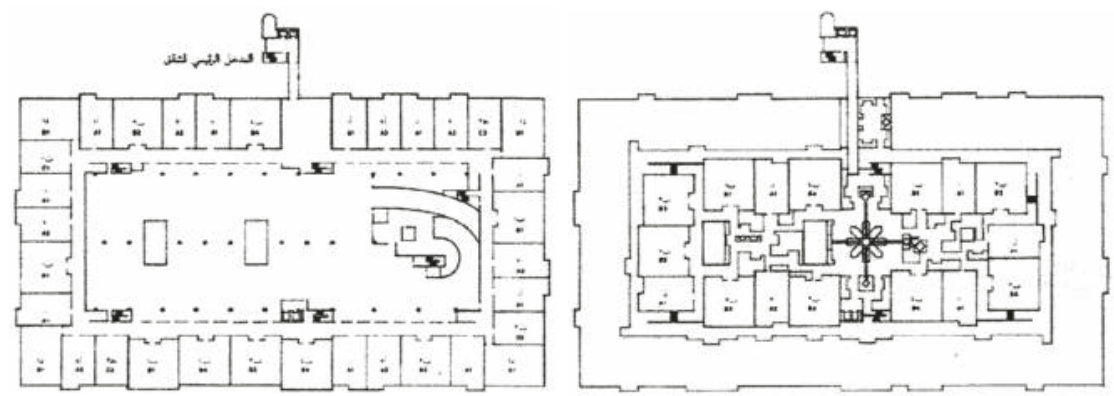

Souk Al-Wataniya, schematic layout of upper and lower level residential units. Sixth floor apartments on the left; roof garden apartments on the right (Source: Edward Nilsson's personal collection. Reuse not permitted).

gathering space in the form of a fereej (a traditional neighbourhood). In a typical fereej, 10-12 courtyard houses are grouped around a small, open, semi-public space: the micro-social unit forming a large and extended family. ${ }^{15}$ This allows the social life of the neighbourhood to be intimately integrated with the private life of the home.

Other traditional features at Al-Wataniya include a fina, sabat, mashrabiyya, and liwan. A fina is an approximately onemetre deep area in front of a façade that the owner or tenant had certain rights for using, such as for exterior seating or to expand floor area by adding a cantilevered floor above (sabat), as with many of the apartments. A mashrabiyya, or open decorative screen, typically used to provide shade or privacy, at Souk AIWataniya provides ventilation to the apartment level garage.

The arch form is incorporated in the windows and also in the colonnade, or liwan, which surrounds the building on four sides, protecting from sun and heat and providing open access from surrounding buildings and walkways.

The shops are focused around two skylit interior courtyards as large gathering spaces with fountains, similar to the rooflevel apartments formed around a landscaped gathering space with fountains. The multilevel zoning concept inherent in the BBPR plan is expressed by the separate residential entrance, a free-standing elevator/stair tower and bridge that bypasses the souk and open parking level to arrive directly at landscaped terraces at the upper two residential levels. This entrance, also requested by the client, offered an option to access the residences directly without going through the busy souk. The separation of the rooftop residences from the souk by the intermediate open parking deck enables the housing to effectively float above in relative spatial and acoustic isolation from below. 

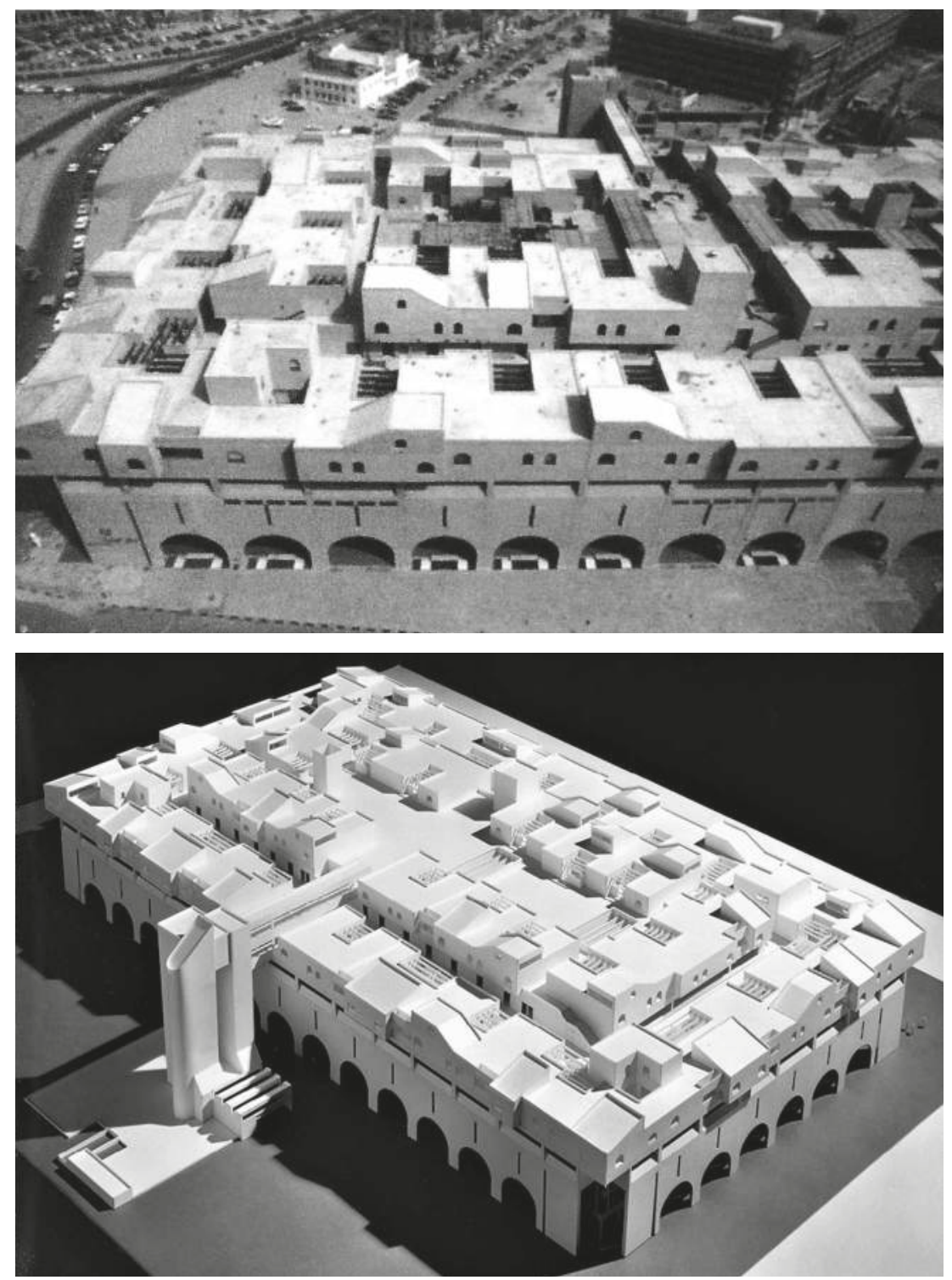

fig.6 Souk Al-Wataniya, 1980s. Above: view of rooftop courtyard units and landscape areas (Source: MIT Visual Collection - Aga Khan Visual Archive, Boston. Reuse not permitted). Below: presentation model with the entrance tower and bridge to upper level shown at the left side of the picture (Source: Edward Nilsson's personal collection. Reuse not permitted). 


\section{Memory images, preservation, adaptive reuse}

In reflecting on the post-oil cultural environment Suhair Al-Mosully, Iraqi architecture and planning consultant observes:

Kuwaitis managed to dismantle the traditional city and eradicate the memory with which it was associated. In the late 1980s about two-thirds of the city centre was empty. At that time the people and the government realized that their city was missing something they could not identify, something to do with its traditional spirit.... They became sentimental about the lost traditions. Both the memory and nostalgia of the past became important. A three-quarters scale Kuwaiti village was built in the city centre on the seashore; it was built to remind the young generation of their history. ${ }^{16}$

The context of Souk Al-Wataniya's site offered an interpretative juxtaposition of the reconstructed low-rise traditional courtyard housing found in the medina with a modern high-rise structure, what later becomes the Liberation Tower (designed 1981, completed 1995) - a powerful symbol and expression of the country's rebound after the Iraq invasion. The Liberation Tower became a precursor of the expanded high-rise development begun a decade later when the municipality greatly increased the allowable floor-area ratio in 2004.

Noted architectural critic Ada Louise Huxtable observed that in preservation planning, "one faces a dilemma peculiar to the very process of preservation: in saving the thing, the thing is lost and a substitute provided; the past is as evanescent and irretrievable as time itself". ${ }^{17}$ In searching for the architectural imagery needed for the continuity and cultural heritage of a particular site, a reconstruction of that which came before presents a similar dilemma of interpretation. The US Secretary of the Interior's Standards for the Treatment of Historic Properties defines reconstruction (unlike restoration, rehabilitation, or renovation) as follows:

The act or process of depicting, by means of new construction, the form, features and detailing of a non-surviving site, landscape, building, structure, or object for the purpose of replicating its appearance at a specific period of time and in its historic location. ${ }^{18}$

A reconstructed setting and its narrative may reflect both the visual imagery (tangible heritage) and the underlying lifestyle that defined the character of a particular setting (intangible heritage). The rooftop housing at Souk Al-Wataniya may be viewed through the metaphor of a palimpsest, or memory image, of what previously occupied the site - a present representation of an absent element or feature but layered atop an open parking deck and contemporary souk below. The pre-oil era setting, however, was integrally connected to its surrounding community. Without 
that corresponding historical context, the building may be viewed as an isolated and inward-looking structure; and the courtyard housing as a memorial to the former demolished residences that were symbolically lifted from their foundations and transported to the newly formed single-family district of villas south of the old city. This could be interpreted alternatively, however, as both a visual memory image of the past and a precursor of a new building typeone that could reintroduce residential use, along with commercial, cultural, and educational uses in the inner city, for a more holistic, diverse, and vibrant Kuwait.

This latter scenario can be instrumental in narrating the social growth of the city. For example, in describing Beirut's reconstruction after its civil war, professor Caroline Nagel observes:

The city, in this respect, is a text in an ongoing discourse about the shape and meaning of ... nationhood and identity. And like many texts, the built environment is significant not only for what it says, but for what it neglects to say about the past and present. ${ }^{19}$

Maya Malas expands that concept by arguing that "the city resembles a multiplicity of overlapping texts, in an on-going process of being written, re-written, modified and erased". ${ }^{20}$ And perhaps most importantly, professor Andreas Huyssen completes the thought by adding, "At stake in the current history/ memory debate is not only a disturbance of our notions of that past but a fundamental crisis in our imagination of alternative futures". ${ }^{21}$ The urban designers in the 1968 APC study mentioned earlier sought re-connection with the city's pre-oil heritage, and their imagined futures continue to evoke discussion on how to make the city legible, particularly at the pedestrian level within an automobile-centred society. In broadly defining alternative futures, Georges Candilis' partner, Shadrach Woods notes, "The goals of urbanism are relatively simple to enumerate [:] the distribution of economic, social, and cultural activities throughout the urban fabric". 22

Unlike the demolition of existing structures and replacement with new construction, adaptive reuse can often provide the economic benefit of reduced construction cost, preservation of historic heritage, and greater sustainability. It is often stated that the 'greenest building is an existing building', given the carbon energy embodied in the process of its production and operating life-cycle. As Shadrach Woods described in the 1960s:

Unfortunately, most futuristic visions of urban life and form do not include any provision for recovery and conversion of the existing built domain, which represents the major investment of materials and labor since the world began. Such a massive investment can hardly be simply ignored or discarded. ${ }^{23}$ 
Though damaged during the 1990 Iraq invasion and substantially repaired, Souk Al-Wataniya's fabric has suffered from neglect and deterioration. Changes of use have already taken place during the four decades since it was built. Shortly after construction, many of the residences were repurposed into offices to obtain higher rents; however, the outward appearance remains a visual link with the setting of Kuwait's pre-oil years. The brief 'residential community', evoking an image of the traditional medina originally on the site before its wholesale demolition, was repurposed into a 'business incubator' through adaptive reuse.

\section{Potential futures}

These souks may continue to serve their programmes of offices, shops, and parking indefinitely; however, their interiors are flexible and, indeed, have already adapted to new uses. From a wider perspective, one may look forward and ask, what are the spatial characteristics of a particular building that reflect its heritage and that could also determine its potential alternative futures? Interpreting the past in consideration of the present poses the question of how the useful life of the souks might be more effectively extended through restoration and/or adaptive reuse to protect its tangible and intangible heritage.

As previously noted by Candilis, early Kuwait City was a vibrant mix of functions - a close association of habitation, commerce, worship, and administration. Coincident with the growing interest in the preservation of urban heritage, as an expression of national identity in an increasingly globalized world, is a parallel concern aimed at restoring greater diversity and vibrancy to city centres through the reintroduction of housing and related uses. Contemporary cities throughout the Gulf area, such as Kuwait, are growing with a spate of new mostly isolated, and inward-looking, high-rise office towers. The potential convergence of additional new housing, preservation planning, and the sustainable adaptive reuse of existing structures offers an effective strategy for revitalizing and reconnecting Kuwait's inner city and preserving its historic urban fabric.

Around the time Candilis, Josic \& Woods presented their urban design proposal for Kuwait's Old Town to the APC, Woods contributed an article to the Harvard Education Review titled "The Education Bazaar" on the subject "Architecture and Education". A long-time critic of isolating formal education from city life, Woods believed that the city itself is the school, college, and university, and to be relevant education requires an urban context: "Where a global viewpoint can be reflected in the education process, urbanism and education come together. Education will become part of the physical milieu". ${ }^{24}$

Kuwait's masterplan has been extended and revised several times since 1951, the fourth version currently underway 
and targeting completion by the year 2040. Among the suggested ideas contained in the first masterplan of $1951,{ }^{25}$ and also in BBPR's 1969 proposal Future Development of the Old City of Kuwait, was the notion to bring an urban university into the centre of the city. The BBPR study, headed by Professor Ludovico Belgiojoso, was "based on a survey of historic Arab cities from Morocco, Egypt, Syria, Yemen, and examples of Western old town regenerations. The urban design recommendation ... [was to include] an urban university, much like Al-Azhar University in Cairo or Edinburgh University in Scotland" ${ }^{26}$ This would create a vibrant population of students, bringing in creativity and attracting business, similar to educational campuses in many major cities.

As a recent example, Babson College, an American business school rated highly for its entrepreneurship programme, has an inner-city complement to its main residential campus in several "front on the street" locations: Boston, San Francisco, Miami, and - in the Middle East - Dubai at the International Finance Centre (DIFC). As described on the college's website:

These [in-city campus] spaces provide opportunities for students, alumni, faculty, staff, as well as corporate and nonprofit partners, to learn, gather, collaborate, and innovate through graduate-level courses, special programming, and networking. The classroom and convening spaces are in-city complements to the main residential [campus], extending the ways in which [the] community can both strengthen and leverage the entrepreneurial ecosystem that is flourishing in the city.... [The] drop-in co-working space provides alumni with a place to network, brainstorm, and collaborate right in the heart of the financial district. ${ }^{27}$

Woods' endorsement of including an educational component within the inner city exemplifies the current trend of Gulf cities in transitioning from carbon-based economies to more sustainable, knowledge-intensive urban development. A branch campus in the former Old Town could be a feasible alternative use within flexible, multilevel structures such as Souk Al-Wataniya, Souk Al-Safat, and Souk Al-Manakh. The latter building's comparatively small and irregular footprint limits the potential area of adaptive reuse without significantly diminishing parking. However, the larger capacity and structural framing system of Souk Al-Wataniya, on the other hand, lends itself into large interior spaces at the groundfloor level and individualized office, classroom, dormitory, or related educational spaces at the upper rooftop level. As noted above, the ground-level and mezzanine commercial floors are currently subdivided by non-structural masonry walls. While the existing souk appears to be economically stable, conveniently serving the local community, the flexible construction system allows adaption into various size spaces as the market may require. At ground-floor 
and mezzanine levels, the masonry dividing walls can be removed and areas expanded into numerous $18 \mathrm{~m}$ wide $\times 35 \mathrm{~m}$ long spaces, if needed for a larger gathering or assembly space. Similarly, if approximately 175 parking spaces at the upper parking level between the shops and residences (now offices) can be removed (out of the building total of 1,000 spaces), the building could be modified to provide an additional 5,000 square metres of adaptive reuse space, meeting egress and access requirements. Lastly, the roof-level, former apartments could also be expanded into adjacent units as needed for larger classroom or individual studio spaces. Woods observes:

One of the essential goals of architecture and urbanism is to conceive of structures which will make the city more adaptable to necessary and electable changes in function and in the relationships between functions, which must continue to occur. In any urban future, the urban past will play a major role. In this sense, the only possible future lies in the past, i.e., the reuse or continued use of existing investments in construction. ${ }^{28}$

In today's Kuwait, with the selection of the new Kuwait University Shadadiyah site outside the city centre planned to consolidate seven scattered campuses for 30,000 commuter students by 2025, an in-city satellite branch presence with relevant programmes would broaden the educational experience and revitalize the downtown area. Offering up to 20,000 gross square metres of floor space, adequate parking, proximity to public transportation (bus station), and flexible commercial adjacencies, Souk Al-Wataniya could be repurposed into such a facility.

In conclusion, the 1973 BBPR urban design plan indicating a series of multi-use car parks, or new souks, spread throughout the Central Business District suggested a new building type for Kuwait City, one that would bring together compatible, mixed uses of urban living in a multilevel setting reminiscent of the holistic environment found in earlier eras. Broadly based on the courtyard residences of the medina, Souk Al-Wataniya also offers a memory image of the past during the mid- to late twentieth-century Golden Era of prosperity and change. Today, the goal of many is to sustainably preserve and link such structures and memory images from the past in serving the needs of today and the future. Inner-city parking still remains one of the threads connecting these buildings, however, the souks' substantial construction type and flexible framework can accommodate a variety of compatible uses, such as inner-city housing, cultural centres, or an urban campus for Kuwait University and, in so doing, achieve a more diverse and vibrant inner city of Kuwait. 


\section{Notes}

1 Caline Malek, "Rising Gulf Cities Look to Protect Landmarks", Arab News, September 3, 2018, http://www.arabnews. com/node/1366346/middle-east.

2 Muhannad Albaqshi, "The Social Production of Space: Kuwait's Spatial History" (PhD diss., Illinois Institute of Technology, 2010), 11.

3 Adl Alblushi, "To Whom Are We Giving Custody of Our Modern Architecture Heritage", in Essays, Arguments \& Interviews on Modern Architecture Kuwait, eds. Ricardo Camacho, Sara Saragoça Soares, and Roberto Fabbri (Salenstein: Niggli, 2017), 29-36.

4 Edward Nilsson, "Urban Memory and Preservation in Kuwait: A Case Study of Souk Al-Wataniya" (presentation, Society of Architectural Historians annual conference, Glasgow, Scotland, 2017). 5 As quoted in Fernandes Cinatra, "Modern Heritage Worthy of Preservation", Arab Times, May 4, 2016, https://www. pressreader.com/kuwait/arab-times/ $20160504 / 282398398618908$.

6 Farah Al-Nakib, Kuwait Transformed: A History of Oil and Urban Life (Redwood City: Stanford University Press, 2016), 15. 7 Sara Saragoça Soares, "Souq Brutal: Kuwait's Modernity and the New Souqs", in Essays, Arguments \& Interviews on Modern Architecture Kuwait, eds. Camacho, Soares, and Fabbri (Salenstein: Niggli, 2017), 171.

8 The Central Business District (CBD) was divided into numbered commercial areas: Area 1 through Area 15 ranging in size from roughly two to ten hectares each. The author and their colleague William Hall were appointed project architects for Souk Al-Manakh (Area 5) and Souk Al-Safat (Area 9), respectively. The design of Souk Al-Manakh was initiated by TAC Associate Basil Hassan in between his frequent trips to Kuwait as liaison with local clients.

9 Helen Chapin Metz and the Library of Congress, Federal Research Division, Persian Gulf States: Country Studies (Washington, DC: Federal Research Division, Library of Congress, 1994), 70, accessed November 2, 2020, https:// www.loc.gov/resource/frdcstdy. persiangulfstate00metz_0/?sp=110. 10 Magdy Tewfik, "The Architectural Originality of the Arab Traditional Souk", Ekistics Journal 59, no. 354/355 (May/ June, July/August 1992): 230-234.

11 For additional information on PACE and TAC, see also Michael Kubo's chapter in this volume "Building Identity: Authorship and Transnational Exchange in the Construction of Modern Gulf Heritage".
12 Projected conservatively at $12 \%$ return with no rent increases over time, and $25 \%$ with rent increases.

13 Saba G. Shiber, The Kuwait Urbanization (Kuwait: Kuwait Government Printing Press, 1964), 297.

14 Asseel Al-Ragam, "Representation and Ideology in Postcolonial Urban Development: The Arabian Gulf", The Journal of Architecture 16, no. 4 (July 2011): 461.

15 Mohammed Alajmi, "History of Architecture in Kuwait: The Evolution of Kuwaiti Traditional Architecture Prior to the Discovery of Oil" (PhD diss., University of Nebraska, 2009), 146.

16 Suhair Al-Mosully, "Revitalizing Kuwait's Empty City Center" (Master's thesis, Massachusetts Institute of Technology, 1992), 119.

17 Ada Louise Huxtable, The Unreal America: Architecture and Illusion (New York: The New Press, 1997), 4.

18 "Standards for Reconstruction", Technical Preservation Services, US Department of Interior, accessed November 3, 2020, https://www.nps.gov/ tps/standards/four-treatments/treatmentreconstruction.htm. 19 Caroline R. Nagel, "Reconstructing Space, Recreating Memory: Sectarian Politics and Urban Development in Post-War Beirut", Political Geography 21 (2002): 717-725.

20 Maya Malas, "Urban Palimpsests: Reconstruction and the Politics of Memory" (Master's thesis, University College London, 2013), 7.

21 Andreas Huyssen, Present Pasts: Urban Palimpsests and the Politics of Memory (Palo Alto: Stanford University Press, 2003), 2.

22 Shadrach Woods, The Man

in the Street: A Polemic on Urbanism (Baltimore: Penguin Books, 1975), 48. 23 Ibid., 35.

24 Shadrach Woods, "The Education Bazaar", Harvard Educational Review 39, no. 4, (December 1969): 116-125. 25 Sharifah Alshalfan, "The Aftermath of a Masterplan for Kuwait: An Exploration of the Forces That Shape Kuwait City", in "Wise Cities" in the Mediterranean? Challenges of Urban Sustainability, ed. Eckart Woertz, (Barcelona: Barcelona Center for International Affairs [CIDOB], 2018), 215.

26 Steven Caton and Nader Ardalan, New Arab Urbanism: The Challenge to Sustainability and Culture in the Gulf (Boston: Harvard Kennedy School, Middle East Initiative, 2010), 72.

27 Woods, The Man in the Street, 35. 28 Caton and Ardalan, New Arab Urbanism, 83. 
PART III 


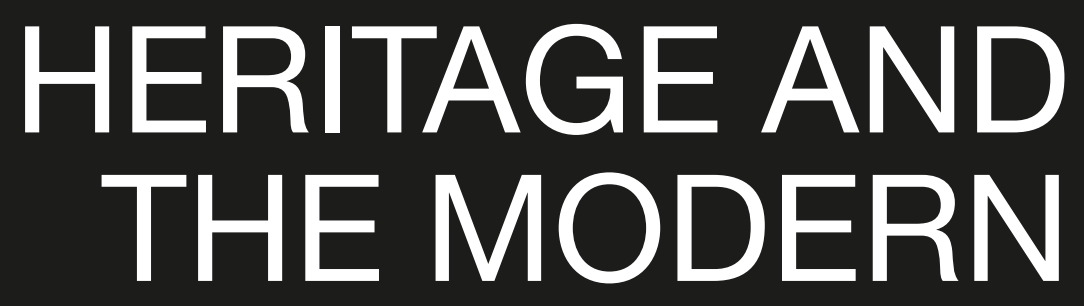




\section{INTERSECTIONS BETWEEN THE PUBLIC AND PRIVATE SPHERES OF CULTURE Modern heritage practices in Kuwait}

Asseel Al-Ragam 


\section{Kuwait's modern heritage in context}

The concept of modern heritage in Kuwait has its historical roots in the emergence of an eighteenth-century political entity that linked space and place with the ideas of community, power, and culture. ${ }^{1}$ The centuries that followed maintained these socio-spatial connections but on a much larger scale. As noted in previous studies, the decades between the 1950 s and the 1980s, in particular, are characterized by the dynamic and rapid changes that took place in the built environment, transforming class dependencies and socio-economic structures. ${ }^{2}$ The emergence of a complex state apparatus helped institutionalize modern myths of heritage and identity that shaped the socio-spatial landscape according to a top-down, modernist vision of a nation and society. ${ }^{3}$ This imagined tradition legitimated a modern project of a progressive state in a geographical location rife with tension. ${ }^{4}$ In parallel, historical gaps that did not fit neatly into this top-down narrative were filled in the private spaces of culture, either embedded in everyday spaces of the home or modernist buildings retrofitted for this purpose. On this basis, this study situates Kuwait within a much larger debate on modern cultural production, engaging briefly with the connected terms of modernity and modernism as they relate to public and private spaces of culture. This context provides the historical supports that anchor more recent calls to engage with modern heritage in ways that ensure its survival and put an end to its destruction.

While this study contends with the historically linked terms of modernity and modernism, unpacking the often-blurred theoretical threads is outside the scope of this paper. Briefly, modernity here is defined as a value system often set against tradition or what is considered to be a more conservative worldview while modernism is connected to a set of aesthetic values inspired by a 'will to change'. ${ }^{5}$ These theoretical systems paralleled industrialization and rapid urbanization, that radically transformed global systems of governance. Indeed, modernism developed as a reaction to these conditions and unfolded at the different scales of existing and newly created cities. As David Harvey argues, modernism is site-specific and interchangeable with modern methods of city planning, zoning, and separation of vehicular and pedestrian movement. ${ }^{6}$

On the scale of architecture, universal design values upended historical connections to the styles and constructions of the past. Although many of these ideas were short-lived, they assumed a prominent position in the history of modern architecture. In the European and North American context, the utopian proposals of Le Corbusier's Radiant City, Frank Lloyd Wright's Broadacre City, Ebenezer Howard's Garden City, and Arturo Soria y Mata's Linear City - and traced further back to the revolutionary theories of Henri de Saint Simon, Robert Owen, and François Marie Charles Fourier - were reactions against the socio-economic 
inequities of industrialization. These diverse proposals were united by a common intention that architecture and urban planning were the answers to the social ills of the modern metropolis. While each proposal was unique to its time and location, they all integrated modern aesthetic values within specific modes of capitalist production, including public housing and urban administration of the built environment. ${ }^{7}$ This ambition to locate architecture and planning within an equitable social cause continued up until the mid-twentieth century when economic and political developments began to split modern ideology from built work. ${ }^{8}$ This split widened with the everyday realities of built projects and the political and economic demands that infamously led Manfredo Tafuri to claim that critical architecture is dead. ${ }^{9}$ The failure of modernism's goals can be mapped in the polemical divide between the old and new guard of the Congrès internationaux d'architecture moderne (CIAM) that led to divergent forms and values adopted by different national chapters. Although Eurocentric scholarship has collectively moved beyond this debate,${ }^{10}$ this study draws from this connection between architecture and ideas of socio-cultural progress as it relates to the production of modern heritage in the Gulf region. ${ }^{11}$ Addressing this connection anchors the physical spaces of Gulf modernist heritage in a broader and seminal period of dynamic social transformation.

\section{Al-'Imara Al-Hadītha as cultural expression}

For the most part, scholars of Gulf studies have to contend with the displacement of their field from the centre of knowledge production. In fact, modern architectural histories in non-Western contexts are often measured against a dominant canon of Eurocentric origins and non-Western peripheries. Histories outside these defined geographical and temporal locations are often marginalized in academic research. As Mercedes Volait argues, it is assumed that modernity is intrinsically Western and reached non-Western settings through acts of imperialism and colonialism. ${ }^{12}$ Not unlike other contributions in this book, this study illustrates the ways in which urban and architectural modernity is shaped by the context in which it has been developed and dislocates its privileged associations with European and North American cities. This will help redress its meaning and assert its plurality and diversity.

In contrast to European and North American modern experiences that reacted to the environmental perils of industrialization and the disruptive social effects of capitalist production, Kuwaiti modernity unfolded in tandem with and as a critique of a modernization process brought about by a welfare state that unevenly controlled new social conditions through housing, education, and health. ${ }^{13}$ The new destabilized societal customs and accelerated a cycle of innovation and destruction. These 
"aesthetics of modernism" were used "simultaneously to exhibit power and to mitigate discontent". ${ }^{14}$ These dynamics seized everyday life and brought into question a never-before-considered relationship between tradition and modernity. Indeed, different strands of modernity existed and gathered strength from a range of sources, including Pan-Arab ideas, top-down modernization processes, regional progressive literature, and modern education. While these local and regional influences coexisted opposingly, they nevertheless inspired modern social norms and cultural production. Indeed, modern concepts of heritage and tradition are rooted in this transformative period.

During the 30-year period between the 1950s and the 1980s, Kuwait's modern heritage developed as a result of a crosscultural exchange of knowledge between local, regional, and international design experts. ${ }^{15}$ In Kuwait, local actors equipped with adequate funding and expertise navigated a problematic path towards modernity. Standardization of new construction methods and building techniques facilitated rapid growth of Kuwait's midtwentieth-century modern heritage. Known as al-'imara al-haditha, modern architecture emerged as the signifier of cultural expression, shaping various narratives of progress. Inspired by the simple forms of the International Style, it was distinguished by its elaborate façade detail that took climate and context into consideration. The state built civic buildings as well as cultural centres at record speed to adapt to the socio-political transformations of the time. This dynamism that accompanied the unfolding of a modern project is often described by scholars as a "tumultuous experience" that moved at a "breathless pace". ${ }^{16}$ At first, al-'imara al-hadītha was celebrated in daily and weekly Arabic magazines with wide circulation. However, this adulation turned to aversion firstly towards the commissioned architects, considered 'foreign' and therefore ill-suited to build for Kuwait's climate and social customs, and secondly towards the built form that some claimed lacked architectural authenticity. While some modernist buildings were retrofitted with façades inspired by Islamic motifs, others were neglected and even destroyed when the tides shifted towards nostalgic expressions for an imagined tradition and conservative values, cultivated in the late 1970s. ${ }^{17}$ As a second wave of destruction continues to unfold - the first wave achieved the almost complete erasure of the traditional city - concepts such as architectural heritage, cultural identity, and authenticity are once more at the forefront of debates. The importance of modern heritage is once again questioned with those arguing for and against its survival in Kuwait's built environment. In parallel, and with little consideration to this discussion, the state continues to build new developments on existing heritage sites. Top-down initiated development is cyclical and tied to economic stimulus plans. Indeed, the most recent development of state-built cultural centres anticipates a post-oil economy. 


\section{Cultural centres as representations of state progress}

At the outset, the term 'cultural centre' is used here to refer to the myriad of spaces established to legitimate different interpretations of culture and history for political, social, or economic purposes. It is the space where "museuming", in the words of Pamela Erskine-Loftus et al., takes place and where different countries visually demonstrate their culture. ${ }^{18}$ These spaces include private and public museums, art galleries, and heritage centres. In short, the appropriation of space to disseminate and exhibit culture and the intimate and reciprocal relationship that exists between the production of space and the production of culture are the subject of critique here. The concept of space in these cultural centres thus supports Hilde Heynen's model as "a stage in which social processes are played out ... where the spatial structures of buildings, neighbourhoods and towns accommodate and frame social transformation". ${ }^{19}$ It also brings to mind Doreen Massey's analysis of "space as the product of interrelations" and as this thing that is "always under construction". ${ }^{20}$ This social dimension explores on the one hand the microscale of space appropriation as a mode of resistance, submission, or compliance and on the other hand the macroscale where structural indicators might trigger more complex modes of negotiations.

As explored in earlier studies, the first modern wave of heritage production began in earnest as part of a nation-building project in the late 1950s. ${ }^{21} \mathrm{~A}$ proposal for a national museum marked a significant step towards a Kuwaiti modern project. A museum was imagined by the newly independent state to bolster its credibility as a progressive nation and to construct an official historical narrative for a modern Kuwaiti society. The underlying aim of the National Museum was the codification of selected knowledge as a form of commodity. ${ }^{22}$ This cultural process of heritage production is primarily a political act, where a range of struggles is negotiated and where certain social and cultural artefacts are validated as part of the dominant narrative. ${ }^{23}$ As Stuart Hall explains, "National Heritage is a powerful source of such meanings. It follows that those who cannot see themselves reflected in its mirror cannot properly 'belong'". ${ }^{24}$ The end goal is to unify different members of society and marginalize countermyths competing for dominance. ${ }^{25}$ However, this founding-myth model used to establish state legitimacy, citizenship, and a sense of belonging closely associated with national museums was lost in Michel Écochard's architectural plan. ${ }^{26}$ This is one reading of the historical becoming and unfolding of the National Museum. It serves as an example of top-down cultural models challenging arguments that suggest national museums succeed in serving larger political goals. Low-visitor turnout and the atypical organization of the museum disrupts "the temporal dimension of national 
progress envisioned by the state". ${ }^{27}$ "The damage done to some of the buildings" in the 1991 Gulf War "served as a final blow". ${ }^{28}$

Eilean Hooper-Greenhill suggests another theoretical approach for a more critical reading of cultural centres. She argues that "effective history" rather than the founding-myth model frames a more nuanced understanding of knowledge construction in cultural institutions. ${ }^{29}$ She notes that effective history

is an opposition to the pursuit of the founding origin of things, a rejection of the approach that seeks to impose a chronology, an ordering structure, and a developmental flow from the past to the present. History must abandon its absolutes, and instead of attempting to find generalization and unities, should look for differences, for change, and for rupture... The question to be asked, therefore, is not "How have things remained the same?" but "How are things different; how have things changed; and why?"30

From this reading, the recent expansion of state and private cultural centres, after a period of inactivity, begins to take on new meanings with mid-twentieth-century, modern architectural heritage entangled in this dynamic frenzy of development. Limited by the uninterrupted refrain of 'develop-or-fall-behind,' modernist buildings are often the first casualties of an enduring race for destination branding in the Gulf region.

Today, the state has resumed government spending on cultural centres after a period of post-war reconstruction, residential planning, and general improvement of outdated road networks and infrastructure. Mounir Bouchenaki argues that until recently the cultural policy of Gulf states has been grounded in the "modernist" vision of its rulers. ${ }^{31}$ Efforts to restore the National Museum are also ongoing, and a new cultural district is underway that includes the recently inaugurated Jaber Al-Ahmad and the Abdullah Al-Salem Cultural Centres. They are state funded cultural centres that, although advertised as public spaces, invite a certain demographic group due to higher ticket prices. While the former offers a range of events from local and international shows, theatres, and workshops, the latter operates under the museum type with curated exhibitions. These projects tie into the existing state museums nearby, mainly the National Museum, Museum of Modern Art, Maritime Museum, and Dickson House.

These recent attempts to resurrect a dormant cultural project mark state re-engagement with concepts of heritage after a cycle of divisive policies. Still, development projects of this nature face political pressures from an antagonistic legislature, and few come to fruition; those that do come to fruition are often backed or initiated by the Amiri Diwan, the headquarters of the country's ruler. The Amiri Diwan has gained a reputation of decisiveness among the local population. Both the Jaber Al-Ahmed and the 
Abdullah Al-Salem Cultural Centres are Amiri Diwan projects that were realized in record speed. They remain object-oriented architecture that do not tie into the surrounding context. Not unlike the National Museum, their museum narratives avoid political ruptures, difference, and social dissonance that might cause local or regional fissures and discontent. This top-down approach seeks to unite a nation and society and follows a founding-myth model that "impose[s] a chronology, an ordering structure, and a developmental flow from the past to the present" ${ }^{32}$

\section{Filling the historical gaps: Private spaces of culture}

As others have mentioned, locals are filling in the historical gaps and in so doing are challenging museum spatial archetypes. ${ }^{33}$ Different accounts of gallery exhibition and display are performed within the relative autonomy of the private museum and the art gallery. Karen Exell has noted that the value of private collections as "documentation and memorialisation of local and regional history is recognized by the owners and regarded as being more authentic than those in state museums". ${ }^{34}$ The private Saif Marzooq Al-Shamlan Museum represents these goals that are positioned, in the words of Exell, "to accommodate the realities of recent social and historical developments and ruptures". ${ }^{35}$ In the case of Al-Shamlan's museum, it marks an "anxiety over the loss of traditional heritage". ${ }^{36}$ Bait Al-Othman and Kuwait House for National Works Museums both are other notable examples. These models, as Marjorie Kelly presented, rely on an "expositionary" rather than an "exhibitionary" model of display oriented towards the "visitor [and is] non-sequential, multisensory and social". ${ }^{37}$ These narratives frame "a critical understanding of knowledge construction"38 and represent the struggles locals encounter when navigating between the comforts of modernity, or hadātha, and what some perceive as a more authentic heritage, or turāth. Thus, as Kelly rightly argues, "as citizens edge towards alienation, heritage displays organized by citizen volunteers ... implement a plan of action that addresses the needs of the society as they perceive them". ${ }^{39}$

Unlike state cultural centres that rely largely on a narrative of destruction and building anew, many of the aforementioned examples are private residences or, in the case of Kuwait House for National Works, vacated buildings provided by the state. Their reuse activates neglected urban nodes and halts the deterioration of modernist heritage. As of 2018, the total building stock in Kuwait is over 723,000 , with around 180,000 buildings abandoned and not in use. ${ }^{40}$ Their adaptive reuse would not only be environmentally sustainable, but the practice would also verify historical traces erased or ignored, affording private museums and galleries a space that offers other versions of history. Adaptive reuse is practiced locally for buildings marked as 'heritage' 
sites, whereby spaces are converted to fit the functional requirements of a museum. In fact, adaptive reuse should be a more common practice.

Article 13 in Kuwait's Law of Antiquities supports this process, noting that historical buildings are to be preserved and converted into museums or permanent exhibitions to illustrate the history of the site. ${ }^{41}$ Although not put into practice as often as it should be, it did provide a roadmap for the conservation of the Mubarakiya School in the Sharq district of Kuwait City, which was adapted by the state as a museum for education. While adaptive reuse has its precedents in the 1950s with Abdullah Al-Jaber Al-Sabah's house converted into the first state museum, today's reuse of the existing building stock signals a new relationship between everyday space and user interaction. These shifting tides bring different spatial priorities and leanings towards unconventional spaces of display. As this process of cultural reflection goes on, "the identity of the museum shifts and modulates". ${ }^{42}$

Industrial warehouses and malls are also serving as the new spaces of culture for locals in Kuwait. One example is the Sultan Gallery set up in $1969 .{ }^{43}$ At the time, it performed as an important site for established and up-and-coming artists in the region. ${ }^{44}$ It also introduced international artists to a Kuwaiti public that welcomed "these alternative cultural expressions". ${ }^{45}$ Today, it continues this important role. The gallery was originally located at the Thunayan Al-Ghanim Building, on the "prominent Sheraton Roundabout that connects the first suburbs with the modern capital city". ${ }^{46}$ After a long hiatus, it relocated to a family-run warehouse in the industrial district of Sabhan in 2006. While the relocation has its economic advantages, as the renovated warehouse falls under a Sultan-run business, the choice of moving its operations and gallery space to an industrial area "along the skirts of many government subsidized factories" 47 pushes the boundaries of where and what exhibition space should look like.

Contemporary Art Platform (CAP) is a more recent example of art galleries that have embedded themselves into existing buildings. CAP was established in 2011 by art collector Amer Huneidi, who happens also to own the Life Centre mall where CAP is located. The main stores include a furniture showroom franchise and a large electronics shop patronized by a diverse local population. Like other private art galleries in Kuwait, CAP provides artists greater freedom to engage in difficult topics often evaded in state museum displays. In 2016, in her "It's a Mad World" series, local artist Shurooq Amin presented another controversial exhibition at CAP. ${ }^{48}$ One of the rooms was concealed behind closed doors. Once inside visitors were confronted by the installation titled The Last Sip, a nod to Leonardo da Vinci's The Last Supper. Empty bottles were strung by plastic cords from the ceiling. A mixed media diptych of a woman in contorted positions performed as 
a background for the hanging bottles. The complicated margins that exist between public and private social norms in Kuwaiti society play out in the spatial layout of the exhibition. In an interview with the local magazine bazaar, Amin stated that the installation "is extremely relevant and timely for me. Geographically, it is also site-specific, as it explores the damaging ramifications of [substance abuse] in a society where it is forbidden". ${ }^{49}$ By drawing the visual boundaries between visible and invisible display space, Amin becomes her "own overseer in the ongoing process of normalization". ${ }^{50}$

In this regard, the relative flexibility of mall architecture affords Amin greater agency to curate the exhibition both spatially and conceptually. It equally provides visitors the freedom to move without the restrictions often imposed in museums. Visitors walk through a series of spaces before accessing Amin's more contentious The Last Sip installation. They are first confronted with the spatial characteristics of the mall where they take on the role of a hypermodern flâneur, visually engaging with the displayed goods for sale. They are then brought into CAP's seemingly unassuming, modernist open plan with its archetypal white walls. As visitors make their way through the exhibition, they are then prompted to enter a third space, concealed behind closed doors. Visitor performance can therefore vary at different spatial turns that range from material consumption to critical engagement and contending with socio-cultural taboos. They can also exit at any given point. This spatial dissonance counteracts what Hooper-Greenhill notes as "the connection between visibility and the establishment of deep-seated relations of advantage [and] disadvantage. It also [opposes] the idea of an apparatus designed for observation". ${ }^{51}$ While the subject matter might disturb certain viewers, the familiarity of the mall as a space of consumption and even voyeurism creates a less threatening relationship between the art and its audience. The spilling out of visitors to the pop-up cafe just outside the gallery space is perhaps the moment of convergence, between gallery visitors, curators, displayed work, and importantly the mall's everyday users. They are in full view of each other and even intersect at different junctures. This tension inspires diverse user behaviour and elevates this performance to a value equal to that of the exhibition.

The art gallery or museum in the mall is arguably the logical conclusion in the loss of Walter Benjamin's artistic aura. To this end, exhibition display and art objects find their place in what Benjamin described as the "dream-world" of capitalism. This "marriage of display and commodity" has its long history where new spaces of culture encourage "the pleasures of consumption and a heightened awareness of exhibition and fashion". ${ }^{52}$ By appropriating spaces inside the mall, a gallery or museum visit offers a consumer experience through which one sees culture. 
It is the space where the non-specialist spectator weighs in on values packaged as art, and in turn the distance between art and the everyday object narrows. ${ }^{53}$

This is certainly not a call for galleries or private museums to set up in malls, but it is an opportunity to understand the relationship between everyday spaces such as malls and user behaviour and experience. They do not subscribe to the powerful myth of the museum as a fortress for the elite and cultured. They are not the synchronized spaces of the curator or the setting for hegemonic knowledge or the place where codes of conduct are outlined by cultural institutions that are reinforced by uniformed guards. ${ }^{54}$ The Foucauldian argument that disciplinary technologies depend on enclosed spaces where the subject undergoes unconscious reprogramming gives way to critical engagement between audience and museum display. ${ }^{55}$ Visitors' movements in these nonconforming spaces chip away at museum surveillance and at the "transmission model" that lays out "knowledge for the visitor such that it may be absorbed". ${ }^{56}$ Museums today, according to Hooper-Greenhill "are no longer built in the image of that nationalistic temple of culture". ${ }^{57}$ With these shifting tides, different values emerge. This is a more democratic engagement with the subject matter, where the urban and the familiar become part of the exhibit.

\section{A proactive approach towards re-engaging modernist heritage}

The socio-economic advantages of cultural institutions' embedding themselves within the existing building stock should also be observed and analysed. These spaces reinforce existing communities and provide much-needed support for their growth and development. The attack taking place today on modernist buildings, that locals once proudly called al-'imara al-haditha, has to be situated within what was already a volatile and ever-changing urban condition. The fluctuating attitudes towards proposed and built work, as well as a cycle of development and destruction, have been constants in the architectural and urban discourse. Whereas in the 1960s architects and planners, such as Saba Shiber, called out against the destruction of the traditional urban vernacular, today a local community of architects, academics, and planners are doing the same for mid-twentieth-century buildings. However, the dangers that emerge from today's attack on the modern 'project' are the erasure of its progressive ideals that occasioned a re-evaluation of socio-cultural norms and customs. The push back that is taking place today through urban interventions, art installations, city walks, and public debate on social media might not be enough to hold back that destructive tide. Certainly, the regional trend for destination branding that requires spectacular buildings built on the debris of modern heritage contributes significantly to the problem. 
This period of demolition is not unlike the one that took place in mid-twentieth-century Europe and North America. The destruction of modernist buildings signalled a departure from modernism's social and aesthetic ideals. This ideological crisis of the modern project developed beyond an intellectual debate..$^{58}$ However, Eurocentric discourse shifted with many still defending its progressive values..$^{59}$ The Kuwaiti project of modernity, in a similar manner, will continue to unfold and its history rewritten. In practice, preservation policies that include activating and updating the Law of Antiquities are ways that challenge demolition arguments and cultivate a critical debate on mid-twentieth-century modern heritage. The historical layers of the city that mark the cycles of change will add diversity and enrich the built environment. Building codes that take into account informal practices such as popup markets and the adaptive reuse of the existing building stock are additional models of resistance. These grassroot exercises challenge outdated forms of economic strategy and building typology and offer a method of cultural engagement alternative to top-down models. As maintained in earlier studies, the cultural material of the modern project is therefore maintained, and its communities supported. ${ }^{60}$ This is an ongoing conversation that questions the nature of heritage production within the complex realities of local and regional transformations as well as of development and decay. 


\section{Notes}

1 Asseel Al-Ragam, "'Denial of Coevalness': Discursive Practices in the Representation of Kuwaiti Urban Modernity", Traditional Dwellings and Settlements Review 28, no. 2 (2017): 7-20. 2 Asseel Al-Ragam, "Kuwaiti Architectural Modernity: An Unfinished Project", The Journal of Architecture 24, no. 3 (2019): 366-384.

3 Al-Ragam, "Denial of Coevalness", 9. 4 Ibid.

5 Ali Zarei and Kaveh Tagharobi, "Modernism in the Middle East and Arab World", in The Routledge Encyclopedia of Modernism (Taylor and Francis, 2016), doi:10.4324/9781135000356-REMO14-1; Mari Hvattum and Christian Hermansen, Tracing Modernity: Manifestations of the Modern in Architecture and the City (London: Routledge, 2004), 5; Jennifer Robinson, Ordinary Cities: Between Modernity and Development (London: Routledge, 2006), 40; Al-Ragam, "Kuwaiti Architectural Modernity", 366-384.

6 David Harvey, The Condition of Postmodernity: An Enquiry into the Origins of Cultural Change (Oxford: Blackwell, 1989), 10-38.

7 Kenny Cupers, The Social Project: Housing Postwar France (Minneapolis: University of Minneapolis Press, 2014) [kindle edition loc. 5715 of 9137].

8 David Harvey, The Condition of Postmodernity, 25.

9 Manfredo Tafuri, Architecture and Utopia: Design and Capitalist Development (Cambridge, MA: MIT Press, 1976), 41. 10 Michael K. Hays, "Critical Architecture: Between Culture and Form", Perspecta 21 (1984): 15-29; Jane Rendell, Mark Dorrian, Jonathan Hill, and Murray Fraser, eds., Critical Architecture (New York: Routledge, 2007), 1-21.

11 See for example Sandy Isenstadt and Kishwar Rizvi, Modernism and the Middle East: Architecture and Politics in the Twentieth Century (Seattle: University of Washington Press, 2011), 17; Duanfang Lu, Third World Modernism: Architecture, Development and Identity (New York: Routledge, 2011), 32.

12 Joe Nasr and Mercedes Volait, eds., Urbanism: Imported or Exported? Native Aspirations and Foreign Plans (Chichester: Wiley-Academy, 2003), xii. 13 See Asseel Al-Ragam, "Towards a Critique of an Architectural Nahdha: A Kuwaiti Example" (PhD diss., University of Pennsylvania, 2008).

14 Al-Ragam, "Kuwaiti Architectural Modernity", 2.

15 See author's publications.
16 Marshall Berman, All That Is Solid Melts into Air: The Experience of Modernity (New York: Penguin, 1988), 23.

17 Al-Ragam, "Kuwaiti Architectural Modernity", 3.

18 Pamela Erskine-Loftus, Victoria Hightower and Mariam Ibrahim Al-Mulla, "National Representations or Representations of the Nation: Museums, Heritage, Identity and Narratives", in Representing the Nation: Heritage, Museums, National Narratives, and Identity in the Arab Gulf States, eds. Pamela Erskine-Loftus, Mariam Ibrahim Al-Mulla, and Victoria Hightower (Abingdon: Routledge, 2016), 5.

19 Hilde Heynen, "Space as Receptor, Instrument or Stage: Notes on the Interaction Between Spatial and Social Constellations", International Planning Studies 18, no. 3-4 (2013): 342-357. See also G. A. Bremner, Johan Lagae, and Mercedes Volait, "Intersecting Interests: Developments in Networks and Flows of Information and Expertise in Architectural History", Fabrications 26, no. 2 (2016): 227-245.

20 Doreen B. Massey, For Space (Los Angeles: SAGE, 2005), 9. 21 Asseel Al-Ragam, "The Politics of Representation: The Kuwait National Museum and Processes of Cultural Production", International Journal of Heritage Studies 20, no. 6 (2013): 1-12.

22 Eilean Hooper-Greenhill, Museums and the Shaping of Knowledge (London: Routledge, 1992), 2.

23 Laurajane Smith, Uses of Heritage (London: Routledge, 2006), 58.

24 Stuart Hall, "Whose Heritage? Unsettling 'The Heritage', Re-Imagining the Post-Nation", in The Politics of Heritage: The Legacies of "Race", eds. Roshi Naidoo and Jo Littler (New York: Routledge, 2005), 24.

25 Al-Ragam, "The Politics of

Representation", 6.

26 Ibid., 11.

27 Ibid.

28 lbid.

29 Hooper-Greenhill, Museums and the Shaping of Knowledge, 11.

30 Ibid., 10

31 Mounir Bouchenaki, "The Extraordinary Development of Museums in the Gulf States", Museum International 63, no. 3-4 (2011): 93-103.

32 Hooper-Greenhill, Museums and the Shaping of Knowledge, 10.

33 Karen Exell, Modernity and the Museum in the Arabian Peninsula (Abingdon: Routledge, 2016), 165.

34 Ibid., 171.

35 Ibid.

36 Ibid. 
37 Marjorie Kelly, "Kuwait's Museums: For Locals Only", in Museums in Arabia: Transnational Practices and Regional Processes, eds. Karen Exell and Sarina Wakefield (Abingdon: Routledge, 2016), 146.

38 Hooper-Greenhill, Museums and the Shaping of Knowledge, 11.

39 Marjorie Kelly, "Kuwait's Museums", 145.

40 Statistics are based on Public

Authority for Civil Information data. https:// www.paci.gov.kw/stat/SubCategory. aspx?ID=4

41 Government of Kuwait, Princely Decree no. 11 of 1960, Law of Antiquities (Government Press of Kuwait, 1960).

42 Hooper-Greenhill, Museums and the Shaping of Knowledge, 6.

43 Kristine Khouri, "Mapping Arab Art through the Sultan Gallery", in ArteEast Quarterly (spring 2014), accessed August 21, 2020, http://arteeast.org/ quarterly/mapping-arab-art-through-thesultan-gallery.

44 Ibid.

45 Al-Ragam, "Kuwaiti Architectural Modernity", 9.

46 Ibid., 10.

47 "About Us", The Sultan Gallery, accessed June 19, 2017, http://www. sultangallery.com.

48 For images of the exhibition, see http://bazaar.town/its-a-mad-world. 49 Shurooq Amin, "It's a Mad World", interview by Bazaar Staff, accessed August 21, 2020, http://bazaar.town/ its-a-mad-world.

50 Hooper-Greenhill, Museums and the Shaping of Knowledge, 171.

51 Ibid., 169.

52 Nick Prior, "Postmodern

Restructurings", in A Companion

to Museum Studies. 1st ed. Blackwell

Companions in Cultural Studies,

ed. Sharon Macdonald (Hoboken: Wiley,

2011), 514.

53 Ibid.

54 Hooper-Greenhill, Museums and the Shaping of Knowledge, 183.

55 Ibid.

56 lbid., 15.

57 Ibid., 1.

58 David Harvey, The Condition

of Postmodernity, 29.

59 Jürgen Habermas, "Modernity-an Incomplete Project", in Postmodernism: A Reader, ed. Thomas Docherty (New York: Routledge, 1993), 98-109. 60 Asseel Al-Ragam, "The Destruction of Modernist Heritage: The Myth of Al-Sawaber", Journal of Architectural Education 67, no. 2 (2013): 243-252. 


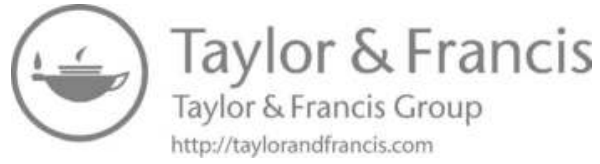




\title{
A[N] ABSENT SPACE: 1355
}

\author{
Suha Hasan
}


It is 1979. Palestinian artist Mona Hatoum creates a kinetic sculpture, entitled Self-Erasing Drawing. The sculpture that was reproduced in 1994 and 2004 as + and - contains sand held within a circular plate, with a rotating mechanical arm, smooth on one side and jagged on the other. As one half of the arm rotates smoothing the sand, the other half disrupts it; or as one half builds patterns on the sand, the other devours it, depending on your vantage point. Within Mona's work is a juxtaposition of opposing forces that need to coexist. Absence is shaped by presence, and presence is shaped by absence - both meeting at a liminal point before one replaces the other.

This chapter occupies that liminal space of erasures, where absences are revealed and presences are obscured in a cyclic manner, and uses this liminal space as a means to reflect on and expose challenges facing discourse on Modern architecture heritage in the Gulf. Modern is deliberately spelled with a capital $M$ to describe Modernity as a political project and contested term within this chapter. The discourse on the Gulf is one that has yet to reconcile with an obfuscated past, a discourse lost in terminologies and translations of various forms, a discourse that ought to transcend national boundaries. The chapter unravels some of the issues pertaining to these challenges through consideration of the temporal evolution of a space within the Customs House (now operating as the Manama Post Office), a newly conserved building in the capital of Bahrain.

A venture into the literature of urban development in the Gulf reveals a fascination with quick urbanization reflected in the rise of towers and the rapid, inconsistent planning over the years among other connected issues. Previously, researchers have fallen into the tendency of labelling such developments and related issues with Gulf exceptionalism, arguing that the presence of these conditions are specific to the Gulf and cannot be found elsewhere. More recently this has been counter-argued in an attempt to shift the discourse of Gulf exceptionalism towards one that relates to transnational processes. ${ }^{1}$ There have been new approaches to the architecture conversation that attempt to go beyond political and geographical imaginations of the Gulf region to include both Arab and Iranian coasts of the Gulf and to extend further into the Indian Ocean. ${ }^{2}$ Simultaneously, there have been studies that look into the specificities of Gulf cities, comparing similarities yet also highlighting nuances and differences in how these cities have evolved. ${ }^{3}$ Occasionally within these studies, specifically when conducted by researchers with personal connections to the context, a nostalgic undertone and longing for a 'better' past can be detected. ${ }^{4}$ This emerging scholarly body of work reconnects discourse of the Gulf to global processes and enables a better understanding of the 


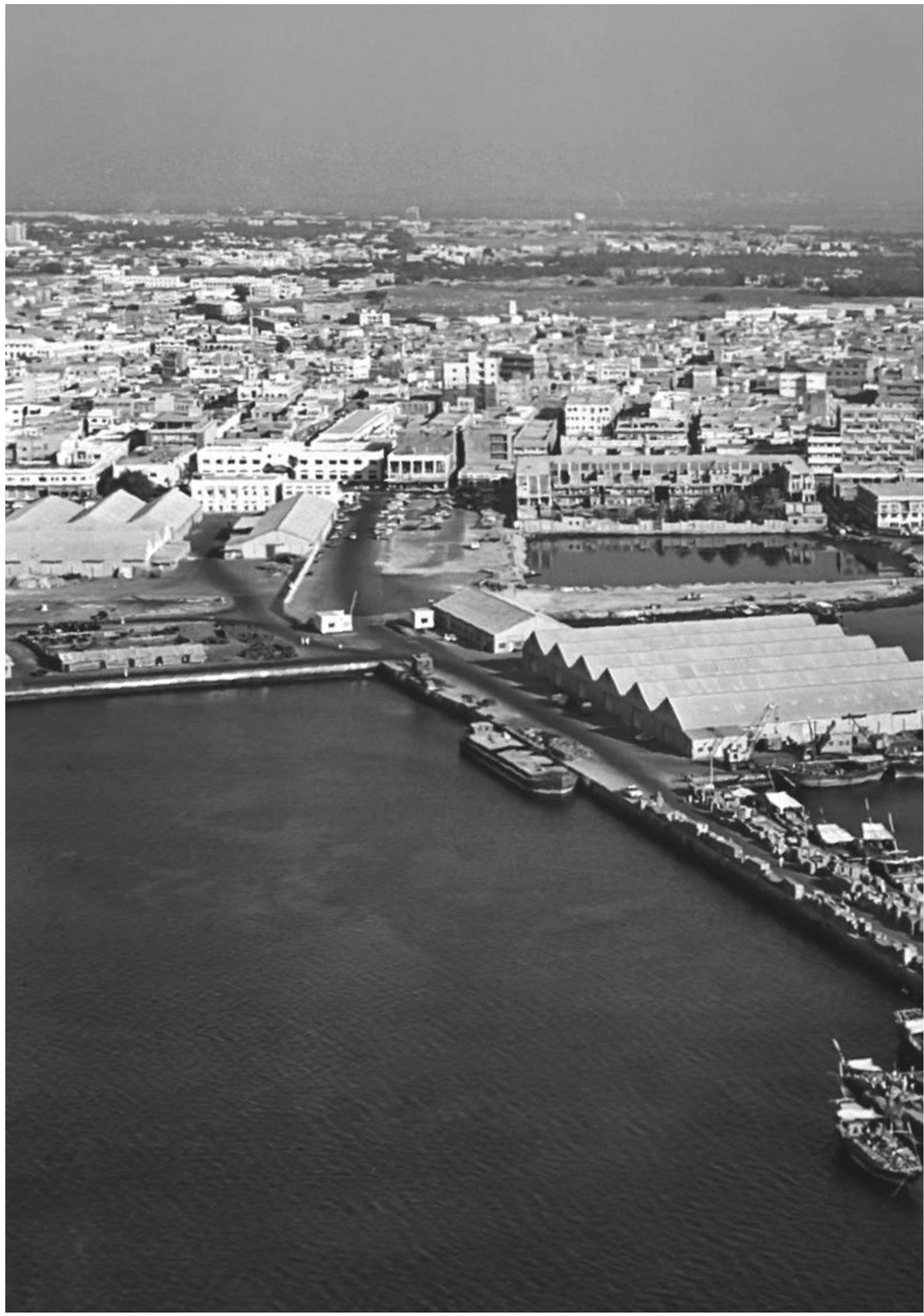

fig.1 Customs House, sheds, and pier in 1963 (Photo: Abdulla Al-Khan. Source: Bahrain House of Photography. Reuse not permitted). 


\section{$\because \ldots \mathrm{nu}_{\mathrm{n}} \rightarrow \mathrm{x}$}

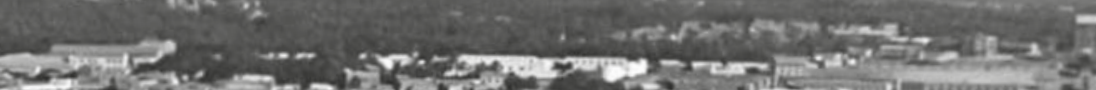

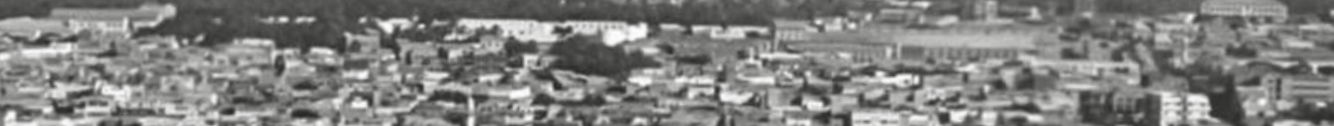

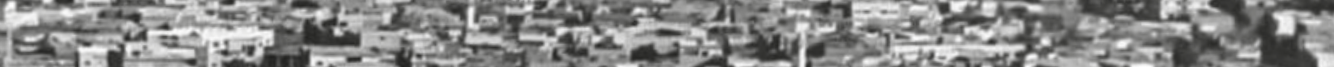

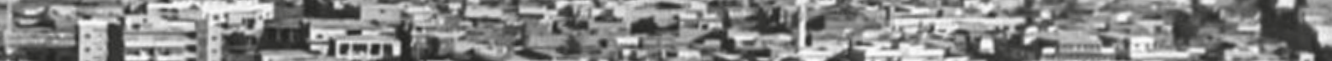

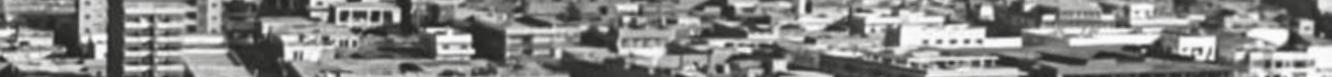
Fin P.X.

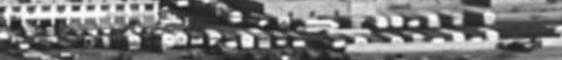

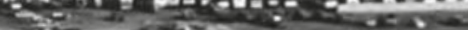

5

$\lim _{2}=\frac{1}{2} \pi$

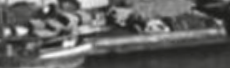

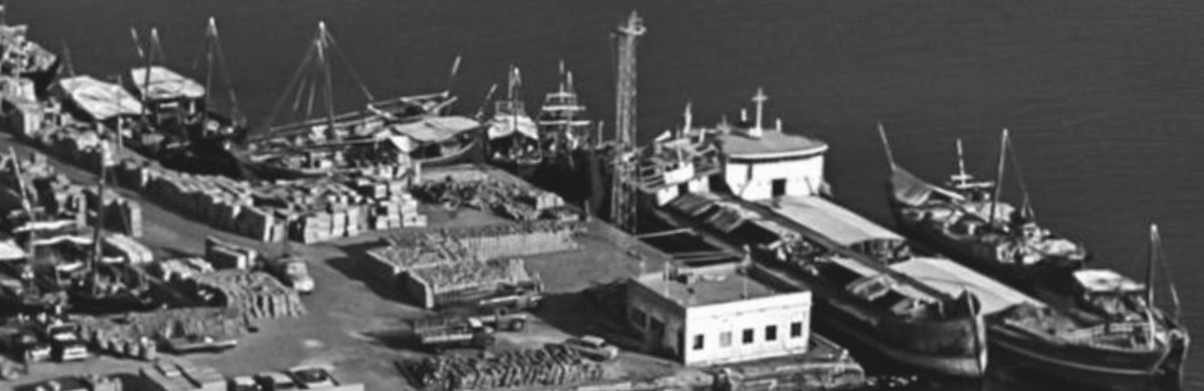

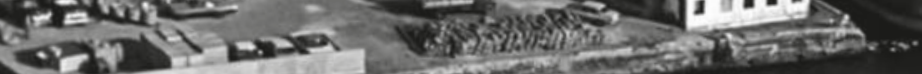


conditions found within the region while deconstructing the myth of exceptionalism. However, studies of and writing on architecture of Arab Gulf countries still, for the most part, dwell on the starting point of the discovery of oil, as if prior to the year 1931, when oil was discovered in Bahrain, the area was a barren land, devoid of civilization.

This is partly due to narratives of progress being intertwined with narratives of oil. Such narratives have been propagated by both the state and oil companies to legitimize its governance and their presence, respectively. A common challenge faced by researchers of the Gulf region relates to the lack of documentation or the deliberate obscuring of information as narratives of history continue to shift and change over time. ${ }^{5}$ This has perhaps contributed to the creation of this rupture within Gulf history, challenging the emergence of any discourse that attempts to draw from the past to address the future - as conveyed by the question posed by the editors of this book, "What future can be envisioned for the Gulf modernist [sic] heritage?". ${ }^{6}$ It is vital to understand the future as a temporality strongly connected to the past, for the further we can delve into the past, the more possible it becomes to identify future trajectories of Modern heritage. This longue durée approach to history is a means of understanding that widens the temporal scope of study to enable deeper attention to the slow unravelling of historical events that construct present conditions. ${ }^{7}$

The following is an attempt to provide a close reading of the formation of the 'Gulf Modernist city' through an inverted lens of an absent space within the Customs House. The project destabilizes concepts of time and Modern heritage through its practices of demolition, resurrection, and until recently an unrealized design. Therefore, Modern heritage as a concept is addressed critically through this project. Ann Laura Stoler elaborates on what she defines as conceptual habits, acknowledging the need for concepts as organizing guides, yet warns of both the epistemological and ontological violence that such a stability would entail. Following her line of argument of looking beyond conceptual habits, that consequently result in destabilizing and activating concepts, leads to a different understanding of Modern heritage and enables linking it to ambiguous colonial conditions. Stoler explains that such readings can enable perversion of unclear colonial conditions linked to temporalities that share common conditions to that of imperialism - that are as operative in Victorian India as in the periphery of the empire and its protectorates, in military bases today, and equally in intimate relations where one is vulnerable. ${ }^{8}$

The aim is to embark on an excavation in search of an absent space hidden in between what is visible and highlight the agency of that space within urban history. The invisible is interesting not only because it provokes many questions but also because it can potentially provide us with alternatives and opportunities 
long discarded. This chapter is a response to the broader topic of this book, and it denotes a tension in the process of the production of the built environment. The following research utilizes various archives but eschews the nostalgia, or at least attempts to, usually associated with unearthing the past and using archival material.

\section{Somewhere between 1936 and 1937: \\ A failure of interpretations}

This chapter can make many contradicting claims about the start of Bahrain's Modernity. The first claim is that Modernity started in 1931 when oil was discovered, leading to Bahrain's inclusion in the global network and providing resources for the industrial infrastructure of Modernity. The second claim is that Modernity of Bahrain started with the inclusion of its port in the global network in 1869, when Manama was incorporated into the shipping route of the British India Steam Navigation Company. ${ }^{9}$ On further reflection, another claim can be made that it goes back to 1783 when Ahmed ibn Muhammad Al-Khalifa also known as Ahmed Al-Fateh (the conqueror) arrived in Bahrain - a state narrative of the beginning of the story of Modernity in Bahrain, as displayed at the National Charter Monument. The final claim is to go 'forward', to understand Modern Bahrain, to Wednesday, March 31, 1926, when British administrator Charles Belgrave arrived at Manama's coastline by boat from Bushehr in Iran to resume his duties as advisor to the ruler, arguably soon to become one of the most influential (and controversial) individuals and historians - by virtue of his diary - in the history of Bahrain. ${ }^{10}$ There are many dates that can be chosen, from which a story of the Modern city can be netted out, subsequently from which a story of progress can be fabricated.

Bruno Latour challenges such a determination of a Modern era that breaks away from the past in his book We Have Never Been Modern. Although it does appear as if he addresses what seems to be primarily an audience in the West, a lot can be taken from his engagement throughout the book with what he describes as the "Modern Constitution [sic]" that disconnects from time, from the 'other' non-modern, and from nature. Latour attempts to revisit the term and show a non-linear and far more complicated set of relationships with both the past and the other. ${ }^{11}$ Similarly, George Arbid has argued in one of his talks that there are no contradictions between traditional and Modern and that the latter is a continuation and only a part of what constitutes the former. ${ }^{12}$ Essentially both arguments are connected; however, it is interesting to note that Latour is attempting to move away from the concept of the Modern while Arbid attempts to move towards using Modern in lieu of 'traditional'. Perhaps the intersection and juxtaposition of these two discussions, one emerging from Europe 


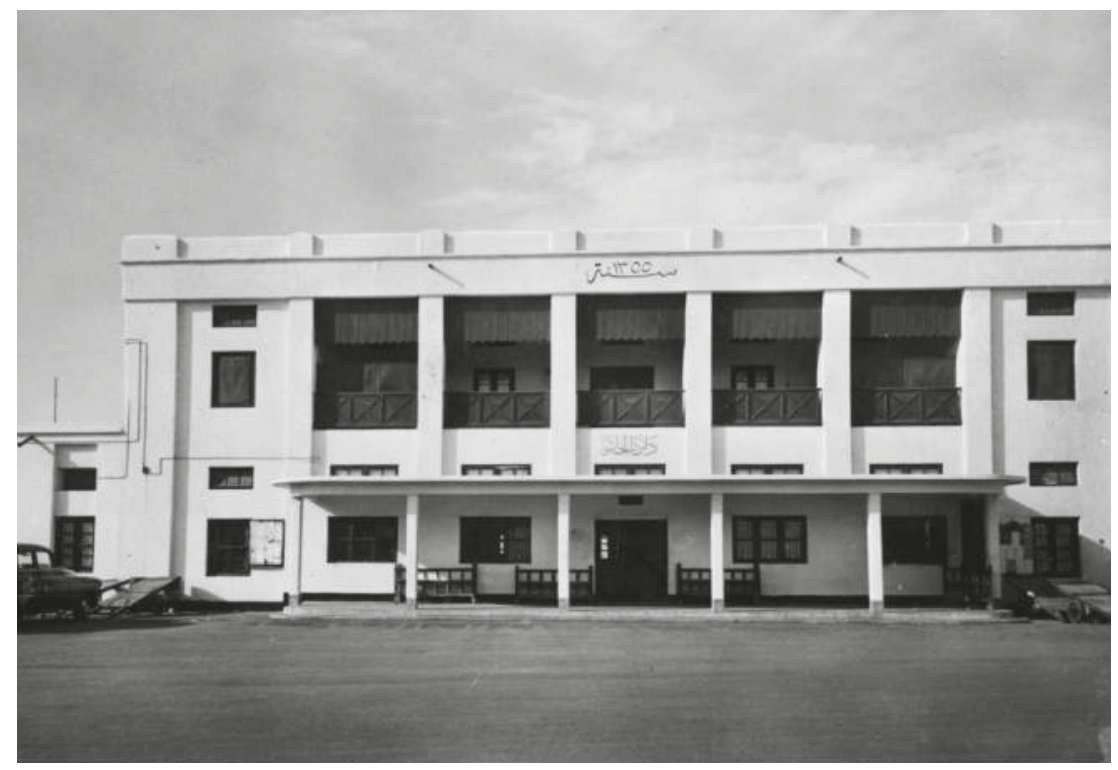

Customs House in the late 1940s (Source: Mary Evans/Pharcide, n.d. Reuse not permitted).

and another emerging from the Arab world, can become an indicator of the hybrid nature of the Modern project and the different forms it has taken in both the built environment and the discourse it is embedded within.

Both Arbid and Latour are critical of temporal borders that demarcate the past. Nonetheless, this paper shall go along with the popular practice among architects of using a date as shorthand for the birth of a Modern project. This chapter claims that Modernity started in Bahrain in the Hijri year of $1355 .{ }^{13}$ These numbers can be found engraved within the embrace of the gracious flow of the word sanat (year) in Thuluth Arabic calligraphy on the south façade of the Customs House, as seen in old black and white images of the building. It is considered to have housed the first department organized by the government, communicating a start of institutionalization and regulatory processes within the Modern nation. The architects working at Bahrain Authority for Culture and Antiquities (BACA), Alaa Al-Habashi and Marwa Nabeel, involved in the conservation of the building refer to the numbers always with excitement, in a more abstract form as "the inscription". ${ }^{14}$ The calligraphy was concealed for years, buried under a thick layer of plaster, and clad with a steel and concrete façade that covered both the year and name of the building one floor below, Daerat Aljamarik. ${ }^{15}$ The name of the building literally fig.2 translates to 'the circle of customs', meaning customs services. 


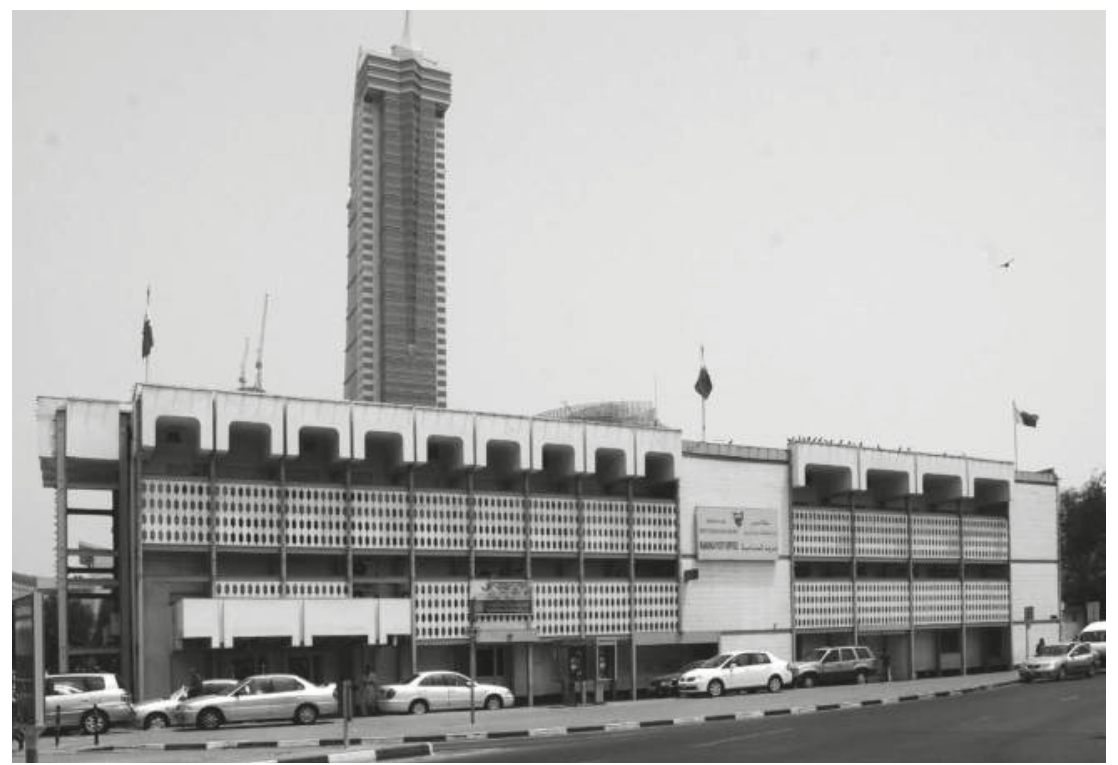

fig.3

Customs House after the 1970s conversion to a post office (Source: Bahrain Authority for Culture and Antiquities, n.d. Reuse not permitted).

Contrary to what would typically be expected when encountering an 'inscription' with numbers and text, it would not be the text that would be difficult to decipher, comprehend, and translate but rather the numbers. The year was written in the Hijri, or Islamic, calendar, and at first the year was converted to the corresponding Gregorian year taking into account only the start of the year, the first day of the first month of 1355; as a result, the corresponding year was 1936. Initially, the author did not take note of the effects of variations in days and months that would affect the conversion of the year, which resulted in some confusion to be clarified below.

Various historians who have frequented the Bahrain Historical and Archaeological Society asserted in May 2019 that the inscription was added years after the building was inaugurated. ${ }^{16}$ There was an agreement, it seemed, among these historians that the building was built before the 1930s; as a result, what had occurred in 1355 and why it was important to document that year on a building façade facing the market of Manama remained a mystery. The interest in the year was motivated firstly by its being covered for so many years and secondly by the belief that it was added to the building years after the first inauguration of the Customs House. Therefore, the year 1936 became important to investigate - to consider important historical events. In search of material evidence of history within the built environment, what can be more obvious than a muted scream of a building: 
"I am 1936". The following study, therefore, departs from the knowledge provided by historians encountered at the Bahrain Historical and Archaeological Society and conservation architects at BACA with the aim of demystifying the importance of engraving the year 1355 on a building.

As has been common among researchers of Bahrain's history, Belgrave's diaries were consulted in search of a significant event in 1936; however, nothing beyond the ordinary in the grand scheme of things stands out. The author remembered that a year was missing in the diary entries, and the description of the diaries was consulted to confirm whether the year corresponded with 1936. The description of the Belgrave papers reads, "They date from 1926-1957 (with a gap for 1937)". ${ }^{17}$ The author then noted that, although the conversion of the year was correct, it was inaccurate. The Hijri and Gregorian calendars do not start and end on the same dates - the beginning of the former does not necessarily coincide with the end of the latter. On converting the last date of the Hijri year, it became clear that those numbers could also refer to the year 1937, and whatever event had encouraged such inscription could have taken place anywhere between Tuesday, March 24, 1936, and Friday, March 12, 1937, to be precise. Whatever the celebration of the engraving of these numbers was, it would soon be deemed unimportant and plastered. It is completely erased from the building's façade, echoing the obscured diary entries in the Belgrave papers. The occluded history, held within these numbers referring to a temporality and engraved on a façade, leads the way to an exploration of the milieu in which the Custom House emerged as a Modern building. ${ }^{18}$ The complex milieu in which Modern buildings manifest on the landscape is far more important than the single designer credited with the work. ${ }^{19}$ It is from here that we proceed to understanding the complex apparatus through which the Customs House has been produced and reproduced over time.

\section{The Customs House: $1440^{20}$}

The building today embodies, within the rehabilitation intervention, the dichotomy of old and new, modern and perhaps avant-garde, preservation and progress. The story behind this recent renovation is embedded in a remarkable contemporary design and cultural scene in Bahrain. ${ }^{21}$ The building was brought to the attention of Alaa Al-Habashi, the conservation consultant at BACA through his intermingling with historians at lectures in various venues outside his workplace. He began researching the building with a junior architect at BACA, Marwa Nabeel, and they were both ready to work on the project officially when BACA made a decision to intervene in Manama, continuing the organization's ongoing efforts to preserve heritage and culture. BACA's long term plan is to register Manama as a UNESCO World Heritage Site, 


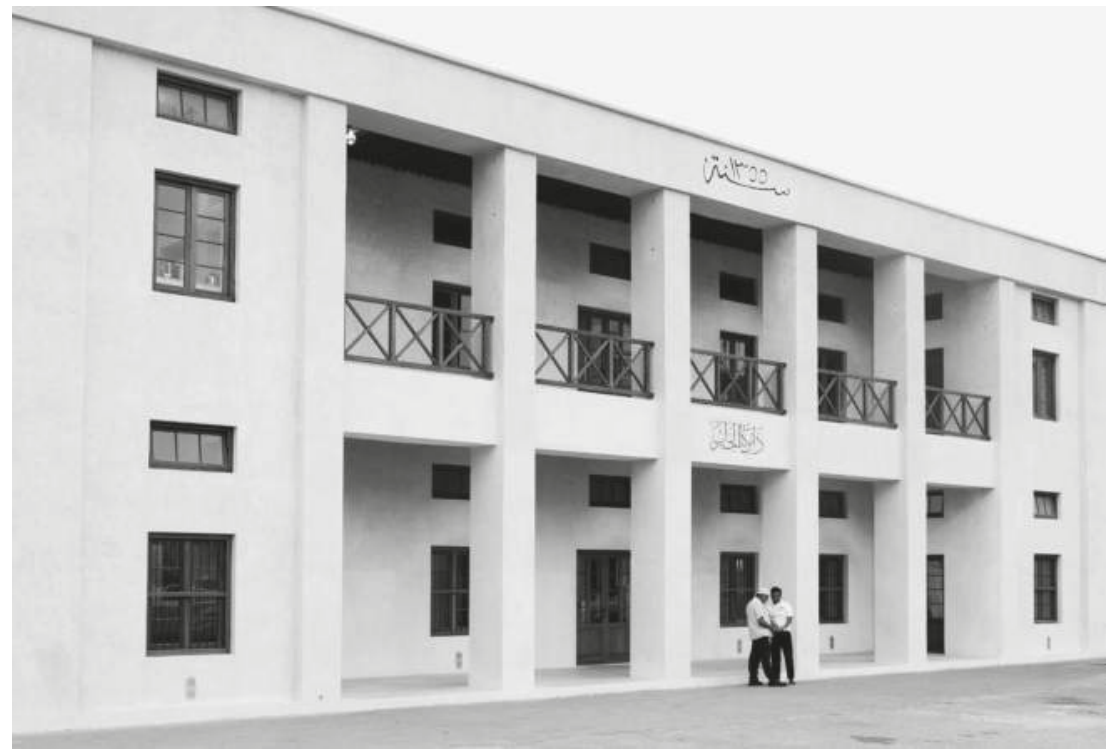

fig. 4 Customs House, 2019 (Photo: Khalid Al-Jabri. Reuse not permitted).

and it is currently on the Tentative List under the title, "Manama, City of Trade, Multiculturalism and Religious Coexistence". ${ }^{22}$ Alaa and Marwa encountered historical images with 'the inscription' while conducting their research, and they noted that the original looked entirely different from the existing building. At the time of their investigation, the building served as the Manama Post Office and no longer as the Customs House. The façades were entirely covered, and it was impossible to recognize the original building's features. Therefore, the process of conservation started with an fig.5 archaeological excavation, in search of a buried Modern moment of heritage in Bahrain's history as seen in the images. ${ }^{23}$ This was achieved through the careful removal of the steel and concrete façade of the building built in the 1980s to expose a hidden layer of the original building. Furthermore, material that was added over the years in the interior of the building was also removed to expose the hidden wood ceilings and a chimney among other things. ${ }^{24}$ An architecture studio, Studio Anne Holtrop, was commissioned to carry out the rehabilitation of the building; the office is known for its signature designs and interventions in heritage buildings. ${ }^{25}$

The studio's intervention model in historic buildings, first implemented in the Pearling Path in Muharraq, was adapted for the design of the new extension of the Customs House in Manama. These interventions digress profoundly from the original building and stand in strong contrast with original heritage buildings, rightfully gaining the term new architecture. The term new architecture 

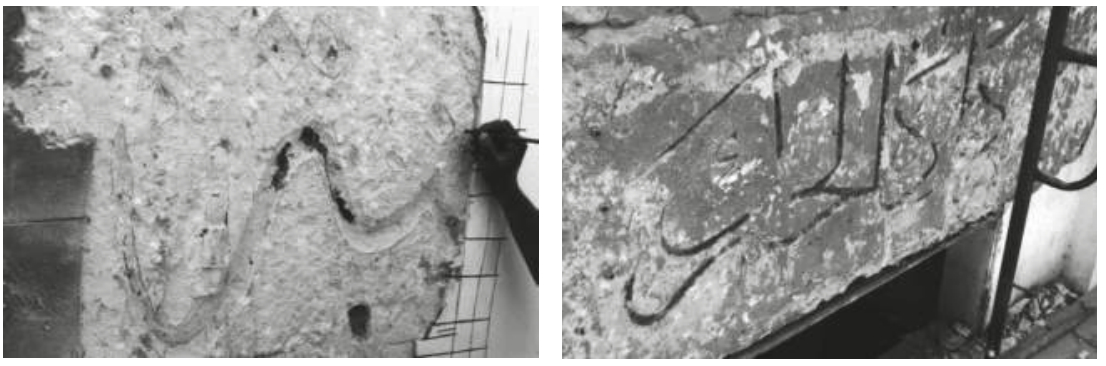

The inscription revealed on Customs House's façade during rehabilitation works (Source: Bahrain Authority for Culture and Antiquities, n.d. Reuse not permitted).

is the term deployed within BACA to differentiate between the more subtle interventions that blend in and those that create a visual rupture within the historic fabric. Therefore, the new intervention by Studio Anne Holtrop in the Customs House is an additional twist, literally and figuratively, to the building excavated by BACA. $\boldsymbol{\Delta}$ It is in the form of an extension that extrudes from the ground, wrapping the building on the west side as it twists and p.19 encircles the roof. It displaces a small building, now demolished, that had been added as a concrete extension to the Customs House in the 1970 s or 1980 s. There seemed to be a consensus between both Al-Habashi and Holtrop that it was the right decision to demolish the extension as there was nothing interesting within it to preserve ${ }^{26}$ However, Al-Habashi did show some regret in regard to not keeping a small part of what was removed, as it was important to maintain, according to him, a reading of history through its different layers - beautiful or not. He stated that he would have done things slightly differently if he could go back, for instance exposing the different layers of the building throughout the years, including the 1970s and 1980s "vicious interventions". ${ }^{27}$ The decisions and paths taken in conserving and rehabilitating the Customs House contribute to an emerging debate among architects in the country about conservation practices and around the value of what is being lost through these practices. This can be witnessed also in the Pearling Path in Muharraq, where diverging approaches are being adopted in its two North and South Sections. ${ }^{28}$ Conservation in the South Section of the trail is subtle and blends in with the old fabric while in the north it is evident and stands in contrast from the environs. Studio Anne Holtrop is leading the North Section of the project, and the executed design for the Customs House is aligned with the studio's approach.

The removal of the latest additional layers of the Customs House to uncover the original building - yet demolishing part of it to make space for a contemporary layer - provides a rich example of the range of aesthetic choices. Furthermore, some architects 
appreciated the design of the Customs House in its later years as the Manama Post Office, as they have always known it, with the façade that covered the original building. The ongoing work and diverse opinions around it have activated concepts among architects and historians related to authenticity, conservation, rehabilitation, and heritage. This created a dialogue, though still young in its formation, to emerge within Bahrain in relation to practices of conservation that one can argue are heavily inherited from global organizations. ${ }^{29}$ Neither of the architects involved knew of the historical significance of the building aside from its being a customs house later converted to a post office. Al-Habashi stated that an interpreter is usually brought in after the project is conserved to interpret the history based on the historical resources provided by BACA. This process of content creation was initially supposed to go hand in hand with the conservation project; however, this became a challenge as the priority of BACA, which is leading this project, was to intervene to prevent demolition of the building..$^{30}$ The architects were able to provide a detailed account of their interventions; however, no research was carried out utilizing the historical documents related to the building. Archives, specifically those of the British Library, that contained information on the building which could have facilitated conservation, were not consulted.

\section{The year 1355}

As a result of the information provided by the conservation architects at BACA and the historians encountered at the Bahrain Historical and Archaeological Society, namely, that the year 1355 was added on at a later date, a survey was conducted on the important events that took place around that year, which is coincidently also missing from Charles Belgrave's diaries. It seems that the most important event, according to the consulted sources and to the writings of various historians, is the introduction of the Nationality and Property Laws in 1937. This was partially fuelled by a rise of nationalism during the 1920s and partially due to the regulations of compulsory property registration. The National and Property Laws of 1937 came as a response from the administration of Bahrain to what was considered the 'growing Iranian problem', which relates to the many property owners considered Iranian subjects in Tehran. A citizenship law was introduced that restricted property ownership to Bahraini nationals, and as a result many Persians had to become Bahrainis to maintain their properties. ${ }^{31}$ This new law created a disruption to the previous pattern of immigration, movement, and transnational connection - a rupture in the social fabric, forging new relations within society and constructing a new form of connection with the land. While these borders were being drawn between Bahrain and Iran by both governments, Bahraini-British relations were thriving. 
In the same year, the ruler Shaikh Hamad bin Isa Al-Khalifa visited Britain to meet King Edward VIII, and the event was highly publicized in the British media. ${ }^{32}$ Meanwhile in Bahrain, the Municipality of Manama was draped with British flags to celebrate the coronation of King George VI in 1937. ${ }^{33}$ These two events are precedents of shifting networks and new emerging relations facilitated by the British, no longer bound by geography. A global network emerged, made possible by the Modern infrastructure of communication and transportation. The development of the Customs House enabled an expansion of processes of importation and exportation.

Many developments occurred in the built environment during that year. A policy was introduced in 1937 related to 'morality zoning'; it moved prostitutes, who were part of Manama's overseas economy, from around the city, specifically the harbour and market, and relocated them to an area to west of the outskirts of the inner city called Grandol. The area became a red-light district regulated by systematic health checks. ${ }^{34}$ Meanwhile, the ruler attempted to modernize the open market and was able to transform it from a space used by street agriculture vendors to a commercial complex with a regulated system of rent collection. ${ }^{35}$ Outside of Manama, and close to the first oil well, the American company BAPCO had completed the first oil town in the Gulf: a gated community isolated by a different architectural language and physically by a wall from the rest of the country. ${ }^{36}$ Furthermore, the first ban was issued on the construction of huts along the main routes. In the following years and by the initiative of Belgrave and other British political agents, the ban was extended to other areas being prepared for a Modernization project as they were designated to host the public institutions of the country. ${ }^{37}$ In the administrative report prepared by Belgrave after his first ten years in Bahrain, he states that the country had changed drastically since his arrival:

Changes are taking place all over the Gulf, but of the Arab States, Bahrain is changing most rapidly. The most conspicuous visible changes in comparing Bahrain to-day and ten years ago are in the capital, where a person returning to the country would notice the wider streets, better buildings, and a decrease in straw huts, trees, gardens and more vegetation, large shops selling European goods, motor traffic, European dress worn by natives, increasing use of machinery, partly owing to the installation of electric power, knowledge of English language, and a far greater interest taken in outside world affairs. ${ }^{38}$

The year 1355 seems to be significant; however, any event occurring within it is the accumulation of previous events, in addition to the report being submitted in 1937, making it likely that these affairs could have taken place during the preceding years. It is vital here to note that the available information does not shed 
light on why Charles Belgrave's entries from that year were missing or why the calligraphy on the Customs House was covered - or if either was a deliberate act of erasure. According to BACA's technical report of the building, "The traditional plaster used was strong enough to survive". ${ }^{39}$ However, it is possible that the first layer of plaster, which was most likely a mixture of lime, gypsum, and other additives, had worn due to humidity and therefore was covered. Fragility of material has always posed challenges to conservation practices in the Gulf.40

\section{The Customs House: 1355}

John Gordon Lorimer, a British historian and diplomat who authored an encyclopaedia about the Gulf, documented in the 1860s the regulatory processes in Bahrain when customs collecting duties were delegated to Hindu merchants by the ruler. The process seemed to have upset all involved parties, including the ruler himself, who did not profit from this arrangement. ${ }^{41}$ According to Belgrave, however, the first regular centralized customs department in Bahrain was established in 1923 by a public servant of the Indian government who based it on the Indian Methods and Bill of Entry System. In the following year, Mr. C.L. DeGrenier was appointed as customs director. On its initiation, the department would serve as a regulatory body for customs revenues as well as for the collection of pearling, boat licenses, and registration of craft evolving into a point of entry for foreign individuals. ${ }^{42}$ According to a government report prepared by Charles Belgrave, the public encouraged regulating these processes as this shifted the authority from individuals to institutions. ${ }^{43}$ By 1937, the Customs House personnel consisted of the formerly mentioned director in addition to nine senior and experienced Indian clerks, a dozen local clerks, and 25 naturs ${ }^{44}$ - an organizational model that could be argued to be roughly still in place to this day, especially in the Bahraini private sector. The significant size of it was due to the position of Bahrain in the trade routes of the British Line Steam Navigation, Hansa Line Steamer, Yamashita Line, Mitsui Line, and occasionally the Strick Line Steamer. ${ }^{45}$ Therefore, the Customs House revenues were partly collected from the transit of goods, including to mainland Saudi Arabia.

The Customs House was in fact, contrary to the urban myth about the date of its construction, completed and inaugurated in 1355 as can be found in different sources. The inscription therefore simply communicates the date in which the building was built, whether it was added at the opening or after. There is a possibility that the confusion of the date is from one of the most widely circulated books, Bahrain in Original Photographs, 1880-1961, in which the inauguration of the building is attributed to the early 1930 s. ${ }^{46}$ Furthermore, in relation to Charles Belgrave's diaries, the entries of 1937 were not missing or expunged; rather, 
they were not available according to James Downs, the Middle East Collections Project archivist at the Special Collections at Exeter University. ${ }^{47}$

The first building was assigned to the Customs House in 1917, following the building of Manama Port in $1912 .^{48}$ The pier sheds were built in 1924; a trolley line system was added in 1925 to facilitate and accelerate the removal of cargo; and small docks were constructed in 1927 alongside a small harbour mole. In 1937, the mole was widened with the addition of the Customs House building, located on the site of the docks. The site of the building was built on reclaimed land that provided additional space for storing cargo. Further services were developed to serve the port, such as improvements to lighting in 1931, enabling work to continue during the night. Belgrave had also proposed future plans for the Customs House, which entailed the expansion of the pier into deeper waters to enable larger boats to come into the port during times of low tide. ${ }^{49}$ The building itself contained "light, airy" offices on the ground floor and a flat on the first floor, with the northern façade facing the waterfront and the southern towards the market. ${ }^{50}$ And between the building and the market was a square, called by Belgrave at the time the customs square, that had a round garden with a fountain in the centre. The roundabout, or "circle garden" as Belgrave called it, was used to control the flow and direction of traffic as the use of cars had increased within that neighbourhood..$^{51}$ The garden was added to beautify the area - one of the occupations of Belgrave was to create more green spaces in Bahrain. ${ }^{52}$ The building is what would typically be referred to as colonial architecture although it was built using the cross-pollination of building techniques between Bahrain, Iran, and India, facilitated by pre-existing trade routes developed further by the British. The use of 'colonial' to describe the buildings could be attributed to three explanations: size, programme, and the relations between the inhabitants of the country and the British. The building was larger than the older fabric of the city. In a photo taken of Manama in 1936, the proliferation of administrative buildings that disrupt the intricate urban fabric is evident. ${ }^{53}$ Though, it is not possible to state if the Customs House was one of the buildings that appears in this image in particular. The second connection to colonial buildings is through programme: what the building represents rather than its architecture. It was an institutionalization of processes that align with those of British institutions. ${ }^{54}$ The third explanation for it being perceived as a colonial building pertains to the British presence within the country, considered a colonial presence. Therefore, any building used by the British was considered a representation of colonization. For example, 1956 protests in Bahrain in solidarity with Egypt against the British targeted buildings occupied by the British, either through assembly of protesters around or direct attacks on the buildings. ${ }^{55}$ 


\section{5 as a decisive [modern] moment}

The disappearance of spaces from the cityscape, their resurrection, new-found value after the passage of time, and confinement to the drawing board and in spaces of archives raise questions about what these spaces represent in the historical narrative of a country, exposing a duality occasionally and many times a multiplicity of history. The resurrected 'inscription', or the year 1355 , can indeed be used as a shorthand for various issues related to Modernity, or a Modern moment. Foremost is the widespread knowledge as to when the building was first built, and the multiple confirmations regarding the inscription being added after years of its inauguration in the 1920s or early 1930s. The void of archives and documentation enables an oral practice of knowledge exchange and rumours, that with repetition leads to the circulation of unquestionable facts. This could relate to a loss in translation, inaccessible documents, and citations of the same popular sources for history. In the case of Manama, and specifically the era till its independence in 1971, there is an abundance of documents that can be used to verify information; however, this is not always the case. These documents along with oral history can enable more comprehensive historical narratives to emerge and can forge new connections between the various events that constitute the production of a building. Furthermore, it is clear that the notion of a Modern moment, or the beginning of regulatory processes within society and of modernization, was not a product of an event; in fact, there are precedents, and they change according to the story of progress being told. For example, the description of the town of Manama differs between being a Modern metropolitan town in Lorimer's gazetteer in the 1860s and being deemed backwards when Belgrave arrived in the 1920s in Bell's description in Life magazine. ${ }^{56}$ The latter inflated the agency of Belgrave in developing the country, which is challenged by new research. ${ }^{57}$

Bahrain, and the Gulf in which it is located, have yet to reconcile with intertwining Modern and colonial heritages. Perhaps it is worth asking, what does this mean when attempting to (re)search (for) narratives of Modern heritage in societies where facts are subject to the prevalence of vulnerability on different levels? Vulnerabilities related to facts, accessibility of archives, translations, narratives of history, and obscured spaces within the city. "Can the Subaltern [spaces in our city] Speak?"58 and does it matter if they do? 


\section{Notes}

1 See Ahmed Kanna, Amélie Le Renard, and Neha Vora, Beyond Exception: New Interpretations of the Arabian Peninsula (Ithaca: Cornell University Press, 2020); Harvey Molotch and Davide Ponzini, The New Arab Urban: Gulf Cities of Wealth, Ambition, and Distress (New York: New York University Press, 2019).

2 Murray Fraser and Nasser Golzari, Architecture and Globalisation in the Persian Gulf Region (Abingdon: Routledge, 2016). 3 See Nelida Fuccaro, Histories of City and State in the Persian Gulf: Manama since 1800, Issue 30 of Cambridge Middle East Studies (Cambridge: Cambridge University Press, 2009); Pascal Menoret, Joyriding in Riyadh: Oil, Urbanism, and Road Revolt, Vol. 45 of Cambridge Middle East Studies (Cambridge: Cambridge University Press, 2014); and Farah Al-Nakib, Kuwait Transformed: A History of Oil and Urban Life (Redwood City: Stanford University Press, 2016).

4 Farah Al-Nakib. Kuwait Transformed, 16.

5 Rosie Bsheer, Archive Wars: The Politics of History in Saudi Arabia (Redwood City: Stanford University Press, 2020).

6 Sultan Sooud Al-Qassemi and Roberto Fabbri, "Re-Engaging with the Gulf Modernist City: Heritage and Repurposing Practices", (call for 10th Annual Gulf Research Meeting, Gulf Research Centre, Cambridge, UK, July 2019).

7 See Fernand Braudel, On History (Chicago: University of Chicago Press, 1982), 25-54.

8 Ann Laura Stoler, "A Recursive Mode: Concept-Work for Colonial Histories", talk at Boğaziçi Üniversitesi, Istanbul, Turkey, May 10, 2013, accessed October 26, 2020, https://youtu.be/kj_OTbSsoKM.

9 James Onley, "Britain's Informal Empire in the Gulf", Journal of Social Affairs 22, no. 87 (2005): 29-45.

10 Charles Dalrymple-Belgrave, Papers of Charles Dalrymple-Belgrave, 1926-1957, March 31, 1926, (Special Collections, University of Exeter), 3; James Bell, "He Said Forward to the Backward!", Life, November 17, 1952: 157-158.

11 Bruno Latour, We Have Never Been Modern (Cambridge, MA: Harvard University Press, 2012), 10-15.

12 George Arbid, "The Identity Trap by George Arbid | Executing Culture Shock | Nuqat 2013", accessed October 26, 2020, https://www.youtube.com/watch? $\mathrm{v}=0 \mathrm{Ffz}$ UXI_BX4. Arbid states, "Of how we could look at history of architecture. Because I argue that what we call tradition today is actually centuries of modernisms compiled across time. So, it is absolutely wrong to take tradition as something that came to us, that is a given. It is actually something that has been transformed. And if we look at modernism today as one of those stages then we do not see the contradiction between learning from tradition and being modern".

13 The year according to the Hijri calendar. Throughout the text, there is a mediation between the Hiji and Georgian calendar. The use of a year as a shorthand for major events follows Bruno Latour's use of the year 1989 in his book We Have Never Been Modern as a shorthand for major world events, both the victory of capitalism with the fall of the Berlin Wall and the start of its decline with the first Paris Conference on the global state of the planet.

14 These observations are based on semi-structured interviews conducted in 2018 and 2019 by the author with

Alaa Al-Habashi, a former conservation consultant at Bahrain Authority for Culture and Antiquities (BACA), currently practicing and teaching in Egypt, and Marwa Nabeel, a junior architect in BACA, who worked under Alaa.

15 Marwa Nabeel, Conservation \& Rehabilitation Project - Phase 1 Summary Report (BACA: Bahrain, 2014), 2-4.

16 The Bahrain Historical and Archaeological Society organizes a series of lectures bringing together a community interested in history. The discussion with the historians about the date of this building specifically occurred on May 15 , 2019, a year after a lecture by Nader Kadhim, researcher and author of the book La ahad yanam fi al Manama (No One Sleeps in Manama). 17 "Record: EUL MS 148 - Papers of Charles Dalrymple-Belgrave Relating to Bahrain", University of Exeter, The Bill Douglas Cinema Museum, and Falmouth University archive catalogue, accessed October 26, 2020, http://lib-archives.ex. ac.uk/Record.aspx?src $=$ CalmView. Catalog\&id=EUL+MS+148\&pos $=5$. 18 Ines Weizman has conducted a similar investigation on customs houses found in the Golan. In her work, she does a forensic analysis of the building material to understand transnational processes. Ines Weizman, "Bauhaus Modernism across the Sykes-Picot Line", in Dust and Data, ed. Ines Weizman, 544-572. 19 Adrian Forty states, "History of architecture and design is full of attempts to make sense of buildings and objects through careers, ideas and theories of known designers, and their approach is to be found even in works that are not specifically biographies". Forty, Objects of Desire: Design and Society since 1750 (New York: Pantheon Books, 1995), 239. 
20 The Hijri year corresponding with the date this paper was written.

21 Alaa Al-Habashi, Skype interview with author, May 21, 2019; Marwa Nabeel, interview with author, Manama, 2019; Anne Holtrop, interview with author, Muharraq, August 22, 2018.

22 UNESCO World Heritage Convention Tentative List, "Manama, City of Trade, Multiculturalism and Religious Coexistence", accessed November 24, 2020, https://whc.unesco.org/en/ tentativelists $/ 6354$.

23 Al-Habashi, interview; Nabeel, interview.

24 Nabeel, Conservation \& Rehabilitation Project - Phase 1 Summary Report, 4.

25 See the work of Studio Anne Holtrop in the Pearling Path in Muharraq, a UNESCO World Heritage Site registered as a "Pearling, Testimony of an Island Economy". It consists of 17 buildings in Muharraq City and three offshore oyster beds. There are ongoing efforts to register Manama as a "City of Trade, Multiculturalism and Religious Coexistence".

26 Al-Habashi, interview; Holtrop, interview.

27 Al-Habashi, interview.

28 Lucia Gomez-Robles, site director for the South Section of the Pearling Trail, interview with author, Manama, September 11, 2018.

29 Anas Alomaim mentions the role of invited international agencies, such as the World Bank Group, United Nations, and International Council of Museums, in releasing countries of their colonial trauma through education, Modernization, and culture. Yet universal values are pursued within this decolonizing process that is implemented by these organizations as opposed to allowing them to develop naturally from the context. Anas Alomaim, "Nation Building in Kuwait 1961-1991", (PhD diss., UCLA, 2016), 2-25.

30 Ghassan Chemali, urban conservation consultant at BACA, interview with author, Manama, December 18, 2018.

31 Nelida Fuccaro, "Mapping the Transnational Community", in Transnational Connections and the Arab Gulf, ed. Madawi Al-Rasheed (London: Routledge, 2004), 39-58.

32 Bahrain Ruling Family's Desire to Visit Other States, File 19/209 I (C 73), British Library (BL), India Office Records and Private Papers (IOR), IOR/R/15/1/363, in Qatar Digital Library, accessed October 26, 2020, https://www.qdl.qa/en/ archive/81055/vdc_100000000193. 0x000150.

33 Fuccaro, Histories of City and State in the Persian Gulf, 121-122.
34 Elham Fakhro, "Belgrave's Quest for Moral Order in Bahrain, 1926-1957" (PhD diss., University of Oxford, 2018), 253-259. 35 Government of Bahrain Administration Report for 1926-1937 and Annual Reports for 1937-1944, BL, IOR, IOR/R/15/1/750, in Qatar Digital Library, accessed October 26, 2020, https://www.qdl.qa/archive/ 81055/vdc_100000000193.0x0002d7. 36 Fuccaro, Histories of City and State in the Persian Gulf, 191.

37 Ibid., 198.

38 Bahrain Administration Report for 1926-1937, IOR/R/15/1/750, in Qatar Digital Library.

39 Nabeel, Conservation \& Rehabilitation Project, 4.

40 See Silvia Mazzetto, "Heritage Restoration as a Tool to Promote Architectural Identity in the Gulf Regions", Preservation, Digital Technology \& Culture 47, no. 1 (2018) 3-11; Marco Motisi et al, "The Bahrain Pearling Path: Urban Planning, Structural Investigation and Design of the Strengthening Interventions", in Structural Analysis of Historical Constructions: An Interdisciplinary Approach, eds. Rafael Aguilar et al. (Cham: Springer, 2019), 1830-1838.

41 Gazetteer of the Persian Gulf. Vol I. Historical. Part IA \& IB. J G Lorimer. 1915 [928] (1083/1782), BL, IOR, IOR/L/PS/20/ C91/1, in Qatar Digital Library, accessed October 26, 2020, https://www.qdl.qa/ archive/81055/vdc_100023575946. 0x000054.

42 Bahrain Administration Report for 1926-1937, IOR/R/15/1/750, in Qatar Digital Library.

43 Ibid.

44 Natur is an Arabic word that means watchman. In Bahrain, the naturs were under the command of the ruler and would be given weapons; however, they were not instructed in how to use them. They were usually descendants of Baluchi bodyguards and would soon be enrolled in the police force whenever a vacancy arose. 45 Bahrain Administration Report for 1926-1937, IOR/R/15/1/750, in Qatar Digital Library.

46 Andrew Wheatcroft, Bahrain in Original Photographs, 1880-1961 (London: Kegan Paul International, 1988), 80.

47 James Down, email communication, September 18, 2020. Down is Middle East Collections Project archivist at the Special Collections, Exeter University.

48 As per the timeline provided by the Kingdom of Bahrain, Ministry of Interior, Customs Affair's website, accessed in October 26, 2020, http://www. bahraincustoms.gov.bh/history_customs. php?SID=WWxR d2VVcHVUblJRVkZFOQ $\% 253 \mathrm{D} \% 253 \mathrm{D}$ 
49 Bahrain Administration Report for 1926-1937, IOR/R/15/1/750, in Qatar Digital Library.

50 Ibid.

51 Ibid.

52 Doherty Gareth, Paradoxes of Green: Landscapes of a City-State (Berkeley: University of California Press, 2017), 23.

53 Persian Gulf States (excluding Kuwait), Muscat and Oman: towns. 1961 Jan 01 1961 Dec 31. DEFE 60/172, Arabian Gulf Digital Archive, accessed October 26, 2020, https://www.agda.ae/en/catalogue/ tna/defe/60/172.

54 See Peter Williams, Technical Assistance: A Factual Survey of Britain's Aid to Overseas Development through Technical Assistance, Vol. 4 of British Aid (London: The Overseas Development Institute Ltd., 1964); Valentin Seidler, "Institutional Copying in the 20th Century: The Role of 14,000 British Colonial Officers", Journal of Contextual Economics 137, No. 1-2: 93-119.

55 Abd Al-Rahman Al-Bakir, Al-Bahrain ilti al-manfri Sant Hilrinah [From Bahrain to Exile in Saint Helena] (Beirut: Dar Maktabat Al-Hayat, 1965), 122-123.

56 Gazetteer of the Persian Gulf, IOR/L/ $\mathrm{PS} / 20 / C 91 / 1$, in Qatar Digital Library; Bell, "He Said Forward".

57 See Omar H. Al-Shehabi, Contested Modernity: Sectarianism, Nationalism, and Colonialism in Bahrain (London: Oneworld Academic, 2019).

58 The question is inspired by Gayatri Chakravorty Spivak's work that questions if a subaltern can speak when it is weighed down by the load of imperial, past and present, conditions. Spivak, "Can the Subaltern Speak?" in Can the Subaltern Speak?: Reflections on the History of an Idea, ed. Rosalind Morris (New York: Columbia University Press, 2010), 237-292. 


\section{MODERNISM IN QATAR Survival through reuse}

Trinidad Rico 


\section{Introduction}

The heritage industry in the state of Qatar has grown exponentially over the last decade. In fact, heritage preservation now forms part of the 2030 Qatar National Vision, a government framework for economic, cultural, and social development drafted in 2008. In this document, the need for heritage preservation is balanced against the need for progress in Qatar, which includes the more familiar goals of economic development and sustainability. ${ }^{1}$ A concern with the preservation of cultural heritage was articulated as early as 1980 when the administration of tourism and antiquity at the Ministry of Information of Qatar issued the Law on Antiquities No. 2 for the year $1980 .{ }^{2}$ In line with a series of existing legal edicts and in consultation with the Majlis Al-Shura (consultative assembly), then Emir of Qatar Hamad bin Khalifa Al-Thani (ruled 1995-2013) decreed that

\footnotetext{
...any item inherited from past civilizations or generations that has been found or excavated is regarded as antiquity. It could be a building or a passed-on knowledge of science, arts, literature, moral values or beliefs, daily life or public events and otherwise that predates 40 years or more that holds artistic or historical value. ${ }^{3}$
}

Therefore, "antiquity" and, by association, 'heritage value' was at the time defined chronologically as having the temporal limit of the year 1940. This window of time that defined the heritage value of tangible and intangible heritage objects and practices embraced, at the time, any surviving traditional (pre-modern) architecture but did not necessarily address the arrival of modernist styles as an architectural period that contained potential or actual heritage value. A review of the preservation practices responsible for maintaining the existence of different historical periods across the built landscape of the capital city of Doha today suggests that state policies have placed the architectural remains of the second half of the twentieth century at odds with other heritage preservation agendas in Qatar.

A modernist turn in Qatar is, on the one hand, unmistakeable: the prominence of the iconic Sheraton Hotel, a 1978 modernist landmark designed by William L. Pereira Associates, has defined since its construction the skyline and the waterfront landpp.152-156 scape of Doha. $\boldsymbol{\Delta}$ However, I would argue, its noteworthy presence is not an indication of the value placed on modernism in the heritage preservation practices of Qatar. While the portfolio of cultural heritage preservation efforts in this country since the 1980s ruling is diverse, it shows some marked tendencies that help bring clarity to a neglect for the heritage of the second half of the twentieth century. For example, historic preservation projects focus on the conservation and promotion of pre-oil sites and aesthetics more than any other historical period for Qatar. Overall, archaeological 
and heritage preservation efforts here have followed a trajectory that emphasizes more local or regional rather than global heritage constructs. The onus of the work remains on a preservation of heritage places that buttress the earlier phases and narratives of nation-building. The establishment of the first National Museum and accompanying concerns with heritage preservation in the 1970 s was followed by systematic preservation of sites of historicalpolitical significance such as Barzan Towers and Al-Zubarah Fort and of socio-historical significance such as Souq Waqif and AlWakrah Village and Souk. In addition, the emergence of a national heritage discourse is marked by the preparatory archaeological and museological work that supports the nomination of Al-Zubarah - an eighteenth-century pearling town - to the UNESCO World Heritage List in 2013. This trend is followed, more recently, with the reopening of the National Museum as part of a broad network of thematic museums across the city. The heritage-making narratives in these projects follow similar principles of preservation of historic structures that are uniquely local and locally coherent: while they do not necessarily align with Western practices of preservation in their approach to material authenticity and integrity, they nonetheless capture a vernacular language and thus participate in the crafting of a heritage narrative and visual language. Under the patronage of two state institutions, Qatar Museums (QM) and the Private Engineering Office of the Emir (PEO), these efforts create the cultural heritage assemblage that defines an official visual and discursive heritage sensibility in this country.

In this chapter, I consider that an emphasis on pre-oil traditional architectural styles in the preservation efforts of Qatar has happened at the expense of a specific exclusion in this assemblage that corresponds to a broad 'modernist' period. The most characteristic of these practices amongst the projects listed above is the famed reconstruction of Souq Waqif (2004-2007). Reimagined as a pre-modern urban centre that largely erases traces of post-1940s use and reuse, it stands as a dramatic case of selective restoration that favours pre-oil aesthetics, erasing latter periods from its architectural fabric. Accordingly, the period of cultural production not preserved, in this case, corresponds with a period not clearly articulated as a matter of concern in modern preservation policy. This temporal imprecision that falls through the cracks of heritage policy is echoed in the way in which I refer to a 'modernist' period and aesthetic throughout this chapter. I do not seek to define the modernist turn in strict architectural or art historical terms except through the views of the interlocutors themselves, that is, experts who are concerned with the erasure of architectural features from the very broad period that spans the 1920 s to the 1980 s. This discussion stems from a five-year ethnographic project that examines the emergence of heritage preservation instruments in contemporary Qatar, bringing attention 
to preservation practices that may not invoke famous architectural authors or visible contemporary patron institutions yet contribute to a cultural heritage landscape nonetheless. These narratives fall under practices of reuse: that is, continuity or revival of a historic structure for contemporary purposes and uses that is not carried out in accordance with any defined preservation standard. In examining these narratives and practices, I invoke various intersecting discourses: the establishment of state-sponsored attitudes towards modernization in general; imported value-systems brought about by projects of urban development and their experts; and local agency and innovation that remix all of the above. This work does not seek to construct an overarching and total narrative that justifies the direction and appreciation of modernism in this country but rather aims to highlight the distinction between formal and informal ways in which a concern for specific and idealized pasts is carried out independently of national initiatives.

\section{Heritage revivals}

Despite constituting the core of heritage preservation strategies, mobilizing pre-oil traditional architectural languages in restoration projects has received mixed reviews in Qatar, which may suggest a general discomfort with the artificiality of excluding the better part of the twentieth-century modernizing experience. For example, some refer to the restored Barzan Towers as 'Barzan 2008', highlighting the year of its rebirth as a heritage site through restoration and, in doing so, somewhat mocking its authentic origins in a deeper past. Similarly, Souq Waqif has been described quite openly as a "Disney version of Qatar's past", ${ }^{4}$ despite having been shortlisted for the prestigious Aga Khan Award for Architecture in 2010 for constituting a "unique architectural revival". ${ }^{5}$ There are different degrees of acceptance between expert and public circles when it comes to restoration and reuse practices such as these ones. In the case of Souq Waqif, efforts to homogenize a preoil 'sense of place' involved the removal of post-oil architectural additions and features such as bulky air conditioning units alongside the elimination of entire additions and decorative features that correspond to less desirable historical periods. This type of selective practice of preservation is not unique to Qatar as heritage preservation discourse generally promotes single-period 'heritagization'. It is not difficult to conclude that a whole generational experience of the built landscape has been erased, drawing criticism from Qatari and non-Qatari residents alike who have experienced the authenticity of a place as a palimpsest of features and life-histories that accompany the fast-growing nation.

At the other end of the chronological spectrum, and taking a gigantic leap in the historical timeline of Qatar, traditional architectural languages are carried forward in the form of ultramodern works of infrastructure designed to reflect the production 


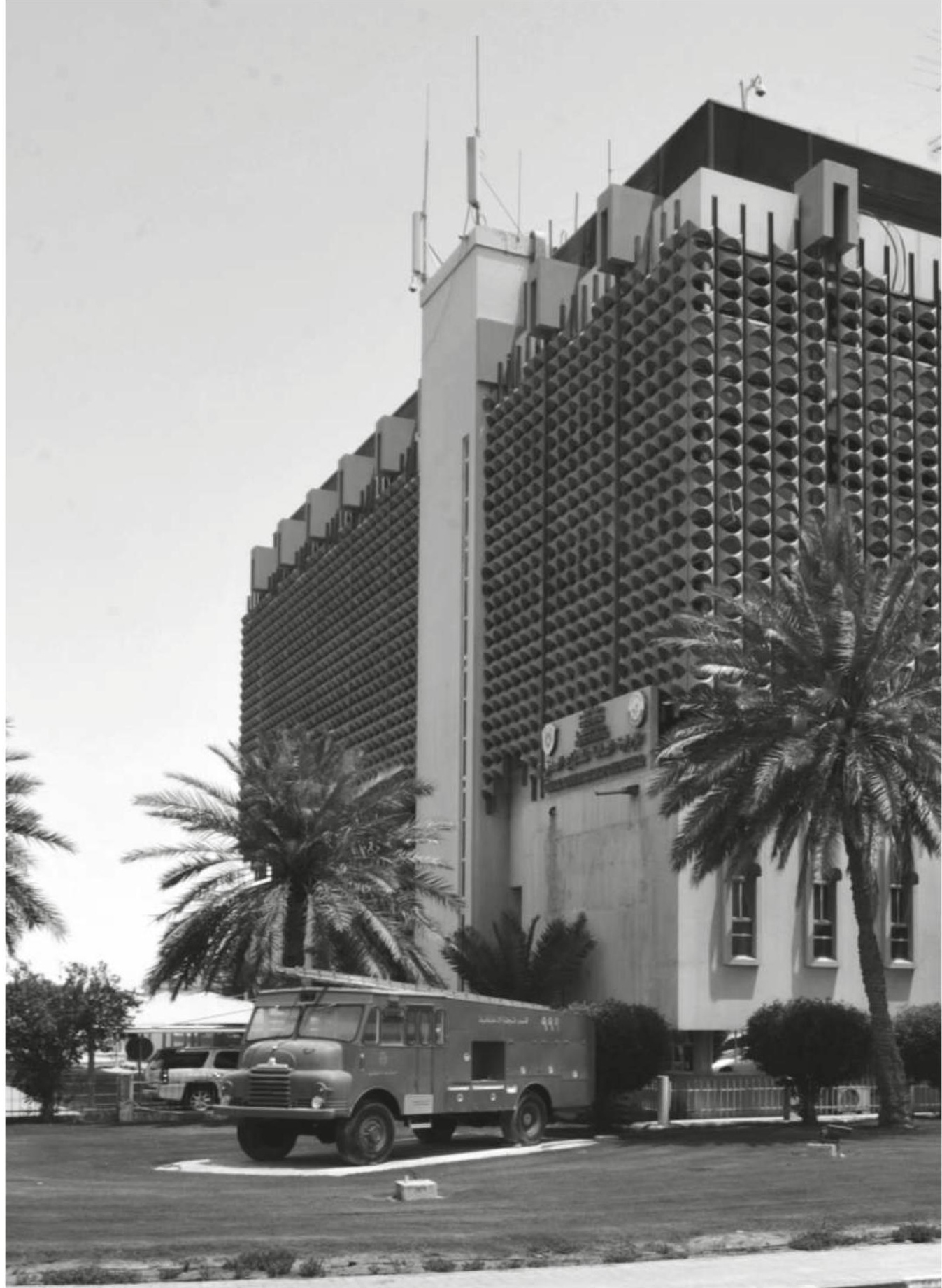




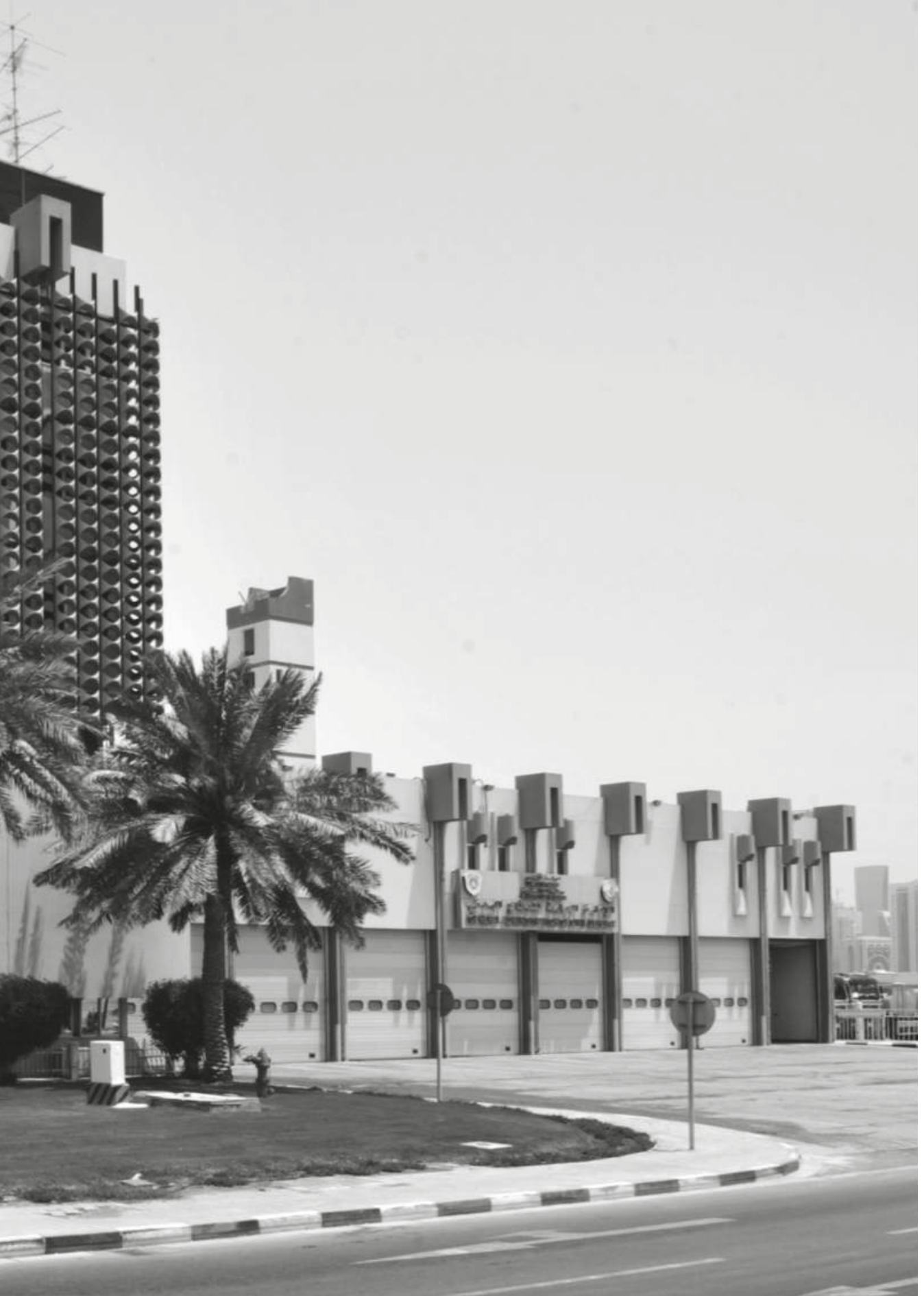


of heritage of the country as a continuous process. For example, the new metro stations inaugurated across Doha in 2019-2020 were designed as vaulted spaces to reflect traditional Bedouin tents. Supporting the mobilization of heritage languages across temporal boundaries, Qatari architect Ibrahim Jaidah, CEO and chief architect at Arab Engineering Bureau, has advocated for a new architectural movement which combines the far-reaching influences of Islamic art with modern styles. His firm is responsible for the realization of several landmark structures in the modern skyline of Doha, such as the Kempinski Residences and Suites tower (completed in 2009), which reflects an exploration of scale, shape, and proportion of the traditional "wind tower". ${ }^{6}$ An admirer of the work of modernist British architect John Harris who designed the State Hospital of Doha in 1952 and then moved on to design the master plan of Dubai, Jaidah also supports an architectural vocabulary that brings together climatic and environmental concerns, traditional forms, and economic and social needs.

But Ibrahim Jaidah's legacy is more far reaching than the contributions he has made to the new skyline of Doha. He is coauthor of The History of Qatari Architecture: From 1800 to 1950, ${ }^{7}$ a compendium that defines a unique visual culture and architectural history for Qatar. He has also contributed to the emerging discussion on the value of modernism in the built landscape of Qatar in various ways. At a public panel that accompanied the opening of the National Museum of Qatar in 2019 (but held at the Qatar National Library), titled Architecture as a Face of a Nation, ${ }^{8}$ he called attention to the loss of architecture of modernism, starting with structures from the 1920s, and all the way through the $50 \mathrm{~s}, 60 \mathrm{~s}$, and $70 \mathrm{~s}$. While he adds that demolition of these types of architectural remains has dramatically decreased in recent times, he concludes that "we [Qataris] tend to forget our early modern history". A few years before, giving a lecture in the Georgetown School of Foreign Service in Qatar in September 2016, Jaidah called for a more careful consideration of what it means to think in traditional or vernacular terms, adding that “it doesn't have to be a mud house to become history". Recognizing the selective marginalization of some styles in the preservation efforts of Qatar, Jaidah was also involved in the documentation of the remains of an 'Arabian Deco' (what British architect Tim Makower calls the 'Doha Deco') in anticipation of large-scale demolition that was carried out at the Msheireb area. He intends to highlight its significance and relationship to Art Deco expressions across the Middle East in a future publication. In addition, his advocacy has been reflected in his firm's restoration work of the former Civil Defence Building with its iconic honeycomb façade, now renovated and converted into the Fire Station: a complex of 24 artists' studios, a gallery, and a café that hosts the Qatar Museums Artists-in-Residence Program.

Built in 1982, the building was vacated in 2012 in order to make 
way for its preservation and conservation under the patronage of Qatar Museums. This project joins other efforts at upkeeping and ensuring the continuous use of other structures within this broad but neglected period of architectural expression: the old Ministry of Education, Marmar Palace, the Old Emiri Diwan, and various mosques across Qatar.

Yet, considering both formal preservation projects and more informal reuse practices, the survival of modernist architecture in the contemporary landscape of Doha and across the countryside of Qatar is rare. Besides the much-publicized project of refurbishment of the Fire Station building that resulted in a thriving centre for the arts, many of these practices of reuse happen more casually, with an emphasis on function and practicality rather than on the value of preserving modernist aesthetics. One could even say this accidental act of safeguarding is hidden in plain sight without the publicity afforded by contemporary modes of cultural production attached to the heritagization of traditional pre-oil architecture. These projects of accidental preservation are found primarily in residential areas of the city and involve the repurposing of modernist residential structures for new commercial uses in areas of Doha that were once residential but have been transformed into mixed residential-commercial throughways. In this way, much of the modernist architecture that survives in some way across the city of Doha has survived driven by profit, that is, repurposed and often significantly altered while avoiding the cost of demolition and rebuilding, as Jaidah points out. As such, they remain unincorporated to a preservation sensitivity for Qatar. For example and notably, businesses across the fareej (neighbourhood) Al-Sadd reuse or, rather, continue to use modernist-style residential villas either as actual residences or transformed into cafés and restaurants. The practicality of reuse/continuity for villas dating to the 1970 s and 1980s here is concurrent to an accelerated process of demolition across this fareej in order to make way for high-density, mid-rise residential structures that accommodate expat workers. An informal and unregulated preservation trend, therefore, is the natural result of a financial rationale and practical appreciation for existing structures, enabled by the transformation of residentialto-mixed use or commercial zoning in this part of the city.

However, I would like to draw attention to an intentional practice of reuse and beautification that preserves and celebrates modernist features in two specific buildings in the neighbourhood of Al-Sadd around the year 2015: the opening of a Caribou Coffee shop on C-Ring Road and the relocation of Lo Spaghetto restaufig.2/3 rant to a villa on Al-Kinana Street in Al-Sadd. Aerial photography of Doha during the 1970s shows that these structures were built sometime between 1971 and 1977, a time when Doha expanded outward, towards and past the annular road called C-Ring (or, its literal translation, Third Ring Road). The Caribou Coffee shop now 


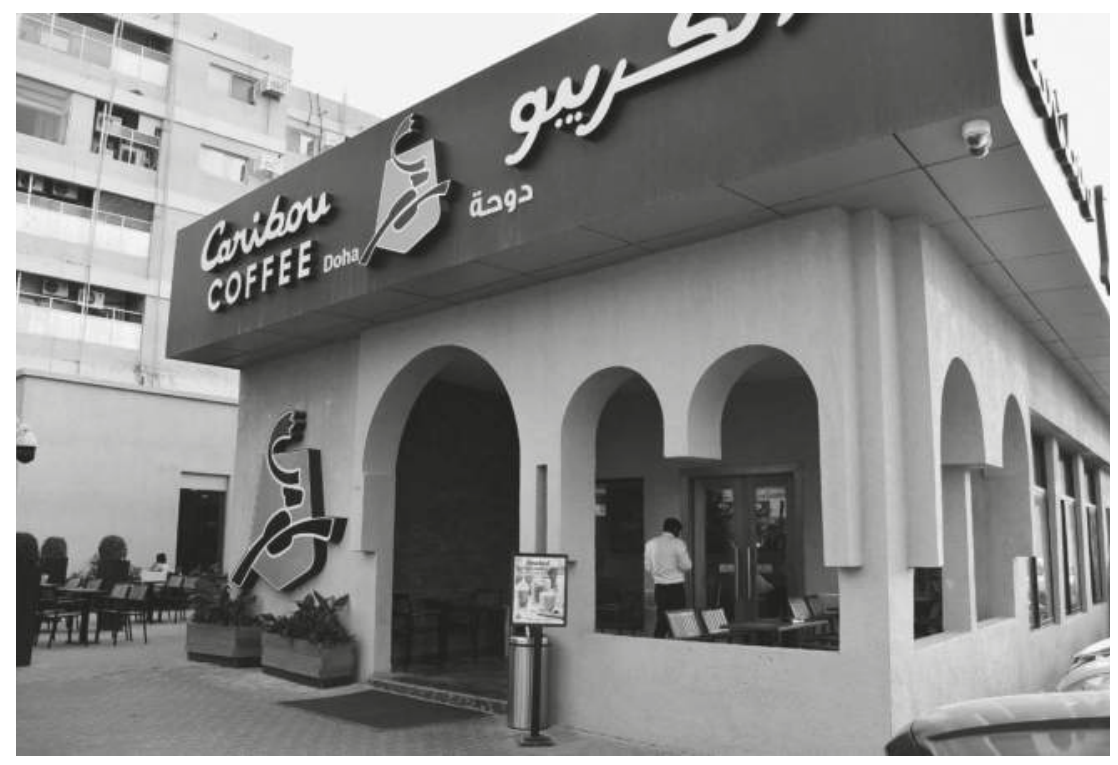

Façade of Caribou Coffee on C-Ring, Al-Sadd, Doha, Qatar (Photo: Trinidad Rico, 2019).

fig.2

occupies an adapted residential structure in a one-of-a-kind compound of different modernist buildings. Initially, its reuse as a café stood out for maintaining its smaller original footprint and arcaded windows, but these have now been replaced and the footprint expanded, making it less recognizable as a modernist structure over time. The other structures in the compound of which it was once part have also undergone dramatic transformations, erasing their original unique features. Meanwhile, Lo Spaghetto has been built in a single-storey villa (bayt shaabi), part of a cluster of villas in a former gated community in Al-Sadd. Before the restaurant, the building had already been transformed into a commercial structure that maintained its open floor plan and landscaping similar to its original design. However, the Italian owners of the restaurant specifically sought a modernist villa that could be adapted to their needs, confirming an interest in maintaining and enhancing its remaining modernist features, including the outdoor dimensions. One of the features of this villa that adds to its authenticity is the surrounding cluster of original villas just like this one, most of which are in a visible state of decay except for the quaint Green Door - an antique, architectural salvage, and trinket store housed in one of the residential villas nearby. Beyond the intimacy of these clusters of contemporaneous structures, the city of Doha advances with much taller and overwhelming architecture that would take away from maintaining the modernist feel of these particular places, their façades, and surrounding landscaping. 


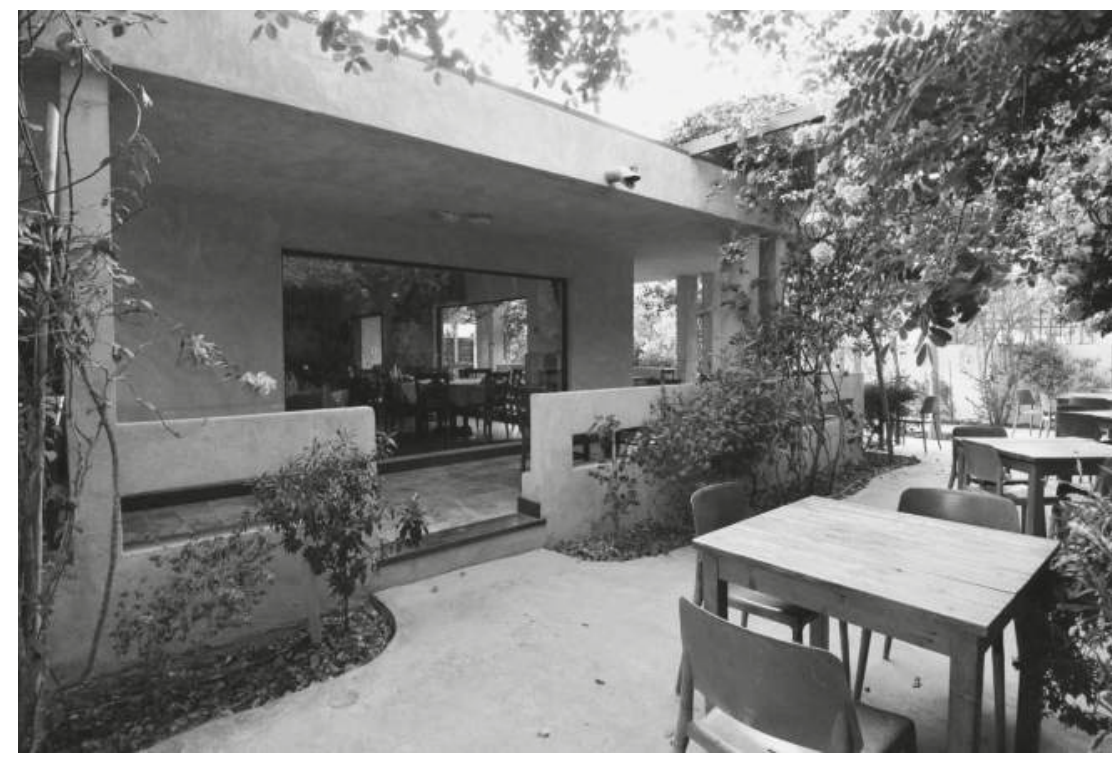

fig.3 Lo Spaghetto on Al-Kinana Street, Al-Sadd, Doha, Qatar (Photo: Trinidad Rico, 2019).

\section{Heritage languages in flux}

Emerging heritage preservation languages in Qatar can, therefore, be observed and documented in both institutional/ formal and non-institutional/informal ways. But the informal way in which heritage languages are preserved in urban development not intended to carry forward a heritage preservation agenda is difficult to capture. I would argue that this is due to two factors in Qatar: a heritage preservation expertise concerned exclusively with institutional/formal cultural agendas and a relative absence of a civil society to create a complementary narrative of heritage value along less represented heritage languages. Therefore, there is potential for a study of expanded heritage languages with a broader institutional agenda that could incorporate practices of reuse into practices of heritage preservation.

As an example of observing heritage as a potential rather than an actual place, I refer to my first fieldwork impressions arriving in the state of Qatar in the middle of the summer of 2011, a preliminary look into the construction of Qatari heritage assemblages on both formal and informal scales. On the one hand, the urban landscape at the time was marked by an ongoing process through which apparently abandoned or neglected landscapes were being restored and rebuilt to take their rightful place in a coherent cultural heritage narrative, for example, the 'ruins' of the Umm Salal Mohammed historic farm outside of Doha were undergoing the early stages of restoration which appeared to include a 


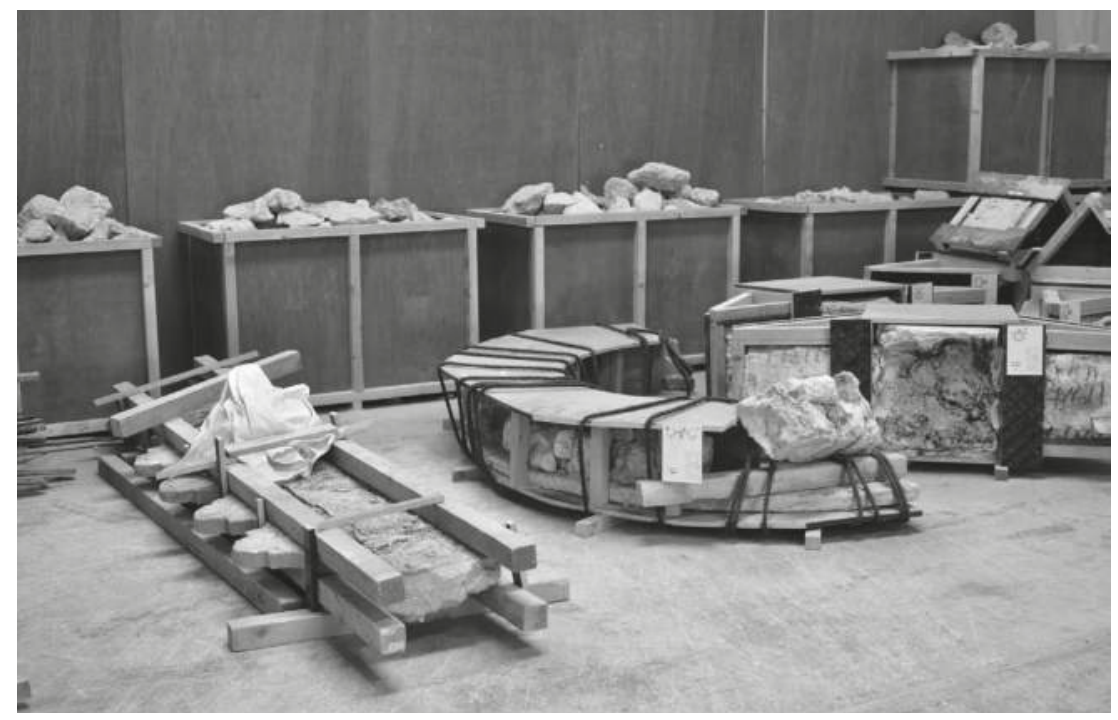

Stored remnants of a modernist city, Industrial City, Qatar (Photo: Trinidad Rico, 2012).

fig.4

removal of modernist features. But, less visibly, a heritage narrative was waiting to be forged in Industrial City - a location outside of the capital city comprised of body shops and mechanics, wholesale stores, storage facilities, and housing for a large number of migrant workers. In this unglamorous and functional urban environment unrelated to the heritage renaissance of Qatar, in a giant storage room, rested disassembled remains of the fareej Msheireb, now a 31-hectare, downtown redevelopment project adjacent to Souq Waqif that was, at the time, already undergoing a dramatic urban renewal. Msheireb is also the name of the subsidiary of Qatar Foundation that carried out the redevelopment of this neighbourhood - Msheireb Properties. Originally called Dohaland, then the Heart of Doha, and finally Msheireb Downtown Doha, the project involved large-scale demolition of most of the existing urban fabric, but it preserved most of its original layout (e.g. the original 'electricity street') as well as few original structures. Four historic buildings were spared from demolition, to be incorporated into the new master plan in situ: the Radwani, Mohammed Bin Jassim, Bin Jelmood, and Company Houses. The movable features of the old neighbourhood after it had been vacated had not been entirely destroyed; rather, many had been redistributed and put away. What was once part of the urban landscape, ornamentation, and, generally speaking, visual culture of this area of the city was represented by the contents of this storage facility: wooden and metal doors, light fixtures, mashrabiyya-style coverings, decorative fences, shop signage, bundles of denchel (also called chendel) wood 
beams, bits of masonry, columns, entire arches and walls, old TV units, mannequins, and so on. These fragments once constituted the urban fabric and last chapter of the life-history of Msheireb and thus represent different historical periods of Qatar up until the eve fig.4 of the demolition. After this transformation, the neighbourhood was reborn as a modern sustainable city, deploying a new vernacular architectural language ${ }^{9}$ that centres on a pre-modernist, cross-temporal citation instead.

These stored objects were not simply disposed of in a storage facility: some of these fragments were labelled, carefully supported, and wrapped in plastic film while others were collected by type: wood with wood, doors with doors, shop fittings with shop fittings - a collapsed stratigraphy. The haphazard collection of fragments was, in fact, curated by members of the Echo Memory Project, or Sadaa thakerat al-makan, an artist-led initiative that collected, documented, and safeguarded found objects. It was launched in 2009 by Issa Al-Mohannadi, then CEO of Msheireb Properties, in collaboration with the Architectural Language Advisor for Msheireb, Tim Makower, and two London-based artists. Accompanying the demolition and later redevelopment of Msheireb, this initiative aimed to provide an archive of the material culture of the area which could be eventually used as a foundation for the generation of new artwork for Msheireb once it (re)opened. This vision was never realized, for Msheireb is currently being populated by public art unrelated to its past materiality. The Echo Memory Project set up its base at the Msheireb Arts Centre (MAC), located in the Al-Asmakh neighbourhood, adjacent to the bustling construction site that Msheireb has been for the larger part of the last decade. The MAC occupies a very distinct pale green modernist building in the middle of the Al-Asmakh area: a former school building from the 1950s (the old Girls' School, Al-Wassad), abandoned in 2005 and renovated by Msheireb properties to host some of these collections. An estimated 3,000 to 4,000 objects had being gathered as part of this project, many of which were displayed and stored at MAC while others remained in the aforementioned, oversized storage facility in Industrial City. ${ }^{10}$ According to Karen Exell's interpretation of the curatorial decisions that gave rise to this collection, these remnants of the built landscape, which once constructed the façades and sense of place of the bustling streets of Msheireb, held no intrinsic value beyond being intended to support the state agenda of 'Qatarizing' or 'Arabizing' Doha's history through objects that represented a Qatari past. However, I would argue instead, decisions to build this unusual historical archive for Qatar that puts emphasis on a modernist aesthetic were carried out by the individuals in the curatorial team, comprised of various nationalities and artistic agendas not necessarily in alignment with a 'Qatarizing' agenda as she speculates. The collection, therefore, was valorized through a specific lens in the 
process of its formation. Furthermore, the transformation of this relatively raw assortment of portable objects into the displays that can be seen at the museums today was approved by the CEO and the Director of Museums of Msheireb. In her work, Exell further argues that "the only genuine Qatari elements were the architectural fragments, which reflected an earlier Qatari architectural aesthetic dating to the period when more affluent settled lifestyles were possible following the discovery of oil in 1939". ${ }^{11}$

Overall, this assessment of what is and is not genuine narrows down authenticity to an imagined undisturbed Qatari aesthetic, detached from the cosmopolitan cultural contact that defines the history of the region, and ignores the ability of a Qatari audience to appreciate and experience its own cosmopolitan engagement with this type of material culture. In preventing Qataris from channeling their experience of the modernist turn (as well as a more general modernization) through these objects, such an assessment demonstrates the way in which foreign expertise intervenes to designate what is and what is not a genuine Qatari experience, contributing to the marginalization and even erasure of modernism. The reality is also that the remains in question are not easy to attribute to a single architectural period because they represent a palimpsest of design styles over a long period of time. Therefore, establishing their place in a timeline of architectural history to make claims about their ability to represent authenticity is not accurate or useful to advance discussions of indigeneity in the cultural heritage languages and practices of Qatar. Furthermore, archaeologists from the Old Doha project have examined aerial and satellite imagery of Msheireb and indicated that Msheireb proper was not built until 1953, with most of the area filled in during the 1960s and 1970 s - firmly constituting a 'modernist' urban expansion. But the footprint of what today is called Msheireb includes other districts (fareej Mohammed bin Jassim and a western extension of Jasra that includes the current Radwani and Company heritage houses), allowing the timeline of construction of this district to be pushed to an even earlier date. ${ }^{12}$ Stylistically, and stratigraphically, most of these structures fall into a palimpsest of styles, making the identification of structures pertaining to different styles and periods challenging. On the one hand, this challenge manifests as a problem of identifying what the transition to early modernism looks like in Qatar. On the other hand, this challenge sets up an interesting framework for examining the preservation of different historical and cultural periods in the history of Qatar. Safeguarding efforts, therefore, can simultaneously preserve pre-oil architecture and aesthetics as well as post-oil additions to the spaces and material culture of the city that may be preserved unintentionally. In this sense, these suspended collections have the potential to represent a continuity and heterogeneity of use by different segments of the population through time, including various phases of modernism. 
Eventually, in more recent years, elements of these collections-in-waiting in Industrial City and the MAC made their way to the museum universe of the Msheireb development where new museums display today the curios of modernization itself. The Company House is set in the actual headquarters of Qatar's first oil company, holding objects and stories of oil discovery and exploitation, and featuring narratives of petroleum industry workers who accompanied the process of industrialization that took place in Qatar during the pioneering years of oil exploration. This narrative of progress is kept distinct and physically separate from the cultural and heritage narratives represented by the other three museums projected and already opened in Msheireb, despite the temporal, spatial, and cultural overlap of their respective themes during the course of the twentieth century. The Radwani House is a residential structure built in the 1920s in the traditional courtyard style and located between Al-Jasrah and Msheireb. Today, it has been restored and incorporated into the Msheireb master plan to present a snapshot of traditional Qatari family life before the advent of the oil era and the modern conveniences that it brought about. In contrast, the Mohammed bin Jassim house was built originally by Sheikh Mohammed bin Jassim Al-Thani, son of the founder of modern Qatar. In this restored, traditional courtyard house, the transformation of the urban fabric of Msheireb - and therefore, Doha - is featured through interactive models, archives of the first iconic structures of Qatar, and objects from the Echo Memory Art Project. Finally, the Bin Jelmood House, informally called 'the slavery museum', raises awareness of formerly enslaved people in Qatar, across the Indian Ocean, and the world.

The Msheireb museums are set in buildings that reflect traditional pre-oil architecture, holding pre-oil and post-oil material culture, and restored to be surrounded by cutting-edge architectural design, the "new architectural language ... created to counteract the depletion of Qatar's unique cultural and architectural heritage", ${ }^{13}$ and used "to create buildings of a shared DNA, reviving local heritage and culture through a unified architectural idiom". ${ }^{14}$ In this sense, the Msheireb project represents an excellent prototype of the complexity of studying heritage preservation narratives and efforts in Qatar during 2011-2016: it systematically erased pre-modern and modernist architecture to make space for a new architectural fabric that is, ironically, informed by those endangered structures, sprinkled with the restoration and reuse of select pre-oil features. But in the careful exercise of curating the aesthetics and spaces of tradition in the face of modernization, what was lost first and foremost was the landscape of modernization itself, except in the cases in which modernism hitched a ride on the preservation of so-called pre-oil architecture-considering the frequency of transitional styles. ${ }^{15} \mathrm{An}$ adjacent initiative exemplifies the practical aspects of operationalizing continuous or mixed 
periods of occupation into stricter categories used in architectural surveys. The Mapping Old Doha project launched by Qatar Museums aimed to pre-emptively assess heritage value in the fareej immediately bordering Msheireb, Al-Asmakh, and Najada. During the period 2012-2014, this Qatar Museums initiative aimed to record the old urban fabric of these areas comprehensively. Launched by the Restoration Department of Qatar Museums, the emphasis of this initiative appeared to revolve around traditional buildings from the first half of the twentieth century, followed by some attention paid to early modern buildings (mid-1950s to 1970). The survey forms that were used to capture these resources show evidence of a strict architectural periodicity that underpins the initiative, asking surveyors to mark each structure as belonging to one of four categories: "traditional with inner courtyard without arcades", "traditional with inner courtyard and with arcades", "early modern", and "modern". The volunteers and professionals coordinating this initiative were not given much instruction on how to translate the complex palimpsest of styles into these fixed categories, inevitably resulting in a database that is forcefully periodic - that is, erasing mixed-period occupation and styles.

\section{A 'negative heritage' of modernization?}

Confronted with such a complex built environment and landscape of expertise, the challenge of encountering modernism and putting it into dialogue with other heritage languages is magnified by heritage preservation policy documents produced so far in Qatar that fail to address the marginalization of early and late modernist aesthetics. Because of this, the study of heritage preservation practices has to rely on the analysis of approaches, debates, and in particular an examination of the allocation of resources that build specific tendencies in the heritage profile of contemporary Qatar. The intentional exclusion of modernism in the growth of heritage assemblages could be interpreted through the lens of 'negative heritage', that is, heritage that "becomes the repository of negative memory in the collective imaginary". ${ }^{16}$ lan Simpson has argued that the disparity in the way in which different pasts are presented across the heritage landscapes of the Gulf is associated with the relative value of the industrial cultures of pearling and of petroleum exploitation measured against each other in heritage discourses. ${ }^{17}$ This contrasting attitude, he argues, has been exacerbated by mounting discussions of pollution, environmental damage, and unsustainable consumption that magnifies the different types of livelihoods and puts post-oil lifestyles at odds with modern discourses of progress. Therefore, he observes that, across the GCC, heritage practices and cultural references to natural pearls and pearl-diving thrive due to the social and environmental values, political histories of resource exploitation, and human-environment interactions that they invoke. Meanwhile, 
the production of heritage of the oil era - what would be represented in the heritage of modernism - has been actively marginalized as impure. This is also intimately related to the way that pearling is seen as a heritage of citizens while oil exploitation and thereafter is inevitably a heritage that has to navigate an exponential input of migrants.

On the other hand, academic and disciplinary debates on the topic of a heritage of modernization observe complex and perhaps contradictory narratives for the relative value of modernity as it may be reflected in the built landscape. Karen Exell and I have argued prior that the interaction between these two distinct periods in heritage practices does not reflect an opposition but rather an assimilation of modernization into more traditional heritage assemblages. ${ }^{18}$ In this argument, we saw heritage preservation in Qatar undergoing conceptual changes since its formal emergence in the 1970 s as a reaction and in adaptation to fast-paced economic development and urbanization. Today, I would propose a different argument after a more thorough examination of heritage discourse and practice in Qatar in addition to a much longer period of ethnographic engagement in the region. I would argue instead that the allocation of effort and resources for heritage preservation is not reflective of a clear embrace of modernization. The uneasy management of modernization continues to be obstructed by coexisting legacies that marginalize post-oil architectural appreciation and its incorporation into the fabric of heritage resources in Qatar. Evidently, European expertise dominates heritage preservation efforts in Qatar, not necessarily due to the actual nationality of experts but mostly to the source of this expertise, which continues to be grounded in European knowledge and values. ${ }^{19}$

But there are other historical, social, and political processes that need to be further explored and taken into consideration in any discussion of the marginalization of modernism in the heritage assemblage of Qatar: first, I consider Farah Al-Nakib's detailed exploration of different urban planning policies that were instituted throughout the modernization of Kuwait, explaining the way in which Kuwaitis are made to detach from their own urban heritage. ${ }^{20}$ With the past becoming a hindrance to the modernist planning in Kuwait, she argues, "Reaching the imagined future required the removal of all historical context". ${ }^{21}$ Likewise, I suggest that the modernization of the city of Doha and of the country overall may have required a discursive and affective detachment from pre-modern and modern landscapes during mass relocation away from the old city. ${ }^{22}$ The land that comprises a neighbourhood like Msheireb was acquired by the state for eventual redevelopment projects, and a transitional use of these structures as rental properties made stewards of migrant workers who occupied them, further detaching these spaces from the discourse of traditional authentic heritage that followed. ${ }^{23}$ 


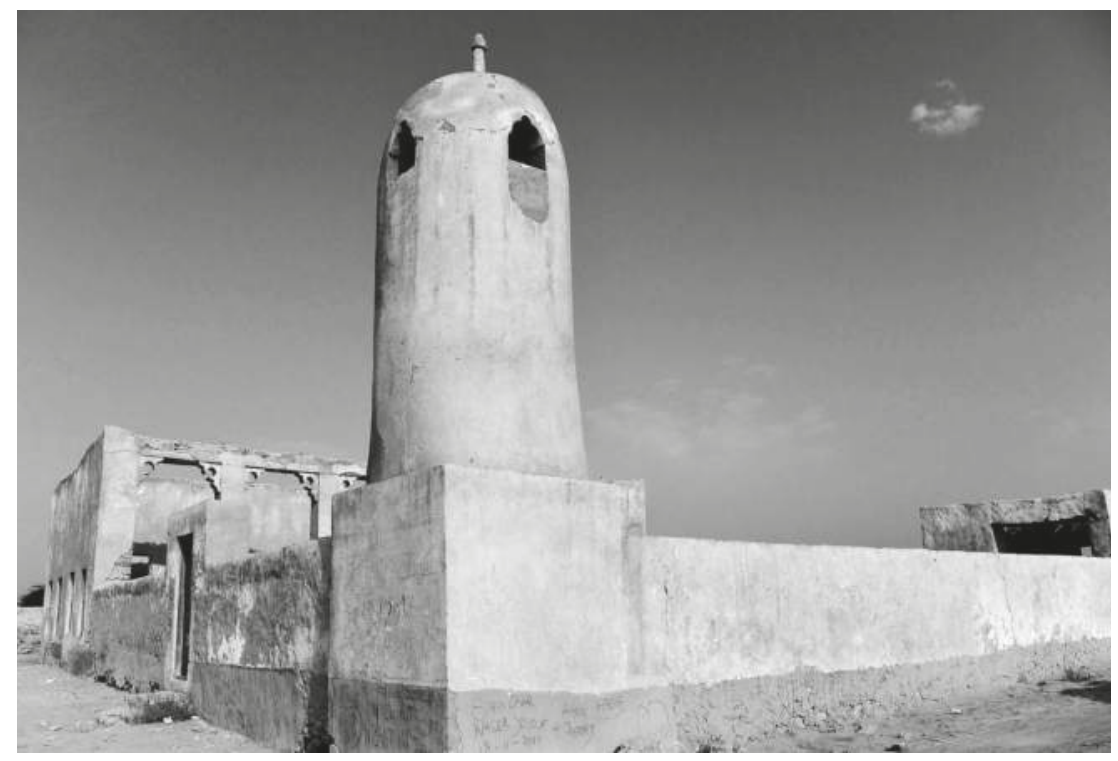

Al-Jumail Mosque, circa 1940, Al-Jumail, Qatar (Photo: Trinidad Rico, 2016).

fig.5

Second, despite the unquestionable neglect that modernism endures as a style, not only in Doha, but also in the region and beyond, ${ }^{24}$ there are recent institutional efforts that demonstrate an emerging interest and appreciation for modernism in the expansion of heritage assemblages of Qatar. For example, the heritage preservation of modernist features is implanted in the preservation of mosques across the country, some of which maintain their modernist features. The restoration division of Qatar Museums has identified and documented heritage mosques across the country, with dates of origin ranging from the nineteenth century (extremely few) to the mid-1960s, but most of these structures date to the 1940s. While the active restoration of these mosques is ongoing, there is no indication of whether pre-modern mosques are being prioritized over the (more numerous) modernist ones. However, with mosques being - according to one of the heritage experts in Qatar Museums involved in an initial survey of this historic resource - "the only heritage left in Qatar", these comprise the largest assemblage of relatively undisturbed modernist architectural structures in Qatar. More recently, the Gulf Architecture Project under the rapidly expanding Qatar National Library has widened the conventional scope that heritage preservation discourse has on traditional pre-oil architecture. Through conferences and their ongoing collection of resources that includes architectural, archival, and oral resources, the emphasis of their work expands from the dominant concern with traditional/pre-oil 
architectural styles to include modernism and beyond. Ibrahim Jaidah is one of the key consultants in this project.

Private initiatives to raise awareness of the significance of modernism as a legitimate and valuable period in the architectural history of Qatar are also emerging. Fatma Al-Sahlawi, the founder and manager of the Atlas Bookstore in Qatar, curates a collection of resources and oral histories that together form an archive on the rise of modernism in Qatar. Although it once held a base in William L. Pereira's iconic Sheraton Hotel in Doha, she uses her transient book collection referencing the architecture and urbanism of the Middle East and North Africa to promote the study of and appreciation for the modernist turn. Her work captures both the structures and debates featured in various archives and publications as well as the narratives of expertise attached to them. In particular, Al-Sahlawi reconstructs through interviews and other resources the encounter and appreciation of modernist styles that took place during the modernization of Qatar itself, highlighting the figures and interests that were involved in this architectural turn - American, British, and even Japanese visions of modernity.

\section{Conclusion}

In this chapter, I examine the way in which cultural heritage preservation projects exclude post-oil heritage narratives in general, caught in between the charm of traditional and premodern aesthetics under the patronage of cultural institutions, on the one hand, and the allure of the ultra-modern and sustainable city, emerging by the hand of famous local and foreign architects and visionaries, on the other hand. The heritage preservation narratives of Qatar have, in different ways, erased the areas in between these two foci, either discursively or physically.

Against an examination of Qatari instruments for cultural heritage preservation and the debates and discourses that result from it, I bring attention to a handful of preservation efforts that bring to life the existence of modernist structures in the lifehistories of the urban landscape. These are comprised of different initiatives both deliberate and unintentional in their efforts to preserve modernism. Some preservation projects target the disappearing modernist fabric of Qatar, often through isolated initiatives by local and foreign experts to bring value to the modern architectural fabric of the city and attach ideas of cultural heritage, safeguarding these otherwise undervalued styles and structures. Some of these are run by established architects who have taken an interest in the matter as part of a concern with the marginalization of modernism worldwide, for example, a local concern with Doha deco. Other conversations are fuelled by early career, Qatari interlocutors who seek to revalorize those periods obscured in the historical and economic development of the country yet hold significance in its cultural and social development. On the 
other hand, there are also practical and economic efforts to reuse modernist structures across the city, a sort of accidental preservation of structures that would have otherwise been demolished to make way for commercial real estate. These may emerge from practical and economic reasons rather than in alignment with a historic preservation dogma and its strict ideas of authenticity that circulate globally; therefore, some or many of the original features could be erased in the process of reuse. The ongoing struggle of preservation of modernism in Qatar indicates that traditional studies of heritage preservation, focusing on institutional practices and policies, are not capable of capturing the informal spaces in which a preservation sensibility is being forged and practiced. The study of unofficial, emerging, and informal heritage languages and practices gives an indication of the future landscape of cultural heritage and completes an otherwise partial picture of the relationship between a people and a built landscape under constant construction.

\author{
Acknowledgements \\ This ongoing discussion would not be possible without the support \\ and contribution of expert views from many colleagues in Qatar: \\ Ibrahim Jaidah and team, Nada H. Fouad, and Lejla Niksic as well as \\ Prof Robert Carter, Haitham Al-Abri, Gizem Kahraman, Omer Çan Aksoy, \\ Gizem Kahraman, and Sebastian Betancur-Montoya. In addition, \\ Sultan Sooud Al-Qassemi, Roberto Fabbri, Todd Reisz, and Michael \\ Kubo provided generous feedback on an earlier version of this chapter.
}




\section{Notes}

1 General Secretariat for Development Planning, Qatar National Vision 2030 (Doha: GSDP, 2008), 3. See also discussions in Karen Exell and Trinidad Rico, “There is no heritage in Qatar': Orientalism, Colonialism and Other Problematic Histories", World Archaeology 45, no. 4 (2013): 670-685, 678.

2 Al-Meezan, "Law No. 2 of 1980 on Antiquities", 2019, accessed June 3, 2019. https://www.almeezan.qa/LawView.aspx? opt\&LawID=3976\&language $=e n$

3 Ibid., Article 1.

4 Rachel Morris, "Souq Waqif, Doha's Resilient, Labyrinthine Market", BBC Travel, August 3, 2011, accessed June 3, 2019, http://www.bbc.com/travel/feature/ 20110802-souq-waqif-dohas-resilientlabyrinthine-market

5 The Aga Khan Development Network, Aga Khan Award for Architecture, AKAA 2010 Cycle, accessed June 3, 2019, https://www.akdn.org/architecture/project/ souk-waqif

6 Ibrahim Jaidah, personal communication, March 17, 2019.

7 Ibrahim Mohammed Jaidah and Malikaa Bourennane, The History of Qatari Architecture from 1800 to 1950 (Milan: Skira Editore, 2010).

8 Architecture as a Face of a Nation, Qatar National Library, March 27, 2019.

9 Tim Makower, "Doha Renaissance: Msheireb Reborn", in Architecture and Globalization in the Persian Gulf, eds. Murray Fraser and Nasser Golzari, (Abingdon: Routledge, 2013), 359-382.

10 Karen Exell, Modernity and the Museum in the Arabian Peninsula (Abingdon: Routledge, 2016), 152. 11 Ibid., 153.

12 Robert Carter, personal

communication, March 10, 2019.

13 Msheireb Properties, "Msheireb

Downtown Doha Mandate", 2012, accessed

November 1, 2012, https://www.msheireb. com/msheireb-downtown-doha/aboutmsheireb-downtown-doha/mandate/ 14 Green Building Review, "Msheireb Properties", 2012, accessed November 1, 2012, http://greenbuildingreview.com/ directory/msheireb/

15 Daniel Eddisford and Robert Carter,

"The Vernacular Architecture of Doha,

Qatar", Post-Medieval Archaeology no. 51, (2017): 81-107, 10.

16 Lynn Meskell, "Negative Heritage and Past Mastering in Archaeology", Anthropological Quarterly 75 no. 3 (2002), 557-574, 558.

17 Ian Simpson, "Concern amid the Oysters as Pearling Is Honoured: Nature and the Environment in Heritage
Practice", in Cultural Heritage in the Arabian Peninsula: Debates, Discourses and Practices, eds. Karen Exell and Trinidad Rico (Farnham: Ashgate, 2014), 33-49.

18 Exell and Rico, “There is no heritage in Qatar'", 670-685.

19 Rodney Harrison, Heritage: Critical Approaches (Abingdon: Routledge, 2012). 20 Farah Al-Nakib, Kuwait Transformed: A History of Oil and Urban Life (Stanford: Stanford University Press, 2016).

21 Ibid., 17.

22 Sharon Nagy, Social and Spatial Process: An Ethnographic Study of Housing in Qatar (PhD diss., University of Pennsylvania, 1997); and Florian Wiedmann, Ashraf F. Salama, and Alain Thierstein, "Urban Evolution of the City of Doha: An Investigation into the Impact of Economic Transformations on Urban Structures", METU Journal of the Faculty of Architecture 29, no. 2 (2012): 35-61. 23 Gizem Kahraman and Robert Carter, "Traditional Architecture and its Appropriation in Old Doha: Al-Ashmakh Neighbourhood", Post-Medieval Archaeology 53, no. 1 (2019): 38-65. 24 For example, Herbert Muschamp, "ART/ARCHITECTURE; It's History Now, So Shouldn't Modernism Be Preserved, Too?" The New York Times, December 17, 2000, accessed June 3, 2019, https:// www.nytimes.com/2000/12/17/arts/artarchitecture-it-s-history-now-so-shouldnt-modernism-be-preserved-too.html; Sandy Isenstadt and Kishwar Rizvi eds., Modernism and the Middle East:

Architecture and Politics in the Twentieth Century (Seattle: University of Washington Press, 2008); World Monuments Fund, "Modernism at Risk", accessed June 3, 2019, https://www.wmf.org/project/ modernism-risk. 


\title{
URBAN PORTRAITS Preserving the memory of modern architectural heritage in the United Arab Emirates
}

\author{
Marco Sosa and Lina Ahmad
}




\section{Introduction}

The United Arab Emirates (UAE), comparatively to European countries, is a relatively young nation. The country was established in 1971. The period after formation, or etihad as it locally known (1971-1991), saw the construction of a nation not just in geographical and political terms but also in physical shifts: cities and infrastructure formed where, once, there were small settlements and sometimes only desert. This period is within what Abu Dhabi Municipality refers to as the second main phase of the growth of Abu Dhabi, between 1969 and 1988. Abu Dhabi is currently undergoing its fifth stage. ${ }^{1}$ Architecturally, the country is internationally recognized, defined by older architectural heritage such as the Qasr Al-Hosn, the royal palace in Abu Dhabi (1761), and the very new and extraordinary structures such as Burj Khalifa, Dubai (Skidmore, Owings \& Merrill, 2010); Sheikh Zayed Desert Learning Centre, Al-Ain (Chalabi Architekten \& Partner, 2013); and Opus Hotel, Dubai (Zaha Hadid Architects, 2020). The buildings from the post-etihad period can be categorized as 'recent or modern' architectural heritage. It is important for local communities to understand the value of these buildings in their neighbourhoods, not only from an architectural point of view in that they echo the design and construction practices of the time but also from a historical perspective, considering them as places engraved within the memories of the city dwellers, past and present. These memories intertwine with inhabitants' personal attributes, traits, space usage, and perception. Over time, they accumulate complexity, creating layers of memory of place. In 2014, the architecture of this period was celebrated and acknowledged at the 1st National Pavilion UAE at the 14th International Exhibition of the Venice Architecture Biennale. The Pavilion responded to the Biennale's curator, Rem Koolhaas, and charted 100 years of architecture in the UAE. The excitement of culturally and climatically aware architecture of the region, represented at the National Pavilion, provided the perfect platform to integrate architectural modern heritage, appreciation, awareness, and the research developed in the interior design studios by the authors at Zayed University, Abu Dhabi.

How can the design studio, in the learning environment, become a conduit for understanding the value of these buildings within the local community? This chapter answers the question with a series of case studies, varying from the introduction of adaptive reuse as a sustainable solution for modern heritage buildings, reproduction, and reinterpretation of existing façades to surveying these buildings in Abu Dhabi. The narratives provide a glimpse into the creative consciousness of young Emirati female designers, who are yet to play a role as future contributors of the growth and further development of their nation. The chapter describes adopted processes for developing different 
methodologies to record the UAE's architectural modern heritage. The devised systems attempt to capture something beyond the metaphysical appearance of the structures by using different media such as photography, reproduction of building façades, and 3D scanning. How to preserve a memory of a city? How do you prolong its architectural identity in the consciousness of its inhabitants?

\section{Context}

The UAE is among the few nations to experience fast, pervasive economic growth and social change. ${ }^{2}$ This was instigated by the oil and gas reserve discovery and the subsequent commercial revenues, leading to radical social and economic transformation. Since then, the country has undergone a rapid flow of transformation and has experienced international recognition since 1971. The modernization and globalization experienced across the country have rapidly altered lifestyles as society shifts from dependency on fishing and pearl diving to one with nearly the world's highest GDP per capita and with social benefits such as free health care and education. ${ }^{3}$ The local population, however, remains the minority in their own country: approximately $11 \%$ Emiratis to $88 \%$ expatriate as per 2014-2015 statistical data. ${ }^{4}$ It is this fast transformation of the nation and sudden injection of income, coupled with visionary leadership and a large influx of migrant workers, that has contributed to the development of infrastructure and the built environment. In the context of the UAE, the term 'modern architectural heritage' refers to the buildings constructed between the late 1960s and early 1990s. These buildings played an integral role in bringing modernity to the UAE, following the political union of the seven emirates in 1971. The buildings from this period are often overlooked, regarded as 'unimportant', sometimes described as 'old', 'tired', and in need of demolition to make space for new development. Their successors are the high-rise, glass tower buildings following the International Style, seen nowadays in many cities and neighbourhoods worldwide. Due to the rapid development, many modern architectural heritage buildings are undocumented, their memory remaining through oral history, mainly of their past inhabitants.

In the past two decades after the turn of the new millennium, the UAE has experienced various surges of interest in reviving architectural preservation. Some of these initiatives have included restoration projects such as that of the walled historic centre of Sharjah in 1990, followed by the creation of Sharjah Heritage area (an initiative instigated by the ruler of the Emirate of Sharjah) ${ }^{5}$ in addition to the protection and restoration of Al-Fahidi neighbourhood in Dubai (spearheaded by Rashad Mohamed Bukhash). ${ }^{6}$ Other initiatives launched by governmental bodies such as the Abu Dhabi Department of Tourism and Culture, directed by 
Amel Chabbi and Hossam Mahdy, ${ }^{7}$ reflect an awareness of modern architectural heritage. Similarly, academic interest has fuelled publications such as the Abu Dhabi Guide by Pascal Menoret, documenting some of city's built environment between 1968 and $1992,{ }^{8}$ work by Yasser Elsheshtawy, ${ }^{9}$ essays by George Katodrytis and Kevin Mitchell ${ }^{10}$ focusing on projects from the UAE, and the Lest We Forget UAE initiative, by Michele Bambling, documenting Emirati life and culture through a public collection of photographs, later published in a book series and several exhibitions. ${ }^{11}$ All these initiatives planted seeds in the collective consciousness of the nation to increase awareness and instigate action, recently manifested in the last three UAE national pavilions at the Venice Biennale of Architecture: Lest we Forget: Structures of Memory in the UAE (2014), Transformations: The Emirati National House (2016), and Lifescapes beyond Bigness (2018). ${ }^{12}$ Finally in 2019, the Ministry of Culture and Knowledge Development in partnership with Zayed University launched the Zayed Institute for Architecture, Heritage and the Arts. ${ }^{13}$

As active academics and architects who have lived and practiced in the region, the authors use available academic platforms to educate young Emirati designers, thus encouraging their voices and visions on the development and growth of their country. $90 \%$ of our students are female Emiratis. Despite their rich cultural backgrounds paired with the country's global and international setting, the majority of our students come from protected, sheltered environments. They join the programme with limited exposure to design and very basic, acquired, design skills yet with an extensive yearning to learn. We recognize an opportunity to merge design education and awareness of local culture and the built environment as a way of learning or gathering meaningful research. The presented case studies were all conducted at the College of Art and Creative Enterprises at Zayed University, Abu Dhabi Campus. Their scopes vary and draw from classroom initiatives, field studies, and research endeavours aiming to understand why buildings from this period are worth studying, recording, and possibly preserving. Design studios, in the learning environment, can become a conduit to discover the meaning of these buildings. This is demonstrated in two approaches: first, by illustrating a series of case studies of adaptive-reuse design proposals for buildings in Abu Dhabi and, second, by developing different methodologies for recording the UAE's architectural modern heritage.

\section{Preservation through adaptive reuse}

The concept of adaptive reuse in architecture in Europe and North America is not new; rather, allowing a building to adapt to its new context is common practice. Brooker and Stone define the term 'adaptive reuse' as follows: 
The function is the most obvious change, but other alterations may be made to the building itself such as the circulation route, the orientation, the relationships between spaces; additions may be built and other areas may be demolished. ${ }^{14}$

There are plenty of examples throughout history of reappropriating the use of a building. For example, Musée d'Orsay in Paris, originally designed as a railway station, transformed into a museum - likewise, Tate Modern in London, from a coal power station to a contemporary art museum. According to Bie Plevoets and Koenraad Van Cleempoel, the theoretical approach to adaptive reuse was established in the nineteenth century when Eugène Emmanuel Viollet-le-Duc "recognized adaptive reuse as a way to preserve historic monuments". ${ }^{15}$ The approach in the modern context celebrates the architectural or historical merits of a building and repackages it to become a part of the life of the community. Peter A. Bullen even argues that the approach also has financial and sustainability merits. ${ }^{16}$

The concept of adaptive reuse in UAE architecture and its built environment is still a new 'ideology'. Until very recently, buildings tended to have a lifespan of 30 to 40 years before being demolished and replaced by newer, more 'trendy' structures. One example of this phenomenon is the ADNOC (a national oil company) residences and headquarters complex. The building was a landmark designed by Constantine D. Kapsambelis \& Associates. A concrete prefabricated structure often compared to the Watergate complex in Washington, DC - designed by Luigi Moretti with Corning, Moore, Elmore \& Fischer (1962-1971) - for its use of semicircular form and its volumes of concrete verging on brutalism. The building marks the western start of the corniche in the city of Abu Dhabi, and construction was completed in 1977. By 2009 , one of the semicircular structures was already demolished, and the complete flattening of the complex culminated in summer 2018 when it was replaced by the current tallest tower in Abu Dhabi, measuring 342 metres and featuring 76 floors. In complete contrast, the Watergate complex, completed just six years before in 1971, is still standing, remains extensively used, and has become part of American architectural history.

This timeframe of development, between 1971-1990, is relatively short when compared to many European and even North American cities yet nevertheless important to document and preserve as it constitutes part the young's nation history. The projects implemented in class were sought as mediums to inform the young generation on the importance and relevance of adaptive reuse, introduce them to concepts of adapting and retrofitting, and engage them in more sustainable approaches to designing their built environments. As educators, we work towards increasing awareness and emphasizing the historical importance of these 
structures by engaging students in a series of afterlife, designactivity scenarios. The adopted exercise produced a series of case studies of adaptive reuse design proposals for prominent buildings in Abu Dhabi. The buildings included the following: the Abu Dhabi Bus Terminal by Bulgarproject, 1989 (Case Study 1), aforementioned ADNOC residential buildings by Constantine D. Kapsambelis \& Associates, 1977 (Case Study 2), and a few abandoned modern 'ruins' (Case Study 3). Through the students' projects, the design investigations explore a series of 'afterlife' possibilities for these buildings, showcasing the pragmatic and the bizarre, the incredible and the poetic.

\section{Case study 1: The Abu Dhabi bus terminal}

The main bus terminal of Abu Dhabi was built in 1986 . It was the first major work by the Bulgarian architecture firm Bulgarproject. $\boldsymbol{\Delta}$ Located in the heart of Abu Dhabi, it serves the bus networks within the emirate of Abu Dhabi and routes to the other emirates. In an article published by The National newspaper in 2012, "In a Growing City Like Abu Dhabi, What Makes a Building Worth Keeping?", the building has been described by architect Deborah Bentley as "the big green giant of Abu Dhabi [which] is either loved or hated but could be revitalised for the 21st century without losing its heritage value". ${ }^{17}$

Located at the intersection of Hazza Bin Zayed Road and Muroor Road, the terminal consists of two floors; the ground floor comprises a huge waiting hall with seats, small derelict shops, a cafeteria, ticket machines, reception, male prayer room, and toilets. On the first floor, there is a row of offices no longer occupied. The offices lead to an empty dark hall and dead or underused spaces, a restaurant, and a former wedding hall. The internal space of the building is vast and dramatic. At the moment, the main purpose for entering the bus station hall is for customers to purchase bus tickets, use the public washrooms, and take a shortcut from the main boulevard running parallel to the station and the adjacent shopping mall. Ironically, the outside areas - including the bus platforms, taxi stands, minibus stops, and public gardens - are more popular with visitors than the interior space. This is an interesting phenomenon that exists despite the extreme temperature in the summer months. In spring 2018, students surveyed the building to track the visitors' trajectories, monitoring directions, speed, and movement through the space. Their findings revealed physical occupation of the hall of some forgotten spaces, such as the wedding hall located on the first floor, and niches providing sanctuary to visitors. The students concluded that the main users are low-income workers travelling between emirates and drivers for the buses and taxis using the station's facilities. Student design proposals explored the spaces on the upper floor as these were the most under-used. Their design proposals included instigators of new activities such as coffee 
areas, libraries, screening areas, and gallery spaces making the station a 'destination', a place to visit, and not just a space to walk through. The longitudinal nature of the building inspired long sections from the students showing the horizontality of the spaces and the interconnected verticality between levels. This typology of drawing allowed students to devise 'narratives' that occurred within and that interacted with the activities outside and in neighbouring buildings: the idea was to create new 'places' within the city. Proposals included reading facilities, public exhibition spaces, sculpture parks, and indoor gardens reminiscent of Rafael Moneo's Madrid Atocha railway station (1992).

\section{Case study 2: The ADNOC residential building, Abu Dhabi}

Built in 1977, the Abu Dhabi National Oil Company (ADNOC) residential complex was designed by Constantine D. Kapsambelis \& Associates. ${ }^{18}$ The 16 -floor structure had a unique circular building typology that enveloped a private courtyard setting and took advantage of adjacent coastline views. The three semicircles had balconies, with both façades providing access to apartments and forming horizontal public circulation. The elevator towers located on the inner façade shaped the vertical circulation. A typical floor plan followed a modular system and was composed of 29 bays. The width of each apartment spanned from one façade to the other inhabitation, four-to-five bays of every floor. For many years, it was considered as one of Abu Dhabi's landmarks. In 2004, a new master plan proposed the construction of a 342-metre, 76-floor ADNOC tower building. ${ }^{19}$ One of the semicircles was demolished in 2009 to make room for the new headquarters tower, completed in 2015 . The other sections were demolished in summer 2018. The students' projects took place as part of the intermediate interior design studio in fall 2015. The students proposed alternate programmatic scenarios that expanded vertically as well as horizontally. This approach challenged expected programmes that follow horizontal proposals by designing vertical expansions across floors, thus creating programmatic solutions and new spatial opportunities. The students explored the different architectural possibilities using and photographing largescale physical models. As well as breaking through the physical boundaries, the programmatic proposals included traditional Emirati homes expanded across multi-storey residences, urban roof parks, fitness gyms with running tracks expressed and hanging outside the building, galleries, and shops - all responding to the form and structure of the existing buildings.

\section{Case study 3: Abu Dhabi 'ruins'}

According to the Baroque imagination as interpreted by Caitlin DeSilvey and Tim Edensor, ruins are defined as "dwelling 

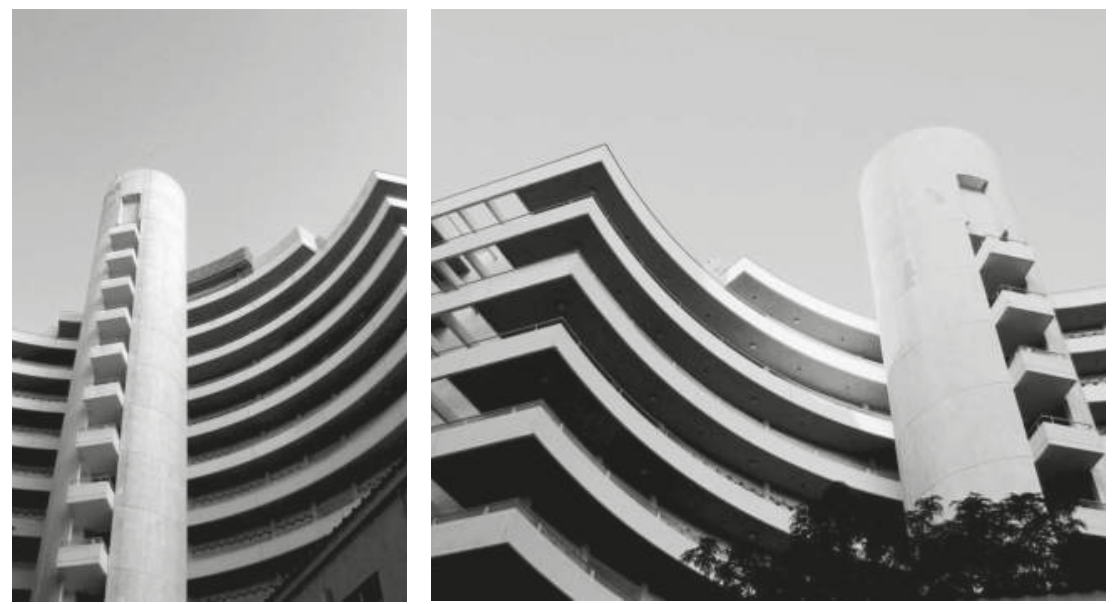

fig.1

ADNOC residential complex in 2015, demolished in 2019, Abu Dhabi (Photos: Deborah Bentley, 2015. Reuse not permitted).

on the melancholic power of transience and decay". ${ }^{20}$ The term 'ruins' is often used to describe the architectural remnants of past civilizations. For a country as young as the UAE, it is very difficult to contextualize the term as some would argue it is not old enough to have ruins. This is in context of UAE's urban cities established after the unification of the emirates in 1971. The country has traces of ancient structures and archaeological sites that testify to the presence of various ancient civilizations, such as the Iron Age building and burial grounds at Jebel Buhais as well as the Hafit period beehive tomb at Jebel Hafit. ${ }^{21}$ Edensor provides a great description of ruins as "exemplary alternative sites of memory". ${ }^{22}$ This definition fits perfectly to describe the site for our next case study. The term 'ruins' was used to describe the remains of an abandoned modernist structure strategically located on the eastern bank of the waterway in close proximity between Al-Maqta and Sheikh Zayed Bridges in Abu Dhabi, two of the three bridges that connect Abu Dhabi island to the mainland. There is hardly any documentation of the structure's origin and use. It occupied an area of approximately 4,900 square metres. The majority of the bounded areas are exposed to the elements, and only one quarter is enclosed with wall structures. The student's assignment was conducted as an independent research and design study as part of a senior interior design graduation project under the direct sufig.2 pervision of the authors. In the example represented, the student engaged in a photo documentation exercise, closely observing and recording activities occurring in and around the site. She also conducted a series of interviews with the older Emirati generation, people who remember using the place, before reconstructing 

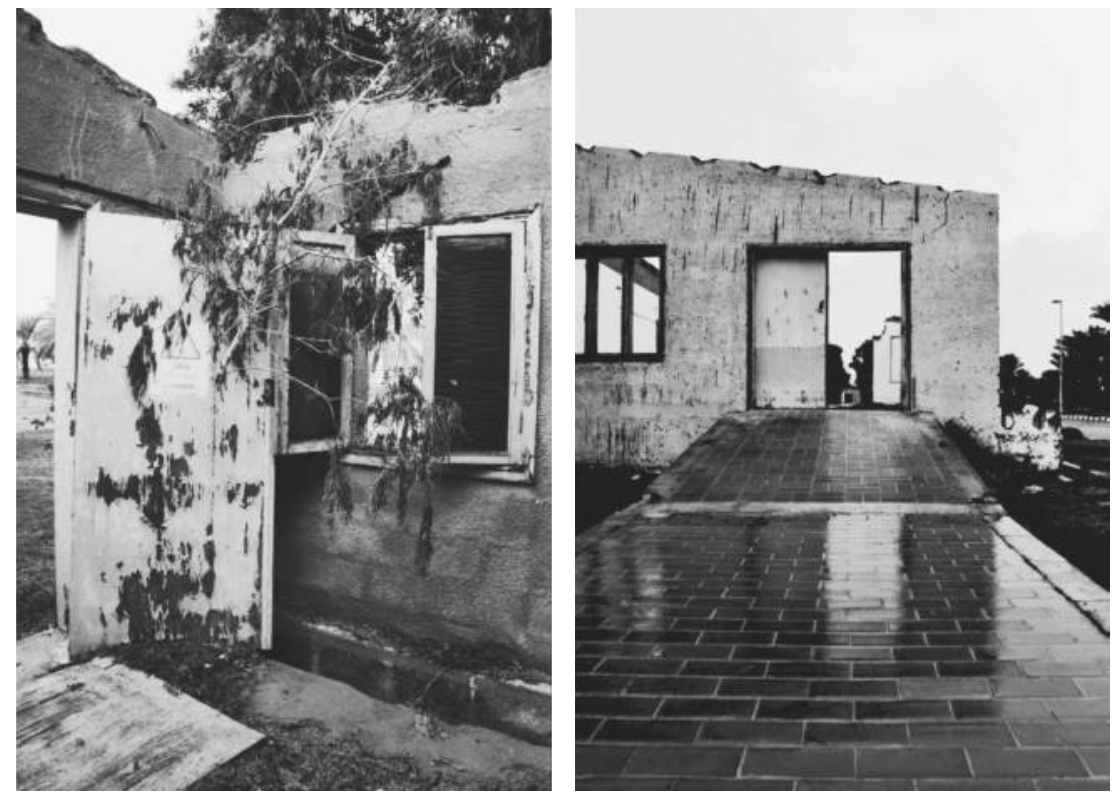

Photos of 'ruins' by Raysa AlKetbi (Source: Zayed University. Reuse not permitted).

a series of visuals, depicting the building's past functional and spatial use. The interviews unearthed how it was once one of the few wedding halls available in the capital. Weddings, like in most cultures, became vessels of memory and emotion. The structure was demolished in September 2016. The design proposal portrayed scenarios of alternate public use. Using scaffolding systems, a series of injected platforms - carefully offset from the main structure and ground surface - formed avenues for public use. Proposed functions were derived from the existing, mapped ones while proposed design charted scenarios for possible alternate uses such as study area, coffee shop, exhibition space, and contemplation zone. The project manifested itself by proposing an ephemeral structure which acts as a conduit to connect memories of the past, the present, and with an eye to the future. The interventions transcended the friction between the new spatial proposals and the old decaying structure. Even the existing rubble and old trash were respected and treated as urban 'relics' available for contemplation. The project impact extended beyond the studio and garnered more than the appreciation of peers when the student was selected to conduct a talk as part of a TED Talks satellite conference on technology, entertainment, and design at Zayed University's Dubai campus. ${ }^{23}$ This approach prolongs the life of 'forgotten' and neglected pieces of history that are part of the rich tapestry of urban fabric. 


\section{Preservation through awareness, recording, and response}

This section of the chapter presents the authors' adopted methodologies for recording the UAE's modern architectural heritage. The systems devised include not just a quantitative survey or photographic recollection of the buildings but an attempt to capture something beyond the physical appearance of the structures using different media. This allows for a deeper understanding of the buildings, whether pragmatic or poetic. The three methods represent approaches implemented at Zayed University by faculty and students to document and collect material about modern architectural heritage in the UAE.

Method 1: Image Stitching. The aim of the proposed technique is to produce seamless panoramic photographs showing the façade of a building. The photograph is composed of many photographs blended together to form a single image. This method is often referred to as digital 'image stitching':

Two images $\mathrm{I}^{1}, \mathrm{I}^{2}$ capture different portions of the same scene, with an overlap region viewed in both images. The images should be stitched to generate a mosaic image I. A simple pasting of a left region from $\mathrm{I}^{1}$ and a right region from $\mathrm{I}^{2}$ produces visible artificial edges in the seam between the images, due to differences in camera gain, scene illumination or geometrical misalignments. ${ }^{24}$

The process adopted by the authors involved digitally photographing a building's whole longitudinal façade by positioning the camera directly in front of the building at approximately 10-15 metres and at a 90-degree angle. After taking a photograph, the authors changed the position of the camera at various points along an imaginary line parallel to the building's façades. The images are then 'stitched' together in post-production using a digital manipulation software. During this stage, the software minimizes or completely eliminates the perspective distortion at the edge of images, an undesirable effect resulting from the camera's lens. The final image represents the building's façade as flat as possible, just like a photographic version of an architectural elevation. The photography of the façades will conjure a portrait record of the building. The method will not just systematically 'record' the existing structures but will also reveal a meaningful image of the site. The image captures an essence of the recent architectural past and its impact in the context of today's built environment. This is found through the materiality of the structures, their urban presence, the neighbouring buildings in the surroundings, and the people that use the structures. Each photographic composition is a representation of the subject within the site. Similar techniques, digital and non-digital, were used by artist Ed Ruscha in his 1973 


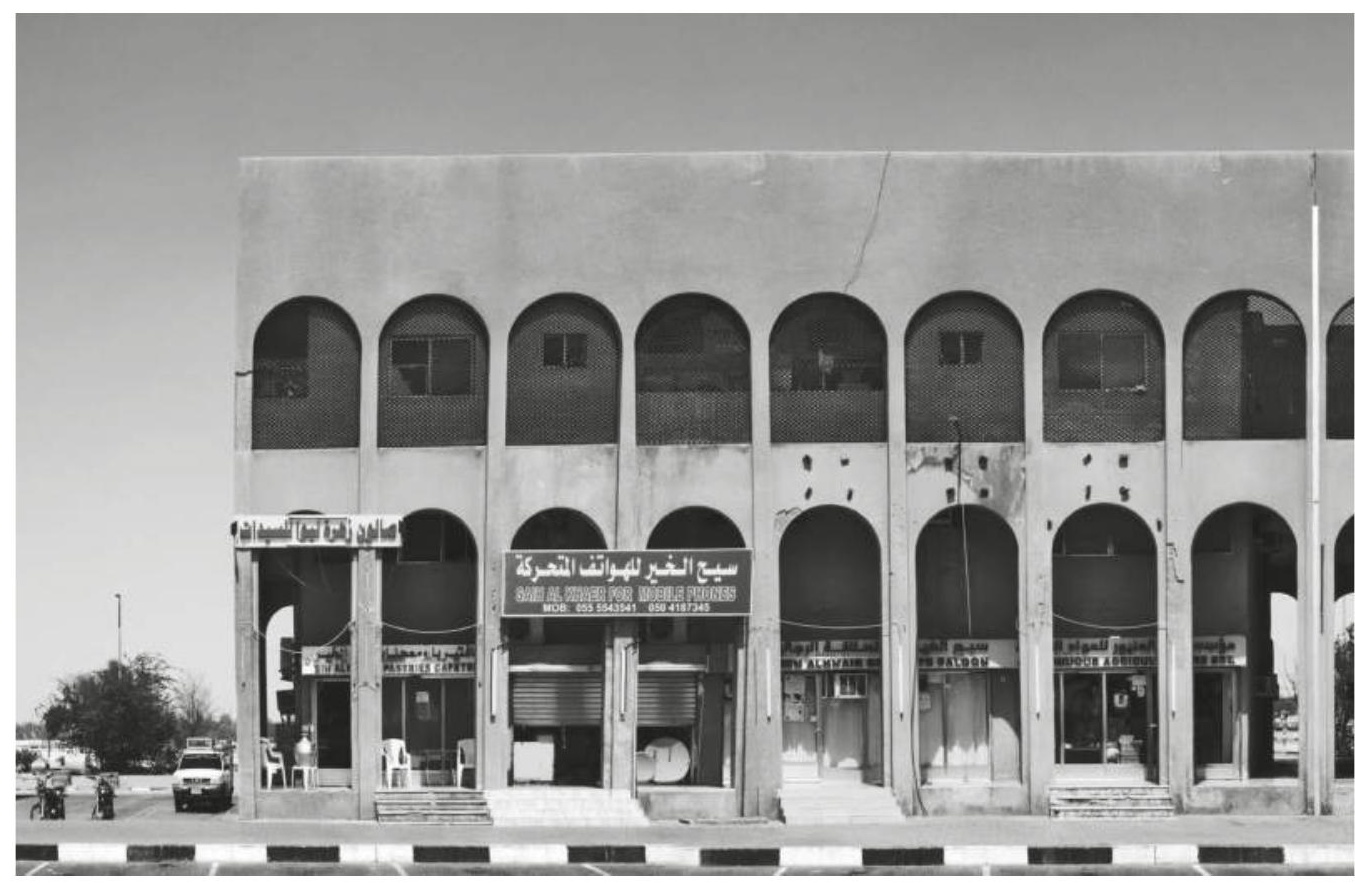

and 2002 documentation of Hollywood Boulevard, Then and Now, ${ }^{25}$ by photographers Bernd and Hilla Becher for their publication Typologies of Industrial Buildings ${ }^{26}$ and in the main bulk of photography work by artist Andreas Gursky.

The research project strategy adopted by the authors was to photograph as many buildings as possible from the period between 1970 and 1992. The images reproduced were part of the exhibition at the National Pavilion UAE at the 14th Venice Architecture Biennale. The elevation photograph becomes a representation of reality; though, it does not look real as we are used to seeing the world with our eyes and through a lens distorted in perspective. The architectural drawings are meant to reproduce spatial concepts as intended or built. These elevational photographs, and in turn the orthogonal drawings generated from them, are the representation of reality as built. Richard Whitlock describes the elevational photographs as "if everything in it has come fig.3 to attention and has also started to pay attention to us". ${ }^{27}$

Method 2: Making. The second working method follows the aforementioned technique by photographing buildings' façades, but not necessarily of a longitudinal structure. The final 


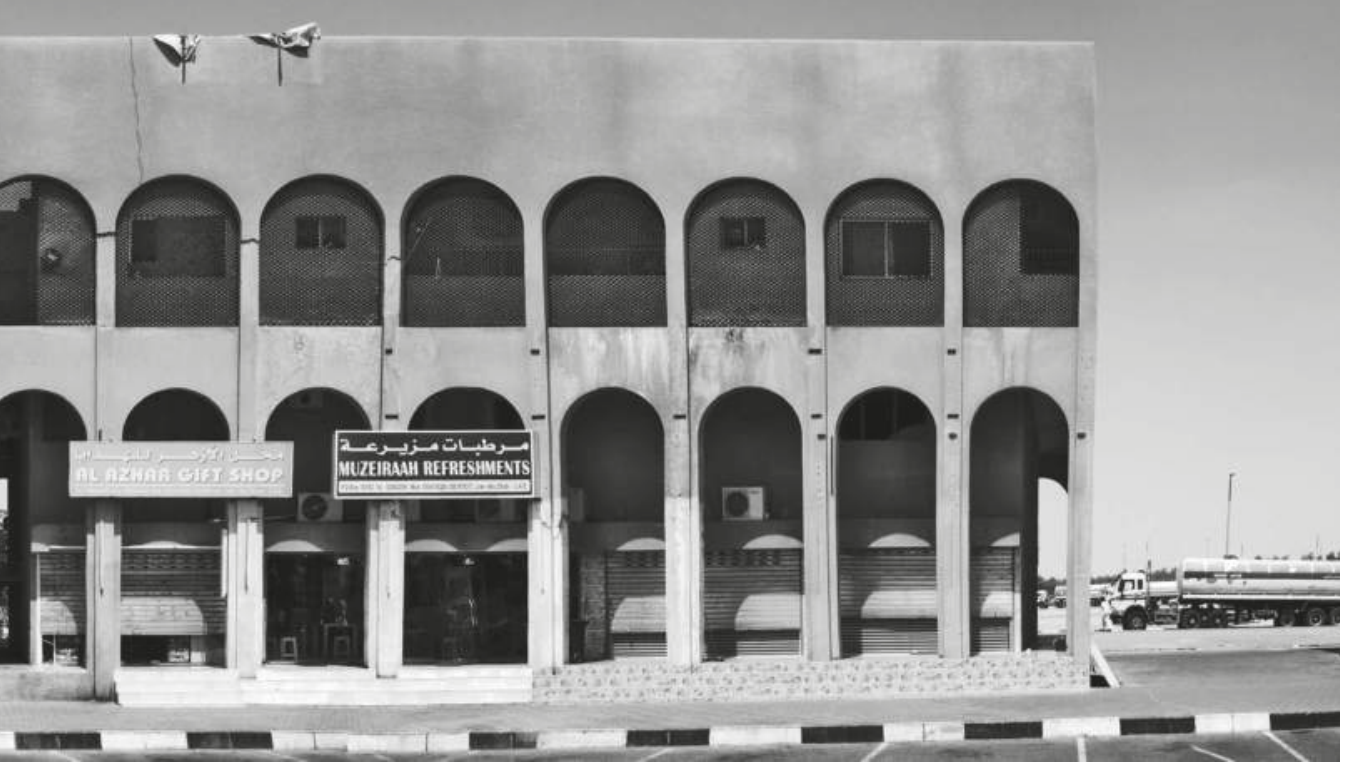

fig.3 Mzeer'ah shopping building, Liwa, Abu Dhabi (Photo: Marco Sosa, 2014. Reuse not permitted).

product of this method is not just the visual representation of the façade but also its physical reproduction in the form of a relief model. The model showcases the modular system that composes the façade of the building.

Similar to Method 1, the camera is positioned directly at 90 degrees in front of the building, at approximately 10-15 metres, depending on the width of the street. Using digital manipulation software, the photograph is then 'flattened' by ridding it of the camera's lens distortion. The newly flattened image of the building is then divided in an imaginary grid, and a scale is calculated using an architectural feature within the photograph and measured on site for exact dimensioning. This method is commonly referred to as photogrammetry, ${ }^{28}$ wherein you take measurements from photographs. The resulting 'gridded' photograph is then imported into a Computer Aided Design (CAD) software. A scaled elevation of the building is then generated by working out the modular system composing the façade. The drawing is then used to reproduce a significant area of the elevation, using digital maker technology. In this instance, a laser cutting machine accurately shapes the chosen material (exhibition white matt board), producing all the necessary parts to assemble the façade. The point of the exercise 

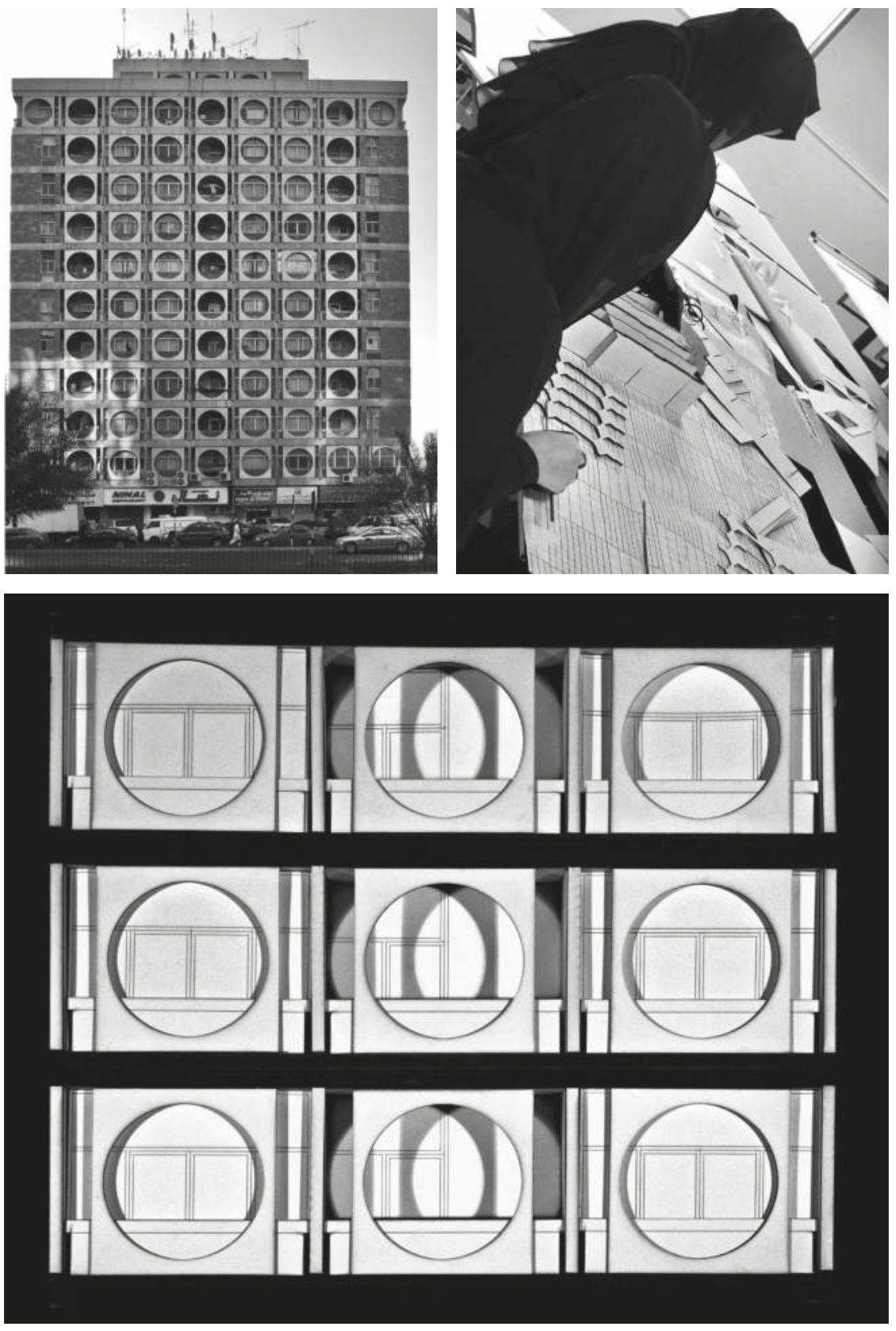
is not to reproduce a physical representation of the façade but to educate by making the model. The participant learns about modular architecture and assembling by using digital fabrication technology and the advantage of modularity in construction. The observer of the piece gains an insight into the variety of architectural features and aesthetics used for construction at the time. These systems were not just following a logic around the construction of the structure, but they also afford a glimpse into how these buildings were designed in layers to adapt to the climate and culture of the region. The efficiency of construction and economy of materials coupled with a modernist aesthetic perfectly symbolizes the spirit of the age. The buildings have a physicality that is at once predominant in the contemporaneous Middle East and Gulf region and representative of a modernist 'tradition'. The outcome of this method is to produce a collection of material featuring an orthographic elevation drawing and a physical model of each façade.

Method 3: Scanning. Over the past three decades, 3D digital reconstruction and 3D model augmentation have become commonly used methodologies to create accurate, as-built recordings of architectural structures and heritage sites. ${ }^{29}$ This provides an understanding to the object physicality and its transfer into digital media and serves as a means to record and archive for future studies. The primary application of the above technology remains to date in the manufacturing industries; it has also been used in areas such as civil engineering, film special effects, forensic sciences, archaeology, and most recently within academic endeavours. Laser scanner technology varies in its type. While airborne platforms exist and are mainly used for landscape topography surveys, ${ }^{30}$ the authors refer here to ground-based systems. The study involved the use of a FARO Focus 3D Laser Scanner device, which allows outdoor and indoor scanning operations. It enables high-speed, three-dimensional laser scanning for collating detailed measurement and qualitative documentation. The 3D scanner is able to generate accurate digital representations of interior and exterior spaces by assembling millions of 3D measurement points into a so-called 'point cloud'. The latter is a collection of XYZ coordinates that record the configuration of a space and which is stored and visualized by specific computer software. The accuracy stems from the recorded point density, known as scanning resolution.

\section{Case study 4: Bait 15}

Bait 15 is an artist-run studio and exhibition space, cofounded by three Emirati artists in 2017. It is located in a residential neighbourhood in downtown Abu Dhabi. The two-level residential villa was constructed in concrete in the 1980s and can be described as an 'ordinary' or 'typical' example of development in the family neighbourhoods. The house was previously owned by 

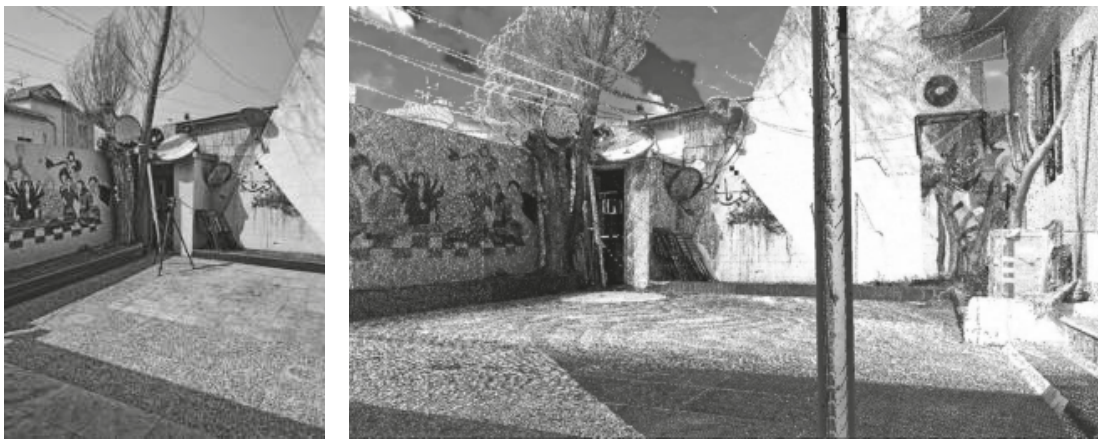

Left: view of the exterior spaces. Right: 3D point-cloud render (Photo and render by Lina Ahmad and Marco Sosa. Reuse not permitted).

Mohammed Al-Janahi, an Emirati actor famous from a popular UAE TV show in the 1970s and 1980s. ${ }^{31}$ Currently, it is occupied by three local artists who adapted the bedrooms and living spaces into art studios. Each bedroom acts as a private studio while the living room on the ground floor is a multifunctional space that constantly changes from exhibition to performance space to social gathering site. The house was selected as a case study for its importance in modern, local cultural history; it is rapidly becoming a successful working example of adaptive reuse in the UAE and of being a non-institutional, bottom-up cultural initiative. The latter is less common in the UAE context. The site was first surveyed and studied in the fall of 2018 with a group of intermediate interior design students from Zayed University over the span of three-anda-half months. The students surveyed the spaces using traditional manual techniques and laser measuring devices as well as a basic form of analogue photogrammetry analysis, where measurement and distances between objects were extracted from photographs on the base of known dimensions of identifiable elements. The results recorded the main spatial characteristics of the house: width, depth, length, and height of various spaces in addition to the locations of doors, openings, and windows. These approaches, however, failed to capture the features' complex surfaces, various textures, and numerous scattered irregular objects - all constituting parts of the overall spatial aesthetic. The digital outcomes were visions of white, pristine, concrete structures which accurately described the basic building geometry, but they failed to portray the effects of ageing and material decay. The dense, complex information was simplified into generic, accurate-enough structures that sufficed for surveying and studio-design exercise purposes. It however neglected the influence of time, specificity of use, and particularity of function, all of which are vital traits that make up the present space. 


\section{Conclusion}

The approaches described in this chapter have produced a body of documentation of built modern heritage in the UAE through participatory actions and academic research, simultaneously resulting in a shared learning experience for students and participants. The role of the authors, as educators, is trying to emphasize a way of understanding how the buildings from this era can be recorded, archived, and sometimes rejuvenated by repurposing methods implemented in design studio classes. This is particularly important when trying to re-engage with the contemporary city in the Gulf region. Spatial exploration, in the form of human occupation, is at the heart of the interior design pedagogy at Zayed University: the process entails the realization that the spaces which users occupy and objects which they utilize are merely a response to humans' lavish or primitive needs. City dwellers often familiarize themselves with their own urban environments; it is sometimes difficult to step back and reimagine the city with what is already there rather than what is not. At the beginning of the twenty-first century, the development of contemporary cities and the highlighting of their buildings have often featured in academic publications, such as Salma Samar Damluji's The Architecture of the United Arab Emirates, Yasser Elsheshtawy's The Evolving Arab City: Tradition, Modernity and Urban Development, and OMA's Al-Manakh. However, since the 1st National Pavilion UAE for the 14th Venice Biennale, there has been a huge public interest in architectural modern heritage within the country. This interest has been manifested in numerous creative responses as methods for creating lasting memories of these buildings. Many responses to this interest have involved various methods: from post-production manipulation to vector drawings as those produced by the Emirati urban planner Sultan Al-Ramahi to traditional and digital façade photography by local photographers Hussain Al-Moosawi and Ruben Garcia Rubio, and to robotic drafting and plotting by media artist Patrick Lichty as well as conceptual art based on architecture of the modern period by Emirati artist Afra Al-Dhaheri. Furthermore, the students' investigative projects presented above explored a series of 'afterlife' possibilities for these structures. The design proposals showcased pragmatic solutions to existing environments, endangered of being demolished. The academic and pedalogical purpose of these activities aims to educate this generation of young Emiratis to recognize the historical importance of their recent built environment. Hopefully, as young designers working in the construction industry, they as well will become instigators for preservation and conservation practices, adopting repurposing practices and proposing alternative solutions for redevelopment and keeping the memory and conscience of the Gulf modernist city alive. 


\section{Notes}

1 Yasser Elsheshtawy, ed., The Evolving Arab City: Tradition, Modernity and Urban Development (London: Routledge, 2008), 258-304.

2 World Health Organization, The World Health Report 2006: Working Together for Health (Geneva: World Health Organization, 2006), 176-199.

3 Abdulkhaleq Abdulla, "The Impact of Globalization on Arab Gulf States", in Globalization and the Gulf, eds. John W. Fox, Nada Mourtada-Sabbah, and Mohammed Al-Mutawa (London: Routledge, 2006),190-198.

4 Jure Snoj, “UAE's Population - by Nationality", BQ Magazine, April 12, 2015, 12.

5 Oliver James Picton, "Usage of the Concept of Culture and Heritage in the United Arab Emirates - An Analysis of Sharjah Heritage Area", Journal of heritage Tourism 5, no. 1 (2010): 69-84.

6 Shveta Pathak, "Dubai Aims to Protect 220 Historic Buildings by 2016", Gulf News, April 14, 2012, accessed October 30, 2020, https://gulfnews.com/entertainment/artsculture/dubai-aims-to-protect-220-historicbuildings-by-2016-1.1008142.

7 Amel Chabbi and Mahdy Hossam, "Starting from Scratch: Preserving Abu Dhabi's Modern Heritage", in Proceedings of the International Conference on Intervention Approaches for the 20th Century Architectural Heritage (Conservation of Architectural Heritage (CAH20thC): Madrid, 2011), 14-16.

8 Brian Kappler, "A Study of Modern Architecture in Abu Dhabi, 1968-1992", NYU Abu Dhabi Arts and Culture,

December 7, 2014, accessed October 30, 2020, https://nyuad.nyu.edu/en/news/ latest-news/arts-and-culture/2014/ december/a-study-of-modern-architecturein-abu-dhabi-1968-1992.html.

9 Yasser Elsheshtawy, "UAE Modern", accessed April 30, 2016, https://

uaemodern.com.

10 George Katodrytis and Kevin Mitchell, eds., UAE and the Gulf: Architecture and Urbanism Now, Architectural Design 85, no. 1 (2015).

11 "Lest We Forget", accessed May 21 2019, https://www.warehouse421.ae/en/ media/gallery/lest-we-forget_1/.

12 "2014 Lest We Forget. Structures of Memory in the UAE", accessed May 21, 2019, http://nationalpavilionuae.org/ architecture/2014-2/; "2016 The Emirati National House", accessed May 21, 2019 , http://nationalpavilionuae.org/architecture/ 2016-2/; "2018 Lifescape Beyond Bigness", accessed May 21, 2019, http://national pavilionuae.org/architecture/2018-2/.
13 Rola Alghoul and Nour Salman, "Ministry of Culture Launches Project to Promote Architecture in UAE", Emirati News Agency, April 14, 2019, accessed October 30, 2020, http://wam.ae/en/ details/1395302755198.

14 Graeme Brooker and Sally Stone, Re-Readings: 2: Interior Architecture and the Principles of Remodeling Existing Buildings (Abingdon: Routledge, 2019), 1-7.

15 Bie Plevoets and Koenraad Van Cleempoel, "Adaptive Reuse as a Strategy Towards Conservation of Cultural Heritage: A Literature Review", Structural Studies, Repairs and Maintenance of Heritage Architecture XII 118, no. 12 (2011): 155-163.

16 Peter A. Bullen, "Adaptive Reuse and Sustainability of Commercial Buildings", Facilities 25, no. 1/2 (2007): 20-31.

17 John Henzell, "In a Growing City Like Abu Dhabi, What Makes a Building Worth Keeping?" The National, August 4, 2012 ,

accessed October 30, 2020, https://www. thenational.ae/uae/in-a-growing-citylike-abu-dhabi-what-makes-a-buildingworth-keeping-1.385319.

18 Sherina Al-Sowaidi, "ADNOC Residential Buildings 1977", FIND, accessed January 6, 2016, https://www. f-in-d.com/stories/abu-dhabi-guide-2014adnoc-residential-buildings.

19 "ADNOC Headquarters", The Skyscraper Center, accessed January 6 , 2016, http://www.skyscrapercenter.com/ building/adnoc-headquarters/8763/. 20 Caitlin DeSilvey and Tim Edensor, "Reckoning with Ruins", Progress in Human Geography 37, no. 4 (2013): 465-485.

21 Daniel T. Potts and Peter Hellyer, "Fifty Years of Emirates Archaeology", in Proceedings of the Second International Conference on the Archaeology of the United Arab Emirates (Motivate Publishing, 2012), 62, 95.

22 Tim Edensor, "The Ghosts of Industrial Ruins: Ordering and Disordering Memory in Excessive Space", Environment and Planning D: Society and Space 23, no. 6 (2005): 829-849.

23 "Preserving Old Buildings in Dubai | Raysa Al-Ketbi | TEDxZayedUniversity", TEDx Talks, accessed October 30, 2020, https://www.youtube.com/watch?v= Eg2JPMQ0Mtc.

24 Assaf Zomet, Anat Levin, Shmuel Peleg, and Yair Weiss, "Seamless Image Stitching by Minimizing False Edges", IEEE Transactions on Image Processing 15, no. 4 (2006): 969-977.

25 Edward Ruscha, Then \& Now: Hollywood Boulevard 1973-2004 (Göttingen: Steidl, 2005). 
26 Bernd Becher and Hilla Becher, Typologies of Industrial Buildings (Cambridge, MA: MIT Press, 2004).

27 Richard Whitlock, "The Power of Perspective in the Photographic Image", in Preface, What is Helsinki Photomedia?, 12. 28 Julia Armesto, Izabela Lubowiecka, Celestino Ordóñez, and Fernando I. Rial, "FEM Modeling of Structures Based on Close Range Digital Photogrammetry", Automation in Construction 18, no. 5 (2009): 559-569.

29 Wolfgang Boehler and Andreas Marbs, "3D Scanning Instruments", Proceedings of the CIPA WG 6, no. 9 (2002).

30 Robert H. Bewley, Simon P. Crutchley, and Colin A. Shell, "New Light on an Ancient Landscape: Lidar Survey in the Stonehenge World Heritage Site", Antiquity 79, no. 305 (2005): 636-647.

31 Melissa Gronlund, "At Abu Dhabi's Bait 15, Artist in Residence Takes on Whole New Meaning", The National, June 21, 2018, accessed October 30, 2020, https://www.thenational.ae/arts-culture/ art/at-abu-dhabi-s-bait-15-artist-inresidence-takes-on-whole-new-meaning$1.739096 \# 6$. 


\title{
CONCLUSIONS \\ Modernism's \\ back and forth
}

\author{
Sultan Sooud Al-Qassemi
}




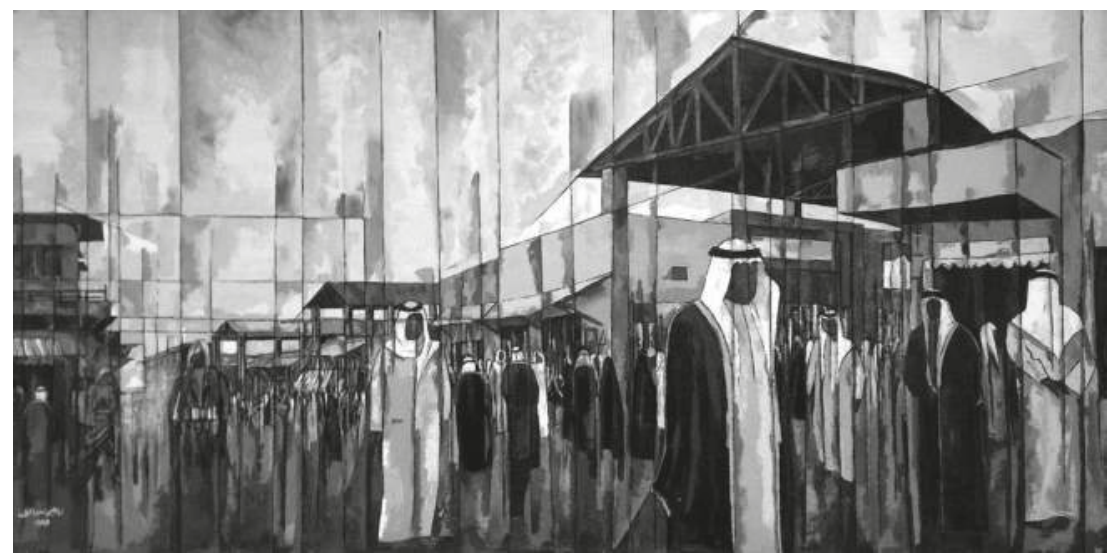

fig.1 Ibrahim Ismail, the Souq, Kuwait, 1995. Oil on Canvas, $100 \times 200 \mathrm{~cm}$. (Source: Barjeel Art Foundation, Sharjah. Reuse not permitted)

When one of the United Arab Emirates' ageing rulers ordered his advisor to convert the emirate's National Museum back to its original state as his residence, the advisor met the decision with incredulity, but the task of stripping down the structure to its original form began. The 'national museum' signboard was dismantled, the glass vitrines were taken out, new furniture was brought in. The change however did not last too long as the ageing ruler's health continued to deteriorate; he spent the last few years of his life confined to his home, and the fort was once again - discreetly - transformed back into a museum.

This anecdote as conveyed orally to me by members of my family who enjoyed close ties with the ruler's household presents one of the many urban and architectural development narratives common in Gulf cities where modern structures are sometimes reused, and in other instances 'modernism' is even reversible. It also reflects how modernism is a gradual process: many structures - through modification and adaptation - include several layers of interchangeability between the traditional and the modern, making it a challenge to assign a date to the beginning of modernism in the Gulf. To quote art critic and essayist Hilton Kramer, "to attempt to assign a specific date to such a fluid historical phenomenon would seem to be about as wise as assigning a birth date to air pollution or traffic congestion". ${ }^{1}$

Over the past few decades, the Arab Gulf states have witnessed an almost unprecedented level of development largely driven by oil capital. As their economies transformed from ones partly dependent on fishing and pearling into fast-moving capitalist centres, an influx of foreign workers led to an increasing demand for housing and accommodation. Citizens, furthermore, expected 
and even demanded better housing from their governments. Today, these developments are being reassessed for their value: some are torn down while others are repurposed. This increasing reassessment has been a primary driving force behind the scholarly research that we have presented in this volume.

The 1970 s oil prices shock coincided with an unprecedented construction boom as the Gulf states struggled to keep up with demands for housing for citizens and expatriates alike. Foreign expertise was relied on not only to design buildings but also to lay the master plans of entire cities. However, the reliance on foreign expertise came with its own set of problems. Many of these experts had no knowledge of the local contexts that they were expected to overhaul. They were further impeded by the fact that they did not have access to basic information such as demographics and societal order, as well as the fact that these states' growth quickly eclipsed any potential plan, no matter how grand. Decades after the introduction of these master plans, ${ }^{2}$ they remain the subject of contentious debate and comprise fertile material for some of this book's chapters. Faisal Al-Mogren, for example, writing in this volume, proposes a reconsideration of Doxiadis' often criticized 1972 master plan of Riyadh. ${ }^{3}$ The plan was conceived to regulate the city as a growing organism until the year 2000 , but as argued in the chapter, its implementation is still shaping the city today, 45 years after the planner's death. This case study offers one an opportunity to reflect on who is or has been responsible for the Gulf city's transformation.

Authorship is also discussed in Jumanah Abbas and Michael Kubo's chapters as a yet unresolved matter in the Arab Gulf states where much of the rapid urban development is attributed either to the 'vision' of one Gulf ruler or to foreign or regional expertise. These issues are also compounded by the fact that state archives, at least until recently, generally did not consider urban- and architecture-related documentation as an essential component of their collections, making it very difficult to identify the actors involved in the construction of many buildings. In Sharjah for instance, Halcrow, the firm behind three iterations of the city's master plan, had discarded almost its entire archival record of the city following its acquisition by an American firm, thereby rendering research and attribution all the more challenging. Access to such archives and documentation is proving instrumental for scholars and academics, not only to understand the built legacies of modernization plans but also to provide a necessary foundation, or basis, for generating contemporary architectural and urban development resolutions. For instance, Jason Carlow and his students relied on Halcrow and Partners' 1980 master plan for Sharjah to cultivate strategic infrastructure proposals for the development of industrial districts in Sharjah. Additionally, Carlow's research investigates sites that have not been studied and locations that have 
not received as much attention, like that of blue-collar migrants who often are hidden in plain sight. In this same vein, my co-editor Roberto Fabbri explores the case study of the bustling Jibla district in Kuwait which once was one of the 'epicentres' of the modernization project; it has now become a home and place for social gathering for various low-income expatriates. The outbreak of Covid-19 in 2020, however, laid bare this inequality, with cases spreading within crowded domiciles that have been overlooked by governments and society alike. ${ }^{4}$ This resulted in hundreds of thousands of migrant workers leaving the Gulf states, costing tens of billions of dollars in lost revenues; and it also raised questions about the viability of a seemingly endless cycle of construction. In an era where working from home has become feasible, can the reuse of existing buildings both accommodate workers and save money?

Modernism can also reflect a political dimension as appears in Todd Reisz's retelling of how the British Political Agency in the Trucial States was repositioned from a mud-brick, courtyard house in Sharjah to a purpose-built structure in Dubai. Ironically, the structure that the British government vacated in Sharjah went on to serve - for two decades - as one of the emirate's primary hotels; it was given the name Seaface Hotel, signalling its prime location on Sharjah Corniche. The British presence in Sharjah leads me to pose another question: what exactly constitutes modernism in the Gulf? I often consider this particular project in my hometown of Sharjah. A British-commissioned airport - now converted into a museum - was inaugurated in 1932 with a structure made of concrete, aluminium, and glass in addition to corals, mud-brick, and palm tree fronds. Is it not a modern structure? While the airport's control room employed some of the latest technologies at that time, the airport cannot be seen as merely an imported structure. Without the local craftsmen and builders, the construction of this building would not have been fully facilitated. Another structure completed in the same year as Sharjah's Airport was Bahrain's Customs House, whose narrative is carefully reconstructed by Suha Babikir Hasan through her investigation. Hasan leads the readers through the many characters that the building 'impersonated' before it was restored to its initial appearance and historicized. Today, 90 years on, both structures, although never attaining the status of architectural icons, continue to function efficiently.

On a similar path, Kevin Mitchell's paper explores how the status of buildings as 'iconic' impacted their eligibility to be preserved. It could be argued here that iconic buildings designed by renowned architects have a stronger chance of being conserved than those designed by lesser known practitioners. However, that is not always the case as the 'iconic' status of the imposing Constantine Kapsambelis \& Associates-designed Abu Dhabi National Oil Company residential buildings on the Abu Dhabi 
corniche did not save it from its fateful end in 2018. That same year, Dubai Municipality launched the 'Modern Heritage Initiative'5 to preserve several structures - many of which are considered 'iconic' - in the emirate including the Dubai World Trade Centre, Clocktower monument, and Al-Baraha Hospital.

A recent example of adaptive reuse of modern buildings in Dubai is Al-Safa Art \& Design Library, which was built in 1989 and had recently undergone renovation when much of the original structure was preserved for reuse alongside the newly built glass extension. In the application of reusability of modern architecture, the coming generations will play an increasingly important role as Marco Sosa and Lina Ahmad demonstrate in their chapter. Sosa and Ahmad utilized their university design studio as a research centre for the documentation of modern heritage structures, proposing numerous studies on adaptive reuse of buildings in the UAE. I also wonder how historians will assess texts on architecture and urbanism that are being produced today. An essential review was conducted for this volume by Mohamed Elshahed whose essay revisits Udo Kultermann's book on contemporary architecture in the Arab states on the twentieth anniversary of its publishing. While the book features projects and buildings from cities across the Arab world, Elshahed raises questions about what he deems the "historian's bias" - what gets featured and what is forgotten. Beyond the realm of academia, social media has proven to be a compelling stage to retell the stories and histories of modernization: numerous accounts and pages steadily engage in archival and on-the-ground documentation. For instance, in my research for a book on modern architecture in the emirate of Sharjah and in the absence of a fully developed archive, my colleagues and I significantly relied on social media to search not only for information on featured projects but also for archival images and to gather oral histories, the latter proving to be a very important source in the region. Social media also reflects the growing sense of appreciation for modern architecture in the Gulf, much of it stemming from grassroots initiatives such as city walking tours in Kuwait, Bahrain, and Oman that compose potent arrangements to cultivate the public's awareness of the histories of architectural and urban landscapes of their surroundings. ${ }^{6}$

As a result of this increasing awareness, we have started to see numerous attempts at preservation with varying degrees of success, what Trinidad Rico terms "preservation sensibility" in her chapter. These attempts include the transformation of existing houses, built in Doha between the 1970s and 1980s, into cafés and restaurants - a trend that has been replicated in Dubai's Al-Fahidi district and in numerous diners in Manama's upmarket Adliya neighbourhood. Furthermore, Asseel Al-Ragam explores the private sector's role and contribution to different typologies of individual cultural spaces in Kuwait, examining how each present 
different programmes - such as private museums, galleries in warehouses, or exhibition venues inside commercial centres. Also in Kuwait, but on a larger scale, Nilsson presents an existing case study of a building that was largely preserved for adaptive reuse. Souk Al-Wataniya, on whose design he worked, not only survived the devastation of the Iraqi occupation of 1990-1991, but a part of it has been successfully preserved, with the residential floors readapted into offices and a business incubator.

Today, even though there seems to be a Gulf-wide trend leaning towards the preservation of modernist architecture, these efforts largely remain not coordinated by a state-wide policy but isolated as can be observed from the papers in this volume. This publication stems from the workshop, "Re-Engaging with the Gulf Modernist City: Heritage and Repurposing Practices", convened by the Gulf Research Centre in Cambridge, England, in July 2019. Many of those presenting and in attendance - through their writing, activism, and creativity - have been behind the increasing appreciation of modern architecture in the region. This creativity was evident in an award-winning short film by Kuwaiti director Noura Al-Musallam called Bait Oboy (My Father's House), ${ }^{7}$ it starts with a son entering a modern-looking house and attempting to convince his elderly father to sell the house for a repurposing project. "A restaurant? I am not moving out of this house. I built it in 1960, before independence". Despite the father's pleas, the movie ends with a sledgehammer being driven at a wall. The house will be turned into a restaurant after all. The movie revolves around the concept of memory and nostalgia for a lost past. These factors, perhaps less academically relevant or less related to disciplinary topics for architects and city planners, could play an important role in preserving modern heritage in the Gulf. The movie presents how memories trigger a deep sense of belonging in citizens, and this can help counter real estate forces that, at the moment, are major threats to the existing building stock.

As I shared the events depicted in the film with my colleague Roberto Fabbri, one of the authors of the Modern Architecture Kuwait: 1949-1989, he mentioned that it reminded him of Bayt Lothan in Kuwait, a cultural centre and former residence of Emir Sheikh Sabah Al-Salem, bulldozed and turned into a food court. Fabbri remarked that "Similar to Bait Oboy, Bayt Lothan" was not meant to be a remarkable example of architecture, nor regional, nor imported, nor traditional, and neither modern. Rather, it was a fond memory for many who remembered or participated in the cultural activities such as training and art classes similar to those now offered in the new cultural centres, some cited by Asseel Al-Ragam, that the government has recently inaugurated".

As touched upon in the introduction, a primary driving force behind this book is the documentation and analysis of modern structures, both obsolete and in use, in order to study their 
present condition and consider alternative uses that would allow for their preservation. The lack or scant amount of archival documents along with the relatively small amount of literature about modern architecture in the Arab Gulf region continues to pose a challenge for both researchers and governments alike at a time when interest in preserving modern architecture is increasing. In her preface, Kishwar Rizvi suggests that modern architecture is not simply an "artefact of the past" but sits at the forefront of contemporary culture and design, potentially inspiring future developments. It is our hope that this book, like others that have been published over the past two decades, would encourage both further research and interest in the structures that have born witness to the promise of modernity. 


\section{Notes}

1 Hilton Kramer, "Contemporary Began When? Times Sets Date at 1970", Observer, January 24, 2000, https:// observer.com/2000/01/contemporarybegan-when-times-sets-date-at-1970. 2 The first master plan for an Arab Gulf city was for Kuwait by the British firm Minoprio, Spencely and Macfarlane in 1951. For further reading, see Sharifah Alshalfan, The Aftermath of a Masterplan for Kuwait: An Exploration of the Forces That Shape Kuwait City (Barcelona: Barcelona International Affairs, 2018). 3 Faisal Mubarak, "Urbanization, Urban Policy, and City Form: Urban Development in Saudi Arabia" (PhD diss., University of Washington, 1992).

4 By 2020, the Arab Gulf states hosted an estimated 23 million migrant workers mostly from South Asia. In the first few weeks of the Covid-19 outbreak, 200,000 Indian nationals registered to be repatriated. For further reading, see Sameer Hashmi, "Coronavirus leaves Gulf migrant workers stranded", BBC News May 15, 2020, https://www.bbc.com/news/world-middleeast-52655131.

5 "Dubai to Preserve Modern Heritage Buildings under New Initiative", Gulf News, August 2, 2018, https://gulfnews.com/ entertainment/arts-culture/dubaito-preserve-modern-heritage-buildingsunder-new-initiative-1.2260871.

6 Grassroots initiatives include Madeenah in Kuwait City which was founded by Deema Alghunaim in 2014. For further reading, see Mai Al-Farhan, "Madeenah: Exploring Urban Development in Kuwait City", Kuwait (blog), The Arab Gulf States Institute in Washington, March 20, 2017, https://agsiw.org/madeenahexploring-urban-development-kuwait-city. 711.1960 Kuwait (@11.1960), “Bait Oboy, Directed and Written by Noora Al Musallam @mshn, Produced by the Ministry of State for Youth Affairs", Instagram video, May 30, 2020, https:// www.instagram.com/tv/CA03sPChUbf/ ?igshid=d9nmjmynfrv4.

8 Ben Garcia, "Planned Demolition of Historic Bayt Lothan Stirs Opposition", Kuwait Times, February 24, 2016, https://www.zawya.com/mena/en/life/ story/Planned_demolition_f_historic_ Bayt_Lothan_stirs_opposition_-ZAWYA 20160224050927. 


\section{AUTHORS' BIOGRAPHIES}

Sultan Sooud Al-Qassemi is a columnist and researcher on social, political, and cultural affairs in the Arab Gulf states. Al-Qassemi is also founder of the Barjeel Art Foundation in Sharjah, UAE. He was an MIT Media Lab Director's Fellow from 2014 to 2016, a practitioner-in-residence at the Hagop Kevorkian Center for Near Eastern Studies at New York University in spring 2017 and a Yale Greenberg World Fellow in 2018. Al-Qassemi was a visiting instructor at the Council of Middle East Studies at Yale University, the Center of Contemporary Arab Studies at Georgetown University, the American University of Paris, the Islamic Civilization and Societies programme at Boston College, and the School of Public Affairs at SciencesPo, Paris. In the fall $2021 \mathrm{Al}-\mathrm{Qassemi}$ was appointed as Kuwait Foundation Visiting Scholar, Middle East Initiative at the Harvard Kennedy School and lecturer, School of Arts and Sciences, Brandeis University. Al-Qassemi, along with Todd Reisz, is co-editor of Building Sharjah (Birkhäuser, 2021).

Roberto Fabbri is an architect, researcher, and associate professor at Zayed University, UAE. From 2016 to 2021 he taught at the University of Monterrey, Mexico, and previously at the University of Bologna, Italy and the American University of Kuwait. As a consultant of the United Nations Development Programme, Roberto participated in the rehabilitation of Kuwait National Museum and completed the transformation of the American Missionary Hospital of Kuwait into cultural hub. He regularly participates in international conferences, recently at Yale, Cambridge, King's College London, and INHA-Paris, and has published extensively in academic journals, such as Domus; Faces, journal d'architecture; and International Journal of Islamic Architecture. He has published two books on the architectural works of Max Bill (Mondadori 2011, inFolio 2017) and co-authored the double-volume, Modern Architecture Kuwait 1949-89 (Niggli 2016, 2017). 
Jumanah Abbas is an architect, writer, and curator based in New York and Qatar. She received her master's degree in Critical, Curatorial, and Conceptual Practice from Columbia University in 2020 and her undergraduate degree in architecture from American University of Sharjah. Using architectural drawings, videos, and objects, her practice looks at how educational pedagogies and environments impact how different forms of knowledge circulate as well as condition the urban landscape. Jumanah has worked on exhibitions such as Makassed: Patron of Modern Architecture at Saleh Barakat Gallery in Beirut and Curricular Exchange in collaboration with CCCP/2020 at the Sharjah Architecture Triennial. Her work was also on display at Sharjah Art Foundation (2016) and Maraya Art Center (2017).

Lina Ahmad is currently employed as associate professor and assistant chair at the College of Arts and Creative Enterprises, Zayed University, Abu Dhabi. Ahmad holds a MArch from the Architectural Association in London. She has over ten years of professional experience working as an architect, and her work has been widely exhibited, including at the UAE's national pavilion at the Venice Architecture Biennale (2014). Her work has been published and presented at various conferences around the world. She was also recipient of the Architecture + Cityscape Award 2003, Designing for a New World, under the category of aspiring architect. In 2015, Ahmad co-authored the book, Cellular 'Network' City, presenting an investigation into the realm of algorithmic architectural design. She is an advocate of digital fabrication technology and its impact in regional higher education and the UAE creative industry. In 2015, Ahmad co-founded, with fellow colleague and architect Marco Sosa, the design research unit LIMass, a design unit dedicated to prompting creative design solutions and delivering products and spatial proposals within UAE community.

Faisal bin Ayyaf Al-Mogren Appointed in November 2019, Faisal is currently serving as Mayor of Riyadh, Saudi Arabia. $\mathrm{He}$ also serves as chairman of Arab Urban Development Institute, chairman of the board at Arriyadh Development Company and Riyadh Holding Company, and board member at Riyadh Region's Council and at the Architecture and Design Commission, among other memberships and contributions in Saudi Arabia. Faisal's previous background in the built environment is diverse as he holds a bachelor's in architecture from King Saud University (2011), master's in architecture and urban design from Columbia University (2014), master's in urban planning from Harvard University (2016), and is a PhD candidate at University of California, Berkeley. Professionally, prior to Riyadh, his professional experiences spanned different settings, working with Zen+Dco in France, Moriyama \& Teshima Architects in Canada, SOM in the United States, and Riyadh City Royal Commission in Saudi Arabia. The scope of work he was involved in throughout those experiences ranged from small-scale projects of interior design, architectural projects, urban interventions, and large master plans to urban economic studies and policy analysis. Additionally, he remained involved in research work, teaching a number of courses and producing scholarship exploring narratives of urbanization in Saudi Arabia, focusing on Riyadh's development, functions, expansion, and management through an approach that combines a multi-model technical analysis with a historical lens.

Asseel Al-Ragam is associate professor of architecture and vice-dean for academic affairs, research, and graduate studies at the College of Architecture at Kuwait University. She is also director of the Architecture Graduate Program. In 2008, she received $\mathrm{a} P \mathrm{Ph}$ in architecture from University of Pennsylvania. Currently, she teaches modern architecture history, criticism, and conservation as well as graduate research and design studio courses. Her research focuses on urban and architectural development in Kuwait, namely, the history and conservation of modern architecture, housing, and public space, drawing links between these subjects and broader debate on socio-cultural modernity. She is author of the award-winning paper "'Denial of Coevalness': Discursive Practices in the Representations of Kuwaiti Urban Modernity". Her most recent article is "Kuwaiti Architectural Modernity: An Unfinished Project", published in The Journal of Architecture. She recently completed a policy paper for a London School of Economics research grant on public space use in Kuwait's residential neighbourhoods. She was visiting researcher and guest lecturer at the École nationale supérieure d'architecture ParisMalaquais. She is an architecture and urban planning consultant and member of the Technical Advisory Committee for Architecture and Urban Planning at Kuwait's Private University Council. 
Jason Carlow holds a BA in visual and environmental studies from Harvard University and a MArch from Yale University and is associate professor of architecture at American University of Sharjah. Prior, he taught at University of Hong Kong for ten years. His recent work focuses on issues surrounding housing for dense urban environments, and he is co-author of the forthcoming book, Cities of Repetition: Hong Kong's Private Housing Estates. Carlow's design and research work has been published and exhibited internationally at the Bi-City Biennale of Urbanism\Architecture in Shenzhen and Hong Kong, Venice Biennale of Architecture, and Beijing Architecture Biennial, and he is the recipient of the 2020 AIA/ACSA Housing Design Education Award.

Mohamed Elshahed is a curator and architectural historian focusing on modernism in Egypt and the Arab world. $\mathrm{He}$ is author of Cairo Since 1900: An Architectural Guide, the first substantive survey of modern architecture in Egypt's capital spanning 226 sites. He holds a master's from Massachusetts Institute of Technology's Aga Khan Program for Islamic Architecture and a PhD from New York University's Department of Middle Eastern Studies. His work spans architecture, design, and material culture. $\mathrm{He}$ is the curator of the British Museum's Modern Egypt Project and Egypt's winning pavilion, Modernist Indignation, at the 2018 London Design Biennale. In 2019, Apollo Magazine named him among the 40 under 40 influential thinkers and artists in the Middle East. In 2011, he founded Cairobserver to stimulate public debates around issues of architecture, heritage, and urbanism in the region. In spring 2020 , Elshahed was practitioner-in-residence at the Hagop Kevorkian Center for Near Eastern Studies at NYU.

Suha Hasan has worked as an architect on various projects, ranging from private residences to large developments in Bahrain, Dubai, and Khartoum, and as a lecturer at University of Bahrain. She also worked for a brief period during her student years as a journalist covering social topics. Today, her time is divided between Stockholm, where she is carrying out her PhD studies at KTH Royal Institute of Technology, and Bahrain, where she engages through Mawane in experimental participatory urban research via public art exhibitions, talks, and workshops. Her $\mathrm{PhD}$ research investigates the absent landscape of architecture in Bahrain. This stems from her interest in post- and pre-colonial studies of architecture and urbanism, more broadly in the global history of spatial cultures and their production through transnational and transcultural processes, specifically those across the Middle East, Africa, and South Asia (MEASA). She is also interested in cross-cultural artistic practice across the region, including its history and legacy. She has recently joined the United Nations Development Programme as a consultant and the Architectural Association as a Visiting School Director.

Michael Kubo is assistant professor and programme coordinator for architectural history and theory at the Gerald D. Hines College of Architecture and Design, University of Houston. He was previously the Wyeth Fellow at the Center for Advanced Study in the Visual Arts, National Gallery of Art, in Washington, DC, and associate curator for OfficeUS, the US pavilion at the Venice Biennale of Architecture (2014). His recent publications on the history of twentieth-century architecture and urbanism include Imagining the Modern: Architecture and Urbanism of the Pittsburgh Renaissance (2019), Heroic: Concrete Architecture and the New Boston (2015), and OfficeUS Atlas (2015). He is currently preparing a book on The Architects Collaborative and the authorship of the architectural corporation after 1945, with particular attention to transnational exchanges between US firms and architects and engineers in the Gulf states.

Kevin Mitchell is professor of architecture and currently serves as chancellor at American University of Sharjah. Areas of research and writing include higher education in the Middle East and North Africa, design education, and contemporary architecture and urbanism in the Middle East. Recent work appears in The Superlative City: Dubai and the Urban Condition in the Early Twenty-First Century (Harvard Graduate School of Design/Harvard University Press), Economy and Architecture (Routledge), and Contemporary Urban Landscapes of the Middle East (Routledge). Professor Mitchell co-edited a survey of contemporary architecture and urbanism in the Gulf titled UAE and the Gulf: Architecture and Urbanism Now. He is founding Editorial Board member of the International Journal of Islamic Architecture.

Edward Nilsson is principal and founder of Nilsson + Siden Associates, Inc., Architects \& Planners, in Salem, Massachusetts. He received an MArch 
from Harvard University Graduate School of Design, BArch from The Cooper Union, and MBA from Babson College. Prior to founding his own firm in 1982 , Nilsson served as lead project architect for Constitution Quarters at Boston's Charlestown Navy Yard, an adaptive reuse of the historic former machine shop/forge complex into 367 apartments and garage (with Anderson Notter Finegold). He also served as lead project architect for two, mixed-use development projects in Kuwait City, including residential, commercial, office, and parking facilities (with The Architects Collaborative). He is former instructor in architectural history and case studies at Boston Architectural College and has guest lectured at MIT, Salem State University, and Northeastern University.

Todd Reisz is an architect and writer. He lives in Amsterdam. His work examines the global practice of architecture, specifically how the architect circulates technologies and cultural narratives. His book Showpiece City: How Architecture Made Dubai (Stanford University Press, 2020) explores architecture's packaging to sell Dubai on a global stage. He is also co-edited Building Sharjah (Birkhäuser, 2021), an archival investigation of the Middle Eastern city's vanishing twentiethcentury landscape.

Trinidad Rico is associate professor in the Department of Art History and director of the programme in Cultural Heritage and Preservation Studies (CHAPS) at Rutgers University, USA, and holds an honorary associate professor position at the Institute of Archaeology, University College London. She holds a PhD in anthropology from Stanford University, MA in principles of conservation from University College London, and BA in archaeology from University of Cambridge. Her research in critical heritage studies includes heritage at risk, ethnographic methodologies, the vernacularization of heritage discourses and expertise, and heritage ethics. Her current research project focuses on the mobilization of heritage practices and religion in the Arabian Peninsula.

Marco Sosa is an architect and associate professor and chair of design at the College of Arts and Creative Enterprises, Zayed University, Abu Dhabi. He holds a BA, postgraduate diploma in architecture, and MA in architecture of rapid change and scarce resources from London Metropolitan University. Sosa has designed, participated, and curated exhibitions, nationally and internationally. His work has been published and presented at various conferences around the world. In 2012, Sosa's photography book about the oldest functional mosque in the UAE, titled Al Bidiya Mosque, A Visual Essay, was published by Zayed University Press. In 2014, he was appointed to join the curatorial team as head of design for the first national pavilion of the UAE at the Venice Biennale of Architecture (2014) curated by Rem Koolhaas. The exhibition and catalogue featured many of his photographs. Sosa is interested in modern heritage in the Gulf, materials, their presence as a space-forming medium adding materiality to a 'place', and how to integrate digital fabrication techniques in the studio for interior design learning. 
Abdallah Al-Salem Street 60 .

Abdelbaki, Ibrahim 20.

Abdul Baqi, Fuad 66.

Abdul Baqi, Sami 66-7.

Abdullah Al-Salem Cultural Centre 197-8.

Abu Dhabi 2-3, 11, 25, 82, 102-4, 108-9, 117, 157, 247-9, 250-3, 257, 259;

Central Bus Terminal 102, 104, 117, 251; Department of Culture and Tourism (DCT) 248; Municipality 247; National Library and Cultural Centre or Cultural Foundation 103-6, 108-9, 116-7; Documentation and Research Centre (National Archives) 47, 49, $52,108$.

Abu-Lughod, Janet 122-3, 135.

Adaptive reuse $70,75,173,184-8$, 198-9, 202, 247, 249, 250-1, 260, 268-9.

ADNOC Residential Complex, 250-1, 252-3, 267.

Advisory Planning Committee (APC) 175, 185-6.

Aga Khan Award for Architecture 133-4, 229.

Ahmadi 35, 63-4.

al-'Imara Al-Hadītha 194-5, 201.

Al-Alousi, Maath 24.

Al-Baraha Hospital 268.

Al-Dafna 139, 144.

Al-Dhaheri, Afra 261.

Al-Emara 19, 32-3.

Al-Fahidi district 134, 248, 268.

Al-Faisaliyah Centre 123.

Al-Hamad, Abdulatif 112-3.

Al-Maktoum, Saeed bin Maktoum bin Hasher 41, 47.

Al-Malaz neighbourhood 160, 162.

Al-Moosawi, Hussain 261.

Al-Quoz 84, 88.

Al-Rayes, Sabah 109, 112, 115.

Al-Sabah, Sheikh Jaber Al-Ali or Shaikh Jabir Al-Ali 64, 110.

Al-Sabah, Sheikh Sabah Al-Salem 269.

Al-Safa Art \& Design Library 268.

Al-Sajaa Industrial Oasis 84, 86.

Al-Sawaber housing scheme or apartment complex 35, 115, 173.

Al-Serkal Avenue 85.

Al-Shamlan, Saif Marzooq 198.

American Mission Hospital (or Al-Amricani or Amricani Cultural Centre) 57, 60, 70-4.

American University of Sharjah 80-1, 87, 89, 90, 92-3, 95.

Amin, Shurooq 199.

Amiri Diwan 142-3, 147, 150, 197-8.

Anglo-Iranian Oil Company 48.

Arabian Mission of the Reformed Church of America 70.

ARAMCO 159.

Archaeology 259.

Art Deco 232.

Ashkouri, Hisham 104-5, 108-9.

Ayub, Raymond [Antonius] 24. 
Bachelors 81, 96.

Badran, Rasem 24, 152.

Bahrain 1, 9, 49, 70, 82, 116, 158, 207-8, 210, 211-2, 214-21, 267-8; Authority for Culture and Antiquities (BACA) 10, 212, 214, 216-7, 219; Center for Strategic, International, and Energy Studies 9; Historical and Archaeological Society 213; Pavilion 8, 11; World Trade Center 135.

Bait (Bayt) Lothan 269

Bait 15, 259.

Bait Al-Othman 198.

Bait Oboy 269.

Barjeel Art Foundation 265.

BBPR (Banfi, Belgiojoso, Peressutti, \& Rogers) 175-8, 180, 182, 187-8.

Bedouin 158, 232.

Behbehani Compound 57, 67-8, 70, 74.

Beirut 11, 25, 34, 64, 66, 185.

Belgiojoso, Lodovico 175, 187.

Belgrave, Charles 211, 214, 217-21.

Bonington Partnership 62.

Britain 2, 42, 218.

British Petroleum 51.

British Political Agency (or agent or residency) $41,42,43,45,49,62$, 218. 267.

Build-Operate-Transfer (BOT) 178.

Bulgarproject 102, 251.

Bunshaft, Gordon 124, 132-3, 136.

Burj Al-Arab 123.

Burj Khalifa 2, 124, 129, 247.

Butler Building 90-1.

Candilis, Josic \& Woods 175, 186; see also Shadrach Woods.

Cairo 1, 25, 30-1, 34-6, 43, 152, 187.

Central Bank of Kuwait (CBK) 124-9, 130, 133-6.

Central Business District (CBD) 176-7, 188.

CH2M Hill 157.

Chadirji, Rifat 24.

Citizenship 8, 61, 75, 196, 217.

Civil society 235.

Clocktower monument 268.

Colin Buchanan \& Partners 121.

College of Art and Creative Enterprises (CACE) 249; see also Zayed University.

Conservation 72, 177, 199, 212, 214-7, 227, 233; Comité de Conservation des Monuments de l'Art Arabe 27; Practice 216, 219, 261.

Constantine Kapsambelis \& Associates 267.

Contemporary Art Platform (CAP) 199.

Corniche: Doha 139-4, 150-4; Abu Dhabi 250, 268; Sharjah 267.

Correa, Charles 30, 152.

Courtyard house 62, 71, 181-2, 239, 267.

Covid-19 267.

Culver City 84

Customs House 10-1, 207-8, 210, 212-20, 267.
Dammam 26, 157.

Dar al-Athar al-Islamiyyah 8, 10, 60, 71-3.

Demolition 7-8, 10, 13, 57, 60, 66-8, 102-4, 116-7, 121, 123, 173, 185-6, 202, 210, 217, 232-3, 236-7, 248.

Department of Municipal Affairs (DMA), Riyadh 160.

Desert 2, 7, 54, 69, 247.

Design Construction Group (DCG) 64.

Dickson House 68, 197.

Directorate of Municipalities, Saudi Arabia 160.

Dissing+Weitling 24, 125-6.

Doha 3, 8, 11, 24-5, 134, 138-45, $147-8,150-1,153,157,227,230$, 232-43, 268.

Doxiadis, Constantinos 156-8, 160-70, 266.

Dubai 3, 11, 40-3, 45-52, 54, 79-86, 89-90, 93-4, 96, 121, 123-4, 129, 254, 267; Al-Fahidi 134, 248, 268; Al-Safa Art \& Design Library 268; Al-Quoz industrial area 88; Burj Khalifa 2, 247; Global Art Forum 143; International Finance Centre 187; Lands Department 47; Municipality 7 , 268; Museum of the Future 135; Creek 50, 51, 124; Plan 157-8, 232; World Trade Centre 36, 268.

Dwelling 83, 85, 88, 90-2, 96, 252; Informal 12, 96; Modes (or forms) of 33, 82; Unit 68, 94, 174.

Dynapolis 161-2, 170 .

Écochard, Michel 24, 196.

Education 20, 93, 133, 186, 188, 195, 248; Architectural 27-8, 249; Building 3, 25, 71, 152, 185, 187, 199, 233; Institutions 13, 26, 65, 92, 194.

Education City, Qatar 3.

Eggener, Keith 29.

Egypt 1, 19-20, 23-9, 31, 34-5, 60, 108, 110, 116, 187, 220.

Ekistics 161.

El-Kafrawi, Kamal 23.

Elsheshtawy, Yasser 12, 102-4, 177, 249, 261.

El-Wakil, Abdel Wahed 23.

Empire: Periphery of 31, 210; Ottoman 3.

Erikson, Arthur or Erickson, Arthur 36, 173.

Etihad 247.

Ewbanks 63-4.

Exceptionalism 25, 207, 210.

Exhibition 200, 247, 249, 257, 269; Centre 73; Space 104-5, 139,152, 199, 252, 254, 259-60; Gallery 198, 200.

Expatriate 43, 79-80, 82, 91, 94, 103-4, $248,266-7$.

Ezzeddin, Ibrahim 108.

Fadan, Yousef 159

Fahed Al-Salem Street 60-2, 75.

Fareej 233, 236, 238, 240.

Farmer and Dark 64-5.

Fathy, Hassan 24, 29-30, 33. 
Fletcher, Sir Banister 28.

Foreign Office, United Kingdom 41-4, 46, 48-9, 64.

Frampton, Kenneth 29, 31.

Freyssinet system 113, 178-9.

Gebhart, Michael 105, 108.

Geography or geographies 2, 3, 11-2, 22, $27,31,43,101,140,168,193-4$, 200, 207, 218, 247; Royal Society 31; Royal Danish Society 125.

Ghantous, Adnan 112.

Globalization 12, 123, 174, 248.

Grid 65, 82, 85-6, 160-1, 163-4, 168-9, 257.

Gulf Cooperation Council (GCC) 7, 11, 121, $129,240$.

Haddad, Charles 109, 111, 115.

Hajj Terminal, Jeddah 2.

Halcrow and Partners or Halcrow \& Partners or Halcrow Corporation 2, 80, 82, 266.

Hammad, Mohamed 20, 33.

Harris, John 7, 36, 157-8, 232.

Harvard Graduate School of Design 105.

Hasted, General William 60, 63-4, 66.

HOK (formerly Hellmuth, Obata + Kassabaum) 124, 128-30.

Holy Family of the Desert 69.

Hooper-Greenhill, Eileen 197, 200-1.

Huxtable, Ada Louise 184.

India 2, 29, 30, 42-4, 60, 62, 210, 219-20, 239; British Steam Navigation Company 211; Ocean 135, 207.

International Congresses of Modern Architecture (CIAM) or Congrès internationaux d'architecture moderne 165, 194

Iran 1-2, 48, 74, 116, 144, 207, 211, 217, 220.

Iraq 19, 23-5, 31, 71, 104, 116, 161, 184, $186,269$.

Islam (or Islamic) 7, 25, 28, 31, 108, 122, 135, 152, 195, 213; Architecture 28, 31, 108, 152; Art 152, 232; Islamism 3; Monument 34.

Islamabad, The Islamabad Plan 161

Ismail, Ibrahim 256.

Jaber Al-Ahmed Cultural Centre 197. Jacobsen, Arne 124-8, 136. Jebel Hafit, Abu Dhabi 253.

Jeddah Tower 124.

Jibla, Kuwait 57, 60-3, 67, 74-5, 267.

Joint Banking Centre competition 115.

Kahn, Andrea 89.

Karim, Sayyed or Sayed 19, 24, 31-2, 34-6, 67.

Kingdom Centre, Riyadh 123.

Kramer, Hilton 256.

Kultermann, Udo 18-9, 21-9, 31, 34, 36, 268
Kuwait 2, 8-9, 11, 25-6, 36, 58, 60-73, 7 $5,103-5,109-10,112-3,114-7,121$, 124-28, 133, 135, 157, 172, 174-5, $177,181,184-8,192-6,198-200$, 202, 241, 265, 267-9; City 35, 56-7, 74, 111, 114, 127, 129-30, 173; National Council for Culture, Arts and Letters (NCCAL) 10; Foundation for the Advancement of Sciences (KFAS) 110-1; Fund for Arab Economic Development (KFAED) 110, 177; House for National Works 198; Institute for Scientific Research (KISR) 110-1; Investment Co. (KIC) 177-8; Law of Antiquities 199; National Museum (KNM) 24, 71; News Agency (KNA) 110; Oil Company (KOC) 64; Towers 8; University 173-4, 188.

Land-use 66, 82, 175.

Landmark 22, 45, 50, 65, 101, 112, $115,129,145,150,153,227,232$, 250, 252.

Larsen, Henning 24.

Laser Scanning 259.

Law of Antiquities 174, 199, 202.

Le Corbusier 24, 92, 193.

Lest We Forget 11, 249.

Liberation Tower 184.

Linear city 161, 193.

Llewelyn Davies 157.

Locality 13, 57, 74.

Louvre Abu Dhabi 3.

Lower Manhattan Expressway 92.

Lutyens, Edwin 62, 71.

Lynch, Kevin 86.

Majlis 66, 147, 227.

Makiya, Mohamed 23-4.

Makkah or Mecca 2, 132-3.

Mall 9, 60, 79, 151, 199-201.

Maqta Bridge, Abu Dhabi 253.

Marginalization 13, 117, 232, 238, 240-1, 243.

Mashrabiyya 67, 128, 182, 236.

Mason Memorial Hospital 70.

Mastaba 127.

McMillen, Louis 105, 108, 112.

MEDSTAR 167.

Migration 9, 25, 57, 60-1, 79-80, 91, 159, 160, 217, 236, 241, 248, 267.

Ministry Complex 140, 146-7, 150, 153-4.

Ministry of Finance 63, 67, 150.

Ministry of Works 45-6.

Minoprio, Spencely and Macfarlane 63, $121,157,175$

Mubarak, Hosni 35.

Monument (or monumental) 28, 33-4, 64, $70,86,103,105,113,133,139,250$, 268; National Charter 211.

Mosque 2, 24, 152, 175, 233, 242.

Msheireb Arts Centre (MAC) 237.

Mubarak, Faisal 165.

Muhaisnah District 86. 
Muharraq 215-6.

Multiculturalism 2, 215.

Murabba Palace, Riyadh 158

Museum of Islamic Arts 140, 152, 154.

Mylrea Memorial 71.

Nasser, Gamal Abdel 25.

Nation-building 3, 7, 104, 117, 140, 152, 196, 228.

National Bank of Denmark 125.

National Museum UAE 256.

National Pavilion UAE 247, 249, 256, 261.

National Real Estate Co. (NRC) 177, 181.

Negative heritage 240 .

Neighbourhood centre 170.

Neubauer, Perry K. 105, 108.

New York University Abu Dhabi 3.

Nilsson, Edward O. 113, 172, 175-6, 179, 181-3, 269

Olcott Memorial 70, 72

Oman 26, 110, 116, 129, 268.

Open City 80-1, 85, 89.

Oral history 221, 248.

Organization of the Petroleum Exporting Countries (OPEC) 2.

Pan-Arab Consulting Engineers (PACE) 8, $62,109-16,124,128,130,180-1$.

Pearling Path 215-6.

Pereira, William 24, 143-8, 151, 227, 243.

Periphery 31, 80-1, 83, 95, 194, 210.

Pevsner, Nicklaus 27, 33.

Photogrammetry 257, 260.

Plan Obus 92.

Point cloud 259-60.

Postmodernism 22, 25-6, 31

Public space 57, 61, 67, 85-6, 93, 95, 145 165, 169, 182, 197.

Public Work Department (PWD) 66.

Qaddumi, Hisham 142-7, 150.

Qasr Al-Ahmar 127

Qasr Al-Hosn 103-5, 109, 247.

Qatar: Foundation 236; Museums (QM) 10, 228, 232-3, 240, 242; National Museum 8, 232; National Theatre 150.

Rabbat, Nasser 25, 31.

Rais, George 7.

Renovation 72, 88, 126-8, 184, 199, 214 , 232, 237, 268.

Revival 3, 20-1, 25, 27-8, 31, 229, 239 , 248.

Riad, Mahmoud 35.

Royal Air Force (RAF) 42-3.

Royal decree 159.

Rudolph, Paul 92.

Sadat, Anwar 35.

Safat Square 57, 63-5, 177.

Salmiya (Al-Anjari) Commercial Complex 115.
SCET International 167.

Seaface Hotel 267.

Sennett, Richard 79-81, 84-6, 88-9.

Shankland \& Cox 121.

Sharjah 10-1, 42-5, 48, 78, 80-96, 134, 248, 265-8; Art Foundation 10; Asset Management 84; Creek 44.

Sheikh Zayed Bridge 253.

Sheikh Zayed Mosque 2.

Sheraton Hotel 24, 140, 227, 243.

Shiber, George Saba 67, 121-3, 135, 181, 201.

Shuaib, Hamid 67, 109.

Sidky, Ahmed 24.

Site analysis 45, 81, 91.

Skidmore, Owings \& Merrill (SOM) 2-3, 24, 115-6, 124, 132, 136, 247.

Slavery 30, 50, 239.

Souk (or souq) 110, 117, 172, 174-5, 176, 265; Al-Manakh 113, 116, 177-8, 180, 187; Al-Safat 177-80, 187; Al-Waqif 134, 228-9, 236; Al-Wataniya 62, 113-4, 174, 177, 179-84, 186-8, 269; Mubarakiya 60, 199; Old Souk District 176-8, 180.

Studio Holtrop or Anne Holtrop 10-1, 215-6.

Suez Canal 1.

Sultan Gallery 199.

Sultan, Ghazi 72-3.

Sultan, Abdul Aziz 72.

Superblock 161-3, 168-9.

Takahashi, Katsuhiko 157.

Tange, Kenzo 147, 150.

Tawfiq Abd Al-Gawwad 20, 33.

Tenca, Emilio 68-9.

Territory $12,46,75,86,140,152,158-9$, 160, 166, 168, 170.

The Architects Collaborative (TAC) 24, 62, 103-6, 108-13, 115-6, 114, 174, $177,179-81$.

Theatre 75, 84, 104, 150-1.

Thenayan, Abdulaziz bin 165.

Thunayan al-Ghanim 67, 199.

Trucial States 41-3, 46, 50-1, 267.

Tukan, Jafar 7.

Type-form 88, 90.

Typology 22-5, 62, 67, 71, 90, 93, $129,162,168,177,202,252,256$, 268.

UN Sustainable Development Goals (SDGs) 9.

UN-Habitat 9

United Nations Development Programme (UNDP) 9, 71, 73.

United Nations Educational, Scientific and Cultural Organization (UNESCO) $7-8,71-3,133,214,228$.

Urban farming $94-5$.

Urban growth 79, 151, 158, 167.

Urban planning 79, 89, 115, 140-2, 144, 151, 153, 158, 194, 241.

Utzon, Jørn 73-4. 
Venice Architecture Biennale 8, 247, 256.

Vernacular 26, 29, 180; Architecture or

building 32-4, 237; Emirati 103-4;

Language 228, 232, 237; Modern 104;

Urban 201.

Waterfront 138-41, 144-6, 151, 153-4, 177, 220, 227.

Wissa Wassef, Ramses 24.

Wiśniowski, Krzysztof 69.

Woods, Shadrach 185-8; see also

Candilis, Josic \& Woods.

World Heritage: List 8, 133, 228; Site 214.

World Trade Centre 7, 36, 42, 268.

Youm-Al-Bahar 57, 68, 79.

Zayed University 247, 249, 254-5, 258, 260-1; see also College of Art and Creative Enterprises.

Zoning 83, 162, 165, 177, 182, 193, 218, 233. 